Portland State University

PDXScholar

$1-1-1985$

\title{
The impact of social networks on mortality, disease incidence, and disease progression
}

Mary Bahner Maxwell
Portland State University

Follow this and additional works at: https://pdxscholar.library.pdx.edu/open_access_etds Let us know how access to this document benefits you.

\section{Recommended Citation}

Maxwell, Mary Bahner, "The impact of social networks on mortality, disease incidence, and disease progression" (1985). Dissertations and Theses. Paper 451.

https://doi.org/10.15760/etd.451

This Dissertation is brought to you for free and open access. It has been accepted for inclusion in Dissertations and Theses by an authorized administrator of PDXScholar. Please contact us if we can make this document more accessible: pdxscholar@pdx.edu. 
THE IMPACT OF SOCIAL NETWORKS ON MORTALITY, DISEASE INCIDENCE, AND DISEASE PROGRESSION

by

MARY BAHNER MAXWELL

A dissertation submitted in partial fulfillment of the requirements for the degree of

\section{DOCTOR OF PHILOSOPHY in \\ URBAN STUDIES}

Portland State University

1985 
TO THE OFFICE OF GRADUATE STUDIES AND RESEARCH:

The members of the Committes approve the dissertation of Mary Bahner Maxwell presented May 3, 1985.

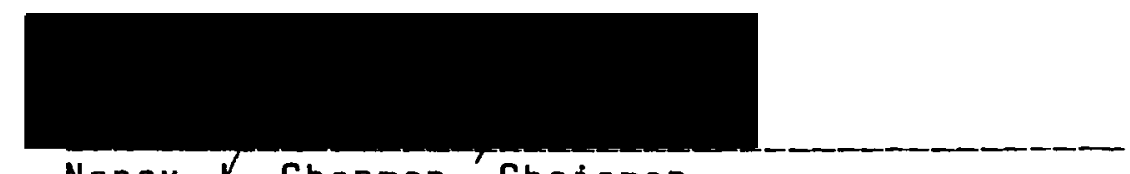

Nancy J. Chapman, Chairman
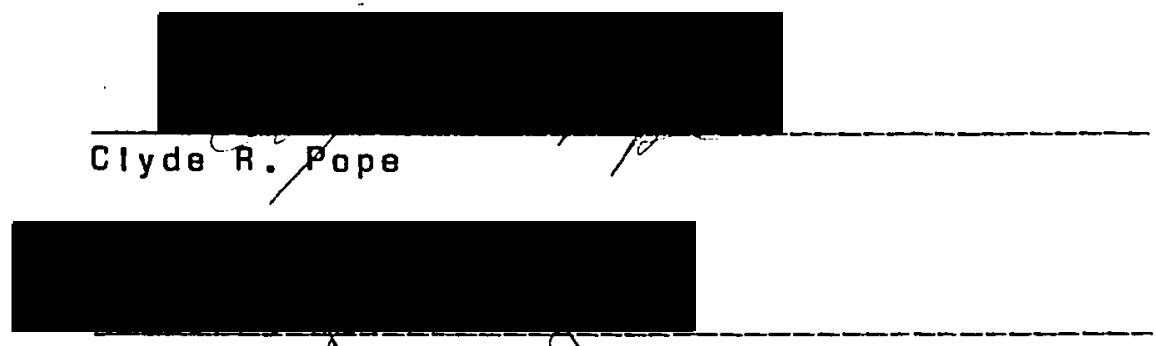

Berit Ingersol1-Dayton

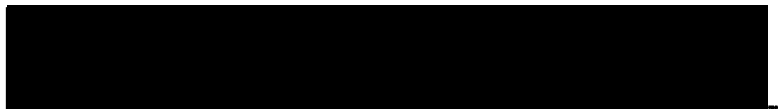

Seymou JAdler

APPROVED :

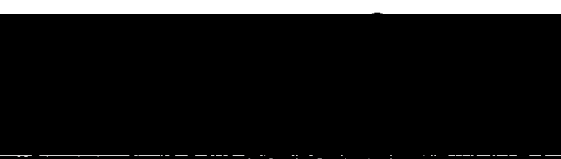

Kenneth Dueker, Acting Dean,

School of Urban and Public Affairs

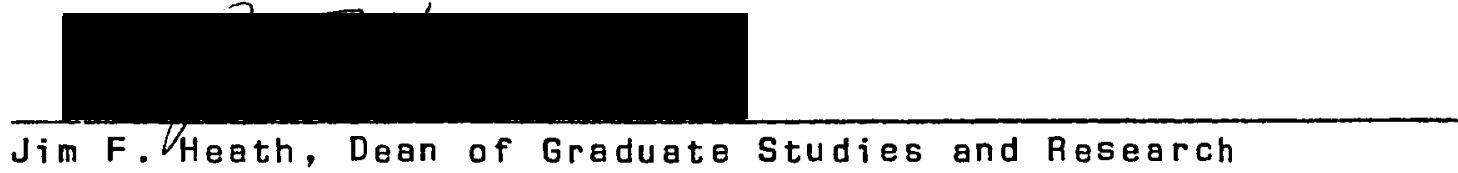




\section{ACKNOWLEDGEMENTS}

The extent of support from my social network, both personal and professional, as I undertook the preparation of this dissertation has been overwhelming. Due to the generosity of key members of the staff at the Portland Veterans Administration Medical Center and the Kaiser-Permanente Center for Health Research, I have been provided resaurces for the accomplishment of this dissertation which I never dreamed possible one year ago. I also wish to thank those individuals who have so generously worked with me during the past year as I developed from clinician to researcher.

First, I express my deep gratitude to Dorothy Magedanz, R.N., M.S., Chief Nurse at the V.A. Medical Center, who was willing to allow me time from my clinical responsibilities to conduct this project. Her vision and perseverance helped secure an educational leave so that I could be at the Kaiser Center to learn research. Also on the V.A. Staff, I thank David Hickam, M.D., coordinator of the Health Services Research and Development Program, for his advice and encouragement. He fortuitously put me in contact with Donald Freaborn, Ph.D., Senior Investigator at the Center for Health Fesearch, who introduced me to the possibilities at the Center. Dr. Freaborn has provided a 
consistent supportive link between the two institutions as the project went forward.

Next, I am grateful to my new colleagues at the Kaiser Center. Of primary importance is Clyde Pope, Ph.D., who is my preceptor at the Center and a member of my dissertation committee. Dr. Pope generously let me use the data from his household interview survey, and oriented me to the organization and interpretation of the complex data files. John Mulooley, Ph.D., has patiently provided statistical expertise. Tom Vogt, M.D., has given the epidemiological perspective, often mingled with the philosophical. Many others at the Center have assisted me in mastering the technical aspects of research. I particularly thank Marilyn Drichas, Lois Drew, Jan Blank, and Dan Azevedo.

To Nancy Chapman, Ph.D., Professor of Urban Studies at Portland State University, who chairs my dissertation committee, I owe a special debt. She has encouraged me from the beginning, and been most generous in giving of her time and advice. I thank also Berit Ingersoll-Dayton, Ph.D., and Sy Adler, Ph.D., who served on the committee.

Finally, my dear husband and children have faithfully endured these years of training, and rejoiced in my progress. My special thanks and love to Farley, Robin, Anne, and Paul. 
TABLE OF CONTENTS

PAGE

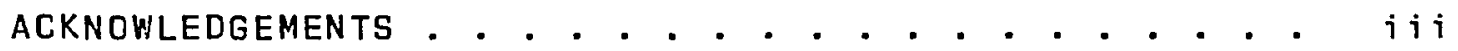

LIST OF TABLES . . . . . . . . . . . . . . . . . . . . ix

LIST OF FIGURES . . . . . . . . . . . . . . . . . . . xi

CHAPTER

I INTRODUCTION

Background. . . . . . . . . . . . . . . 5

Conceptual Framework. . . . . . . . . 10

Hypotheses................. . . . 15

Overview of Methods . . . . . . . . . . 17

il ReView of the literature . . . . . . . . . . 23

Social Networks . . . . . . . . . . . 24

Social Networks and Mortality . . . . . 31

Social Networks and Disease Incidence

vs. Disease Progression... . . . . 39

III BACKGROUND OF THE STUDY . . . . . . . . . . . . . 48

Setting . . . . . . . . . . . . . . . . 49

Data Sources.. . . . . . . . . . . . 51

Coding Schemes. . . . . . . . . . . 61

The Samples . . . . . . . . . . . . . 63 
IV METHODOLOGY . . . . . . . . . . . . . . 68

The Social Network Indexes....... 69

Dependent Measures . . . . . . . . . . . . 90

Control Variables . . . . . . . . . . . . 99

Statistical Tests . . . . . . . . . 104

V RESULTS . . . . . . . . . . . . . . . . . . . 114

Describing the Networks of the

Study Population . . . . . . . . . . 114

Networks and Mortality . . . . . . . 118

Mortality and its Predictors....... 124

Hypothesis 1: Social Networks as

Predictors of Mortality....... . 130

Hypothesis 2: Social Networks as

Pradictors of Disease Incidence. . . 143

Hypothesis 3: Social Networks as

Predictors of Disease Progression . . 146

VI DISCUSSION . . . . . . . . . . . . . . 152

Hypothases................. . . 153

Theoretical Framework. . . . . . . . 158

Network Relationships and Mortality . . 159

Understanding the Contradictions . . . . 166

VII IMPLICATIONS AND SUGGESTIONS FOR

FUTURE RESEARCH . . . . . . . . . . . . . 175

Social In,erventions........... 176

Future Research . . . . . . . . . . 179 
vij

PAGE

APPENDIX . . . . . . . . . . . . . . . . . . . 197

A Forms Used to Record Medical Care

Utilization.............. 197

B Kaiser Clinical-Behavioral Disease

Classification System . . . . . . . . 203

C Age and Sex-specific Responses to

Social Network Questions on Household

Interview Survey............ 206

D Overview Boxes for Network Indexes . . . . . 221

Scope of Immediate Family . . . . . . . 222

Scope of Total Family . . . . . . . . . 224

Scope of Friends. . . . . . . . . . . 226

Scope of Community Involvement . . . . . 224

Scope of Overall Network . . . . . . . 226

Index of Children . . . . . . . . . . . . 233

Family of Origin Interaction . . . . . . 235

Family Ties . . . . . . . . . . . . . . 237

Interaction with Relatives........ . . 238

Close Friends Interaction . . . . . . . . 241

Other Friends Interaction . . . . . . . 243

Work Interaction............ . . 245

Involvement in Organizations or Clubs . 243

Organization and Church Interaction . . 245

Social Leisure. . . . . . . . . . . . . 251

Network Size. . . . . . . . . . . . . 253

Immediate Family Size . . . . . . . . . 255 
vi i i

PAGE

Total Family Size . . . . . . . . . . 257

Friends Network Size. . . . . . . . . 259

Frequency of Contact With Network Members 261

Overall Network Interaction . . . . . . 264

E Zero-order and Partial Correlations

for Dependent, Independent, and

Control Variables ........... . 268

F Coding of Collapsed Variables for Logistic

Regression Analyses . . . . . . . . . . 272

G Mortality Rates for Control Variables and

Network Scope Variable Usad in Table XII. 276 


\section{LIST OF TABLES}

TABLE

PAGE

I Frequency Distributions for Selected

Demographic Characteristics of the

Household Interview Survey Respondents . . 67

I Variable List, Data Sourco, and Measurement

Instrument for Social Network/Mortality/

Morbidity Study . . . . . . . . . . . . . 70

II Questions from Household Interview Survey

Assessing Relationship Domains . . . . . . 71

IV Principai Factor Analysis of Family and

Friend Variables from Household

Interview Survey . . . . . . . . . . . . . 83

V Principal Factor Analysis of Interaction

Indexes from Relationship Domains . . . . 86

VI Principal Factor Analysis of Four Summary

Network Heasures . . . . . . . . . . . . 87

VII Intercorrelations of Summary Network Measures 89

VII Comparison of Age-specific Mortality Rates

per 100 for Men and Women Aged $30-69$ in

the Kaiser Medical Care Plan Portland,

1970-82) and the Human Population

Laboratory (Alameda County, 1965-74) . . . 93 
IX Zero-order Correlations of Indicators of

Heal th Status at Time of Household

Interview Survey and Mortality . . . . . 103

$x$ Mean Scores on Summary Network Indexes

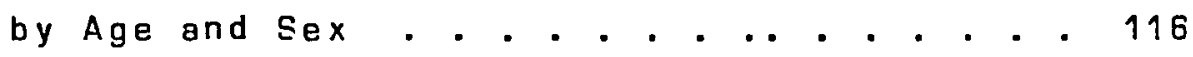

XI Percent of Study Population in Small, Medium, and Large Network Categories by Age . . . 117

XII Age and Sex-specific 12 year Mortality

Rates per 100 for Men and Women Ages

18 and Above . . . . . . . . . . . . 122

XII Age and Sex-specific Mortality Rates per

100 by Categories of Structural Network

Indexes . . . . . . . . . . . . . 123

XIV Age and Sex-specific Mortality Rates for

Marital Status . . . . . . . . . . . 125

XV Results of a Saries of Logistic Analyses of

Effects of Control Variables and Network

Scope on Mortality . . . . . . . . . . 127

XVI Results of a Series of Logistic Analyses of

Effects of Dichotomized Control Variables

on Mortaitty, Adjusted for Age. . . . . . 131

XVII Changes in Relative Mortality Risk for Index

of Network Scope, with Adjustment for

Significant Control Variables . . . . . . . 132 
XVIII Relative Mortality Risk for Sectors of

Network Scope, Adjusted with Significant

Control Variables . . . . . . . . . . . . . 135

XIX Relative Mortality Risk for the Four Network

Structural Indexes, Adjusted with

Significant Control Variables . . . . . . . 137

XX Relative Mortality Risk for Network

Interaction within the Relationship

Domains, Using Full Model . . . . . . . . . 138

XXI Relative Mortality Risk for Network Scope

for Men and Women, Using Full Model . . . 140

XXI Relative Mortality Risk for Network Scope by

Age Categories, Adjusted for Significant

Control Variables . . . . . . . . . . . 141

XXII Relative Mortality Risk for Variables in Full

Regression Model, With and Without Network

Scope Entering Last . . . . . . . . . 142

XXIV Mean Rates per 100 Person Years of Initial

Doctor Office Visits by Age, Sex, and

Network Scope . . . . . . . . . . . . . 145

XXV Hierarchical Multiple Linear Regression

Analyses for Men and Women Predicting

Disease Incidence from Network Scope. . . . 147 
XXVI Change in Mean Rate of Outpatient Contacts by

Age, Sex, and Network Scope . . . . . . 148

XXVII Hierarchical Multiple Linear Regression

Analyses for Men and Women Pradicting

Disease Progression from Network Scope... 150 


\section{LIST OF FIGURES}

FIGURE

PAGE

1. Conceptual Framework . . . . . . . . . . . . . 11

2. A Schema of Structural Aspects of the Center

for Heal th Research Outpatient

Information system . . . . . . . . 54

3. Social Network Model . . . . . . . . . . . . . 74

4. Components of Network Scope Indexes. . . . . 76

5. Components of Network Size Index . . . . . . . 77

6. Components of Network Frequency of

Contact Index . . . . . . . . . . . . . 78

7. Components of Network Interaction Indexes. . . 79

8. Number of Respondents Remaining Eligible for

the Kaiser Permanente Medical Cere Program

in Years Subsequent to the Household

Interview Survey . . . . . . . . . . . . . 91

9. Formula Used by Center for Health Research

to Convert Utilization Summary Measures

to Rates.................. . . 95

10. Model for the Study of the Ability of

Sacial Networks to Predict Mortality

and Morbidity . . . . . . . . . . . . 107 
11. Mean Summary Network Scores of Deceased and Surviving Males by Age. . . . . . . . . 119

12. Mean Summary Network Scores of Deceased and

Surviving Females by Age . . . . . . . . . 120

13. Martality Rates by Levels of Network Scope Index . . . . . . . . . . . . . . . 121 
AN ABStRact OF tHE dissertation OF Mary Bahner Maxwell for the Doctor of Philosophy in Urban Studies presented May 3 , 1985

Title: The Impact of Social Networks on Mortality, Disease Incidence, and Disease Progression.

APPROVED BY MEMBERS OF THE DISSERTATION COMMITTEE:

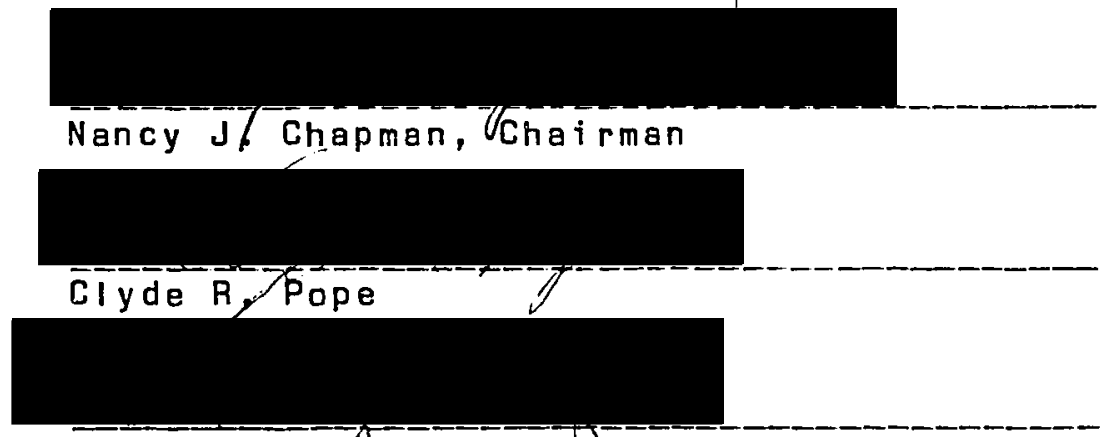

Berit Ingersoli-Daytob

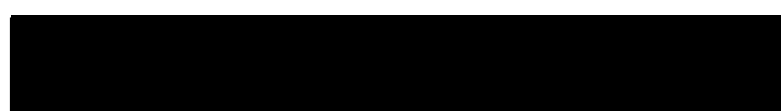

Seymouradier

Cost-effective methods to maintain the health of urban citizens are essential. Social factors have been shown in prior research to be related to disease and its outcomes. Several recent longitudinal studies of large community populations have revealed that people with more extensive network resources live longer. However, it is not known whether this occurs because social ties prevent disease or retard its progression once it occurs. Being able to 
delineate when on the health/illness continuum social connections are important would make possible poijcy directed more specifically at either disease prevention or disease control.

The purpose of this research was to: (1) determine the relationship between social network indicators and mortality in an urban sample; (2) extand that knowledge by addressing the relationship between networks, disease incidence, and disease progression, and (3) delineate which specific network sectors were the strongest predictors of health outcomes. This was uniquely possible because measures of the three dependent variables were available within the same data set at the Kaiser Permanente Center for Health Research. The research design was longitudinal, based on survey data. The conceptual framework posited that social support delivered via social networks modifies disease states.

The setting was the Northwest Region, Kaiser Permanente Medical Care Program, an HMO serving the Portland-Vancouver SMSA. The sample includeg 2603 adults who participated in a 1970 household interview survey. Their health service utilization data from 1967-73 has been con ltarized and linked with the survey information. As of 1982,376 have died.

To measure the independent variables, four summary social network indexes lscope, size, frequency of contact, 
and interaction) were prepared according to a network model based on the survey questions available, network theory, and prior research. Indexes representing relationship domains (spouse, children, family of origin, relatives, work, close friends, other friends, organizations, and social leisure] were constructed. Control variables included age, sex, socioeconomic status, health status indicators, and health behavior measures. Multiple logistic regression was used to assess the first hypothesis because mortality was a dichotomous variable. Since the other two outcomes were continuous, ordinary regression was usad.

Each of the four summary network measures was a statistically significant predictor of 12 year mortality. Network scope was the strongest predictor. When broken down into ralationship domains, marital, family, and kin relationships were not predictive of death, although almost all relationships were in the expected direction. Only the extended ties of close friends, other friends, work associates and social leisure activities were significant predictors. There was no relationship between network scope and either disease incidence or disease progression, so it is still unclear how social connections act to decrease mortality. To put the network contribution in perspective, only .01 of the total variance in the logistic regression 
model of why people in the study population died was due to social factors.

This study of an urban community population in the Pacific Northwest confirmed evidence from other parts of the country that summary measures of the social network are associated with mortality and indicated that friends are the most health-protective part of the network. 


\section{CHAPTER I}

\section{INTRODUCTION}

Since earliest times, humankind has speculated about disease. Why did some members of the group fall ill while others remained healthy? When more than one individual had the same symptoms at the same time, what caused the variations in the time some people took to recover from the illness, or, for those less fortunate, what caused the variation in the time till they died? With the dawn of the scientific era and the microscopic identification of disease-producing organisms, the sources of illness began to be identified. However, overwhelming microbial agents are unable tu explain the occurrence of many diseases in modern technological society.

More than two-thirds of the people in the United States today dwell in cities. Historically, cities were unhealthy (Gluck \& Meister, 1979). Even as late as the turn of this century, disease bred in overcrowded urban areas where large numbers of people had congregated because jobs were available as a result of industrial development lBerry, 1973). Sanitation was poor, and public health programs were just beginning. 
Now the major infectious disaases have been controlled. Instead of tuberculosis, typhoid, and smallpox being the leading causes of mortality, illnesses such as heart disease, cancer, and stroke now claim most lives. These chronic illness etiologies are not well understood, and appear to be related in complex ways to lifestyle and the environment (Dubos, 1965). With current treatment methods, people with such diseases often live for long periods of time. There is a constant search for ways to eliminate, or at least modify, the chronic illness killers of our time.

In post-industrial society where technology has made the treatment of disease once it has occurred extremeiy expensive, finding cost-effective methods of disease prevention and the maintenance of the health of citizens is imperative. Two current trends in this direction are pertinent to ur: an community health. The first involves the movement to modify individual lifestyles by decreasing health destructive behaviors such as cigarette smoking, overeating, and lack of exercise. Maintaining social isolation is also considered a negative health behavior. The second movement involves the attempt to manipulate the social environment of people to provide more social support: solf-help support groups, neighborhood centers, and programs for the elderly using volunteers are examples of this 
approach. The attractiveness of these movements is that they do not need to be costly.

Both of the movements cited above involve the notion that disease can be prevented, or at least controlled, by social factors. However, exactly where social influences may be most partinent on the health/illness continuum has not yet been determined [House, 1982]. This is important to know, because if social support is more important in disease incidence, social and health poljcy in the area of prevention would be most appropriate. If, on the other hand, social ties function primarily to prolong survival, intervention after disease is apparent would be most in order. In this case, social support would be considered a form of therapy.

The two trends in community health described above can be traced in part to a seminal study first reported in 1979. In that year, Berkman and Syme published an exploratory study of a large communty population from Alameda County, California, which reported that poople with more extensive social networks lived longer. This study generated widespread interest because it implied that health of individuals and communities could be improved simply by increasing social interactions. Berkman and syme speculated that the mortality differentials they obtained may have been due to social networks enhancing resistance to the occur- 
rence of disease, or that, once ill, people with more social resources may have experienced slower progression of disease.

Within a short time, other investigators with longitudinal data sets from communities in others parts of the United States reanalyzed their data looking for similar network/mortality relationships. More rigorous controls and methodologies were used. Some found the same results as Berkman and syme, others found them with less clarity, and a few did not find them at all. Thus, it is still unclear whether social networks do prolong life, to what degree, and exactly how they do this. The question of whether mortality risk is lower because social factors act to lessen disease incidence or act to retard disease progression has not yet been explored within the same data set where the network/ mortality relationship is assessed. There are fem places where the type of data needed for such an analysis is available.

The major purpose of this research is to determine the relationship betwean social networks and mortality in a basically healthy population of members of a large urban health maintanance organization which is located in Portland, Oregon. An attempt is then made to delineate whether social factors influence disease incidence or disease progression within this population. This research is important because it attempts to extend our knowledge of 
the networks/mortality relationship by addressing the reasons behind the association of social factors with death. It is significant in that outcomes related to disase incidence, progression, and death are available within the same unique high quality longitudinal data set.

If social connections are significant predictors of mortality or the disease outcomes, it is important to know which specific aspects of the network are the most pertinent predictors. Thus, a secondary research aim involves exploring network components in relation to the outcome variables.

\section{BACKGROUND}

The notion of socially-induced stress as a precipitating factor in disease has gained wide acceptance. It has been found that a variety of social factors in the environment are associated with morbidity and mortality, including such factors as socioeconomic status, marital status, migration, social disorganization, occupational strain, and geographic mobility [Berkman, 1982; Cassel, 1974, 1976; McQueen \& Siegrist, 1982). Dubos (1965) recognized that even susceptibility to microbial infectious disease was probably a function of environmental conditions leading to physiological stress on the individual, rather than simple exposure to an external source of infection. For the past 
twenty-five years, the role of stressful life events li.e., divorce, job loss, bereavementl in the etiology of various disorders has been a productive field of research. In both retrospective and prospective investigations, modest but statistically significant relationships have been found between increased life changes and the onset of sudden cardiac death, myocardial infarction, accidents, diabetes, tuberculosis, and a variety of more minor disorders. For reviews of this literature, see Dean and Lin [1977], and Dohrenwend and Dohrenwend $\{1974 ; 1981\}$, Rabkin and Struening (1976). Life events may also be related to the course of illness and recovery, whatever the etiology of the primary disease [Kagan \& Levi, 1974].

Psychosocial stress may be moderated by supportive social relationships. Although still controversial, during the past 15 years research and theory have pointed to social support as protecting or buffering individuals against life stresses and their negative impact on health lCassel, 1976; Cobb, 1976; Dean \& Lin, 1977; Kaplan et al., 1977). This has been termed the "buffering Hypothesis" (Thoits, 1982). Social support also appears to have a diract effect on health [Gore, 1981; Thoits, 1982]. The effect of social support does not appear to be limited to any one disease state or organ system and ranges from mental to physical (Antonovsky, 1979; Berkman \& Syme, 1979; Broadhaad et al., 1983 ; Casse1, 1974, 1976; Holise et al., 1982\}. Many 
theorists consider the chronic diseases to be particularly influenced by stress and thus social support lBerkman \& Syme, 1979; McQueen \& Celentano, 1982; Rabkin \& Struening, 1976). Although there have been a variety of crosssectional and retrospective studies of small specialized groups which have addressed social support and its effects on health, few longitudinal studies have been conducted which used samples from general populations.

Recently, however, three major longitudinal studies involving community samples have been reported lBerkman \& Syme, 1979; Blazer, 1982; House et al., 1982) that show a direct impact of social networks/support on mortality. Berkman and syme (1979), in a nine-year mortality follow up of a representative sample of 6928 adults in Alameda County, California, first surveyed in 1965, found that individuals with few social and community ties were more likely to die in the ensuing years than those with more extensive relationships. Borkman and Syme's publication generated much attention from social epidemiologists and believers in wellness promotion. Its wide impact was probably due to the size and design of the research, the magnitude and clarity of the outcome, and the fact that apparently merely having a network in itself was protactive (Schoenbach et al., 1983). The quality of the support provided by the network or the amount of stress it buffered against was not assessed in the 
Berkman and Syme study. Subsequent studies hava yielded conflicting support for the Berkman and $5 y m e$ findings. House, Robbins, and Metzner [1982], in a similar study of a cohort of 2754 adults from a more rural community population in Tecumseh County, Michigan, found the same relationship between social connections and mortality after ten years. However, this on! reached statistical significance for men. Blazer (1982) assessed social support along three parameters [these will be discussed in Chapter II) in a community sample of 331 persons 65 years of age and older in Durham County, North Carolina. These parameters significantly predicted mortality after 30 months. The Schoenbach et al. (1983) findings were more modest and Zuckerman et al. (1984) were unable to find relationships between social networks and mortality. Schoenbach states that because Berkman and Syme and House et al. did not employ a priori, specificallydefined social network variables, the results of their studies are open to suspicion.

The work of Berkman and Syme, House et al., and Blazer is unable to determine what produced the positive network mortality relationships thay obtained because only death certificates were available to them as outcome measures. Although mortality is an important endpoint in epidemiological studies, it is not possible to be specific about where on the health/illness continuum social support is having its Effect. As Berkman and $S y m e$ and House et al. have noted, 
thereare two possible ways in which social relationships may impact on mortality: by affecting the occurrence of disease (early on the continuum] or by affecting illness progression (late on the continuum).

Cassel (1976) believed that social processes affected disease incidence. He theorized that such processes, acting as "conditional" stressors, increased the susceptibility of the individual to disease causing agents in the environment by altering the endocrine balance in the body. He envisagad social processes as thus enhancing susceptibility to disease. However, in light of the eforementioned research involving community populations that delineated the networks/mortality relationships, social processes must have also affected people already stricken with disease. Not all people in a community population are in an optimum state of health. The mechanism postulated by Cassel could have been in operation, but in a different context. Social processes could have enhanced the susceptibility of diseased individuals to the physiological decline inherent in the particular disease process and hastened their demise. Thus, the next step in furthering our understanding of how social networks influence disease processes is to sort out where social connections are important. 


\section{CONCEPTUAL FRAMEWORK}

The conceptual framework for this study, which is outlined in figure 1 , is based upon stress theory as it relates to the course of physical i! !ness. In this model, support can buffer ubiquitous anvironmental stress and can directly affect disease. The elements of this conceptual framework are described next.

\section{St묘토으}

The original definitions of stress were developed by Cannon, Selye, and Wolff (Hinkle, 1973). The experience of a threatening or harmful stimulus [stressor] interacts with both physiological and psychological processes to evoke respanses in organisms [stress] which influence physical and mental states. Stressors may be physical or psychosocial. A stressor may be life threatening, signal the loss of relationship or object, or represent an attack on one's belief system. Stress leads to a sustained state of arousal which is catabolic. The sustained physiological mobilization of the organism has biochemical outcomes which predispose the organism to morbidity and ultimately, mortality (Renner \& Birren, 1977). For a recent detailed exposition of the neuroendocrinological mechanisms involved in the stress/illness relationship, see Henry (1982). Thus, psychosocial processes acting as stressors will, by altering 


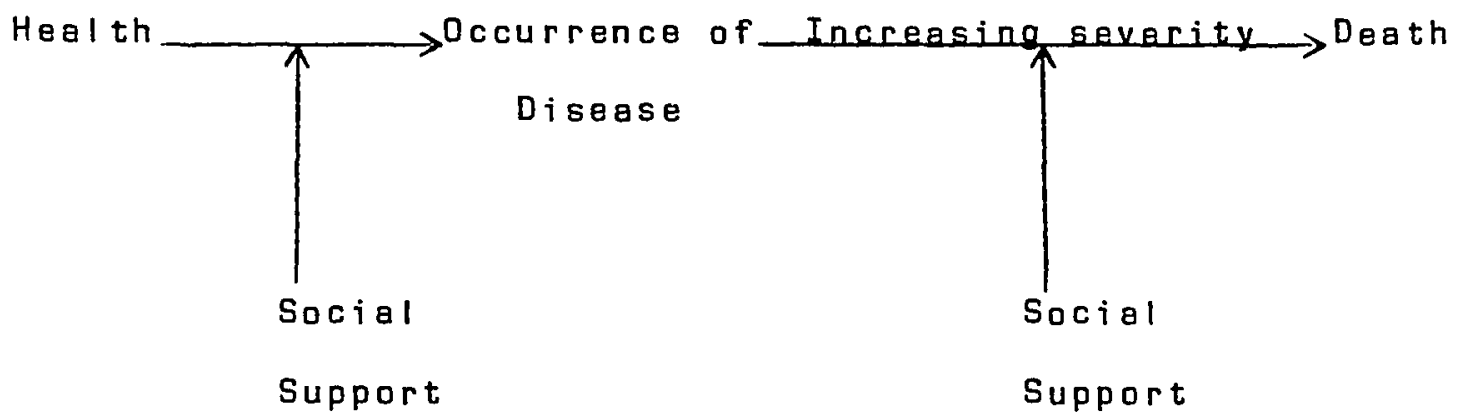

Figure 1. Conceptual framework. 
the endocrine balance in the body, decrease the resistance of the organism to direct noxious stimuli. The psychosocial processes can be envisaged as enhancing susceptibility to disease. The clinical manifestations of this enhanced susceptibility will not be a function of the particular psychosocial stressor, but of the physiochemical or microbiological disease agents harbored by the organism or to which the organism is exposed. Disease manifestations will also be determined by constitutional factors, which in turn are a function of genetic endowment and previous experience [Cassel, 1974]. These latter factors have been outlined in detail by Antonovsky (1979) in his salutogenic model of health. Kasl has racently critically reviemed the research linking stress to health $(1984)$.

\section{Social Support}

Social support as a construct has been defined in a number of ways (Antonovsky, 1979; Caplan, 1974; Cobb, 1976; Kahn \& Antonucci, 1980; Weiss, 1969; J. Mast of the definitions contain some idea of dimensionality, reciprocity, and the implication of feedback from face-to-face interaction. For instance, the characteristics of social support described by Caplan (1974) include the notion that social support occurs through enduring relationships which provide help for the individual in mobilizing psychological resources and mastering emotional burdans, sharing tasks, 
and providing material supplies, skills, and cognitive guidance. The social support system functions by offering information, guidance, and feedback to the individual and by acting as a refuge or sanctuary where the individual may experience stability and comfort. Barrera and Ainlay have recently reviewed the literature discussing the structure of social support $(1983)$.

In terms of the stress model discussed above, it has been theorized that social support exerts a protective effect which buffers the individual from the physiological or psychological consequences of exposure to stressor situations (Casse1, 1975; Cobb, 1976;Rabkin \& Struening, 1976). Social support can have direct effects on health as well [Gore, 1981; LaRocco, 1983; Thoits, 1982). For example, in instances of negative life events such as bereavement, network support can modify resultant stress which could lead to negative health outcomes (Walker et al., 1977). This is an example of a buffering effect of support. In terms of a main effect, ongoing network support may operate to promote health when no stressful events have occurred. Because there are no measures of stressful life events available for this research, it primarily assesses a direct effect model.

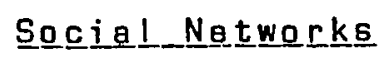

The way in which social support has been operationalized varies from study to study. Most measures fall into 
either the category of quality or content of interpersonal relationships or quantity or structure of relationships. Some instruments measure both. For measuring the quantity of relationships, a social network model [Fischer, 1977 ; Mitchell, 1974] has often been used [Berkman, 1977; Liem \& Liem, 1975; Tolsdorf, 1976; Walker et al, 1977). This has led to scoring network data which provide information about the network as a whole [size, density, functionality] and about the various types of support available to the individual through his or her ties to others. Mitchell and Trickett (1980) and Wel Iman (1981) have discussed applications of network analysis in social support research and the role of social networks in mediating the provision of support .

\section{Diseeㅡ몹}

A disease is a well-defined model of a process of disruption in the normal homeostasis of psychologicalphysiological systems [Gonnella et al., 1984). Diseases can be broadly categorized as acute or chronic, and physical or emotional. Chronic diseases are physiological disorders of long duration which are noninfectious. They are syndromes which may have a long incubation phase and with which an individual may live for many years before death. They are often treatable and able to be stabilized by modern medical methods, but are not "cured" in the usual sanse. Some 
chronic diseases are serious and imply a shortened life span and/or physical impairment.

The incidence rate of a disease is the number of its new cases, in a defined population at risk, over a pariod of time. The preferred method for determining incidence is prospective surveillance of a cohort who are assessed for a variety of possible risk factors and are monitored for the development of new cases (Kasl, 1983). If the monitoring of the new cases of disease were to continue for additional medical outcomes, this process would become a study of the course or progression of the disease.

Health is a state of optimal biopsychosocial functioning.

Death is the absence of life.

\section{HYPOTHESES}

Given all of the foregoing and controlling for the major confounding factors (these will bediscussed later) that would be expected to operate independently of stress in causing morbidity and its outcomes:

1. Adults with moresocial network resaurces will have less risk of death.

2. Adults with more social network resources will have lower incidence of disease. 
3. Adults with more social network resources will have less disease progression.

Detajls of the operationalization and measurement of the social network, mortality, disease incidance, and disease progression variables are given in Chapter IV. Some discussion is appropriate now to explain hypotheses 2 and 3. When a person develaps an illness, he or she comes to the health care system and uses its services for treatment. The first contact with the system usually indicates a new illness is occurring. If hypothesis 2 is correct, people with more social connections would have less of these contacts than those with fewer connections. After a person becomes ill, the amount of contact with the health caresystem is usually in proportion to the gravity of the physical problem. As the individual becomes sicker, more office visits are likely to occur and more resources are likely to be used over time to maintain as healthy a state as possible in the face of decline. Thus, if hypothesis 3 is correct, people with more social network ties should have slower illness progression and hence use relatively less health care and require fewer resources over time. Those individuals with minimal network connections would be expected to have a deterioration in their health status over time and concomitantly use relatively more resources and care. 


\section{OVERVIEW OF METHODS}

To test the hypotheses that social network resources affected death, disease incidence, and disease progression, an existing longitudinal data set at the Kaiser Permanente Center for Health Research was utilized. A detailed explanation of this institution and this data sat is offered in Chapter III. Briefly, a random sample of subscribers to the Northwest Region of Kaiser Permanente, selected in 1967 when the Canter for Health Research began, has continuously had all details of its health care utilization computerized for research purposes. In 1970 , a subsample of this group was selected to be the focus of an extensive household interview. The details of this survey are also explained in Chapter III. The survey elicited information of a demographic, economic, social, and attitudinal nature in terms of lifestyle and health from over two thousand adults. Social network information included 26 questions about numbers and interaction with femily, friends, co-workers, and community organizations. The survey information on each individual has been linked to his or her health care utilization information, which comes from each person's medical record. This linkage of the two types of information is available from 1967 to 1973.

Thus, this dissertation uses a longitudinal design based on survey research which had been conducted in the 
past for the purpose of describing Kaiser Pormanente members. The dependent variables are mortality, disease incidence, and disease progression. The independent variable of major substantive interest is the social network. The research design includes nine control variables known also to affect the network/mortality relationship. The sample comprisad the 2603 adult members of Kaiser Permanente surveyed in 1970,376 of whom had died as of the end of 1982 .

First a conceptual model of the social network construct was developed a priori based on the available questions from the household interview survey, network theory, and previous network/mortality research. The model is presented in Chapter IV. It features four structural network dimensions and several source and relationship domain dimensions. These dimensions were operationalized by combining 26 pertinent questions from the survey. Four overall network indexes were constructed: network scope, network size, frequency of contact with the network, and network interaction. Source indexes assessed family, friend, and community interactions. This model was tested for validity by subjecting its components to factor analysts. Reliability of the indexes was assessed by coefficiont alpha. 
Second, the control variables to be used in the study were selected from the many variables existing on the data files. These nine control variables included three demographic variables, three health behaviors, and three physical health status indicators. Age, sex, and socioeconomic status were the demographic variables. The three health behaviors related to smoking, drinking, and physical exercise. The three physical health status indicators were perceived health, length of hospital stay, and outpatient contacts with the health care system. These were selected for inclusion in the model by assessing the correlation of several available health status variables with each other and with mortality.

Next, the dependent variables were developed. Mortality within the 12 year period (1971-82) was the first dependent variable. The total incidence of new disase during a seven year period was the second independent variable. The assumption was made that there would be minimal network changes three and a half years before the survey, and three and a half years after because network changes usually occur slowly over time. Operationally, this variable was a simple count of all doctor's office visits made by respondents between the years 1967 and 1973 for a new illness or a new episode of disease or illness.

It was assumed that if social networks affected disease progression, this would be revealed by changes in 
health service utilization over time. In other words, people getting sicker would use more resources and would need to make more contacts with the health care system over time. If networks were influential in hastening disease process, as hypothesized, people with more large networks would have a lower rate of use of health services than those with smaller networks.

Finally, to assess hypothesis 1 , that more social network resources would result in reduced mortality, a logistic regression approach (Walker \& Duncan, 1967) was used. This was prefarable to multiple linear regression because mortality is a dichotomous variable and does not meet the assumptions for the more familiar ragression method. Because a loglinear logistic approoch was used, the continuous independent variables had to be collapsad. First, each control variable was evaluated independently against mortality, then with age entered as a control. This process was completed in order to eliminate variables not significantly predicting mortality so as to have the most parsimonious model. The final equation consisted of age, sex, and two of the health status measures, with the network measure entering last. Then, different parts of the network and various social relationship domains were tested to evaluate which aspect of the network was most important in predicting mortality. 
For hypothesis 2 , that social network resources would decrease disease incidence, a multiple linear regression approach was used. This was appropriate because disease incidence was measured on an interval scale. The demographic and hoalth practices variables were used as controls.

Hypothesis 3 also involved using multiple linear regression to assess the relationship between networks and disease progression, which was also measured on an interval scale. In this model, only the demographic variables were used as controls.

In summary, this research uses regression techniques to explore relationships between social networks and mortality, disease incidence, and disease progression. The major aim is to probe reasons behind the networks/mortality association. A related aim is to assess which specific network components li.e., spouse, relatives, friends, co-workersl are most predictive of health outcomes. An overview of the beckground, theoretical framework, and methods was given in this chapter.

Chapter II presents a review of the literature upon which the study was based. Chapter III discusses the data sources and sample to be used in the analysis. The focus is upon the structure of the existing information system as encountered at the Kaiser Permanente Center for Health Pesearch before any manipulation to accomplisn the aims of 
this dissertation began. Chapter IV explains methodology. It highlights the social network index construction and preparation of the variables used in the research and the statistical procedures to which they were subjected. Chapter V gives the results obtained by the research, while Chapter VI features a discussion of these findings. Policy implications and suggestions for further work are given in Chapter VII. 
CHAPTER II

\section{REVIEW OF THE LITERATURE}

Social epidemiology is a field of inquiry wherein the social factors laading to disease incidence, prevalence, progression, and death in large population groups are studied. As described in the previous chapter, the epidemiologist Cassel was one of the first to suggest that social support might be a causal factor in disease etiology [1976). This chapter reviews the literature on social support and social networks as variables in the biopsychosocial theory of disease.

The first section of the chapter addresses the construct of social support as well as the apprach of social networks to its measurement. After tracing the origin of these ideas, the focus of the discussion is on describing the network concepts used in fashioning the network indexes for this dissertation. The second saction of the chapter describes the mortality studies done since 1977, and, in particular, how the social networks ware measured. Also featured are the recent studies shedding light on variables which confound the networks/mortality relationship. The third section of the chapter reviews empirical evidence for 
the disease incidence hypothesis as opposed to the disease progression hypothesis.

PART I. SOCIAL NETWORKS

\section{Sogciial S Support}

The social support construct is rooted in classical sociology. As early as the turn of the century, Emil Durkheim [1950) had suggested that individuals who were not integrated into society were more likely to attempt suicide. Parsons (1951) suggested that the most important element of any aspect of social control was "support." He believed support served to provide reassurance to the individual, impeding the use of aggressive behavior to satisfy needs.

More recently, earlier terminologies have been subsumed under "social support" in reference to the processes by which interpersonal relationships protect people from the harmful effects of stress. Cassel (1976) was the first to suggest that social support buffered stress and reduced illness and its negative outcomes. Many studies have since appeared in the literature in an attempt to document this (Andrews et al., 1978; Barrara, 1981; Bloom, 1982; Davidson et al., 1981; Dimond, 1979; Eaton, 1978; Funch \& Marsholl, 1983; Gore, 1978; Henderson et al., 1978A, 1978B; Holanan and Moos, 1981; Langer et al., 1975; Liem \& Liem, 1976; Lin et al., 1979; Lowenthal \& Haven, 1968; Macelveen, 4972; Medalie \& Goldbourt, 1976; Mermelstein et al., 1983; Norbeck 
\& Tilden, 1983; Nuckolls et al., 1972; Reed et al., 1983; Schaefer et al., 1981; Turner, 1981; Williams et al., 1981; Woods \& Earp, 1978; Winnubst et al., 1982, are but a few], as well as numerous review articles lBerkman, 1984; Broadhead et al., 1983; DiMatteo \& Hays, 1981; EII, 1984; Heller, 1979; Jung, 1984; Thoits, 1982; Wallston et al., 1983; Wortman, 19841. Although there is yet no consensus on the nature, meaning, and measurement of social support lsee Chapter I for definitions and types], many researchers claim that social support has positive effects not only on physical health but mental well-being lsee Leavy, 1983; Mueller, 1980; and Henderson, 1984 for reviews). However, Wallston, Alaga, DeVellis, and DeVellis (1983), in a critical review of research linking social support and physical health, note that the evidence supporting this relationship is actually weaker than often s!eimed.

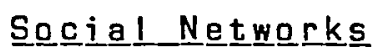

Meanwhile, in the course of ethnographic research, anthropologists had described many aspects of the social relations of the peoples they had studied. It remained to J. A. Barnes in 1954 to give the metaphoric concept of "network" concrete meaning in his classic study of a Norwegian fishing village (Whitten \& Wolfe, 1973). Barnes used cancepts from mathematical graph theory to describe an individual's social field in terms of the linkages sur- 
rounding him or her. This type of network was termed a "personal" or "ego-centered" network. In contrast, the term "social network" was originally usad to refer to the total set of linkages among all members of a particular population. More recently, however, the term social network has been used to refer to both microscopic and macroscopic types of networks (Mitchell \& Trickett, 1980).

The network concept was quickly adopted by Elizabeth Bott [1955], whose studies of urban London families were widely read. Since then, network concepts have proved useful tools for analyzing groups as disparate as preliterato tribes, extended families, and complex bureaucratic organizations. Network analysis has especially helped to advance urban studies [Fischer, 1977, p. 20]:

The nature of urban life, opaque and confusing when viewed through the typical sociological perspectives, becomes much clearer and more amenable to investigation when looked at with network analysis.

A social networkis aspecific set of linkages amonga defined set of persons. The overall structure of the network and the characteristics of the linkages may be used to interpret the social behavior of the persons involved. Information, goods, and services transmitted within networks are called social network support. A number of useful concaptual tools are available in applying a network analytic framewark to health and social support fcraven \& Wellman, 1973; Fischer, 1977; Mitchell, 1974). 
Network Structure. To examine the overall structure or morphology of a network, patternings have been delineated which allow for classification. These include: size lnumber of actors in the network], clustering [extent to which distinct clusters of dense links exist within the network], density lextent to which members know each other independent of the focal person), and dispersion (range of sources of social contacts from which the links are established). Other structural properties are termed anchorage, reachability, range, and homogeneity. The structural form of the network is important bacause it influences the flow of resources through specific ties (Wellman, 1981).

Network Linkages. The links in a network can be studied quantitatively. Terminology describing linkages includes: sector lthe social context from which the link emerged], frequency [the number of times contact is made], duration (how long the link has been in existence), symmetry [the balance of exchanges across a link], multiplexity [the number of different role relationships or distinct activities, exchanges, dependencies, or modes of interactions, intensity (degree of commitment in a link\}, and intimacy (degree of closeness). By constructing a profile of each link or an average for a set of links in terms of these dimensions, a sense of the range of functions performed by the social network for its members can be obtained. 


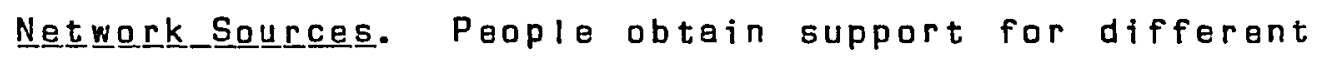
types of needs and crises from various patierns of immediate family, extended family, friendship circles, neighbors, and colleagues from school, church, or the wark place. Role theory helps to distinguish the attributes of various sources of support that have the greatest consequences for health maintenance (Piijsuk \& Froland, 1978).

Personal networks have often been diagrammed as a series of concentric circles radiating out from a focal individual (Berkman, 1977; Kahn \& Antonucci, 1980; Maxwell, 1982). The center circle represents the individual being studied. The next circle, the personal cell, includes closest relatives, i.e., immediate family and perhaps most intimate friends. A farther zone includes very close relatives and friends with whom there are less intimate relations. Friends and relatives with whom one has more passive but still emotionally important relations comprise the next zone. The zone following contains people who are important in a pragmatic sense for the logistics of daily life. The most distant zones include people who are known by the individual but have no great importance in the individual's life. Separating network linkages into different sources is necessary because exchanges tend to occur differentially within each zone.

Exchanges. Social exchange theory promulgated by Blau (1964) views society as structured by its transactions. 
Exchange refers to the content of the linkages between people. Exchange has been operationalized by McCallister and Fischer (1978) as an interdependence between two individuals whereby the behaviors of each impact directly on the outcomes of the other. Social support can be considered a type of exchange commodity. Although there have been many conceptualizations of social support (see Chapter I], the categories of social support offered by House (1981) can sarve as an example.

House outlines four general categories of support that flow back and forth from the focal individual to his network members: (1) emotional support iesteem, affect, trust, concern, listening]; (2) appraisal support [affirmation, feedback, social comparison); (3) informational support [advice, suggestion, directives, information]; (4) instrumental support (aid in kind, money, labor, time]. There appears to be a division of labor in providing support between different roles and zones in an individual's personal social network.

Litwak and Szelenyi [1969) examined the helping functions of kin, neighbors, and friends. They concluded that neighbors can best handle immediate nonrecuring emergencies, kin are most important for long-term commitments and material assistance, and friends can help in areas that require agreement, moral support, and pasitive affect. Each 
sector of an individual's network may provide a unique part of his or her overall support. There is undoubtedly much overlap, and substitution occurs. The nuclear family provides intimacy, nurturance, and reassurance of worth lBerger \& Wuescher, 1975). The presence of a confidante buffers against losses (Lowenthal \& Haven, 1968). Linkages in the community sector serve for problem-solving, social integration, joint action, screening and referral, as well as transmittal of cultural values and norms. Whether there is a differential effect from these various kinds of exchanges in fortifying and strengthening the individual from adverse health consequences is unknown. Johnson (1983) found that among a population of older people, the most comprehensive and least stressful support was provided by a spouse. Many studies have shown positive health benefits from being married (Asher, 1984; Berkman \& Syme, 1979; House et al., 1982; Chandra et al., 1983; Kaskenvuo et al., 1981). The research of Simons (1984) points to the importance of diversity in the social netmork in order to compensate for the absence of a social category ralevant for the satisfaction of a particular nead.

Negative Aspectes. It must be recognized that not all social relationships that make up networks are uniformly positive ones. Networks may or may not be supportive. They may contain both positive and negative aspects at the same 
time, even within the saine relationship |Argy| \& Furnham, $1983 ;$ Rook, 1984$\}$.

Netmork Stability. Network changes as they occur over time are also an important issue. Schulz and Rau (1984), in a theoretical paper on social support through the life course, report that the consensus among most researchers is that network size and frequency of contact, especially with close kin, remain relatively stable across the life span. Dthers have found declines in network size with age, with decreasing frequency of certain types of social contacts with age.

PART II. SOCIAL NETWORKS AND MORTALITY

Lisa Berkman's [1977] classic exploratory study of network/mortality relationships began an era of research aimed at defining the healtheffects of social ties. This longitudinal study of a large general population showed that people lacking personal and community connections were more likely to die in the nine year follow up period than those with more extensive contacts. Networks were assessed using three single dichotomous survey questions Imarriage, church membership, organization membershipl, an index prepared by ranking contacts with close relatives and friends, and a social network index based upon the ranking of the aforementioned sources of social contact weighted by mortality rates. The latter index was not strictly a measure of 
quantity of social contacts: intimate contacts were weighted more heavily than extended ties. Modified chi square statistics were used to assess relationships between the network measures, mortality, and a variety of risk factors and potentially confounding variablas. Each of the sources of social cortact predicted mortality independently. The more intimate ties of marriage, and friends and relatives, were stronger predictors than church and group membership.

In 1982, House, Robbins, and Metzner reanalyzed data from the Tecumseh Community Health study to determine if social connections and activities also predicted mortality in their population. The social variables assessed during the survey which had been done approximately ten years oarlier ware grouped as intimate relationships (marital status, frequency of visiting friends and relatives, frequency of going on pleasure drives/picnicsl; organizational involvements Ifrequency of church attendance, frequency of attending meetings of voluntary associationsl, and active and passive social leisure activities ffrequency of attending spectator events such as movies, plays, fairs, ond sports events, time spent watching television, listening to the radio, or readingl. The House et al. study contained more adequate measures to control for prior physicel health status than did the Berkman and Syme study. Men reporting a 
higher level of social relationships and activities were significantly less likely to die during the follow up period, after adjusting for age and a variaty of risk factors. Trends for women were similar but generally nonsignificant with age and risk factors controlled in multiple logistic regression analysis. There was no association between mortality and satisfaction with the social relationships or activities. The results obtained by House et al. are generally similar to those of Berkman and syme, who had used somewhat differant measures. In the Tecumseh study, however, weaker associations were found between friend and relative contact and religious involvements and mortality, with much stronger associations for arganizational involvements. Leisure activities were not assessed in the Berkman and Syme study, but proved consequential in Tecumseh.

Also in 1982, Blazer reported a study of an elderly population in which social support predicted mortality within a 30 month period. Three parameters of support were constructed from 11 items on the Older Amaricans Resources and Services [OARS] social support scale: [1] roles and attachmants (marital status, number of living childran, number of living siblings); (2) frequency of interaction ltelephone calls during the past week, visits with friends or relatives during the past week]; and [3] perception of social support, made up of six items. Each of these three parameters significantly predicted mortality after control- 
ling for a variety of risk factors in binary linear regression analysis. Impaired perceived support was the strongest pradictor. In contrast to Berkman and Syme, who found increased mortality rates as social ties decreased, no consistent pattern of increased mortality rates was associated with lower interaction or support. Rather, a thresiold effect seemed to be in operation in Blazer's data, in contrast to Berkman and Syme's findings of a doseresponse association.

In an attempt to replicate Berkman and Syme's work, Schoenbach and his colleagues studied the relationship between a social network index and survivorship in an Evans County, Georgia, cohort from 1967 to 1980. They constructed an index similar to Berkman and syme's and tested it in race-sex-specified proportional hazards models llogistic regression without interaction termsl for 2059 subjects who were examined in 1967-69 during the Evans County Cardiovascular Disease Epidemiologic Study. The study emphasized a priori construction of the social network index and specification of the statistical test to be used priar ta the analysis of the data.

Schoenbach et al. found only modest support for the network/mortality relationship. Among white males the ageadjusted hazard ratio comparing the lowest to highest value of their 6-point network index was 2.0, but controlling for 
confounders (primarily cardiovascular diseaso risk faciors) reduced this ratio to 1.5. The coefficient for the social network effect was not significant in the fully controlled model. The network effect among white females, black males, and black females was weaker and clearly nonsignificant. Marital status and church activities mere predictive of survivorship in exploratory analyses. Diminished survivorship among older poople with few social ties was found.

Zuckerman, Kasl, and Ostfeld (1984) studied psychosocial predictors of mortality among the elderly poor in an eastern city. Nine questions on a survey assessed contacts with friends and relatives. Four questions concerned friendships, and two questions asked about children. Strict controls for objective health status were used. It was found that when rigorous control for prior health was introduced, mortality among the elderly poor was not related to friendship networks or frequency of interaction among friends. Only the presence of living children reduced the risk of mortality.

\section{Moderators of the Netmorks/Mortality Relationship}

It is wall known that other variables are related to both networks and mortality to various degrees. Some of these which have been used as control variables in the aforementioned studies have included age, sex, objective health measures, perceived health, socioeconomic status, and 
various psychological states. Apart from age, health, and sex, the latter measures have had minor effects. Recent studies examining psychosocial/mortality relationships have been published and will now be described.

In a paper based on data from the Human Population Laboratory lthe same Alameda County data used by Berkman and Syme), Kaplan (1983) demonstrates the effects on ischemic heart disease mortality of health behaviors, perceived health, social networks, socioeconomic status, depression, helplessness, and life satisfaction. In Kaplan's view, progress in psychosocial epidemiology depends on converting lists of variables into theory or models which show the impact of the variables on disease incidence, progression, and mortality. The purpose of model construction is to allow sight of the common threads, interrelationships between variables, and direct and indirect paths of influence, as the search for underlying pathophysiological mechanisms continues. In Kaplan's path analytic-like models, only social networks and socioeconomic status had exclusively direct effects on ischemic heart disease mortality. The effects of these two variables were also the largest of all those considered. Health practices had diract and indirect effects through social networks and perceived health. Perceived health had some direct effects, with indirect relationships via health practices, socioeconomic status, and helplessness. Depression directly 
affected networks with indirect links to health practices, helplessness, perceived health, and socioeconomic status. Life setisfaction impacted on health practices, perceived health, helplessness, and social networks.

Health Practices. Certain aspects of daily lifestyle were predictive of future health status among survivors in the Human Population Laboratory's nine year longitudinal analysis. Cigarette smoking, alcohol consumption, physical exercise, hours of sleep per night, and weight in relation to height were significantly associated with overall health outcomes later. Socioeconomic level was also associated with the health practices index (Wiley \& Camacho, 1980 ). Using information from the same data set, Wingard, Berkman, and Brand (1982) found that four health-related practicas predicted mortality in her study: never smoking, physical activity, alcohol consumption, and sleeping seven to eight hours per night.

In a study investigating the relationship between individuals' perceived level of social support and their performance of beneficial health practices, a strong positive relationship was found (Hubbard et al., 1984). The two groups studied were not random samples, however. One group consisted of senior citizens, and the other adults attending a health fair. Langlie (1977), in a survey of $383 \mathrm{midwest-}$ ern adults, found that appropriate indirect health risk 
behayiors were associated with high socioeconomic status and a social network characterized by frequent interaction with nonkin. Pratt (1971) found that structural characteristics of the family influenced health practices. Coburn and Pope [1974] reported that socioeconomic status positively affected health practices among their sample of Canadian male workers, and that group membership and participation were also significant indicators of health practices.

Branch and Jette (1984) assessed personal health practices as they affected mortality among the elderly, using data from the Massachusetts Haalth Care Panel Study. They noted that research on young and middle aged adults has demonstrated a correlation between certain personal health practices and reduced mortality, and wanted to see whether these findings could be generalized to elders in their 70 's and Bo's. They examined the association of physical activity, cigarette smoking, hours of sleep, alcohol consumption, and number of meals with five year mortality rates. For elderly women, never having smoked was the only personal health practice that achieved a statistically significant multivariate relationship with lower mortality. None of the personal health practicas were related significantly to mortality among elderly men.

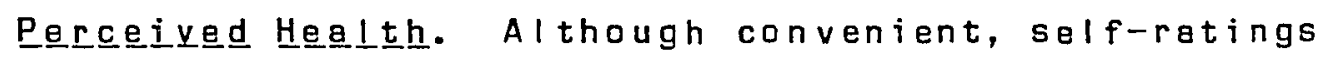
of health have often been considered a rather questionable substitute for objective health status as a predictor of 
such outcomes as morbidity, mortality, or general wellbeing. However, recent studies indicate that parceived health has predictive importance in its own right. Mossey and Shapiro (1982) analyzed data from the Manitoba longitudinal study on aging to test the hypothesis that salfrated health is a predictor of mortality independently of objective health status. Controlling for a variety of confounders, mortality risk for persons who balieved tinir health was poor was significantly greater. In analysis of the mortality experience of a different cohort, perceived hasth made a strong and independent contribution to ischemic heart disease mortality, even with controls for family history, serum cholesterol, blood pressure, and smoking (Kaplan, 1983). In an analysis of data from the Human Population Laboratory, tha perceived health/mortality relationship was strong and consistent across all levels of self-reported physical health status, with other variables including social network participation controlled lkaplan a Camacho, 1983).

PART III. SOCIAL NETWORKS AND DISEASE

INCIDENCE VS. DISEASE PROGRESSION

Studies of mortality alone do not inform us as to where in terms of the spectrum of disease, social networks and support have their greatest effect. It may be that 
social factors affect mortality by reducing disease incidence or they may speed recovery or slow progression once disease has occurred.

Kasl [1983] has written about the difficulties of desining the boundaries between incidence of disease and its course or progression. He argues that the distinction between the two presupposes a discontinuity which it may not be possible to elusidate. Also, the methodology of many studies makes such a distinction impossible. Among the complexities pointed out by Kasl are: [1] an ambiguous initial point of assessment; (2) an often arbitrary distinction between overt, diagnosable disease and the underlying disease process; (3) mortality data, without previous medical history, do not allow distinguishing between incidence or course; [4] the distinction between incidence and course may or may not rapresent a corrasponding social reality for the patient; and (5) whether the risk factors for incidence and for progression will be alike or different seems spacific to the particular disease and yariables being studied. All these points are expanded upon by Kasl [1983), whose chapter features an analysis of research related to psychosocial factors and disease progression. Ha does not deal further with social factors as they impact on disease incidence as he considers disease incidence almost impossible to measure precisely. 
With the above caveats in mind, after review of the available evidence, it appears equiprobable that social ties may be influential in preventing disease or in slowing its course. The following section discusses a sample of studies presenting evidence pro and con each of these two possibilities. In none of the studies has it apparently been possible, within the same data set, to evaluate both outcomes at the same time.

Diseas므 Incidence. Evidencees_Pro

Gore (1978) investigated the health consequences of unemployment due to a factory shutdown. Men who had the emotional support of their wives during unemfloyment experienced fewer symptoms of illness than those who lacked such support.

Nuckolls, Cassal, and Kaplan [1972) studied the interrelationship of stressful life events, psychosocial assets, and complications of pregnancy in 170 army wives. Measurement of psychosocial assets tapped certain elements of social support. Results indicated that in the presence of a high level of life change both before and during pregnancy, women with high psychosocial assets had only one-third the complication rate of women with low assets. Psychosocial assets and complications were not significantly related among women with low life change. 
In a more recent study of pregnancy complications by Norbeck and Tilden (1982), many of the same variables used by Nuckolls et al. were examined more rigorausly within the context of a large urban medical center. Emotional support as well as instrumental support were measured along with life stress and emotional disequilibrium. When tangible support and emotional support were combined, support variables were not independent predictors of total complication retes. However, the interaction of tangible support and life change during the time of pregnancy was significant for each of several types of complications. Subjects with many I ife changes and few supports had the highest complication rates.

Medalie and Goldbourt (1976) conducted a prospective five year study of the incidence of angina pectoris among a cohort of 10,000 male civil servants in Israel. They found that among those who had high levels of anxiaty, the angina incidence rate was significantly reduced by having a loving and supportive wife.

In a study of 7499 Finnish men, the highest incidence of ischemic heart disease occurred among the widowed [Koskenvuo, 1981].

In a cohort of women, clerical workers with nonsupportive bosses were found to be at incraased risk for the development of coronary heart disease over an eight year follow up period [Hayes \& Feinleib, 1980). However, nonsup- 
portive bosses was not a predictor for other groups of working women, nor for men.

Joseph, using a sample of 3809 Japanese-American men I iving in the San Francisco Bay area, showed that social affiliation defined as ties to spouse, a religious group, and organizations is a significant independent risk factor in coronary heart disoase. This work is as yet unpublished [Barkman, 1984].

The above seven studies, although highly different, provide evidence that social support may be able to prevent disease from occurring.

\section{Disegase Incidence, Evidence Con}

Reed and his co-workers in Hawai published longitudinal analyses in 1983 and 1984 of a large cohort of JapaneseAmerican men who had participated in a heart program. They assessed the social networks of these men as related to several types of morbidity. Their network measures were constructed a friori from nine suryey questions lcloseness of subject's parents, closeness of wife's parents, marital status, number of living children, number of persons in the household, frequency of social activities, frequency of attending church, frequency of attending social organizations, and frequency of discussing serious problemsl.

In their 1983 publication lReed, McGee, Yano, \& Feinleibl which concerned coronary heart disease, the net- 
work indexes did not predict incidence, using logistic regression models with controls. Further, no indiyidual question was associated with incidence rates. However, the index did predict coronary heart disease prevalence, although the social questions alone still did not.

In a publication one year later using the same cohort and network measures but investigating incidence of other chronic diseases as well as coronary heart disaase, Reed, McGee, and Yano [1984] continued to find no association. Social networks measured eight years earlier were unabie to predict the incidence of stroke, cancer, heart disease, and all diseases combined.

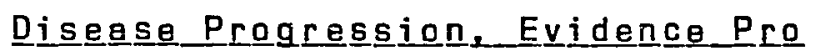

In a study of steroid therapy in chronic asthma [DeAraujo, 1973), a measura of psychosocial assets was used that tapped some aspects of social support as well as other factors. Findings indicatad that patients with high psychosocial asets required relatiyely low daily steroid doses regardless of the emount of life change, while patients with low assets and high life changes required high doses.

Cobb (1976) studied the effect of social support in preventing joint swelling precipitated by job loss in patients suffering from arthritis. He found that $4 \%$ of the men who received much support had two or more swollen joints, in contrast to $41 \%$ of the men with little support. 
Finlayson (1976) studied 75 men one year after discharge from the hospital where they had been traated for myocardial infarction. She divided the patients into those with best, intermediate, and poorest outcome and investigated the degree of nonprofessional help and advice obtained from neighbors, friends, and relatives by tha wife of each man during the year. The wives of patients with the best outcomes had more sources of support than those with poor outcomes.

Good social relationships were also associated with surviving longer than expected based on prognosis among terminal cancer patients (Weisman \& Worden, 1975).

Dimond [1979] found that less detarioration in social functioning led to better adjustment to hemodialysis.

Chandra, Szklo, Goldberg, and Tonascia [1983) studied a group of 1401 patients in Baltimore who had experienced an acute myocardial infarction. They were classified as "married" or "unmarried." A 10 year follow up of 888 of the subjects who were discharged alive showed a significantly better survival rate for the married compared to the unmarried. This held true for both men and women.

Kaplan and DaLongis (1983), using data from tha Human Population Laboratory, assessed the role of prior distress, social networks, and marital strain on the course of arthritis. They studied 693 arthritics who developed the disease 
during a 9 year period. They assessed four different types of resulting disability. Belonging to groups made no difference for any of these disabilities, but for three out of four of the disabilities assessed, large risk factars were obtained for both marital status and closereiationsips. These findings suggest an important role for interpersonal relations in determining the progression of arthritis.

Diseaae Progression, Evidence

Cassileth, Lusk, Miller, and Brown [1984] have studied social ties, marital history, and other psychosocial variables to see if they cauld predict survival in cancer patients. Analysis of data on 326 patients indicates that none of these factors, either individually or in combination, influenced length of survival or time until relapse. These investigators state that, although it is still possible that psychosocial factors may contribute to the initiation of cancer, they do not seem to play a role once the disease is established. The biology of cancer appears to predominate and override the potential beneficial influence of lifastyle and psychosocial assets. This is interesting in light of Asher's work on social support and adult haalth. Asher $(1984)$ believes that social support networks have no impact on explaining health outcomes for illnesses over which the individual has little control. Although some might disagrea, cancer would appear to be a good example of 
such an illness. However, when a wider range of illnesses is considered, Asher believes social networks probably do play a role in affording improved health.

Berkman (1984) has reviewed the findings on social networks as related to morbidity. She finds the state of the art to be that: (1) social networks appear to influence illness states in a nonspecific way; (2) results are not as robust in the morbidity studies as in those measuring mortality, and may be contradictory; (3) measures used to indicate social support or networks have usually been developed post hoc from items included in surveys for other reasons; (4) many studies which claim to measure networks and support use measures too limited to actually do so; (5) more sophisticated measures need to be used which permit the assessment of more specific network characteristics.

In conclusion, with the exception of the work of Reed et al. [1983, 1984], the morbidity studies just reviewed have not been designed to specifically answer the question of whether networks are more influential in disease incidence or disease progression as this is reflected in lowered mortality risks in community populations. It is unusual to have a longitudinal data set which contains information appropriate to this task. However, such a datasystem is available at the Kaiser Permanente Center for Health Research. It is to this system and setting that we now turn. 
CHAPTER III

\section{BACKGROUND DF THE STUDY}

In a dissertation involving an analysis of an existing data sot, one is fortunate in not having to collect the data to be used. However, the trade off is that it is usuelly necessary to master a larga and complicated set of files. This chapter discusses the data sources to be used in this analysis, their origin, data organization schemes, coding, and the samples involved. The focus is on the structure of the existing information system as encountered at the Kaiser Permanente Center for Health Research before any manipulation to accomplish the aims of this dissertation began.

First, the setting for the study is described. Naxt, four date sources pertinent to the study are explained. These are the outpatient information system, the inpatient information system, the household interview survey, and the calendar file. Following this, two special coding schemes developed by the Center are discussed. These are the clinical-behavioral disease classification system and the relative value system (for assessing costs). Finally, the samples are described. First, the larger 5\% random sample continually maintained by the Center is explained. Then, a subset of that sample, those participating in the household 
interview survey in 1970, is highlighted. It is this subset which is the specific focus of this research.

\section{THE SETTING}

The setting for this study is the Northwest Region of Kaisar Permanente, a prepaid health maintenance organization serving the Portland-Vancouver SMSA. A prototype health maintenance organization, the Program was estab!ished in 1943 to provide comprehensive medical care to workers in the Kaiser shipyards during World War II. The plan currently enrolls more than 265,000 subscribers, approximately $20 \%$ of the people living in the Portland area.

The members of Kaiser Permanente are a broadly based population group with demographic and social characteristics which correspond closely to the population of the metropolitan area as a whole (Pope, 1982). The health status of this population and the tendency to use medical care is similar to that of populations enrolled in Blue Cross/Blue Shield and commercial insurance plans (Freaborn \& Pope, 1982). Because medical services are readily accessible due to the prepayment scheme, barriers to health care utilization are eliminated. This population is ideal for the study of ssoues related to health in the urban setting.

In the Kaiser Permanente system, medical and health care personnel, practicing full time in an integrated hospital-ambulatory cara system, provide comprehensive 
health services within the context of group practice. Most patient care is provided in the physician or nurse practitioner's office, where patients are usually seen by appointment. Walk-in care is also available, as are emergency services at all hours. A basic principle of this method of care delivery is the inclusion of preventive services (Pope, 1976).

The Kaiser Permanente system maintains a single centralized medical record for each member. Every medical care contact made by the member is recorded in his or her chart. These records provide highly reliable indicators of all aspects of health care utilization. Pope (1982) reports that members receive virtually all their health care within or through the Kaiser system.

In 1964, the Center for Health Research was established as an affiliate of the Kaiser Foundation Hospitals. The founding objective of the Center was to develop a comprehensive research program that would make the best use of the prepaid group practice setting and of the data available within its system. It was clear that the nature of the medical care system provided unique opportunities for research into the relationship between characteristics of individuals and families and their behavior in terms of health care utilization. Bacause of these possibilities, a multifaceted resarch effort to identify the social and 
behavioral determinants of health care utilization was begun [Greenlick, et al., 1968).

For this research endeavor, the medical records available for the health maintenanca organization (HMO) population could provide information about disease and medical care utilization, and administrative files were available to provide information on some of the sociodemographic characteristics of the subscribers. Detailed demographic, social, economic, situational, and attitudinal data were obtained when a household survey was conducted in the early 1970 's.

\section{DATA SOURCES}

Several different data systems at the Center for Health Research make this dissertation possible. These computerized systems allow the linkage of social network and demographic data to medical care utilization information over a seven year period (1967 to 1973) for the outpatient system, and over a nine year period (1967 to 1975) for the inpatient system. Both data systems are now described.

\section{Qutegatient Information System}

The outpatient information system, initiated in late 1966, was designed and developed to record the outpatient utilization experience of a $5 \%$ random sample of all Kaiser Permanente subscriber units, i.e., subscribers and their 
enrolled dependents (spouses and/or children). As already noted, the Plan uses a single, centralized medical record for each member. The autpatient chart contains information for all medical care contacts an individual has with the program, including office visits, emergency care, laboratory and x-ray services, phone calls, correspondence, and a summary of each inpatient admission.

Whenever the medical record is removed from the centralized file or any information is filed into it, the record is checked lusing an identification system known by medical record personnel] to determine its inclusion in the study project. These charts are immediately routed to the Research Medical Records Department, where a specially trained staff of medical record technicians and clerical personnel peruse the record to collect information for research purposes. Data coded for each contact include time, place, type of service, typo of provider, presenting and associated morbidity, symptoms, episodes, and procedures including laboratory and radiology sarvicas.

Morbidity episodes are coded in the following manner: each time a patient presents for the first time with a new morbidity lor a new episode of a morbidity or illness], this morbidity is coded as an "initial" visit. Subsequent visits for the same illness are considered "continuing" visits. The initial plus return visits are deemed an "episode"for that particular problem. For example, if an individual 
presents only once with a specific morbidity such as influenze and recovers uneventfully, there would be only one visit recorded, and the visit would be coded as initial. However, if the same individual was diagnosed as having diabetes ten years ago, his first visit for diabetes would have been termed initial, with further visits over the years for that chronic illness considered continuing. The ten years of contacts, and those required indefinitely into the future for diabetes care, would all be seen as a single episode.

Figure 2 displays pertinent structural aspects of the outpatient information system. TThe disease classification system is explained later in this chapter.J "Doctor's office visits" refer to number of office visits made. "Contacts" is more inclusive, referring to all interactions with the outpatient system: office visits, phone calls, letters, and emergency room visits.

Detailed recording and coding instructions have been

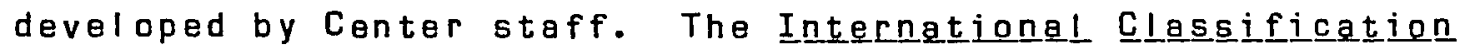

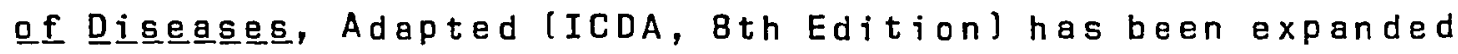
and modified, especially with relation to ambulatory care morbidity patterns. This classification and how it is used to record diagnoses and symptoms will be explained later. Services provided and procedures rendered are coded in terms of an adaptation of the Californiag Re 


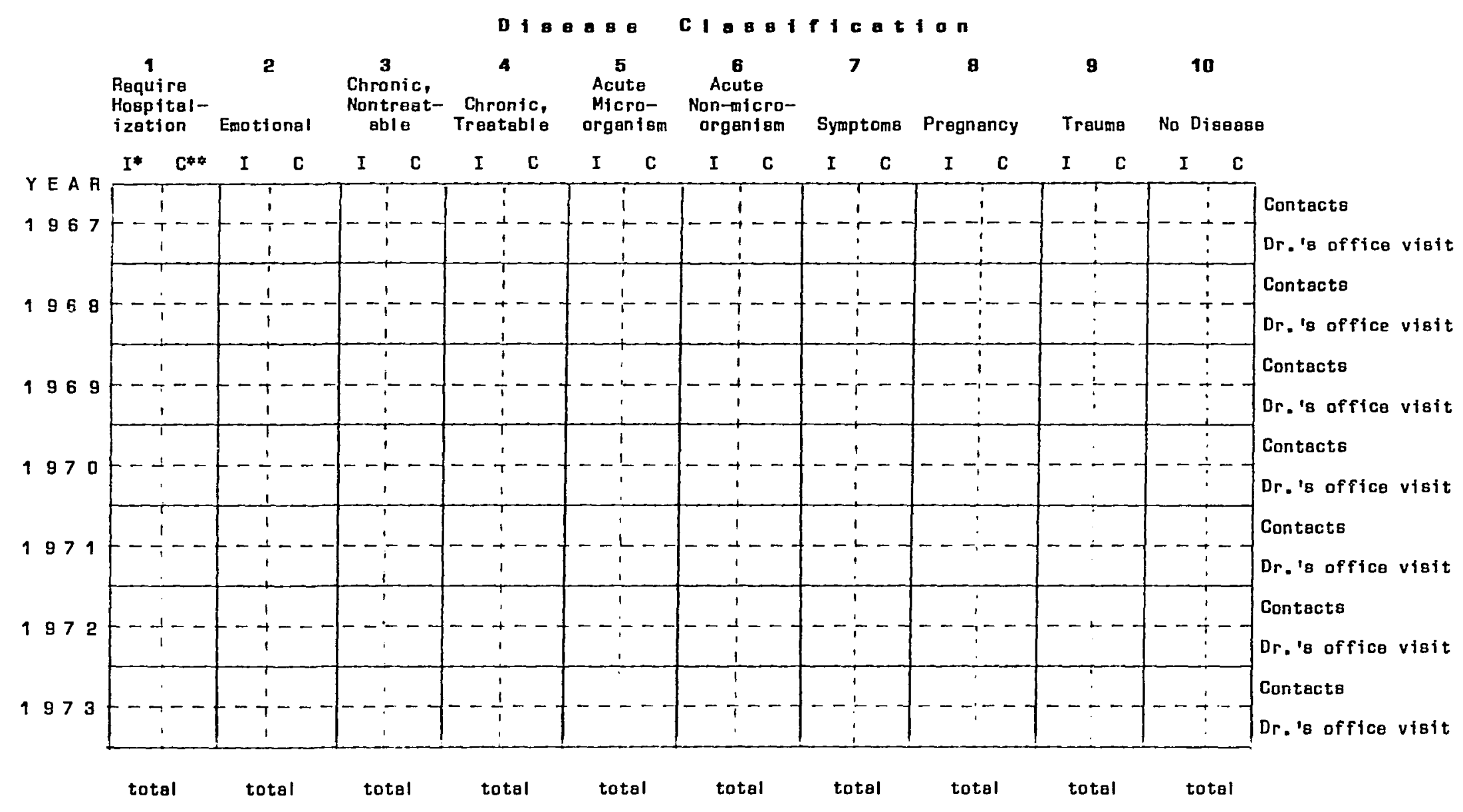

\# $I=$ intitial

${ }^{*} \mathrm{C}=$ continuing

Figure 2. A schema of structural aspects of the Center for Heal th Research Outpatient Information System. 
[CRVS, 4th Edition]. This system will also be explained in more detail later.

Quality control is built into the data collaction system at each step. To assist the technicians with questions that arise and clarifications that are needed during the data collection processes, physicians practicing within the system are routinely available. Assuring the reliability and validity of the data collected is an ongoing concern. Monthly validity checks are conducted to test the standardization of the recording process. At the same time, new or revised recording procedures may be introduced, and questions identified and resolved about the recording processes.

A number of forms are used in the data collection and maintenance prosesses. The basic encounter form, called Form $A$, is used to record each patient contact with the system. Laboratory and radiology services are, in turn, recorded on a Form B. Clopies of these forms are included in Appendix Aol Detailed recording instructions and procedures, entitled, "Recording and Coding Instructions for Medical Cara Utilization Study,"are used by the technical personnel. Completed forms are entered into the data base at the Center by a minicomputer system, with databeing cleaned and edited at each step.

Overall, the outpatient information system is designed to provide a general data base which can be used for a 
variety of research purposes. It can illustrate the health services utilization of a specific patient population, examine the incidence, prevalence, and sarvices provided for specific diseases, examine the use of resources by providers, or describe an episode of illness and its concomitant resource use and outcome. These are only a few examples of the system's capabilities.

Inpatient Information System

The inpatient information system was begun in March, 1965, and continues as an ongoing data system within the HMO. All patients admitted to the two Kaiser hospitals in Oregon are included in this data system. Thus, it is a $100 \%$ sample, as opposed to the outpatient system which is based upon a $5 \%$ sample.

Each inpatient record provides information from three separate data forms. The first is a personal history questionnaire filled out by the patient or family sometime during the hospital stay. The second is a discharge summary completed by a research medical record technician using medical information taken directly from the patient's official hospital record. This includes admission and discharge dates, diagnoses, and surgical and laboratory proceduras, as well as consultations. The third form is the nurse's evaluation form. It is completed by the charge nurse of the 
inpatient floor from which the pationt was discharged. The inpatient data collection forms are included in Appendix A.

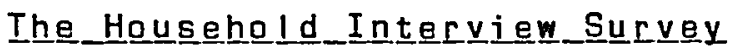

A lengthy household interview survey of a sample of members from the Plan was begun in 1970 and completed in 1971 to provide a data base for the study of the relationship between personal and family characteristics and health care utilization and other health-related issues.

The survey was designed to obtain three difference types of information:

1. objective data, such as demographic and social characteristics of the families and individuals enrolled in the Plan;

2. information about behaviors of the family as a unit and of individual family members, including actions directed toward health problems as well as interaction within the family, at work, and within the community;

3. perceptual or attitudinal data, involving a wide variety of beliefs, opinions, and perceptions about medicine, sickness, the self, and one's personal situation.

The questions asked on the survey included the following: demagraphic characteristics, socioeconomic characteristics, biographical data, family and friendship, religion, voluntary associations, leisure, work and the job 
situation, health status, health beliefs, halth practices, reports on utilization, insurance and the Kaiser Foundation Health Plan, membership perspectives on the Health Plan, attitudes toward medicine and medical care, and general feelings and outlook on life.

Interviews were conducted in the homes of the respondents and averaged over two hours in length. Data ware obtained about all members of the subscriber unit or family. For husband/wife pairs, separate but simultaneous interviews were conducted using different forms. This approach was taken because it was believed that some of the data sought would be more reliable and valid if obtained from the husband/father and others if obtainad from the wife/mother. It was believed [this was in 1970) that men could give more accurate information on family aconomic matters and that women could be more accurate about family social affairs. The perceptual and attitudinal data were reported by each individual for herself or himself on their respective forms. For single individuals, a third form of the survey was used which included all the questions. Details of all aspects of the household interview survey are contained in a monograph by Pope (1976).

Thera wera many provisions for quality control throughout the survey. A pilot study of ovar 100 subscriber units was carried out in early 1969 to test the interview tool and train the interviewers. The survey itself was 
carried out by a private survey organization that specializes in serving researchers in nonprofit organizations, universities, and public agencies. Thus, the respondents in the study could be assured that the person to whom they were talking during the survey was noutral, and not a Kaiser Permanente employee. Interviewers were continually evaluated. For instance, persons not in the sample were "planted" from time to time and completed interviews with these "plants" were tape recorded for review by the evaluation staff. (Interviewers had been forewarned that this could occur.l Other quality control measures taken along these lines as the interviews went forward, were coded, and were organized for computerization are described by Pope (1976).

There were 1659 eligible subscriber units (families). Completed interviews were obtained from 1529 of these units for a completion rate of $92 \%$. All together, 2603 adults participated in the survey. This total number included 988 married couples.

The survey was conducted approximately in the middle of the period during which medical record data was collected for most of the respondents in the study. It will be recalled that health services utilization data from 1967 to 1973 has been computerized and linked with the survey data. The survey data were obtained in 1970. Thus, some utiliza- 
tion information predates and some postdates the household interview survey. The assumption is made, for purposes of this research, that the cross-sectioral survey data would not be significantly different had it been collected in a two to four year pariod either preceding or following the actual survey. This is because most the information gathered concerned stable characteristics that would not be expected to change markedly in a short period of time.

\section{Membership Information and the Calendar File}

The sample of subscribers for which longitudinal data is gathered changes over time. As would be expected, over the years subscribers become deceased or leave the Medical Cara Plan when they move out of the area, change employers, remarry, and the like. A method was needed to keep track of people in research studies.

Kaiser Permanente maintains a membership information system of currently eligible health plan members for administrative and financial purposes. However, this information system does not retain a history of eligibility status of members. To overcome this limitation so as to provide a continuous historic record of the eligibility of every individual in a research study, a calendar file was originated by the Center. The calendar file interfaces with the membership file so that changes in the eligibility status of any individual included in a study are continu- 
ously recorded to maintain a permanent record of health plan eligibility.

\section{THE CODING SCHEMES}

\section{Kaiser Clinical-Behavioral Classification System}

The most common disease classification system in use

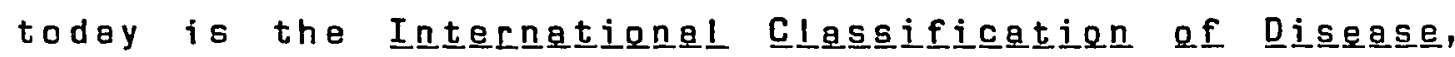
Adapted [ICDA]. In this classification system, each disease entity is given a unique code number, and code numbers are grouped together under either etiology or organ system. However, these codes were developed to classify diseases for statistical purposes for generating morbidity and mortality information, not for the analysis of medical cara utilization. The staff of the Center developed its own classification system, retaining the use of ICDA codes, so as to reflect disease from a clinical perspective while at the same time grouping together those diseases which are likely to produce similar behavioral responses in persons with similar sociodemographic and psychosocial characteristics [Hurtado \& Greenlick, 1971). The clinical subgroupings and algorithms within the classification system can be seen in Appendix $B$.

The Kaisar clinical-behavioral classification system features ten classes of disease, each of which includes conditions believed to produce a similar medical care utilization response. These mutually exclusive classes are: 
1. Diseases generally requiring hospitalization

2. Diseases with a high emotional component

3. Chronic disease with no symptoms or nontreatable symptoms

4. Chronic disease with treatable symptoms

5. Acute microorganism disease

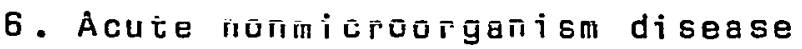

7. Symptoms of undiagnosed disease

8. Pregnancy and complications of pregnancy

9. Trauma and adverse effects of external causes

10. Nondisease, refractive error, preventive care, and miscellaneous

Each code in an expanded ICOA system is convertible to a code in the Kaiser classification system. A complete listing of all the diseases and their ICDA code numbers included in the Center for Health Research system is available (Hurtado and Greenlick, no date). For the purpose of this research which focuses on disease, wherever possible the last three classes will not be considered.

\section{The Relative Value system}

The purpose of the relative value system is to provide a means of assessing costs of health care.

For research purposes, services provided and procedures rendered within Kaiser Parmanente are coded according to an adaptation of tha Cog Lifor 
[CRVS), 4th Edition. This coding system has been modified and expanded to include all additional medical, surgical, laboratory, or radiology procedures introduced since 1964. Drug orders are coded using a coding system developed by the Center.

Every medical, surgical, laboratory, and radiology procedure has a relative value assigned to it. In addition, the Center has created a relative value system for drug orders abstracted from the outpatient medical record.

Comprehensive outpatient system cost data are availabla from Kaiser Parmanente which allow the derivation of a dollar cost per relative value unit for all medical offica visits, surgical procedures, laboratory procedures, radiology procedures, and drug orders. Each type of Rvs unit has a different dollar equivalent. Conversion of relative value units into dollars allows relative value units of different types to be added to produce an estimate of the total medical care utilization costs per person.

\section{THE SAMPLES}

\section{The 5\% Sample}

This section describes the random sample routinely maintained since 1967 by the Center for research purposes. Its purpose is to provide a description of Kaiser Permanente members. 
The membership records of the Kaiser Plan are stored on magnetic tape to allow routine computer processing. Both individual members and their family units lsubscriber plus spouse and dependents when enrolled are identified by unique numbers. Thus, a roliable sampling frame was available. The basic membership record also contained information such as age, sex, place of residence, size of family unit, and enrollment group.

The original 5\% sample for the madical care utilization project was a 2-stage probability sample. Using a simple random sampling technique, a 5\% sample of subscriber units [the primary sampling unit] was selected by computer. The units approximate primary families lsubscriber plus spouse and dependents when enrolled and provide natural clusters of individual elements. All the people [elements] in the cluster were included in the sample because the phenomena of research interest, health care, was considered basically family-oriented. This method provided an equal probability cluster sample of the health plan population. The original sample was drawn from the list of families eligible for service on September 1, 1966. Each month thereafter, a $5 \%$ sample of all new families is added to the overall sample. This continuously updated 5\% sample is designed to represent the overall health plan members at any point in time. 


\section{The Household Interyiew Survey Sample}

The study population for this dissertation is the Household Interview Survey sample.

Because of the effort and expense involved in conducting the household interview survey, it was decided not to include the entire 5\% sample of subscriber units active at the time of the survey but to focus upon s subset of this sample. The subset was defined as all sampled subscriber units enrolledin the Medical Care Plan for the two full calendar years 1969 and 1970 . This provided a minimum of two years utilization data for the subscriber units surveyed. Fifty-five percent of the household interview sample was enrolled as of 1967 when the outpatient information system bagan. The remaining $45 \%$ of the survey sample enrolled some time between 1967 and the beginning of 1969.

Although it was necessary that the subscriber unit be continuously enrolled in the Kaiser Plan throughout 1969 and 1970 to be included in tha sample, not all the individuals in the unit were necessarily coverad for the tmo year period of time. Through birth or marriage, persons could have been added to the units. Through death, leaving the family, or becoming over age, individuals could have left the unit during that time period. For practical purposes, those persons in the family at the time of the interview and covered by the health plan were subjacts of the questions asked. 
Interviewing began in early 1970. This meant that some of the units from which interviews were obtained subsequently left the Plan during 1970. These units were dropped from the sample since they failed to meet the criteria of membership for the two full years of 1969-70. The 101 respondents from those units have been included in this analysis, however, since the objective here is analytic and not to generalize to the Kaiser population. In this project the focus is on testing theory and relationships between variables.

A total of 2603 individuals from 1529 subscribers units were interviewed. Frequency distributions for selected demographic characteristics of this study population are shown in Table $I$. 
TABLE I

FREQUENCY DISTRIBUTIONS FOR SELECTED DEMOGRAPHIC

CHARACTERISTICS OF HOUSEHOLD INTERVIEW SURVEY RESPONDENTS (IN 1970)

A. AGE OF RESPONDENT

$$
\begin{array}{rcccccc}
18-29 & \cdot & \cdot & \cdot & \cdot & 405 & (15.6) \\
30-39 & \cdot & \cdot & \cdot & \cdot & 556 & (21.4) \\
40-49 & \cdot & \cdot & \cdot & \cdot & 493 & (18.9) \\
50-59 & \cdot & \cdot & \cdot & \cdot & 486 & (18.7) \\
60-69 & \cdot & \cdot & \cdot & \cdot & 398 & (15.3\} \\
70-79 & \cdot & \cdot & \cdot & \cdot & 219 & (8.4) \\
80-90 & \cdot & \cdot & \cdot & \cdot & 46 & (1.8) \\
& \text { Total } & & 2603 & 100 \%
\end{array}
$$

B. SEX OF RESPONDENT

Male.... $1202(46.2)$

Female. . . 1401 (53.8) Total $2603 \quad 100 \%$

C. MARITAL STATUS OF RESPONDENT

Married . . 2167 [83.3]

Never married 94 [3.6]

Widowed... $178[6.8]$

Divorced. . 164 [6.3] Total 2603 100\%

D. EDUCATION OF RESPONDENT

$$
\begin{aligned}
& 0-7 \text { years.. } 135 \text { (5.2) } \\
& \text { Bth grade. . } 248(9.5) \\
& \text { 9-11 years. } 431 \text { (16.6) } \\
& \mathrm{High} \text { school } \\
& \text { graduate. } 987(37.9) \\
& \text { Some college. } 427(16.4) \\
& \text { College } \\
& \text { graduate } 144(5.5) \\
& \text { Graduate work } 225 \text { ( } 8.6 \text { ] } \\
& \text { Missing. . } 6 \text { ( } 0.2\} \\
& \text { Total } 2603 \quad 100 \%
\end{aligned}
$$

\section{E. EMPLOYMENT STATUS \\ OF RESPONDENT}

$$
\begin{aligned}
& \text { Working... } 1559 \text { (59.9) } \\
& \text { Housewife. } 785 \text { (30.2) } \\
& \text { Retired . . } 216 \text { [8.3] } \\
& \text { Temp off or } \\
& \text { disabled. } 21(0.8) \\
& \text { Unemployed. . is }[0.6\} \\
& \text { Never had job } 2(0.1) \\
& \text { Missing. . } 4 \text { ( } 4.2\} \\
& \text { Total } 2603 \quad 100 \%
\end{aligned}
$$

F. OCCUPATION OF HEAD

OF HOUSEHOLD

$$
\begin{aligned}
& \text { Professionals } 426 \quad(16.4) \\
& \text { Managers. . 302 (11.6) } \\
& \text { Clerical. . 325 [12.5] } \\
& \text { Crafts. . . } 529\{20.3\} \\
& \text { Operatives. } 407 \text { [15.6) } \\
& \text { Service.. } 280\{10.8\} \\
& \text { Laborers. . } 152(5.8) \\
& \text { Not employed. } 142 \text { [5.5] } \\
& \text { Missing : } \cdot 40 \text { [ } 1.5\} \\
& \text { Total } 2603100 \%
\end{aligned}
$$

G. FAMILY INCOME

$$
\begin{aligned}
& \text { Under } \$ 5000 \text { - } 365 \text { (14.0) } \\
& \$ 5000-7499 \text {. . 306 [11.8] } \\
& \$ 7500-9999 \text {. . } 465(17.9) \\
& \$ 10,000-14,000 \quad 857 \quad(32.9) \\
& \text { Over \$15,000. } 559 \text { (21.5) } \\
& \text { Missing... } 51 \text { ( } 2.0 \text { ) } \\
& \text { Total } 2603 \text { 100\% }
\end{aligned}
$$

H. RACE OF FAMILY UNIT

$$
\begin{aligned}
& \text { White... } 1459 \text { [95.4] } \\
& \text { Black:.: } 51 \text { (3.3) } \\
& \text { Othar... } 17 \text { (1.1) } \\
& \text { Unknown.. } 2[0.2\} \\
& \text { Total } 1529100 \%
\end{aligned}
$$




\section{CHAPTER IV}

\section{METHODOLOGY}

The data systems, satting, and subjects of this research have been describod. This chapter explains in detail the conceptual and technical work accomplished to prepare the variables for analysis.

Construction and preparation of the independent variables to be used took place first. Network measures were created from questions included in the household interview survey. Summary network measures were tested for reliability and velidity. The most appropriate demographic, risk factor, and health status measuras to use as control variables were selected from the extensive data set. The mortality status of the subjects was determined. Dependent measures to assess incidence and change in health status were created. Tablo I gives an overview of the variable I ist, data sources, and measurement instruments for the study. The last saction of the chapter faatures a discussion of loglinear logistic regression, an uncommon statistical method, which it was necessary to utilize because mortality is a dichotomous outcome. The analytic approaches taken to explore the data and then test the hypotheses are explained. 
THE SOCIAL NETWORK INDEXES

Twenty-one questions representing various aspects of social connections were selacted from those administered during the household interview survey [Table III]. [See Appendix C for a complete listing of questions and age and sex-specific responses.l Three of these questions concerned social participation in the community. They assessed frequency of attendance at church and voluntary organizations, and the number and type of leisure activities engaged in. The remaining were questions about the numbers of family, kin, and friends available to the individual and the frequency with which they were seen. These questions were selected with the intent of combining them into indexes to view the network from a number of different perspectives.

\section{Limitations of the Questions}

As often occurs with secondary analysis of data gatherad years before for other purposes, the available questions were less sensitive than if they had been developed solely for purposes of social network research. For instance, the question asking for the number of siblings does not include whether or not they were alive at the time of the survey. Also, when asked about the number of rela- 
TABLE II

VARIABLE LIST, DATA SOURCE, AND MEASUREMENT INSTRUMENT FOR SOCIAL NETWORK AND MORTALITY/MORBIDITY STUDY

VARIABLE

INDEPBNDENT VARIABLES

1. Network Scope

Immediate Family Scope

Immediate/Extended Family Scope

Friends Scope

Community Scope

2. Network Size

3. Network Frequency of Contact

4. Network Interaction

Marriage

Children

Family of Origin

Relatives

Close friends

Other friends

Work

Organizations, incl. church

Sacial Leisure

CONTROL VARIABLES

1. Demographic

Age

Sex

Socioeconomic status

2. Heal th Practices

Smoking

Drinking

Physical Exercise

3. Heal th Status

Perceived Heal th

Length hospital stay, 1967-70

Rate outpatient contacts for 7 di sease classes, 1967-70

DEPENDENT VARIABLES
1. Mortality
2. Disease Incidence
3. Disease Progression

DATA SOURCE AND/OR MEASURE

Indexes developed from

Household Interview Survey

$$
\downarrow
$$

Household Interview Survey

Duncan Index

Household Interview Survey

Household Interview Survey Inpatient Information System Outpatient Information System

KPMCP membership files

Outpetient Information System

Outpatient Information System 
TABLE III

QUESTIONS FROM THE HOUSEHOLD INTERVIEW SURVEY ASSESSING RELATIONSHIP DOMAINS

\begin{tabular}{|c|c|c|c|c|}
\hline SECTOR & SOURCE & \multicolumn{3}{|l|}{$\begin{array}{l}\text { RELATIONSHIP } \\
\text { DOMAIN }\end{array}$} \\
\hline \multirow{8}{*}{ FAMILY } & \multirow{2}{*}{$\begin{array}{l}\text { IMMEDIATE } \\
\text { FAMILY }\end{array}$} & SPOUSE & \multicolumn{2}{|l|}{ Yes or no } \\
\hline & & CHILDREN & \multicolumn{2}{|l|}{ Number ${ }^{1}$} \\
\hline & \multirow{3}{*}{$\begin{array}{l}\text { FAMILY } \\
\text { OF } \\
\text { ORIGIN }\end{array}$} & $\begin{array}{l}\text { FATHER } \\
\text { LIVING }\end{array}$ & Alive or deceased & \multirow{3}{*}{$\begin{array}{l}\text { Perception of } \\
\text { strength of } \\
\text { family ties }\end{array}$} \\
\hline & & $\begin{array}{l}\text { MOTHER } \\
\text { LIVING }\end{array}$ & Alive or deceased & \\
\hline & & SIBLINGS & Number ${ }^{2}$ & \\
\hline & \multirow{3}{*}{ KIN } & $\begin{array}{l}\text { RELATIVES } \\
\text { NEAR }\end{array}$ & \multicolumn{2}{|l|}{$\begin{array}{l}\text { Number } \\
\text { How many see often }\end{array}$} \\
\hline & & $\begin{array}{l}\text { RELATIVES } \\
\text { DAY AWAY }\end{array}$ & \multicolumn{2}{|l|}{$\begin{array}{l}\text { Number } \\
\text { How many see often } \\
\text { How }\end{array}$} \\
\hline & & RELATIVES FAR * & \multicolumn{2}{|l|}{ How often in touch } \\
\hline \multirow{4}{*}{ FRIENDS } & \multirow{4}{*}{ FRIENDS } & $\begin{array}{l}\text { CLOSE } \\
\text { FRIENDS }\end{array}$ & \multicolumn{2}{|c|}{$\begin{array}{l}\text { Number } \\
\text { How often keep in touch }\end{array}$} \\
\hline & & $\begin{array}{l}\text { OTHER } \\
\text { FRIENDS }\end{array}$ & \multicolumn{2}{|c|}{$\begin{array}{l}\text { How many get together wi th/year } 3 \\
\text { How often get together with }\end{array}$} \\
\hline & & NEIGHBORS & \multicolumn{2}{|l|}{ Number ${ }^{1}$} \\
\hline & & $\begin{array}{l}\text { WORK } \\
\text { ASSOCIATES }\end{array}$ & \multicolumn{2}{|c|}{$\begin{array}{l}\text { Number } \\
\text { How often seen outside work place }\end{array}$} \\
\hline \multirow{3}{*}{ COMMUNITY } & \multirow{3}{*}{ COMMUNITY } & ORGANIZATIONS & \multicolumn{2}{|c|}{$\begin{array}{l}\text { How often attend meetings of } \\
\text { organizations belong to (to } 6 \text { ) }\end{array}$} \\
\hline & & CHURCH & \multicolumn{2}{|l|}{ How often attend } \\
\hline & & SOCIAL LEISURE & \multicolumn{2}{|c|}{ Number activities engaged in } \\
\hline & \multicolumn{4}{|c|}{$\begin{array}{l}\text { * Answered by wife for family } \\
1 \text { Discrete data } \\
2 \text { Discrete data primarily, but grouped for largest numbers } \\
3 \text { Grouped data }\end{array}$} \\
\hline
\end{tabular}


tives nearby or a day's drive away, it is possible that the respondents named siblings or parents who had already been counted in earlier questions. There is no way of knowing whether poople named as "close friends" might also have been included in the numbers given earlier for neighbors and relatives. Thus, there is the potential for overlapping categories. How one labels the people in one's network is uncertain if the criteria for inclusion are not clearly defined. Further, questions asking for numbers of individuals in the various categories called for responses that did not always supply entirely discrete data. Some included groupings as well as discrete information, as when the respondent was asked if he or she had one, two, three, or four or more friends. Other questions involved answers with groupings only such as "a faw," "some," or "a great many" rather than specific numbers of people. This becomes a problem when the goal is constructing an individual's network quantitatively. [For details about how such problems Here mangged in the index construction, see the overview boxes in Appendix D. Also, the possible responses to each question can be seen in Appendix C.J Finally, in the case of married couples (approximately two-thirds of the sample), the questions concerning relatives, neighbors, and more distant friends were asked only of wives, who answered for the entire family. The wife's response was subsequently coded to the husband. It is likely that if the husbands had 
provided their own responses to these questions, their personal networks would have appeared different.

\section{The Network Model}

Because there is as yet no standard method for aggregating groups of questions about networks and no fixed standard by which to judge their validity lReed et al., 1983], a conceptual network model was constructed a priori based on the available questions, the way networks had been conceptualized in other mortality studies, and network theory (Figure 3). The model featured three major network sectors: a family sector, a friends sector, and a community sector. These were further subdivided into five sources and fifteen role relationship domains. The most intimate relationship domain, the marital, was placed at the top of the hierarchy. Prior epidemiological studies had revealed the importance of the marital tie in terms of health outcomes. This was followed in descending order of intimacy by children, family of origin, friends, neighbors, work associates, and community involvements.

Based on the kinds of questions available, it seemed possible to combine them such that four different perspectives of the network could be envisaged by summing vertically down the relationship domains. The four structural network perspectives were: overall network scope, 
STRUCTURAL PERSPECTIVE

\begin{tabular}{|c|c|c|c|c|c|c|}
\hline SECTOR & SOURCE & $\begin{array}{l}\text { RELATIONSHIP } \\
\text { DOMAIN }\end{array}$ & SCOPE & SIZE & $\begin{array}{c}\text { REQUENCY } \\
\text { OF } \\
\text { CONTACT }\end{array}$ & $\begin{array}{l}\text { INTER- } \\
\text { ACTION }\end{array}$ \\
\hline \multirow{8}{*}{ FAMILY } & \multirow{2}{*}{$\begin{array}{l}\text { IMMEDIATE } \\
\text { FAMILY }\end{array}$} & SPOUSE & $x$ & $x$ & & $x$ \\
\hline & & CHILDREN & $x$ & $x$ & & $x$ \\
\hline & \multirow{3}{*}{$\begin{array}{l}\text { FAMILY } \\
\text { OF } \\
\text { ORIGIN }\end{array}$} & $\begin{array}{l}\text { FATHER } \\
\text { LIVING } \\
\end{array}$ & $x$ & $x$ & & $x$ \\
\hline & & $\begin{array}{l}\text { MOTHER } \\
\text { LIVING }\end{array}$ & $x$ & $x$ & & $x$ \\
\hline & & SIBLINGS & $x$ & $x$ & & $x$ \\
\hline & \multirow{3}{*}{ KIN } & $\begin{array}{l}\text { RELATIVES } \\
\text { NEAR } \\
\end{array}$ & $x$ & $x$ & $x$ & $x$ \\
\hline & & $\begin{array}{l}\text { RELATIVES } \\
\text { DAY AWAY }\end{array}$ & $x$ & $x$ & $x$ & $x$ \\
\hline & & RELATIVES FAR & & & $x$ & \\
\hline \multirow{4}{*}{ FRIENDS } & \multirow{4}{*}{ FRIBNDS } & $\begin{array}{l}\text { CLOSE } \\
\text { FRIENDS }\end{array}$ & $x$ & $x$ & $x$ & $x$ \\
\hline & & $\begin{array}{l}\text { DTHER } \\
\text { FRIENDS }\end{array}$ & & $x$ & $x$ & $x$ \\
\hline & & NEIGHBORS & $x$ & $x$ & & \\
\hline & & $\begin{array}{l}\text { WORK } \\
\text { ASSOCIATES }\end{array}$ & $x$ & $x$ & $x$ & $x$ \\
\hline \multirow{3}{*}{ COMMUNITY } & \multirow{3}{*}{ COMMUNITY } & ORGANIZATIONS & $x$ & & $x$ & $x$ \\
\hline & & CHURCH & $x$ & & $x$ & $x$ \\
\hline & & SOCIAL LEISURE & $x$ & & & $x$ \\
\hline
\end{tabular}

Figure 3. Social network model. $\{X=$ questions available to assess the relationship] 
overall network size, overall frequency of contact with network members, and overall network interaction (Figures 4 through 7l. Although the network scopa and intaraction indexes were inclusive of most of the relationship domains, fíguency of contact was limited to contacts outside of the more immediate family, and sizedid not include any individuals from the community sector.

The four overall measures, although using information generated by the same questions, were designed to be conceptualiy unique. Network scope assessed whether or not at least one person in a relationship domain was present. Network size was a simple unweighted count of people mentioned by the respondent in response to questions about numbers of family members, friends, work associates, and neighbors. Network frequency of contact summed all the items which asked how often the respondent saw people in the various sectors. Network interaction was a more complicated overall structural measure. It represented the sum of nine separate interaction indexes created for the relationship domains.

To create the overall interaction measure, first, the number of individuals identified by the respondent in each relationship domain was multiplied by the variable corresponding to how frequently the respondent indicated he saw the individuals. Then, each of these separate indexes was collapsed to a metric of six lthe range of scores for the 
STRUCTURAL PERSPECTIVE

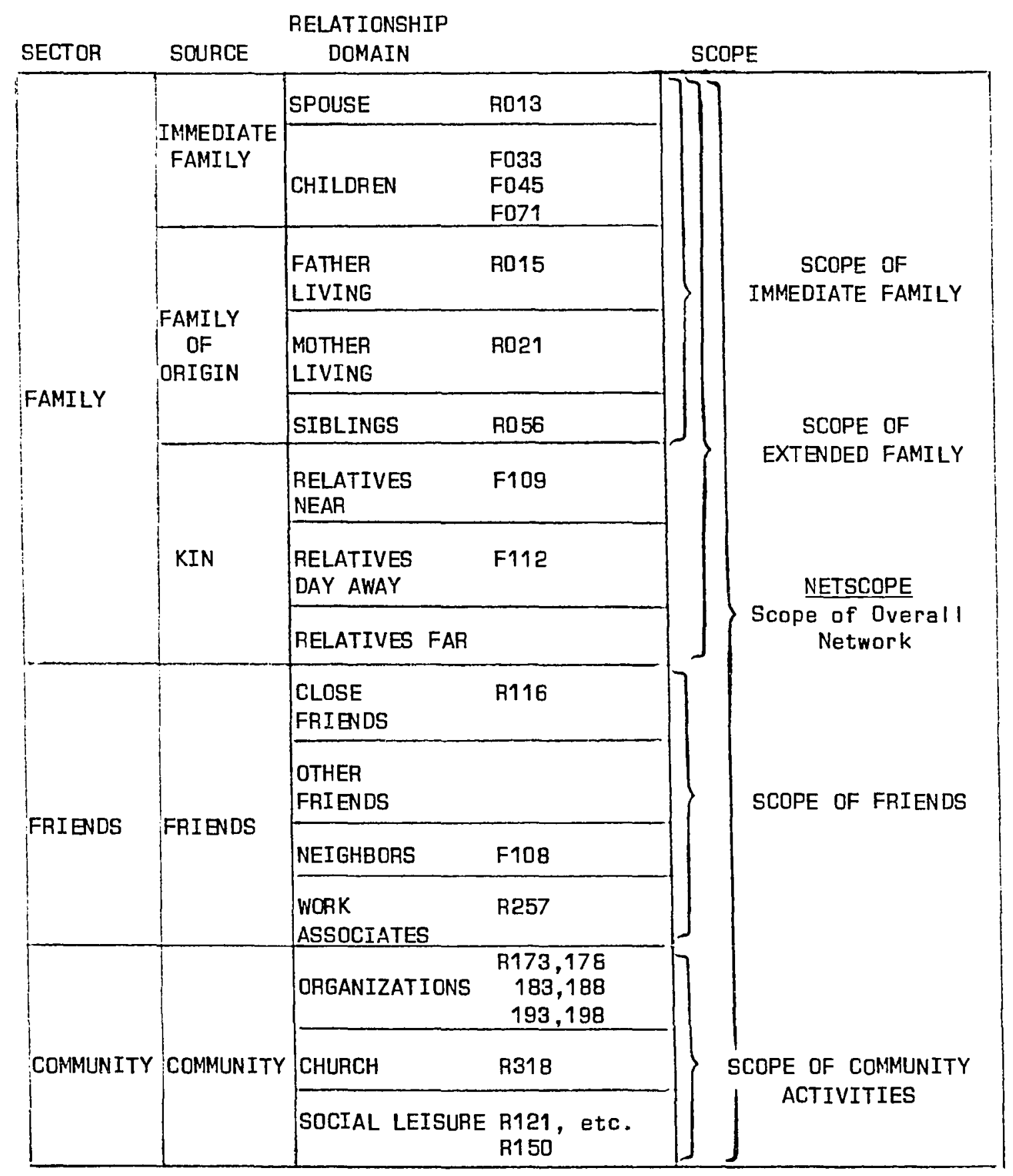

Figure 4. Components of network scope indexes. 
STRUCTURAL PERSPECTIVE

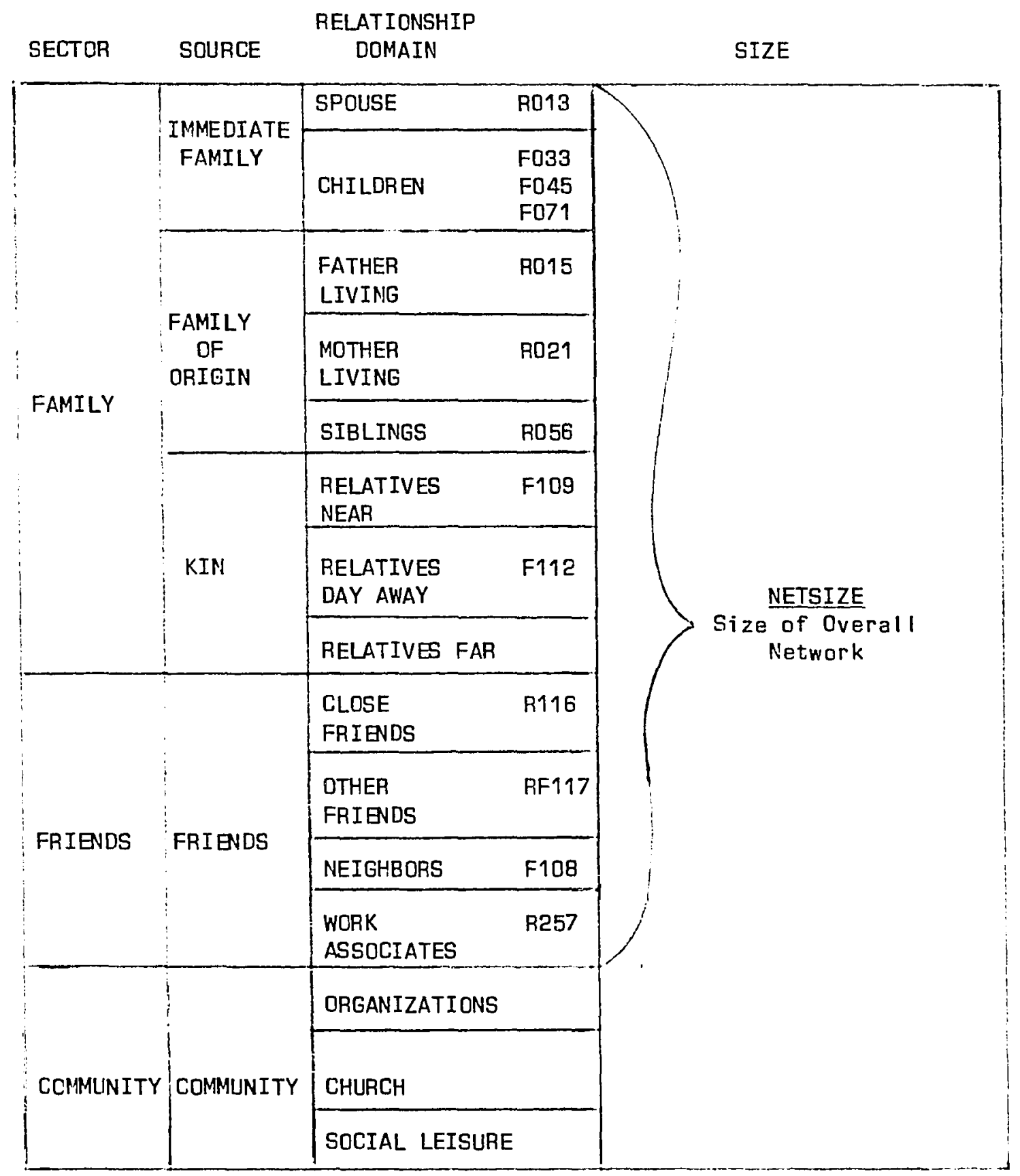

Figure $\underline{5}$. Components of network size index. 
STRUCTURAL PERSPECTIVE

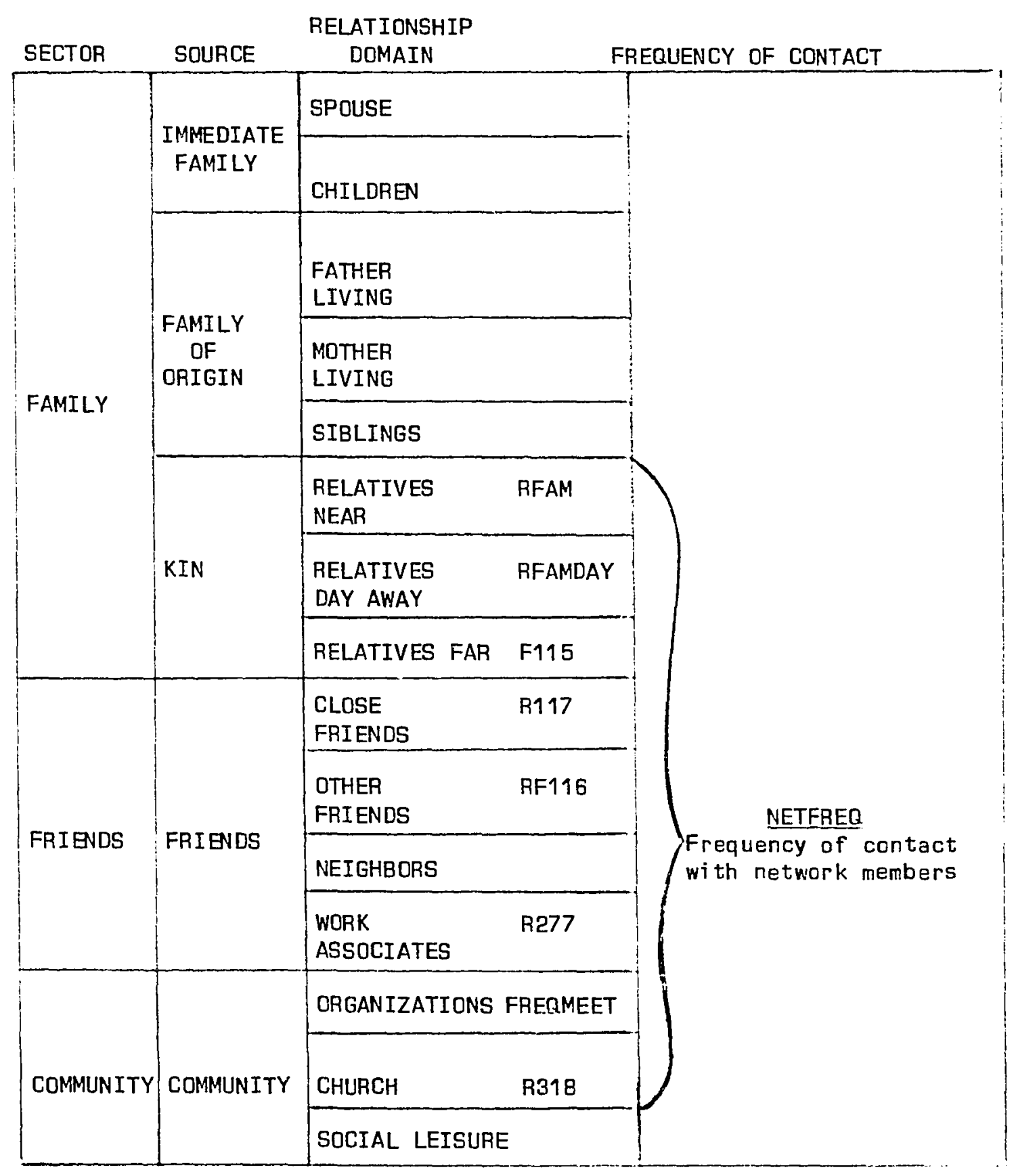

Figure E. Components of frequency of contact index 


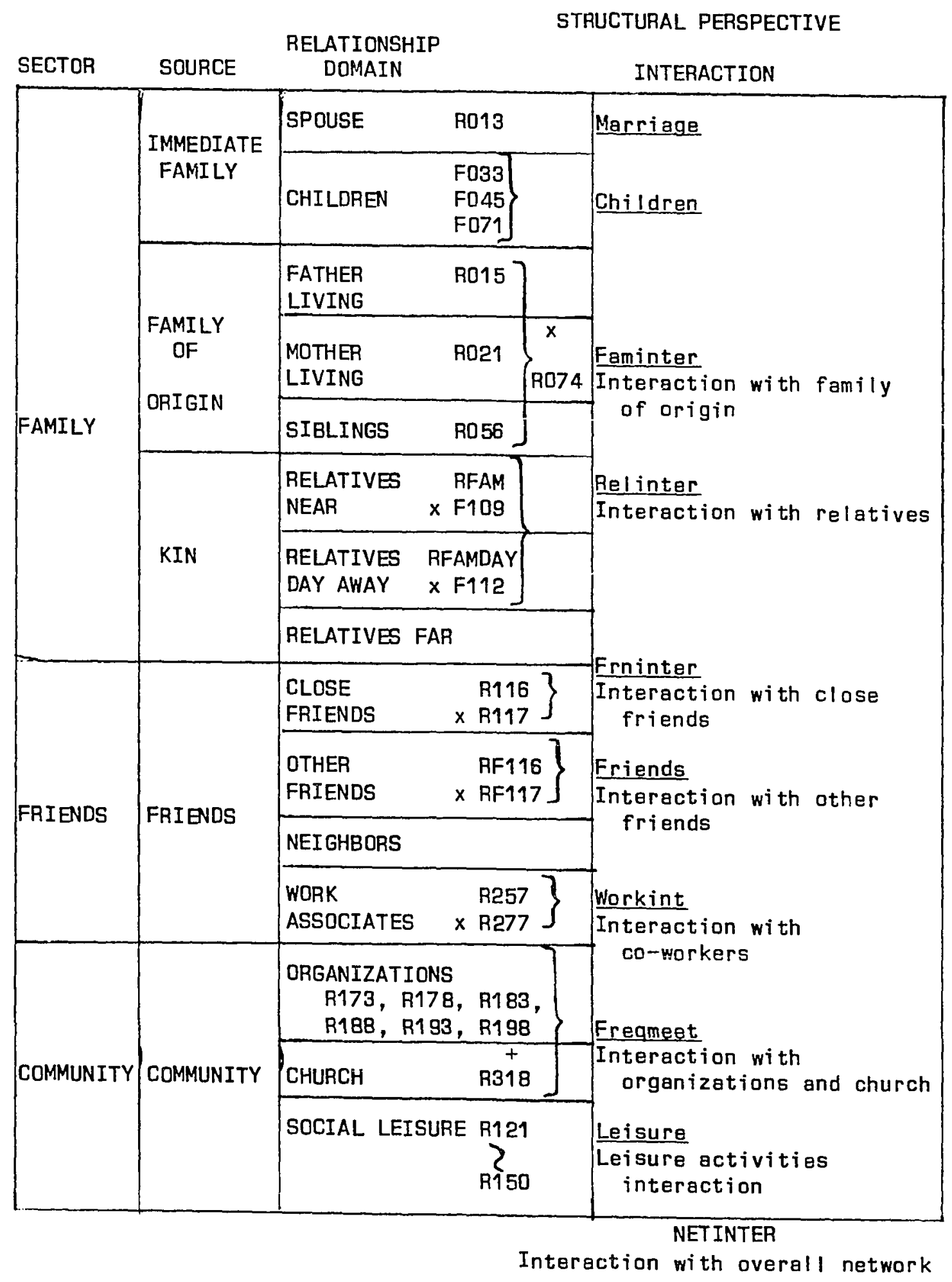

Figure 7. Components of interaction indexes. 
social lejsure index precluded using a larger metric). There were four relationship domains lacking a specific question about frequency of contact by which to multiply the number of network members: marriage, children, family of origin, and social leisure. For marriage and children, it was assumed that maximum frequency of contact would occur; therefore, there was no need for multiplication. Due to tha importance of the marital tie in network/health relationships, a value of 8 was given for having a spouse. This value was an average of the numbers used by other investigators to weight the marital tie (Blazer, 1980; House et al., 1982; Reed et al., 1983). To obtain a proxy measure of frequency of contact with family of origin, a quastion assessing perceived strength of family ties lto brothers, sisters, and parentsj was used. It was assumed that if family relationships were felt to be close and strong, greater frequency of contact would be occurring. Finally, there was no way of knowing how frequently people engaged in their social leisure activities. However, the quastion asking for number and type of social leisure activities was different from the other questions. In response to an openended question, up to fourteen different types of social leisure activities were mentioned. Some of these activities presumably would be engaged in more frequently than others. Thus, there was no way of assessing frequency specifically 
for each one, and it seemed most reasonable to use the total number engagedin. Except for marriage, then, the indexes from each domain were given equal weight in summing for the overall network interaction measure.

The four different perspectives from which to view the network were computed to evaluate which structural aspect of the social network was most important in relation to health. In addition to the overall measures, interaction indexes had been constructed which could give a more focused view of the specific sectors of the network. Indexes were formed and documented regarding: conceptuel meaning, construction procedures, range and frequency distribution of scores, normative data, coefficient alpha, intercorrelations of index components, and percent of respondents with missing scores. Index documentation can be seen in the overview boxes in Appendix D. All the indexes were constructed so that higher scores reflected a larger network.

\section{Validating the Network Model}

Factor analysis procedures were used to validate the conceptual network model as the basis for grouping questions into indexes representing relationship domains and then into overall indexes. First, a principal components analysis was completed using the raw scorevariables concerning family and friends. The purpose of this procedure was to determine whether the dimensions underlying the responses to the ques- 
tions corresponded to the way the questions had been combined in the model.

Next, a principal components analysis was done with the nine interaction indexes representing aspects of the relationship domains that were components of the overall interaction measura. This was done to determine if they combined in terms of the sources and sectors delineated in the model.

Finally, a third principal components analysis was completed to assess whether the four overall network measures were measuring more than one underlying construct.

For the most part, the construct validity of the model was substantiated by factor analysis. As demonstrated in Table IV, a principal components analysis using the raw scorevariables concerning family and friends yielded six significant factors accounting for $51 \%$ of the variance. The eigenvalues of the six factors ranged from 2.10 to 1.04 , indicating that the relative importance of each factor was epproximately the same.

The negative loading of siblings on the second factor was due to the influence of age. A crosstabulations analysis of age and number of siblings revealed that larger families prevailed in the past. The two questions about the status of parents were coded dichotomously $0=$ dead and 1 = alivel. Thus, older people, whose parents would more 
TABLE IV

PRINCIPAL FACTOR ANALYSIS OF FAMILY AND FRIEND VARIABLES FROM HOUSEHOLD INTERVIEW SURVEY*

\begin{tabular}{|c|c|c|c|c|c|c|}
\hline & $\begin{array}{l}\text { FACTOR } 1 \\
\text { Friends }\end{array}$ & $\begin{array}{l}\text { FACTOR } 2 \\
\text { Family } \\
\text { of Origin }\end{array}$ & $\begin{array}{l}\text { FACTOR } 3 \\
\text { Frequency } \\
\text { See } \\
\text { Relatives }\end{array}$ & $\begin{array}{l}\text { FACTOR } 4 \\
\text { Immediate } \\
\text { Family } \\
\text { and Kin }\end{array}$ & $\begin{array}{l}\text { FACTOR } 5 \\
\text { Work }\end{array}$ & $\begin{array}{l}\text { FACTOR } 6 \\
\text { Close } \\
\text { Friends, } \\
\text { Neighbors }\end{array}$ \\
\hline $\begin{array}{l}\text { How often see friends/families } \\
\text { How many friends/families see }\end{array}$ & $\begin{array}{l}.80 \\
.76\end{array}$ & $\begin{array}{l}.04 \\
.13\end{array}$ & $\begin{array}{l}.03 \\
.09\end{array}$ & $\begin{array}{r}-.07 \\
.04\end{array}$ & $\begin{array}{l}.03 \\
.08\end{array}$ & $\begin{array}{r}-.06 \\
.03\end{array}$ \\
\hline $\begin{array}{l}\text { Mother alive } \\
\text { Father alive } \\
\text { Number of sib!ings }\end{array}$ & $\begin{array}{l}.13 \\
.09 \\
.04\end{array}$ & $\begin{array}{r}.75 \\
.75 \\
-.55\end{array}$ & $\begin{array}{r}-.08 \\
-.07 \\
.01\end{array}$ & $\begin{array}{l}.15 \\
.08 \\
.31\end{array}$ & $\begin{array}{r}.02 \\
.00 \\
-.18\end{array}$ & $\begin{array}{l}-.07 \\
-.09 \\
-.17\end{array}$ \\
\hline $\begin{array}{l}\text { Frequency of contact fam rel far } \\
\text { Frequency see relatives near } \\
\text { Frequency soe relatives day away }\end{array}$ & $\begin{array}{r}-.08 \\
.12 \\
.16\end{array}$ & $\begin{array}{r}.06 \\
-.07 \\
-.13\end{array}$ & $\begin{array}{l}.64 \\
.63 \\
.62\end{array}$ & $\begin{array}{r}-.01 \\
-.02 \\
.06\end{array}$ & $\begin{array}{r}.12 \\
-.18 \\
.05\end{array}$ & $\begin{array}{l}.08 \\
-.04 \\
-.10\end{array}$ \\
\hline $\begin{array}{l}\text { Number children } \\
\text { Number relatives near } \\
\text { Marriage } \\
\text { Number relatives day away }\end{array}$ & $\begin{array}{r}-.18 \\
. .27 \\
-.08 \\
.23\end{array}$ & $\begin{array}{r}-.03 \\
.03 \\
.32 \\
.13\end{array}$ & $\begin{array}{r}.14 \\
-.43 \\
.18 \\
-.12\end{array}$ & $\begin{array}{l}.66 \\
.55 \\
.44 \\
.39\end{array}$ & $\begin{array}{r}.03 \\
.02 \\
.01 \\
-.02\end{array}$ & $\begin{array}{r}-.02 \\
-.14 \\
.44 \\
.24\end{array}$ \\
\hline $\begin{array}{l}\text { Number talk to at work } \\
\text { Frequency see co-workers outside }\end{array}$ & $\begin{array}{r}-.06 \\
.22\end{array}$ & $\begin{array}{r}-.02 \\
.12\end{array}$ & $\begin{array}{r}-.04 \\
.05\end{array}$ & $\begin{array}{r}.17 \\
-.17\end{array}$ & $\begin{array}{l}.79 \\
.63\end{array}$ & $\begin{array}{l}-.03 \\
-.03\end{array}$ \\
\hline $\begin{array}{l}\text { Frequency see close friends } \\
\text { Number close friends } \\
\text { Number neighbors }\end{array}$ & $\begin{array}{l}.27 \\
.28 \\
.36\end{array}$ & $\begin{array}{r}.03 \\
-.35 \\
-.08\end{array}$ & $\begin{array}{r}.19 \\
-.05 \\
.21\end{array}$ & $\begin{array}{r}.08 \\
-.06 \\
.18\end{array}$ & $\begin{array}{l}.23 \\
.24 \\
.04\end{array}$ & $\begin{array}{r}-.62 \\
.46 \\
.44\end{array}$ \\
\hline $\begin{array}{l}\text { Eigenvalues } \\
\% \text { Variance } \\
\text { Cum \& Variance }\end{array}$ & $\begin{array}{r}2.10 \\
12.33 \\
12.33\end{array}$ & $\begin{array}{r}1.81 \\
10.65 \\
22.97\end{array}$ & $\begin{array}{r}1.39 \\
8.17 \\
31.14\end{array}$ & $\begin{array}{r}1.35 \\
7.93 \\
39.07\end{array}$ & $\begin{array}{r}1.10 \\
6.46 \\
45.54\end{array}$ & $\begin{array}{r}1.04 \\
6.13 \\
51.66\end{array}$ \\
\hline
\end{tabular}

${ }^{*} \underline{N}=1038$ minimum, pairwise; varimax rotation 
often be deceased, had a greater number of siblings. Frequency of contact with close friends loaded negatively on Factor 6 (close friends, neighbors) with numbers of close friends and numbers of neighbors. It may be that poople with larger numbers of close friends have had the opportunity to reside in several geographical areas. They may have a dispersed friendship network which they are able to see only infrequently but which nevertheless are considered close. Individuals with fewer close friends may have resided only in one area and been able to come in contact with fewer people to be close friends. Because they live within the same area, they may see these people frequently. However, the results of this factor analysis are open to question because, due to an inordinate number of missing values on several of the questions, the minimum number of subjects entered for this pairwise evaluation was only 1038 lout of a potential 2603\}. For instance, there were more than 500 missing answers to the questions about frequency of contact with close friends lbecause over 500 respondents declared they had no close friends) and over 1000 missing answers to questions about work because of the women who were homemakers and the older poople who were retirad.

When the nine indexes representing aspects of the relationship domains which had been summed for the overall network interaction index were factor analyzed lmissing valuas were not a problem herej, three factors were 
axtracted with eigenvalues ranging from 1 to 2 (Table V). These factors accounted for $46 \%$ of the variance. Upon varimax rotation, the three factors defined the network sectors somewhat differently than the conceptual model. The first factor combined the indexes comprising both the community and friends sectors. In the model, these were separated as two distinct areas. The second factor defined by the analysis was equivalent to the immediate family source. The third factor combined the family of origin and relative sources. In the model, all the elements of the family had comprised a single sactor. Ultimately, this information applied only to the network scope indexes. These had been prepared by summing elements in the sectors that had been delineated conceptually. Since these indexes had already been prepared using a rationale based on reports in the literature, it was decided not to change them but to compare them at a later time with the combinations suggested by this analysis.

A third principal components analysis, which had been done to assess whether the four overall network measures were measuring more than one underlying construct, ravealed only one factor. No rotation was done because its interpretation was clear due to the high correlations among the measures. This factor accounted for $71 \%$ of the variance [Table VI]. The intercorrelations were substantial: they 
TABLE $V$

PRINCIPAL FACTOR ANALYSIS OF INTERACTION INDEXES FROM RELATIONSHIP DOMAINS*

\begin{tabular}{|c|c|c|c|}
\hline & $\begin{array}{c}\text { FACTOR } 1 \\
\text { Community, Friends }\end{array}$ & $\begin{array}{c}\text { FACTOR } 2 \\
\text { Immediate Family }\end{array}$ & $\begin{array}{l}\text { FACTOR } 3 \\
\mathrm{Kin}\end{array}$ \\
\hline Interection with other friends & .70 & -.01 & .13 \\
\hline Social leisure interaction & .60 & -.04 & .02 \\
\hline Interaction with close friends & .59 & -.20 & .10 \\
\hline Interaction at meetings, church & .55 & .31 & -.05 \\
\hline Work interaction & .40 & .10 & -.38 \\
\hline Marriage & -.06 & .73 & -.04 \\
\hline Children & .00 & .69 & .10 \\
\hline Interaction with family of origin & .06 & -.07 & .78 \\
\hline Interaction with relatives & .19 & .31 & .60 \\
\hline Eigenvalues & 1.76 & 1.28 & 1.09 \\
\hline \% Variance & 19.60 & 14.18 & 12.07 \\
\hline Cum $\%$ variance & 19.60 & 33.78 & 45.85 \\
\hline
\end{tabular}

${ }^{*} \underline{N}=2379$ minimum, pairwise; varimax rotation 


\section{TABLE VI}

\section{PRINCIPAL COMPONENTS ANALYSIS OF FOUR OVERALL} NETWORK MEASURES *

FACTOR 1

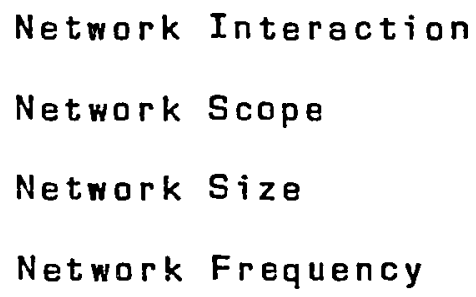

${ }^{*} N=2321$, Iistwise; no rotation 
ranged from .76 to .38 [Table VII]. High intercorrelations among the four indexes occurred because, although they measured different network dimensions, the information used in constructing them derived from the same set of questions.

\section{Reliability of the Network Indexes}

The summative indexes constructed to measure the social networks of the household interview survey sample were a simple aggregation of the relationship domains. The components of these indexas were selected and combined, as explained earlier, based on the survey questions that were available, knowledge of past research results, and network theory.

Most satisfactory indices or scales are homogeneous, have a high average correlation among components, and are dominated by a single factor. However, tha size of an individual's family may be conceptualized as a combination of the number of family members from several sources [spouse, parents, siblings, children\}. One wauld not expect the size of all the various sectors to be highly correlated and yet the combination of these sources is a meaningful way to think about the size of a respondent's family as a construct. The low correlations often found among the variables making up the indexes, although disappointing, were not unexpected. Whether one's parents wera aliye or dead, how many relatives one had, and whether one say co- 
TABLE VII

INTERCORRELATIONS OF OVERALL NETWORK INDEXES

$\begin{array}{cccr}\text { Network } & \text { Network } & \text { Network } & \text { Network } \\ \text { Scope } & \text { Size } & \text { Frequency } & \text { Action }\end{array}$

\begin{tabular}{|c|c|c|c|c|c|}
\hline Network & scope & 1.00 & & & \\
\hline Network & size & .62 & 1.00 & & \\
\hline Network & frequency & .57 & .38 & 1.00 & \\
\hline Network & interaction & .76 & .70 & .67 & 1.00 \\
\hline
\end{tabular}


workers outside the work place are factors not generally related to each other although tha presance of each has the possibility of providing some measure of social support. The internal consistency reliability for the network indexes were low due to the low item correlations. Cronbach's alpha which was computed for each overall index ranged from .30 for network size to approximately .43 for network scope. Each component of the index was then assessed so as to be sure it was making a positive contribution to the total scale. Reliability results can be viewed as part of the overview boxes in Appendix D.

\section{DEPENDENT MEASURES}

\section{Mortality}

Known deaths that occurred among the 2603 respondents between 1970 and 1982 serve as the measure of mortality. The specific causes of death are not available for analysis.

Of the 2603 individuals interviewed in 1970, approximately 1475 were still eligible members at the close of 1982. Each year approximately 100 had left the program lsee Figure 8). Deaths that occurred among respondentos while they were subscribers are known either from hospital records or from the membership information files. It is expected that some of the respondents who left the Plan subsequent to the survey have since died. Without that data, however, the 


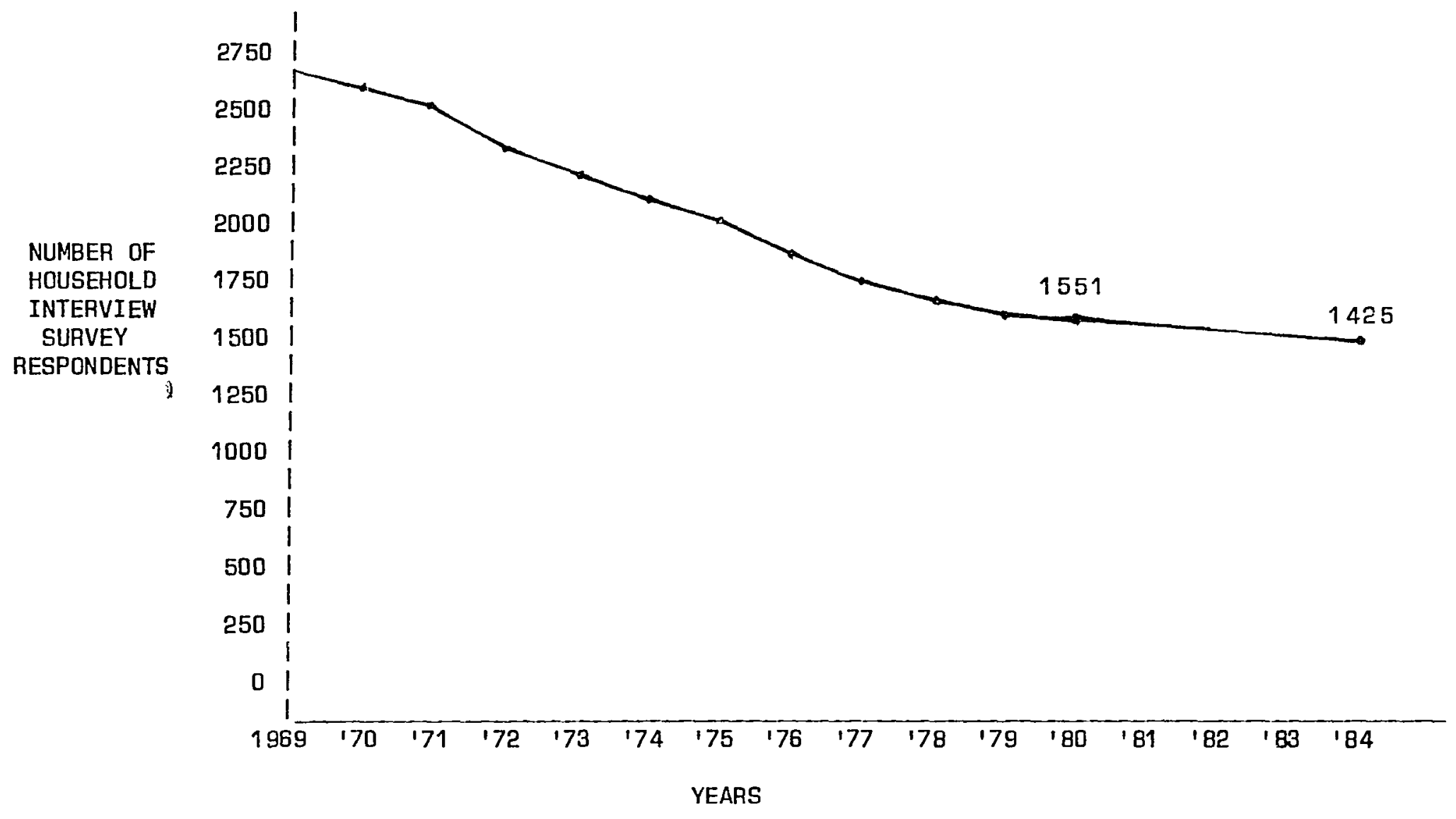

Figure 8. Number of respondents remaining eligible for the Kaiser Medical Care Plan in years subsequent to Household Interview Survey, 1969-1984. 
bast estimate of the mortality rate of the respondents to the household interview derives from known deaths.

How do the mortality ratas calculated from the known deathe within the study group compare with mortality rates from other community populations? If there were many unknown deaths among the study population, their death rates would be unusually low. The 12 year mortality rates for persons aged 30-69 within the Kaiser Permanente cohort were compared to those obtained by Berkman and Syme (1979) over 9 years using the Human Population Laboratory data. The results in Table VIII indicate that the Kaiser mortality rates for men are higher (14.2 compared to 9.5$\}$ while those for women are more similar $\{7.8$ as opposed to 6.4). It would be expected that the Kaiser rates would be at least somewhat higher because the observation period for this Portland sample was three years longer than that of the Alameda County group. This comparison supports the assumption that the number of known deaths among the study population is a reasonably accurate masure of all the deaths that may have occurred during the 12 year pariod.

\section{Disease Incidence}

Incidence of disease is measured using health services utilization data. The disease incidence variables encompassed seven years, in the middle of which the hausehold interview survey occurred. Two different ways were prepared 
TABLE VIII

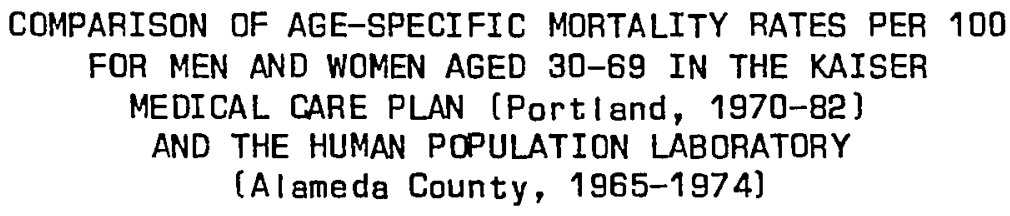

\begin{tabular}{llll}
\hline Age No. of Respondents No. of Deaths $\%$ Died \\
\hline
\end{tabular}

HUMAN POPULATION LABORATORY

MEN

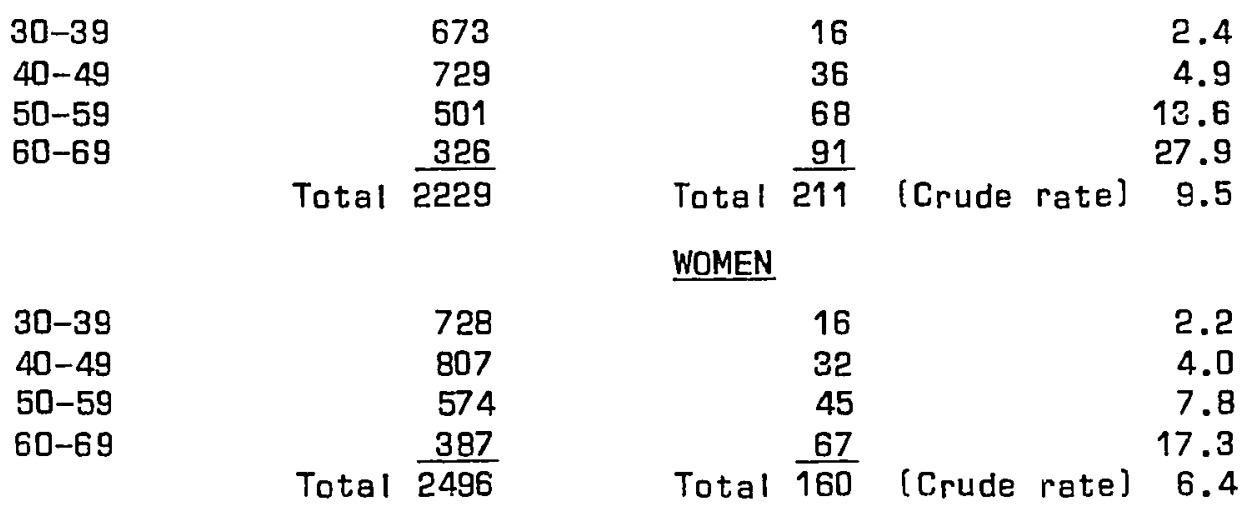

KAISER-PERMANENTE MEDICAL CARE PLAN

MEN

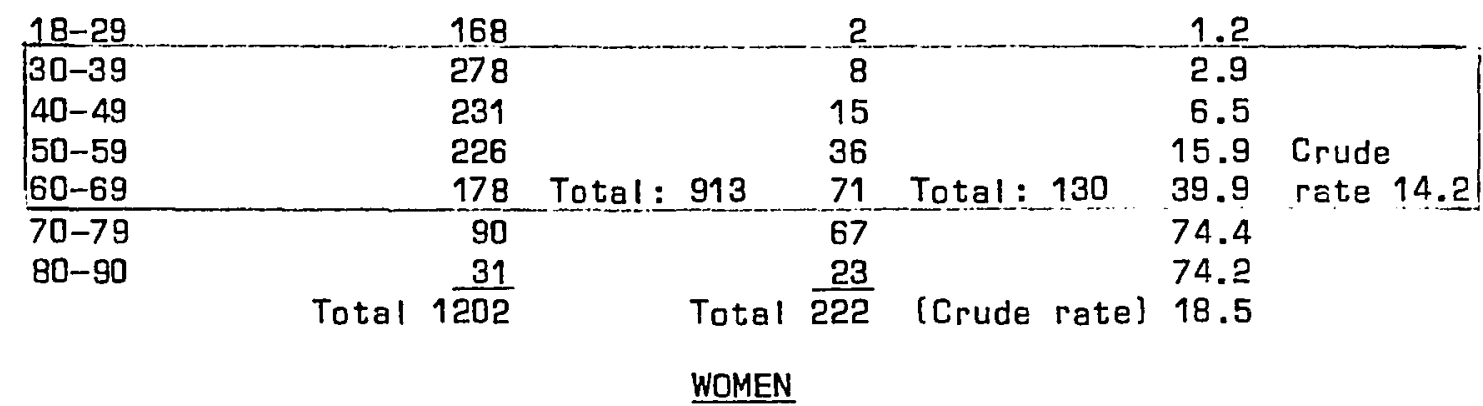

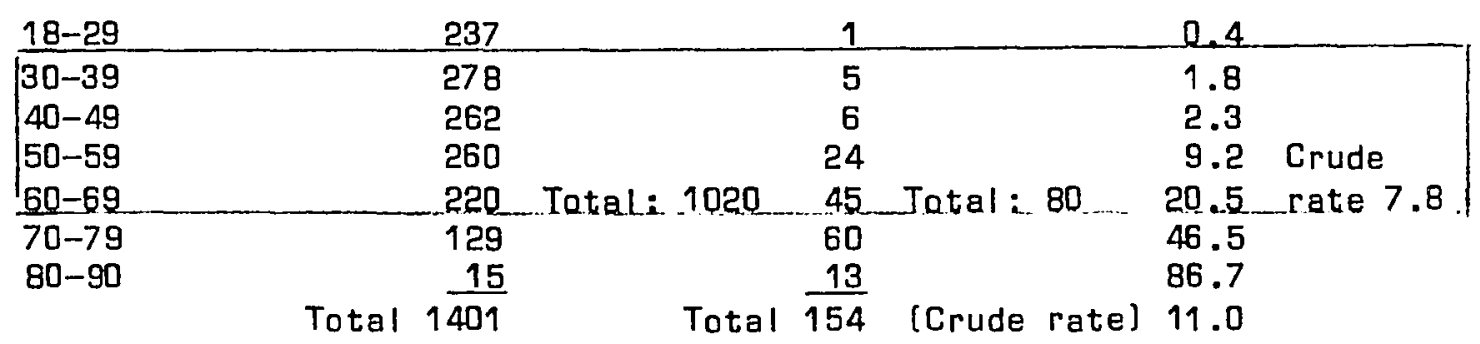


initially to measure disease incidence, but only the first (Version A], was ultimately utilized.

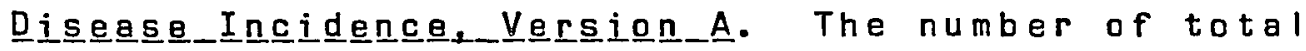
injtial doctor office visits over ell ten disease classes has been summarized for 1967 through 1973 for each person in the study population. These summaries have been converted to mean annual rates per 10 person years to take into account differing lengths of membership in the kaiser Plan. The formula used by the Center for rate calculation is displayed in Figure 9. An "injtial" visit indicates the first outpatient visit for a new morbidity. Subsequent visits for the same morbidity, should they occur, are coded as "continuing." Initial plus continuing visits for a single morbidity are known as an "episode." The first approach to measuring disease incidence consisted of total initial visits over the study time period.

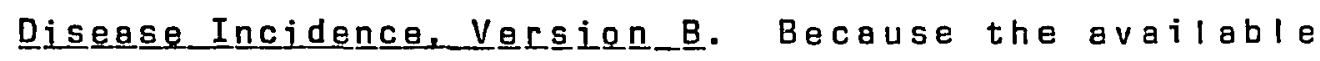
initial visits measure (Version A) is not broken down into its component disease categories, it also contains nondisease visits such as those for preventive care, obstetrics and trauma. In order to overcome this deficiency, but not without limitaicions of their own, a series of new nominal variables was created for each of the first saven ltrue diseasel categories in the classification system. 


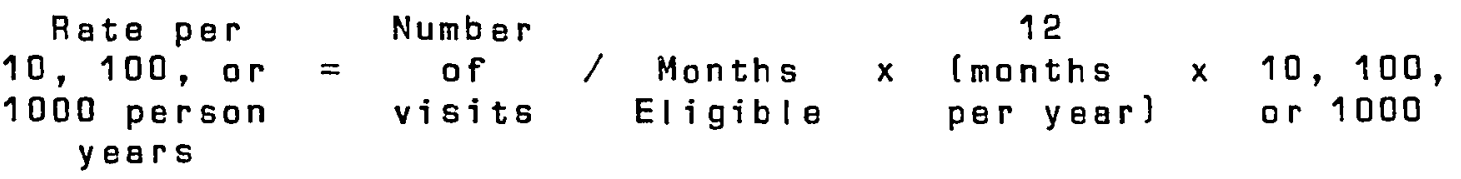

Eigure g. Formula used by Center for Health Research to convert utilization summary measures to rates per person year. 
The new variables measured whether or not at least one initial doctor's office visit (with the health care system) had occurrad within a disase class for the individual, based on visits during the seven year period. Variables were created for classes 1 through 7 . Classes 8 through 10 were disregarded. First, it was assumed that anyone who had an ongoing chronic disease condition would have been seen at least once in 1967 or 1968 , which were considered the baseline years. The purpose here was to eliminate all people making continuing visits. People with one or more visits in 1967 - 1968 were coded 0 , and were meant to be excluded from the analysis because it would be impossible to ascertain whether their visits were continuing or initial. Next, respondents who had no visits at all during the entire seven year period were coded 1. Those remaining, the largest group, had one or more visits during the latter 5 years (1969-73). It was assumed that this would represent at least one initial contact, or new disease, for an individual and this group was coded 2. Thus, if the second hypothesis was correct, people with more network resources would fall more frequently into category 1, which meant no visits to the health care system.

For each of the seven disease classes, then, a dichotomous measure was computed indicating whether or not at least one initial visit had occurred within that disase class during a five year period. Because of their nominal 
nature, these measures could not be converted to rates. Therefore, for statistical testing, only subscribers eligible for the entire seven year time period 19406 individualsl were to be included in the analysis. As noted earlier, these measures ara also conservative, but were meant to serve as an alternate approach to assessing disease incidence. However, their use would have entailed using additional computer resources. Therefore, it was decided to keep them in reserve to be used for further exploration should version A have been statistically significant.

\section{Disease Progression}

To reiterate, the objective of this research is to assess whether social networks impact on mortality by affecting disease incidence or by affecting survival once illness occurs. When a person develope an illness, he or she comes to the health caresystem and uses its services for treatment. The amount of this contact is usually in proportion to the gravity of the physical problem. If the individual becomes sicker, more office visits are likely to occur and more resources are likely to be used over time to maintain as healthy a state as possible in the face of decline. Thus, if hypothesis 3 is correct, pooplewith moresocial network ties should have slower illness progression and hence use relatively less halth care and require fewer resources over time. Those individuals with minimal network 
connections would be expected to have a detarioration in their health status over time and concomitantly use relatively more resources and care.

Change in health status was operationalized as the change in the rate of outpatient contacts and change in the rate of total resource use, as measured by the RVS system. A seven year period of time, 1967-1973, was utilized. In order to control for health/illness level at the time of the survey, the years prior to the survey served as a basaline.

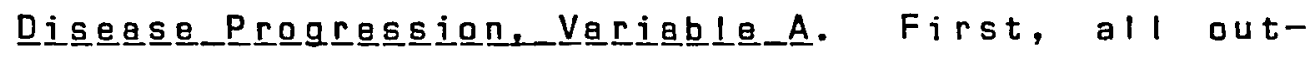
patient contacts for the first seven disease classes (true disease, not trauma, obstetrics, or preventive carel were summed for each year separately. Masures were creatad for $1967,1968,1969,1970,1971,1972$, and 1973. Of these, the baseline years, 1967 through 1970, were combined by summing for a new variable. The subsequent years, 1971 through 1973, were also aggregated for a second new variable. Rates of contact per 10 person years were then computed for each of these two time periods, using the formula in figure 9. The rate of contact for 1967-70 was then subtracted from the rate of contact for 1971-73. This rate of change variable yielded a measure more specific to actual disease.

Disease Progression, Variable B. In a similar manner, two resource use variables were created for the same time periods before and after the survey using RVS codes. Sub- 
traction of the one from the other gave a new variable which could be used similarly to measure rate of change in disease prograssion. This resource variable, however, counted all resource use across the 10 disease classification categories. Thus, it was a less sensitive measure of actual disease than variable A. For this reason it was decided to hold variable B in reserve to be used if variable A proved significant, requiring further exploration of tha networks/ progression data.

\section{CONTROL VARIABLES}

\section{Demographic Variables}

Age. Age was available as a continuous variable (1890). It was also collapsed into four categories for certain analyses. The categories were: under $35,35-49,50-65$, and over 65. A variable reflecting these categories was used which had been created for prior Center studies. Age was further collapsed by combining the two younger categories for some analyses: $18-49,50-64$; and 65 and over.

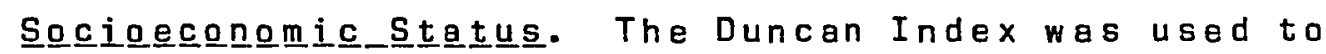
stratify the household interview sample in terms of socioeconomic status. This index had been created by the Canter for all families using the methodology explicated by Duncan (1961). A widely used measure, the Duncan Index is based upon occupational prestige and education. Its reliability and validity have been reported elsewhere (Duncan, 1961). 
This variable was collapsed to a metric of five for some analyses.

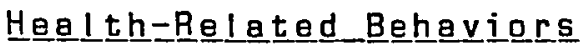

Three indexes assessing health behaviors were used that had been created for prior Center studies (Pope, 1982). Each is described below.

Smaking. Smoking behavior is measured by the number of cigarettes smoked by current smokers and by smoking history. Scores on this index range from 1 to 9 . Light smokers are those who smoke half a pack or less per day, medium smokers smoke one half to one packperday, and heavy smokers are defined as using more than a pack per day. The total index is:

1. Never smoked

2. Formerly smoked but stopped more than ten years ago

3. Formerly smoked but ceased within the past ten years

4. Currently light smoker, having smoked for ten years or less

5. Currently light smoker, having smoked for more than ten years

6. Currently a medium smoker, having smoked for ten years or lass

7. Currently a medium smoker, having smoked for more than ten years 
8. Currently a heavy smoker, having smoked for ten years or less

9. Currently a heavy smoker, having smoked for more than ten years

Drinking. An index of drinking was constructed by grouping together those drinking patterns assumed to be similar in their health impact. Drinking patterns are defined by the quantity of alcohol imbibed per occasion in combination with how frequently the occasions of drinking occur. The scores on the ordinal drinking scale range from 1 to 4 and combine drinking types in the following manner:

1. Abstainers and both regular and occasional light drinkers

2. Occasional heavy drinkers and regular drinkers, occasionally heavy

3. Regular drinkers, frequently heavy

4. Regular drinkers, heavy

Because it includes nothing on the history of drinking, this measure is a conservative indication of drinking behavior. It must be assumed that current drinking status is similar to past practices. However, heavy drinkers in the past may have been converted to sobriety.

Physical1_Acttivity. An index of physical activity based on responses to the open-ended questions about the kinds of leisure engaged in resulted in a measure which had a range of scores from 0 to 12. Six types of activities 
which ordinarily use physical exertion were selected from the responses and weighted arbitrarily in terms of the amount of physical exertion required. Unknown was the amount of time spent doing the activity for any specific time period, how frequently the respondent engaged in the activity, and for how long he had been doing it. Types of activities that were seasonal or did not necessitate a great deal of physical exertion were given weights of 1 , while types of activities that occurred year round or required much exertion were weighted 4. For example, activities given weights of 1 were: camping, fishing, gardening, and hunting. Weights of 4 were assigned to "participating in sports" and "other physical activitios."

\section{Health Stgatus Indicators}

An important variable in the networks/mortality relationship is state of physical health. People in poor health iinay have smaller networks because illness limitations preclude being in contact with other people in social situations. Three different health status indicators are used to control for each individual's health status prior to the survey. These variables were selected by correlating all available health status measures with mortality status (alive or deceased) as of 1982 and with each other, assessing for redundancy (see Table IXfor correlations). Each 
TABLE IX

ZERO-ORDER CORRELATIONS OF= INDICATORS OF HEALTH STATUS AT TIME OF HOUSEHOLD INTERVIEW SURVEY AND MORTALITY

\begin{tabular}{|c|c|c|c|c|c|c|c|}
\hline & Mortality & $\begin{array}{c}\text { Resources } \\
\text { Use, 1967-70 }\end{array}$ & $\begin{array}{c}\text { Outpatient } \\
\text { Contects, } \\
1967-70\end{array}$ & $\begin{array}{c}\text { Length } \\
\text { Hospital } \\
\text { stay, 1967-70 }\end{array}$ & $\begin{array}{l}\text { Hospital } \\
\text { Discharges } \\
1967-70\end{array}$ & $\begin{array}{l}\text { Physical } \\
\text { Symptoms }\end{array}$ & $\begin{array}{l}\text { Perceived } \\
\text { Heal th }\end{array}$ \\
\hline Mortality & 1.00 & & & & & & \\
\hline Resource Use, 1967-70 & .16 & 1.00 & & & & & \\
\hline $\begin{array}{l}\text { Outpatient Contacts, } \\
1967-70\end{array}$ & .18 & .83 & 1.00 & & & & \\
\hline $\begin{array}{c}\text { Length Hospital Stay, } \\
1967-70\end{array}$ & .26 & .41 & .49 & 1.00 & & & \\
\hline $\begin{array}{c}\text { Hospital Discharges, } \\
1967-70\end{array}$ & .22 & .43 & .51 & .86 & 1.00 & & \\
\hline Physical Symptoms & .07 & .14 & .11 & .06 & .06 & 1.00 & \\
\hline Perceived Heal th & .24 & .30 & .32 & .25 & .25 & .23 & 1.00 \\
\hline
\end{tabular}


measure selected seemed to capture a different dimension of health. One measure is subjective (perceived health), one is from the outpationt file (outpatient contacts), and one is from the inpatient file (length of hospital stay). The other items in Table IX were eliminated.

Perceived He日lth. As part of the survey, respondents were asked to evaluate their own health as excellent, good, fair, or poor. Subjective assessment of health has beer found to be a predictor of mortality in longitudinal assessments of general populations (Mossey \& Shapiro, 1982; Kaplan \& Camacho, 1983].

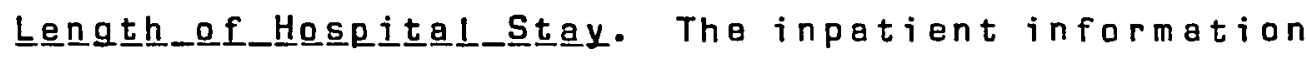
system provides data on the number of days spent in the hospital during the years 1967-70. The days have been summed to create a variable which has been converted to rates. Poople spending more time in the hospital would be expected to be in poorer health.

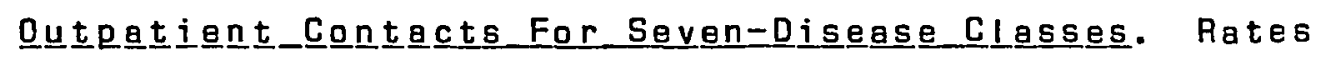
for chronic and acute disease outpatient contacts have been combined for disease classes 1 through 7 , for the time period from 1967-1970.

\section{STATISTICAL TESTS}

This section will be directed toward those statistical tests which were used to determine the relationship between sacial networks and the disease outcomes. Those statistical 
tests which established the reliability and validity of the network indexes have al ready been described.

Crosstabulations and one-way analysis of variance procedures were used to assess bivariate ralationships between dependent and independent yarigbles. Crosstabulations were used for categorical and ANOVA was used for continuous dependent measures. The network structural variables were collapsed and mortality rates calculated for people with small, medium, and large networks. These rates were computed by dividing the frequency distributions into three parts as evenly as possiolabased on cumulative percentages.

Independent, dependent, and control variables were correlated with each other in order to evaluate the extent of multicollinearity that might need to be considered in the interpretation of the results. The correlations are displayed in Appendix E. All control variables had correlations with mortality significant at the $p<.05$ level.

Since there were potentially a large number of regressions possible given the different types of network variables and the different types of outcomes, it was decided to begin the analysis with the network scope measure as the trial independent variable. Network scope was chosen because it was the mast highly correlated with mortality. If a significant relationship was found, the other network 
variables would then be used. If network scope had no impact on the particular outcome, it would be assumed that the other network measures would likewise be nonsignificant. The full regression model is outlined in Figure 10.

\section{Martalitty}

Because mortality was a dichotomous variable, it did not meet the assumptions required for multiple linear regression. Thus, a loglinear logistic regression model was used, as available in the spss computer package. This model provides a means for assessing the relationship between a dichotomous dependent variable and categorical predictor variables, and it can be extended to deal with variables whose categories have an underlying order. The loglinear model predicts the logarithm of the expected cell frequencies in a multifactorial contingency table using a linear combination of predictor variables. Some information and power is lost as the continuous independent variables must be broken into categories to reduce the number of empty cells. [However, House [1982] states that he found that contingency table, ordinary least squares corralation and regression, and multiple logistic function analysis using maximum likelihood estimation procedures [BMD] yielded very similar substantive conclusions in his networks/mortality study.J 


\section{NETWOAK STRUCTURE}

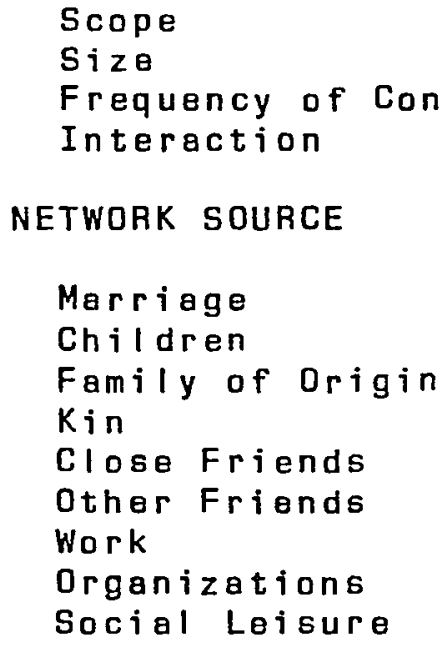

NETWORK SOURCE

Marriage

Children

Family of Drigin

Kin

Close Friends

Other Friends

Work

Organizations

Social Leisure

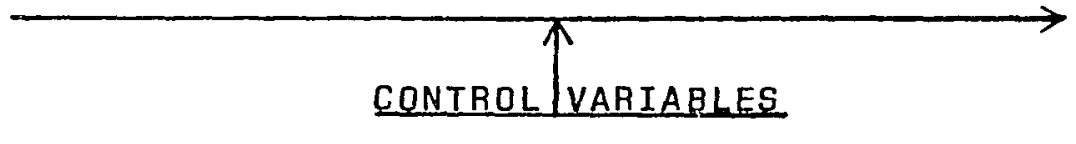

DEMOGRAPHIC

Age

Sex

Socioeconomic Status

RISK FACTORS

Smoking

Drinking

Physical Activity

HEALTH STATUS

Perceived Health

Length Hospital Stay

Dutpatient Visits
MORTALITY

DISEASE INCIDENCE

DISEASE PROGRESSION

Eigure_10. Model for the study of the ability of social networks to predict morbidity and mortality. 
In the general loglinear model, all variables are treated equally, as response variables whose relationships are to be determined by a multiplicative or additive function of an entire set of variables. There is a special case of this general version, called the logit model. Logit models are categorical variable analogs to ordinary linear regression for continuous dependent variables. In logit analysis, as in regression, one variabla is taken conceptually as dependent upon variation induced by the others. The criterion variab!e is the natural log of the odds of being in the first, rather than the second, category of the dependent variable [Knoke \& Burke, 1980; Payne, 1977).

For each model considered, the technique estimates a residual chi square statistic for assessing the overall fit. The strategy employed was to determine the most parsimonious model providing acceptable fit. The residual chi square may be interpreted as the error in prediction for the specified model. If it is statistically significant, the model must be rejected and other models considered. A measure of association between the dependent and independent variable(s), called entropy, can be interpreted as multiple $\underline{\text { in }}$ ordinary regression.

The parameters of the logit model can be interpreted similarly to the coefficients of ordinary regression [Goodman, 1972). Positive coefficients (coefficients are also known as betasl indicate that the independent variable 
raises the odds on the dependent measure while negative betas show that the odds are decressed. In the logit model, computer output includes a coefficient for each category of the independent variable.

In instances where levels of the independent variable form an ordinal measure, a model similar to ordinary regression is used. For this version, a contrast is used to convert the scale to a metric measura. Instead of coefficients for each category of the independent variable, only one coefficient is computed for the variable. It represents the change in the dependent variable per unit change in the independent. As with the logit model, each coefficient is then multiplied by 2 for the logistic coefficient. To obtain the odds ratio [relative risk], the antilog of the coafficient is taken [SPSSX User's Guide]. Statistical significance tests are based on zratios for the logistic function coefficients. Two-tailed tests of significance were applied.

When dichotomous independent variables are used lno contrast needed) in the logistic regression version, they are interpreted in the opposite direction as when three or more levels of the variables are used. This occurs because in the logit model, low levels of the independent variable are compared to high levels. Dichotomous variables are interpreted in a similar manner because a contrast has not 
been used with them. In regression, high levels are compared to low. Thus, tha signs on dichotomous independent variables that appear in the Tables in Chapter V have been reversed from those appearing on the computer printout. Positive values indicate that increases in the independent variable raise the odds on dying; negative values indicate that the odds are decreased. The coding for the variables and the versions to which they were collapsed for the logistic analyses can be sean in Appendix $F$.

The logistic regression analyses proceeded in five phases, with the initial intent of eliminating control variables which did not make a significant contribution to mortality. This approach minimized the decrease in sample size that resulted from missing data, and created the most parsimonious model.

In the first series of logistic analyses, the three demographic, three health status, and three risk factor variables as well as the network scope measure were assessed for their zero-order relationship with mortality. Each was collapsed to a variable involving from 3 to 5 ordered categories. If the resulting model did not fit due to a nonI inear relationship, a quadratic term was added to the linear multiplicative constant required for the approach being utilized.

In the second series of analyses, each control variable which was significant in phase one was again related to 
mortality after being adjusted for age, which had been collapsed to 4 categories. Each control variable was dichotomized due to constraints posed by potentially empty calls. However, in most of the analyses using the full model, to be described next, all the variables were in three ordered categories as this most cansistently provided the best model fit.

In the third series of analyses, the dichotomized control variables still significantly related to mortality were entered one at a time, with those most significant entering first. The network scope variable always entered last, as this was the variable of primary substantive interest. In other words, the strongest predictor, age, was added first, and predictors were added until none of those remaining could significantly $[p<.05]$ increase the prediction of mortality. Tha final model included only age, sex, perceived health, and hospitalization, followed by network scope. Smoking had become non-significant when entered following hospitalization.

In the fourth series of analyses, scope of immediate family, scope of extended family, scope of friends, and scope of community involvement were entered in lieu of the overall network scope variable for the purpose of determining which network scope sectors were most pertinent to mortality risk. Logistic regression procedures were also 
done to ascertain whether networks predicted death mare in older people than in younger people, and whethar a sex difference existed. Then, also using the final model, the summary measures of network size, frequency of contact, and interaction were each entered last, in place of scope, in four additional regression analyses.

Finally, in order to ascertain the relative importance of the various relationship domains contained within the network model (in Figure 3], ten additional analyses regressed the interaction indexes on mortality.

\section{Mongbidity}

The multiple linear regression program contained within the sCss, a conversational statistical package, was used to estimate the relative contribution of network scope to predicting disease incidence and disease progression. All of the variables were used in their continuaus versions. A hierarchical, forced entry strategy was utilized. Age was added as the first control, as age is the intervening variable known to be most strongly related to health outcomes. In subsequent equations, additional control variables were added with network scope always entering last. This same approach was utilized with the disease progression outcome.

In summary, this chapter has highlighted the preparation of the network, control, and outcome measures used in this research. The testing of three hypotheses exploring 
the relationships betweon social networks and mortality, disease incidence, and disease progression was carried out by the logistic and multiple linear regression methods described. The results of these analyses will be the focus of the next chapter. 


\section{CHAPTER V}

\section{RESULTS}

The purpose of this research is to assess whether social networks impact on disease and its outcomes. The major focus of this chapter is to report on the findings of the hypothesis testing activities outlined in Chapter IV. Related statistics will be presented. However, social networks in and of themselves are interesting. Therefore, some data describing the networks of the study population will be presented first.

\section{DESCRIBING THE NETWORKS OF THE STUDY POPULATION}

It can be seen in the overview boxes that there is variability in people's networks. What are the networks of a basically healthy group of individuals representative of the Portland urban area like? How do theydiffer by sex and across the life cycle? What can be said about the structure of their networks? In comparing the social networks of men and women by age, it must be kept in mind that for marriad pairs, both husband and wife had the same scores on some of the variables Inear relatives and relatives living farther away, friends, neighbors: see Table IIIJ. This scoring from ife to husband occurred because by the design of the 
survey instrument, wives answered some questions about social life for the family. Mean scores for males and females in different age categories on the summary network indexes can be seen in Table $x$.

Not surprisingly, older people had smaller networks in terms of all the structural perspectives. This is undoubtedly because those over 65 years of age usually no longer have work networks, and their spouses and parents may be deceased. Sacial networks were greatest in age group 35-49. Men in the first two age categories had slightly more netwirk resources, probably reflecting the fact that many women in the sample were homemakers and did not have work networks. Within the age category inclusive of those 50-65, men's and women's networks approached equality. After age 65, when most men would be expected to be retired, the networks of women became somewhat greater. The networks of men decreased most with age. Table XI displays the percent distribution of the study population in small, medium, and large network categories by age. It can be seen that more young people fall into large network categories, and more older people fall in the small network categories. This trend is most pronounced for network scope and least pronounced for network size. 
TABLE $X$

MEAN SCORES ON SUMMARY NETWORK INDEXES BY AGE AND SEX

$\underline{\text { Under } 35} \quad \underline{35-49} \quad \underline{50-65}$ Over 65

NETWORK SCOPE (Range 1-13)

Male

$\begin{array}{cccc}10.47 & 10.38 & 9.58 & 7.66 \\ {[\underline{N}=275)} & (\underline{N}=346) & (\underline{N}=297) & (\underline{N}=182) \\ 10.06 & 10.09 & 9.29 & 8.07 \\ {[\underline{N}=375)} & (\underline{N}=368) & (\underline{N}=355) & (\underline{N}=226]\end{array}$

$[\underline{N}=1324]$

$[\underline{N}=375) \quad[\underline{N}=368) \quad(\underline{N}=355] \quad[\underline{N}=226]$

NETWORK SIZE (Range 2-40)

$\begin{array}{lcccc}\text { Male } & 23.25 & 24.01 & 22.27 & 19.11 \\ \qquad \underline{N}=1159) & {[\underline{N}=289]} & {[\underline{N}=361]} & {[\underline{N}=310]} & {[\underline{N}=199]} \\ \text { Female } & 22.56 & 22.76 & 21.30 & 20.15 \\ {[\underline{N}=1370)} & {[\underline{N}=385]} & {[\underline{N}=377]} & {[\underline{N}=369]} & {[\underline{N}=239]}\end{array}$

NETWORK FREQUENCY [Range 2-24]
Male
13.59
13.68
13.12
11.22

$$
[\underline{N}=1113]
$$
$(\underline{N}=283)$
$[\underline{N}=353]$
$[\underline{N}=297]$
$[\underline{N}=180]$
Female
12.96
13.36
13.27
13.20
$[\underline{N}=1316]$
$[\underline{N}=382]$
$[\underline{N}=35 q]$
$[\underline{P}=355]$
$[\underline{N}=2 P B]$

NETWORK INTERACTION (Range 3-42)
Male
28.09
29.26
26.65
22.03
$[\underline{N}=1073]$
$[\underline{N}=273]$
$[\underline{N}=336]$
$[\underline{N}=292]$
$[\underline{N}=172)$
Female
27.40
28.29
26.00
22.30
$[\underline{N}=1313]$
$[\underline{N}=375]$
$[\underline{N}=366]$
$[\underline{N}=351)$
$[\underline{N}=221]$ 
TABLE XI

PERCENT OF STUDY POPULATION IN SMALL, MEDIUM, AND LARGE NETWORK CATEGORIES BY AGE

NETWORK SCOPE

\begin{tabular}{|c|c|c|c|c|}
\hline$\frac{\text { SMALL }}{N=632]}$ & $\frac{\text { MEDIUM }}{(N=B 98)}$ & $\begin{array}{l}\text { LARGE } \\
{[N=895\}}\end{array}$ & & \\
\hline $15 \%$ & $36 \%$ & $49 \%$ & Total: & $100 \%$ \\
\hline $14 \%$ & $37 \%$ & $49 \%$ & " & \\
\hline $29 \%$ & $41 \%$ & $30 \%$ & $"$ & \\
\hline $61 \%$ & $33 \%$ & $6 \%$ & $"$ & \\
\hline
\end{tabular}

$$
\text { Total } 2425
$$

\section{NETWORK SIZE}

SMALL MEDIUM LARGE

$[\underline{N}=833] \quad[\underline{N}=792] \quad[\underline{N}=904]$

\begin{tabular}{|c|c|c|c|c|c|}
\hline Age under 3 & {$[\underline{N}=674]$} & $26 \%$ & $35 \%$ & $39 \%$ & Total: \\
\hline $35-49$ & $\{\bar{N}=738\}$ & $25 \%$ & $34 \%$ & $41 \%$ & $"$ \\
\hline $50-65$ & $\{\underline{\bar{N}}=679\}$ & $38 \%$ & $28 \%$ & $34 \%$ & $"$ \\
\hline over 65 & {$[\overline{\underline{N}}=438)$} & $50 \%$ & $25 \%$ & $25 \%$ & $"$ \\
\hline
\end{tabular}

Total 2529

SMALL MEDIUM LARGE

$[\underline{N}=781\} \quad[\underline{N}=725] \quad[\underline{N}=923]$

NETWORK FRERUENCY

\begin{tabular}{|c|c|c|c|c|c|}
\hline Age under 35 & {$[\underline{N}=665]$} & $29 \%$ & $35 \%$ & $36 \%$ & Total: \\
\hline $35-49$ & {$[\bar{N}=712]$} & $29 \%$ & $31 \%$ & $40 \%$ & 1 \\
\hline $50-65$ & {$[\overline{\underline{N}}=652]$} & $34 \%$ & $27 \%$ & $39 \%$ & $"$ \\
\hline over 65 & {$[\bar{N}=400]$} & $41 \%$ & $25 \%$ & $34 \%$ & $"$ \\
\hline
\end{tabular}

Total 2429

NETWORK INTERACTION

\begin{tabular}{|c|c|c|c|c|c|}
\hline Age under & $(\underline{N}=648)$ & $22 \%$ & $39 \%$ & $39 \%$ & Total: \\
\hline $35-40$ & {$[\underline{N}=702]$} & $17 \%$ & $35 \%$ & $48 \%$ & $"$ \\
\hline $50-65$ & {$[\underline{N}=643]$} & $34 \%$ & $33 \%$ & $33 \%$ & " \\
\hline over 65 & {$[\underline{N}=393]$} & $58 \%$ & $27 \%$ & $15 \%$ & $"$ \\
\hline
\end{tabular}

Total 2386 


\title{
NETWORKS AND MORTALITY
}

\begin{abstract}
A total of 222 men $118.4 \%$ of the 1202 male study population] and 154 women [11\% of the 1401 female study population died during the 12 year follow up period. Figures 11 and 12 display mean overall network scores during the 12 year follow up period according to mortality, age, and sex. Interestingly, for the youngest age group, those who later died usually had larger networks than those surviving. This was particularly true for females. However, there were too few deaths in this young age category for this information to be meaningful. From age 35 on, those who succumbed had lower mean network scores than the survivors.
\end{abstract}

In order to assess whether there is a dose-response relationship between networks and mortality or a threshold effect, mortality rates were plotted for levels of the network scope measure. There is a rather consistent pattern of decreased mortality rates for each increase in social resources until the high levels are reached whereupon the network effect becomes smaller (Figure 13).

Table XII shows mortality rates by age and sex. In order to see whether people in the study population with small networks have highar mortality rates as theorized, age and sex-specific mortality rates were calculated by categories of the structural network indexes (Table XIII). 
MALES

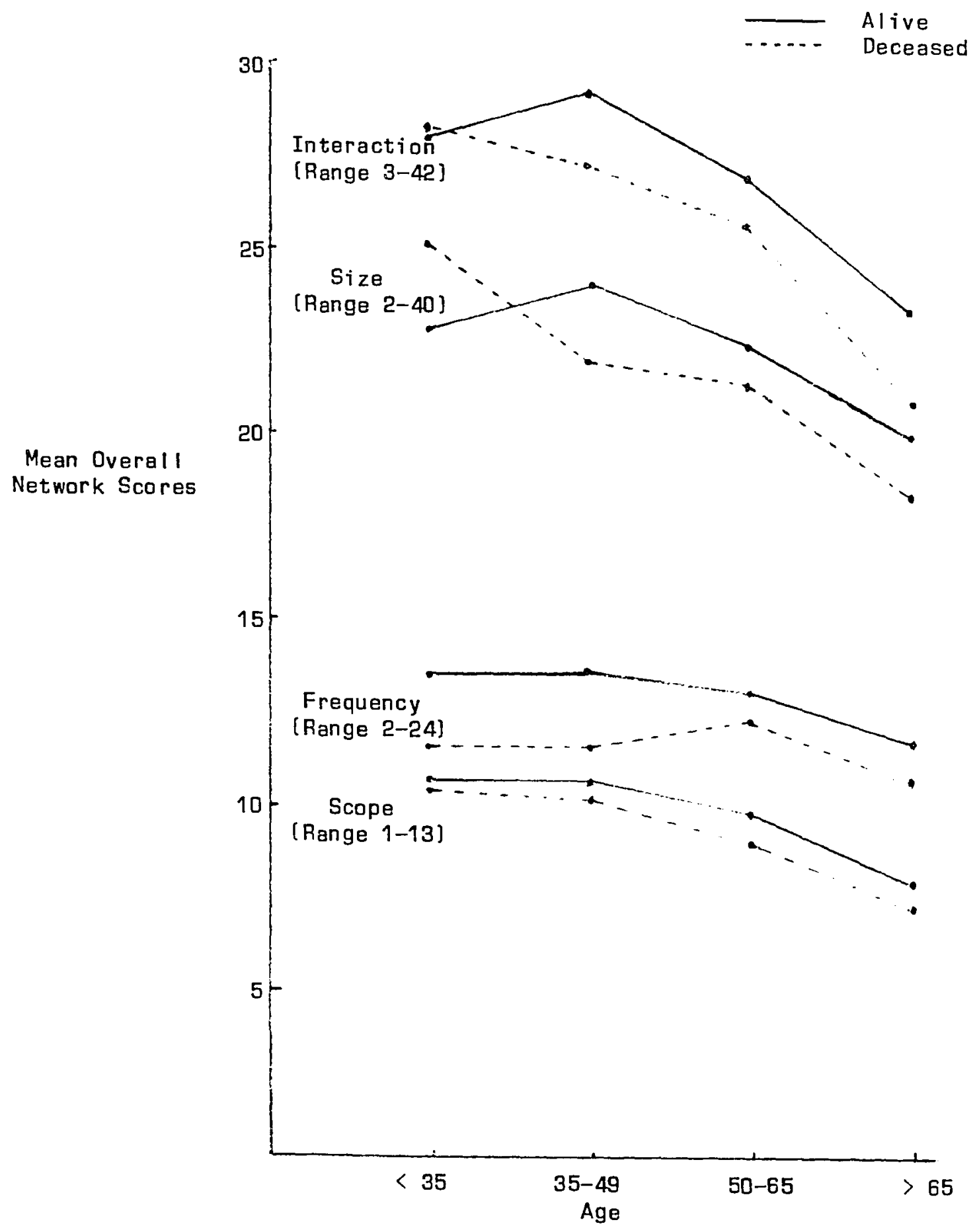

Figure 11. Mean overall network scores of deceased and surviving males, by age. 
FEMALES

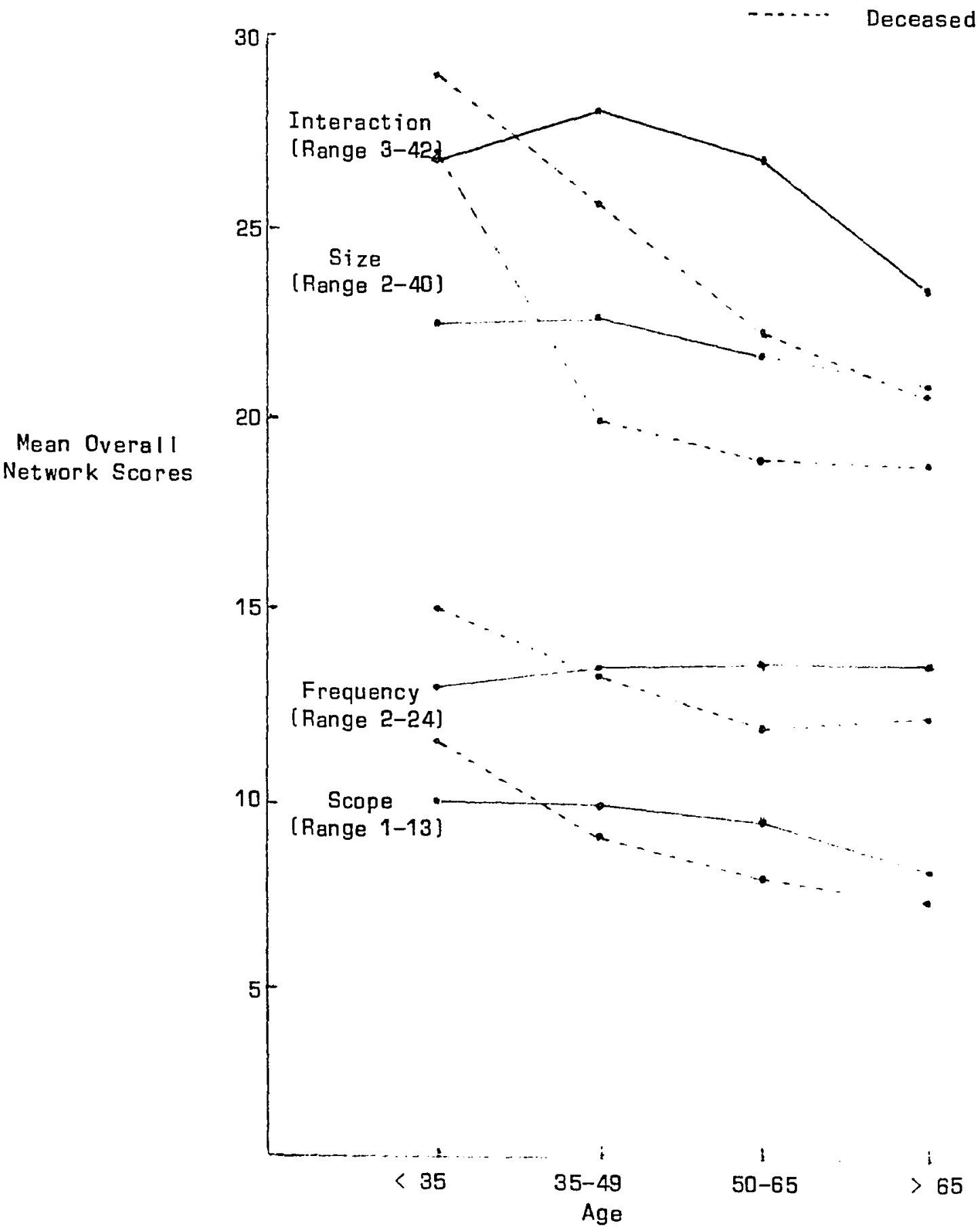

Figure 12. Mean overall network scores of deceased and surviving females, by age. 


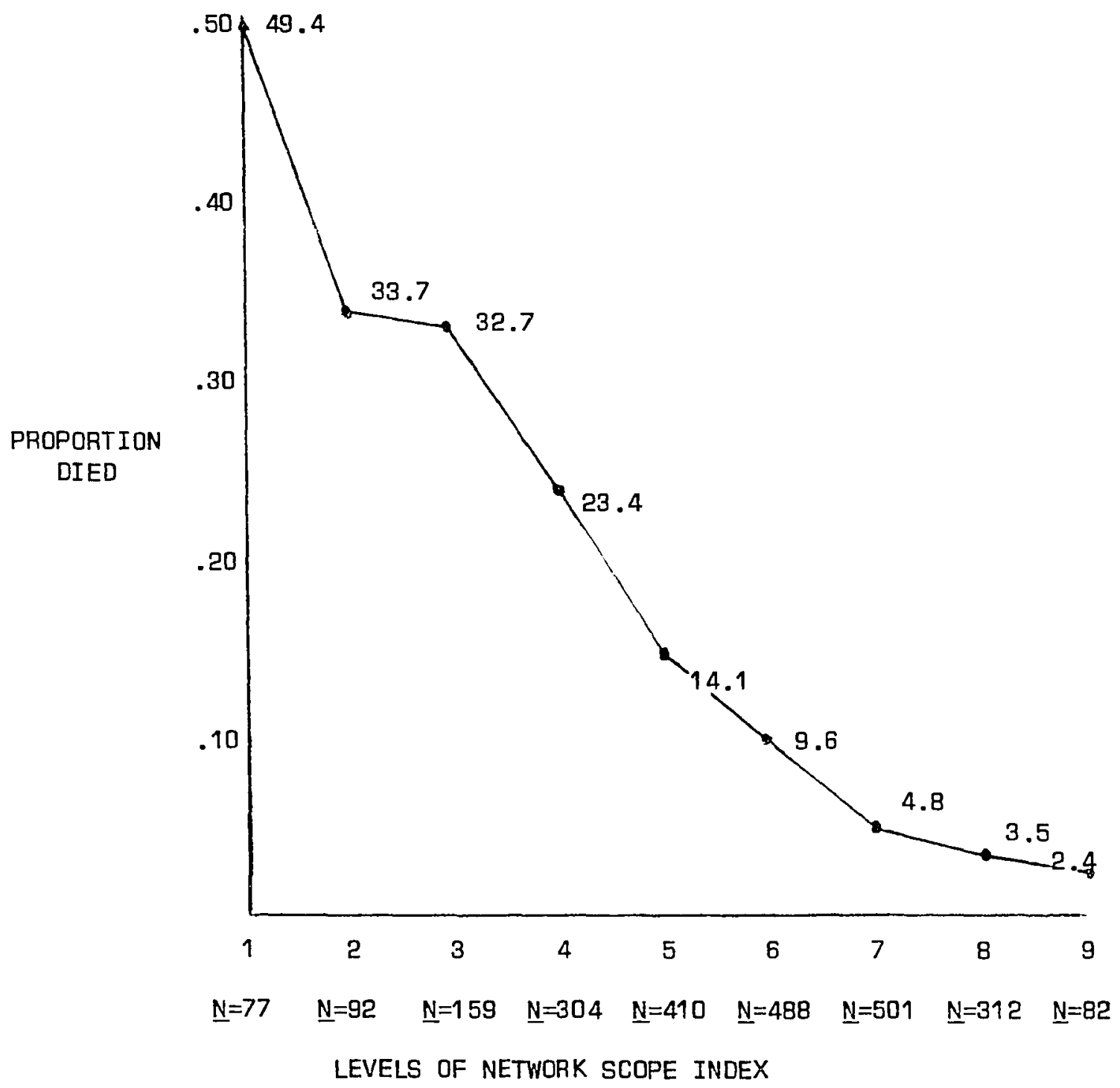

Figure 13. Graph of mortality rates by levels of network scope index. 
TABLE XII

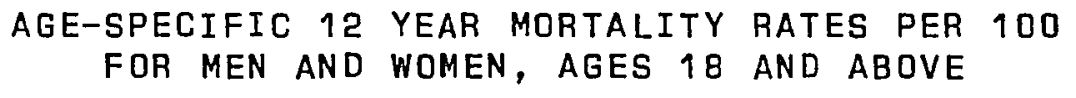

\begin{tabular}{ccc} 
No. of & No. of & $\%$ \\
Respondents & Deaths & Died \\
\hline
\end{tabular}

Me므

$\begin{array}{cccc}\text { Under } 49 & 677 & 25 & 3.7 \\ 50-65 & 316 & 65 & 20.6 \\ \text { Over } 65 & 20 \underline{9} & 13 \underline{2} & 63.2 \\ \text { Total } & 1202 & 222 & 18.5 \text { (crude rate) } \\ \text { Women } & & & \\ \text { Under } 49 & 777 & 12 & 1.5 \\ 50-65 & 378 & 45 & 11.9 \\ \text { Over } 65 & 246 & 9 \underline{39} & 39.4 \\ \text { Total } & 1401 & 154 & 11.0 \text { (crude rate) }\end{array}$


TABLE XIII

AGE AND SEX-SPECIFIC MORTALITY RATES PER 100 BY CATEGORIES OF STRUCTURAL NETWORK INDEXES

\begin{tabular}{cc}
$18-49$ \\
No. No. of & $\begin{array}{c}\alpha \\
\text { Deaths }\end{array}$ Dted STgnif. \\
\hline
\end{tabular}

NETWORK SCOPE

Sma II

Medium
Lerge

NETWORK SIZE

Small

Medfum
Lerge

NETHORK FREQUENCY

Small

Lerge

NETWORK INTERACTION

Small

Medium

NETWORK SCOPE

Sme ! I

Larga

NETWORK SIZE

Medium

Large

NETHORK FREQUENCY

Small

Large

NETWORK INTERACTION

Medium

Large

NS = nonsignificant

$\begin{array}{rrrr}72 & 3 & 4.2 & \\ 212 & 7 & 3.3 & \\ 338 & 10 & 2.9 & \text { [NS }\end{array}$

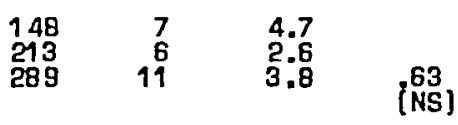

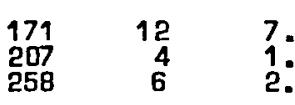

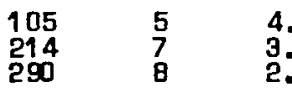

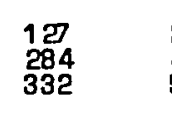

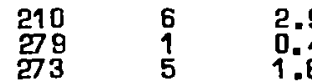

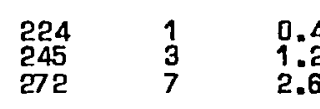

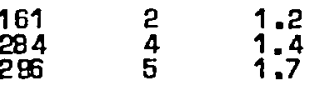

* $\mathrm{e} \leq 0.05$

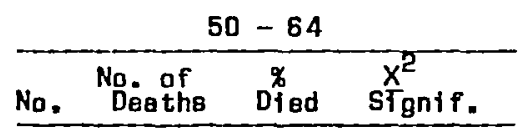

MEN

[NS

$.012^{*}$

[NS

NS)

$$
\text { 개에 }
$$$$
\begin{array}{r}
72 \\
128 \\
97
\end{array}
$$

$\begin{array}{rrr}105 & 23 & 29 \\ 98 & 20 & 22 \\ 116 & 22 & 19\end{array}$

$\begin{array}{rrr}106 & 29 & 27.4 \\ 75 & 12 & 16.0 \\ 116 & 19 & 16.4\end{array}$

$\begin{array}{lll}92 & 22 & 23.9 \\ 94 & 17 & 18.1\end{array}$

$\begin{array}{lll}94 & 17 & 18.1 \\ 106 & 21 & 19.8 \quad \text { ins }\end{array}$

\section{WOMEN}

113
144
1 of

$23 \quad 20.4$

[NS]

(ำs)

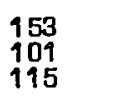

$\begin{array}{rr}117 & 20 \\ 141 & 13\end{array}$

[NS

$\begin{array}{rrrr}124 & 26 & 21.0 & \\ 120 & 13 & 10.8 & \\ 107 & 4 & 3.7 & .000^{* 4}\end{array}$

$* 4 * \mathrm{e} \leq 0.001$

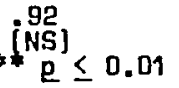

.000

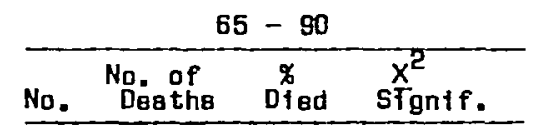

$\begin{array}{rrr}119 & 81 & 68.0 \\ 51 & 28 & 54.9\end{array}$

$\begin{array}{lll}12 & 007 * 4\end{array}$

$103 \quad 71 \quad 68.9$

$\begin{array}{llll}49 & 32 & 65.3 & 10\end{array}$

$\begin{array}{lll}95 & 64 & 67.4 \\ 40 & 25 & 62.5 \\ 45 & 24 & 53.3\end{array}$

$\begin{array}{lll}96 & 66 & 68.8 \\ 49 & 27 & 55.1 \\ 27 & 13 & 48.1\end{array}$

[NS

[NS

$\begin{array}{rrrr}129 & 60 & 46.5 & \\ 82 & 25 & 30.5 & \\ 15 & 2 & 13.3 & .008^{* *}\end{array}$

$\begin{array}{rrrr}114 & 55 & 48.2 & \\ 63 & 16 & 25.4 & \\ 62 & 23 & 37.1 & .01 * *\end{array}$

$\begin{array}{lll}68 & 32 & 47.1 \\ 61 & 27 & 44.3\end{array}$

$\begin{array}{llll}91 & 28 & 30.8 & 07\end{array}$

$\begin{array}{rrr}132 & 63 & 47.7 \\ 55 & 18 & 32.7\end{array}$

32.7
20.6

$.007 * 40$ 
These calculations were done by using cell percentages in contingency tables. Chi square tests were usad to evaluate whether the frequencies obtained in the cells differed significantly from each other. There was a consistent trend in the expected diraction; however, of the 24 crosstabulations, only nine were statistically significant at the $e \leq .05$ level. Six analyses for women reached statistical significance, those involving the older age categories of scope, size, and interaction. For men, three analyses reached statistical significance, two for older people in the scope index and one for the youngest group in the frequency of contact index.

Because marriage had been an important predictor of mortality in other studies, mortality rates were calculated for marital status (Table XIV). Surprisingly, when adjusted for age and sex, whether a person in this samplewas married or not did not significantly affect his of her mortality outcome. Trends were in the expected direction, however.

\section{MORTALITY AND ITS PREDICTORS}

Prior to the hypothesis testing analysas, an attempt was made to eliminate the nonsignificant control variables. Each independent variable lthe nine potential confounding variables and the network scope measurel was regressed separately on mortality. Network scope was used as the 
TABLE XIV

AGE AND SEX-SPECIFIC MORTALITY RATES FOR MARITAL STATUS

\begin{tabular}{|c|c|c|c|c|c|}
\hline $\begin{array}{l}\text { No } \\
\text { Married }\end{array}$ & $\stackrel{\ddot{\%}}{\text { Died }}$ & $\begin{array}{l}\text { No. Not } \\
\text { Married }\end{array}$ & $\begin{array}{c}\% \\
\text { Died }\end{array}$ & $x^{2}$ & p \\
\hline
\end{tabular}

Men

$18-49$

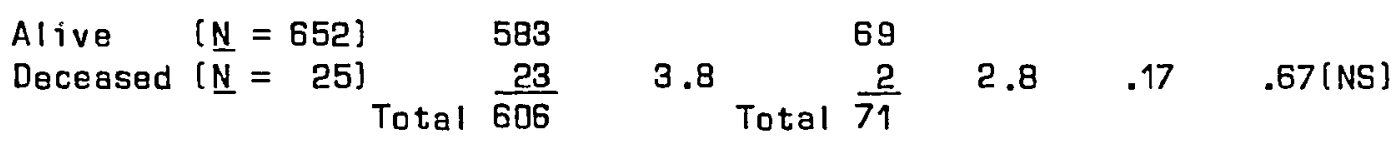

$50-65$

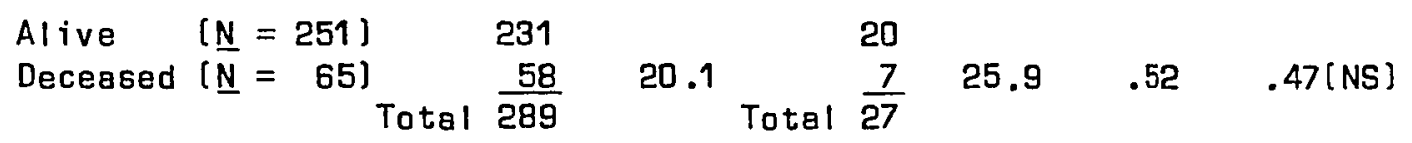

Over 65

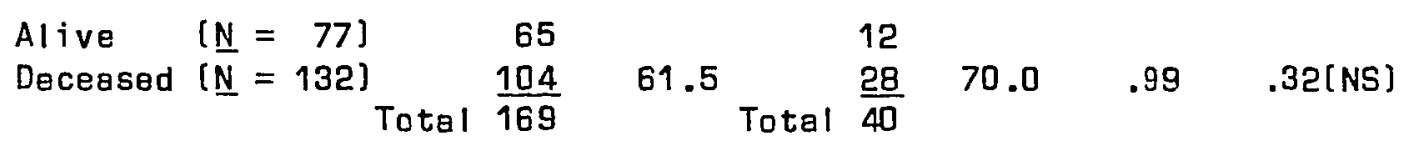

Women

$18-49$

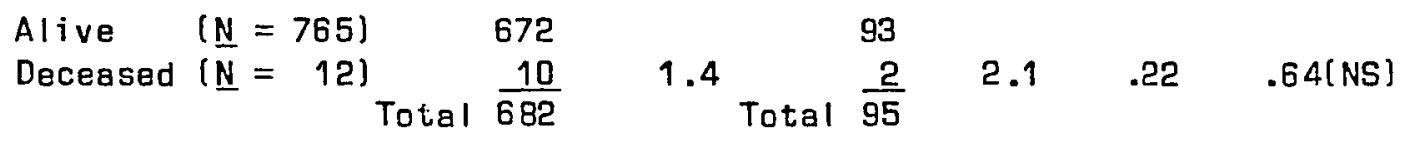

$50-65$

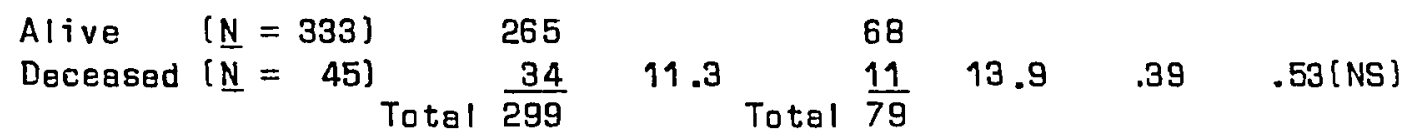

Over 65

$\begin{array}{lrrrrrrrr}\text { Alive } & {[N=149]} & 77 & & 72 & & & \\ \text { Deceased }[\underline{N}= & 97] & & 45 & 36.9 & \frac{52}{24} & 41.9 & .66 & .42 \text { (NS) }\end{array}$

NS $=$ Nonsignificant 
measure of the social network because it was most correlated with mortality. These analyses are displayed in Table XV. I In order to provide background, the mortality rates for the levels of the variables seen in this table can be viewed in Appendix G. From reviewing these mortality rates calculated from the raw data, non-linearity, when it occurs, is readily apparent.\} In each of these anaiyses and those to come, due to missing values on some of the variables, sample size numbers ranged from 2400 to 2603.

Table XV presents more data in terms of each model fit and parameter estimates than are given in later tables. The overall fit is given by a chi square comparison of the observed and expected values in each cell. Chi square must be non-significant: a p value as close to .99 as possible is considered optimal. Entropy, a measure of association between the dependent and independent variables in the model, is interpreted as is multiple R in ordinary regression.

For some control variables, such as drinking and physical activity, model fit could only be achieved by the iniroduction of a quadratic term. If the independent variable had a curvilinear relationship with mortality, a metric contrast fitted the line in one direction leither positive or negativel and a quadratic contrast the other. This gave two betas and their corresponding z values for 
TABLE XV

RESULTS OF A SERIES OF LOGISTIC ANALYSES OF EFFECTS OF NINE CONTROL VARIABLES AND NETWORK SCOPE ON MORTALITY

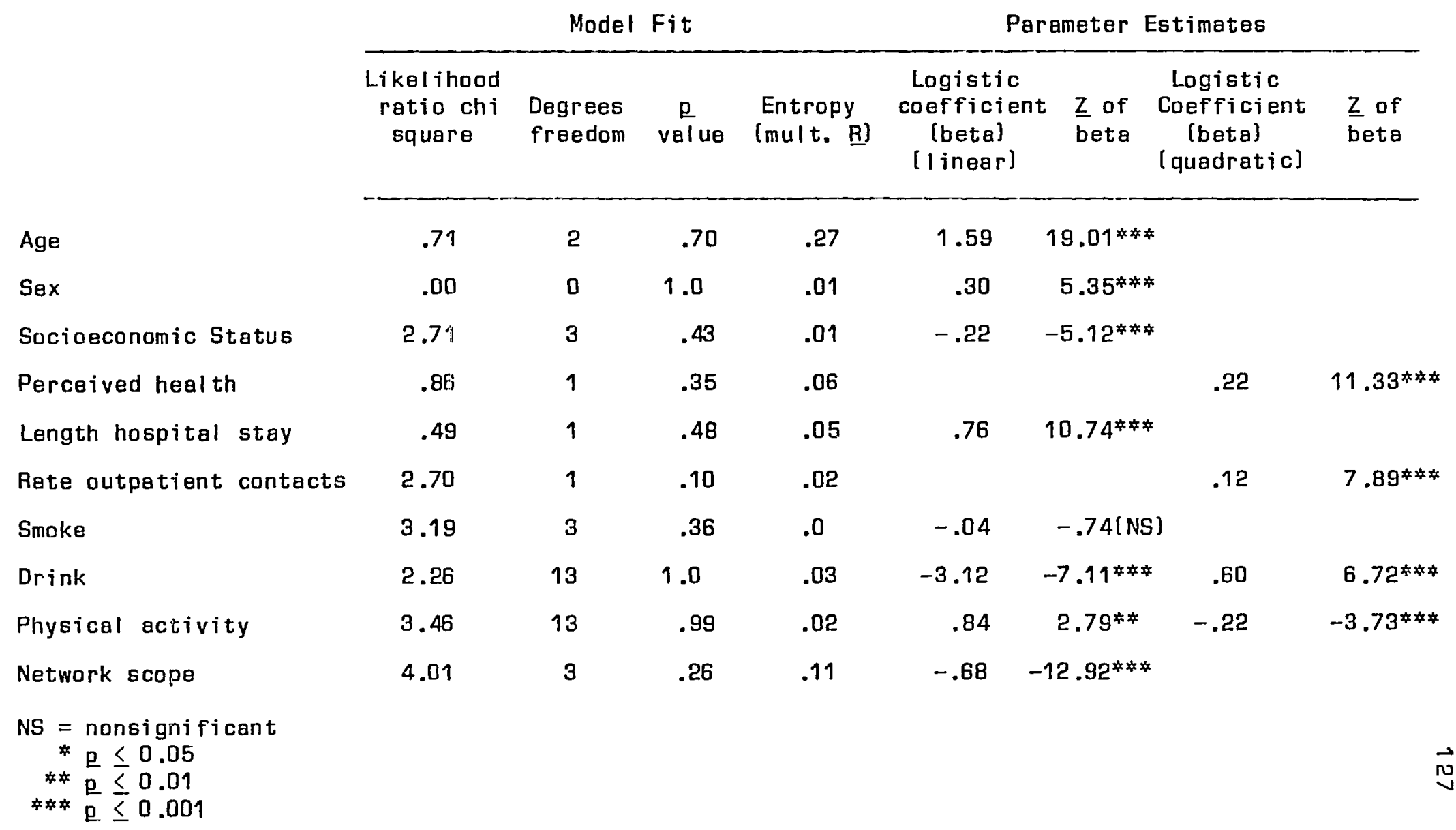


some of the variables in Table XV. On subsequent analyses with more independent variables in the equation, quadratic terms were not required to achieve acceptable fit of the model.

Regression-like logistic coefficients, betas, give a measure of the association between an independent variable and mortality. From these coefficients are calculated predicted relative risk, or odds ratios. It must be remembered that an "odds" is the basic form of the variation to be explained when the outcome has only two possibilities. An odds ratio is the ratio between the frequency of being in one category of the dependent variable and the frequency of not being in that category. Its interpretation in this research is the chance that an individual selected at random will be observed to fall into the category of mortality as opposed to the category of survival. Odds ratios lrelative riskl take only positive values, have no upper limit, and are 1.00 when no relationship exists (Knoke \& Burke, [1977). Using the data on age from Table XV for example, the odds ratio for age, calculated from the logistic coefficient lsee Chapter IV for formulal, is 4.9 . This means that people in the highest age category [oldest] are predicted to be almost 5 times as likely to die in the 12 year observational period as those in the lowest category (youngest). The logistic coefficient for network scope is -.68. This gives an odds ratio, or relative risk, of .50. In this case, the lowest 
network category is the one most associated with mortality, and a beta with a negative sign is produced. Thus, the predicted relative risk of death for a person in the highest category is half that of a person in the lowest. Stated another way, the relative risk of people in the highest category surviving is 2 to 1 . In all subsequent tables, predicted relative risk is calculated and displayed along with the logistic coefficients (betas).

From Table XV it can be sean that age is the most highly related to death, followed by network scope. The strength of association [entropy) between mortality and age is .27; that between mortality and network scope is .11 before any of the control variables are added to the equation.

All of the potential canfounding variables are significantly related to mortality at the $\mathrm{e}<.001$ level, except for smoking. However, bacause it appeared from prior correlations that smoking may interact with age, smoking was not abandoned yet as a potential confounding variable. Except for the health measures, the control variables are not highly associated with mortality, as measured by entropy. Perceived health and length of hospital stay are 0.06 and 0.05 , respectively. All the other control variablas are lese than 0.03. Smoking and drinking have curvilinear relationships with mortality, as can be seen by the mortality rates for the different categories of these 
variables as they are displayed in Appendix G. None of the control variables, then, was able to be eliminatedat this stage of the analysis.

Continuing with the strategy of attempting to eliminate variables, a second series of logistic analyses is summarized in Table XVI. In this series, tha relationship between mortality and each confounding variable is adjusted for age. At this stage, drink and physical activity become nonsignificant, and socioeconomic status and rate of contacts were eliminated because they were no longer significant at the $\mathrm{e}<.001$ level. The individual contribution of each of the control variables is not of particular substantive interest in this research. Of import is the impact of social networks on mortality after removing the variation due to these potentially confounding factors.

HYPOTHESIS 1: SOCIAL NETWORKS AS PREDICTORS OF MORTALITY

The final logistic model, as seen in Table XVII, was decided upon by the strategy of adding the most significant remaining variables one at a time, ending with the network scope measure each time, until none of the remaining confounders could increase the prediction of mortality. Entropy was raised from .28 with age and scope alone to .32 with age, sex, perceived health, hospital stay, and network scope. Smoking was eliminated at this stage. Network scope 


\section{TABLE XVI}

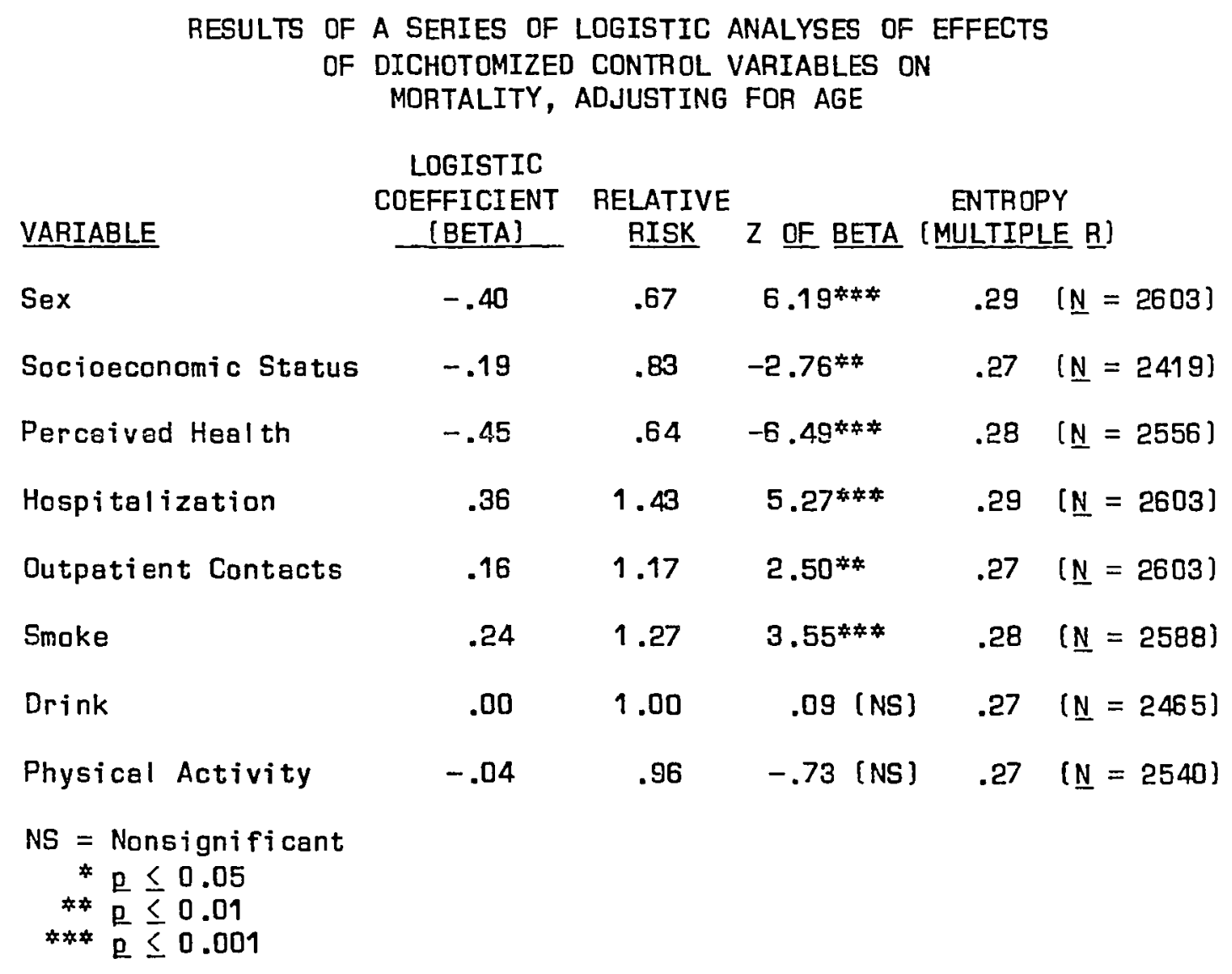


TABLE XVII

CHANGES IN RELATIVE MORTALITY RISK FOR THE INDEX OF TOTAL NETWORK SCOPE, WITH ADJUSTMENT FOR SIGNIFICANT CONTROL VARIABLES

All Independent Variables Dichotomized (except age in 4 (evels)

[Five Multiple Logistic Analyses]

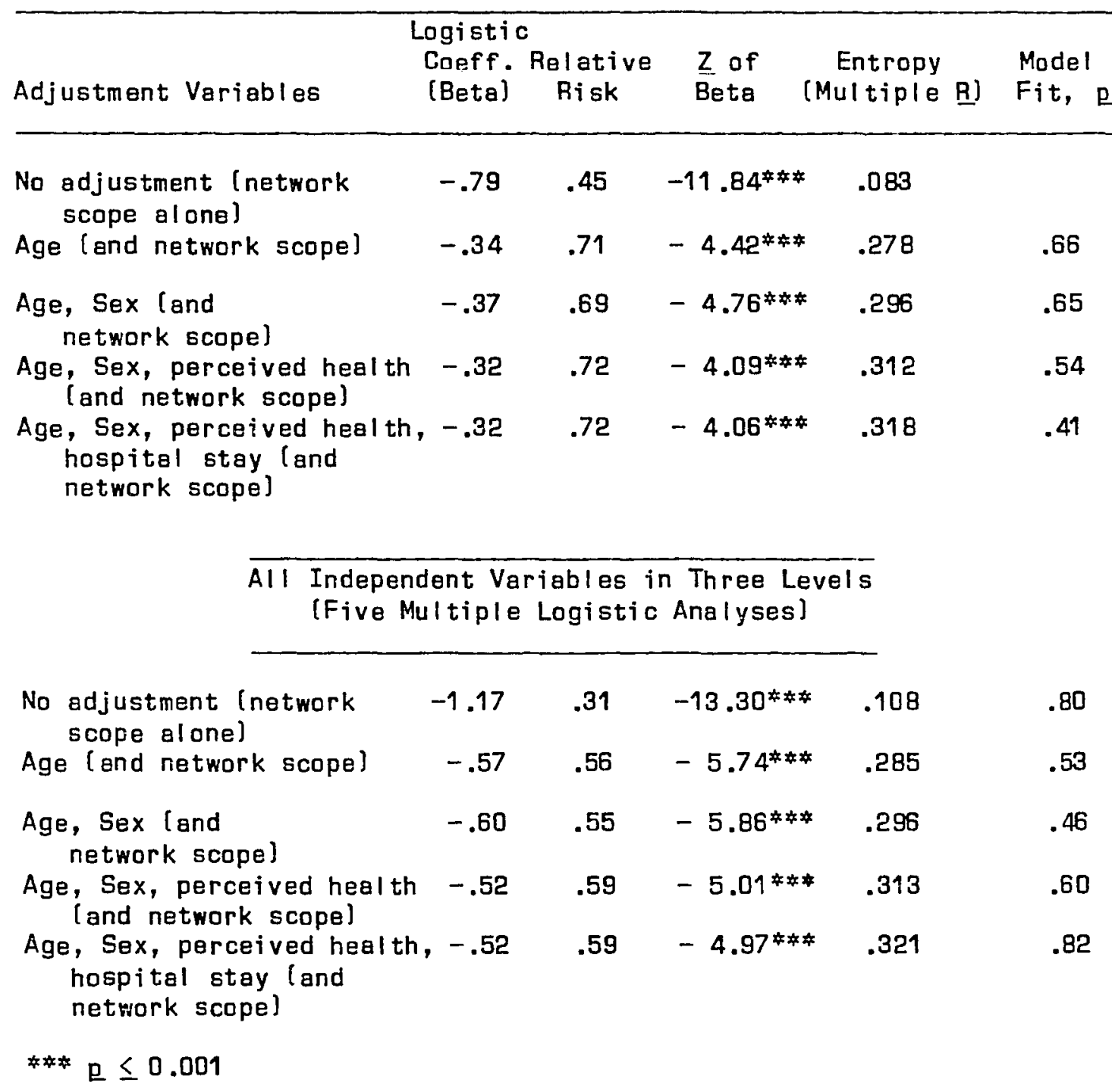


made a statistically significant independent contribution even after adding all the control variables. Although its $\underline{z}$ value fell from 4.42 with age alone to 4.06 in the full model, network scope continued to be significant at the $\mathrm{e}<.001$ level. Thus, ell things being equal in this sample, people with larger network scope have a reduced risk [.72) of dying when compared to people with smaller network scope.

In order to understand what differences might occur when the independent variables were in three ordinal levels rather than dichotomized (two levels), five additional analyses were conducted. It was thought that such an analysis would allow network scope to predict mortality more accurately. It can be seen that there is a slight decrease in predicted relative risk corresponding to a slight increase in z values, but the strength of association remains relatively unchanged. These analyses appear at the bottom of Table XVII. For the majority of the remaining analyses, the variables were used in three ordinal levels wherever possible, because using three levels achieved optimal model fit. For a few of the analyses, age divided into four levels gave superior fit.

As seen in the lower portion of Table XVII, when mortality is regressed on network scope alone, people with extensive network scope have an impressively lower risk of death (.31) as compared to those with networks of small 
scope. It maybe easier to interpret this relationship by reversing it: people with minimal networks have more than three times [3.22] the risk of dying as opposed to those with maximum networks. These calculations can be computed for all the network variables by taking the antilog of the logistic coefficient without its negative sign. When age is controlled for, the relationship between networks is decreased by approximately one-half. In other words, people with miminal networke then have 1.77 times the risk of death as compared to those with maximum networks. As the sex and health status control variables are added to the equation, relative risk of mortality decreases to 1.68 .

The next question is, if the summary network scope index predicts mortality, which part of an individual's social network is most important in this relationship? Each sector of network scope was used separately to predict mortality, with controls for the significant confounding variables. According to Table XVIII, it can be seen that the scope of friends index has the lowest relative risk, .72, followed by the scope of community index. This means that people with more friends and more community ties have a lower risk of daath. The scope of immediate family was nonsignificant, and the scope of extended family index just barely reached minimal significance. 


\section{TABLE XVIII}

RELATIVE MORTALITY RISK FOR SECTORS OF NETWORK SCOPE, ADJUSTED WITH SIGNIFICANT CONTROLS (FULL MODEL) [FOUR MULTIPLE LOGISTIC ANALYSES]

\begin{tabular}{|c|c|c|c|c|c|}
\hline Scope Sector & $\begin{array}{c}\text { Model Fit, } \\
\text { p level }\end{array}$ & $\begin{array}{l}\text { Logistic } \\
\text { Coeff. } \\
\text { [Beta] }\end{array}$ & $\begin{array}{l}\text { Relative } \\
\text { Risk }\end{array}$ & $\underset{B e t a}{Z}$ & $\begin{array}{c}\text { Entropy } \\
\text { (Multiple } \mathrm{B}]\end{array}$ \\
\hline \multicolumn{6}{|l|}{ Scope of Fanily } \\
\hline Immediate & .45 & -.13 & .88 & $-1.38[N S]$ & .307 \\
\hline $\begin{array}{c}\text { Extended [Immediate } \\
+ \text { relatives] }\end{array}$ & .55 & -.14 & .87 & $-2.03 *$ & .308 \\
\hline Scope of Friends & .70 & -.41 & .72 & $-3.87 * 4$ & .318 \\
\hline Scope of Community & .45 & -.28 & .75 & $-3.96 *$ & .319 \\
\hline $\begin{array}{c}\text { NS = Nonsignificant } \\
{ }^{*} \mathrm{D} \leq 0.05 \\
* \mathrm{p} \leq 0.01 \\
* \mathrm{D} \leq 0.001\end{array}$ & & & & & \\
\hline
\end{tabular}


Since the summary network scope measure significantly predicted mortality, three additional analyses were conducted utilizing the other three summary structural network indexes. The results of these analyses appear in Table XIX. All were statistically significant. People with large networks and frequent contact both had decreased relative risks for death of .81 while those with much network interaction had risks of .68, slight ly more than that of network scope $\{.59\}$.

A series of ten analyses were computed to assess the relative mortality risk for network interaction within the relationship domains, using the full model [Table $X X$ ]. Having a spouse, children, interaction with family of origin and with relatives did not predict mortality. However, the logistic coefficients for these relationship domain measures were in the predicted diraction, except for family of origin. The two indexes concerning friends lclose friends and other friends] were significant predictors of mortality at the p<.05 level. Work interaction predicted mortality at the $\mathrm{p}<.01$ level, but church attendance and interactions meetings did not. Those who did not engage in social leisure activities were at the highest relativerisk. People with no such activities had 1.5 times the risk of death compared to those with much social leisure interaction. 


\section{TABLE XIX}

RELATIVE MORTALITY RISK FOR THE FOUR NETWORK STRUCTUAAL INDEXES, ADJUSTED WITH SIGNIFICANT CONTROLS, FULL MODEL (FOUR MULTIPLE LOGISTICS ANALYSES]

Model Fit, $\begin{gathered}\text { Logistic } \\ \text { p level }\end{gathered}$
[Beta]

Network Scope

Netwark Size

Network Frequency of Contact

Network Interaction

${ }^{*} \mathrm{p} \leq 0.05$

$* * 0 \leq 0.01$

**a $\leq 0.001$

$\begin{array}{rrrrr}.88 & -.52 & .59 & -4.97 * * & .321 \\ .34 & -.21 & .81 & -2.51 * & .308 \\ .84 & -.21 & .81 & -2.41 * & .308 \\ .55 & -.39 & .68 & -3.99 * * & .317\end{array}$


TABLE $X X$

RELATIVE MORTALITY RISK FOR INTERACTION WITHIN RELATIONSHIP DOMAINS, USING FULL MODEL [TEN MULTIPLE LOGISTIC REGRESSION ANALYSES ]

\begin{tabular}{|c|c|c|c|c|c|}
\hline Relationship Domain & $\begin{array}{l}\text { Model Fit, } \\
\text { p level }\end{array}$ & $\begin{array}{l}\text { Logistic } \\
\text { Coeff. } \\
\text { [Beta] }\end{array}$ & $\begin{array}{c}\text { Relative } \\
\text { Risk }\end{array}$ & $\begin{array}{l}\text { Z of } \\
\text { Beta }\end{array}$ & $\begin{array}{c}\text { Entropy } \\
\text { [Multiple } \text { ] }\end{array}$ \\
\hline Marriage & .44 & -.09 & .91 & $-1.06[$ NS $]$ & .306 \\
\hline Children & .70 & -.08 & .92 & $-0.84[$ NS $)$ & .306 \\
\hline Family of Origin & .45 & .02 & 1.02 & 0.33 [NS ] & .301 \\
\hline Relatives & .75 & -.06 & .94 & -0.73 (NS) & .308 \\
\hline Close Friends & .90 & -.19 & .83 & $-2.19 *$ & .314 \\
\hline Dther Friends & .33 & -.19 & .83 & $-2.39 *$ & .313 \\
\hline Work & .46 & -.28 & .76 & $-2.64 \%$ & .308 \\
\hline $\begin{array}{l}\text { Church (Frequency of } \\
\text { attendance on }(y \text { ) } \\
\text { Meetings }\end{array}$ & $\begin{array}{l}.50 \\
.37\end{array}$ & $\begin{array}{l}-.15 \\
-.16\end{array}$ & $\begin{array}{l}.85 \\
.85\end{array}$ & $\begin{array}{l}-1.82 \text { (NS) } \\
-1.95(\text { NS) }\end{array}$ & $\begin{array}{l}.310 \\
.306\end{array}$ \\
\hline 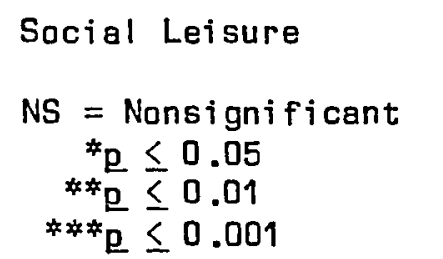 & .52 & -.39 & .67 & $-3.91 *$ & .315 \\
\hline
\end{tabular}


Did networks predict mortality more strongly for men or for women? As can be seen in Table XXI, after adjustment, the difference in relative risk between people who score high and low on overall network scope is greater for women than for men lpredicted relative risk .50 for women vs. .76 for menl. Did networks influence death risk more in young people or older people? It was found that networks were slightly more predictive for people in their older years than in middle age lrelative risk for age 50-65 was .55 vs. .49 for over 65 years of agel. Network scope was not predictive of mortality for the people aged 35-49 [Table XXII].

In summary, many logistic regression analyses were conducted to explore various network aspects and their relationship to mortality. Some of the network measures were independently predictive of demise. However, these analyses do not indicate the importance of the network variables in relation to the other factors that influenced why the people in the study population died. To answer this question it is necessary to look more closely at the association between the independent and dependent variables in the model. Table XXII shows the full logistic regression model with and without the network scope variable entering last. Entropy, or multiple R, is .3213 if network scope is included. If network scope is omitted, entropy 
TABLE XXI

RELATIVE MORTALITY RISK FOR NETWORK SCOPE FOR MEN AND WOMEN USING FULL MODEL (SIX MULTIPLE LOGISTIC ANALYSES)

Model Fit, $\begin{gathered}\text { Logistic } \\ \text { Clevel } \\ \text { (Beta) Relative } \\ \text { Risk }\end{gathered}$
Beta

MEN

$\begin{array}{llllll}\text { No adjustment [network } & .31 & -1.22 & .30 & -10.50 * 4 & .127 \\ \begin{array}{l}\text { scope alone] } \\ \text { Age (and network scope] }\end{array} & .86 & -.53 & .60 & -3.86 * 4 & .314 \\ \begin{array}{l}\text { Age, perceived heal th, } \\ \text { hospital stay land } \\ \text { network scope] }\end{array} & .81 & -.27 & .76 & -2.56 * & .333\end{array}$

WOMEN

$\begin{array}{llllll}\text { No adjustment (network } & .35 & -1.20 & .30 & -8.76 * * & .104 \\ \quad \begin{array}{l}\text { scope alone) } \\ \text { Age [and network scope] }\end{array} & .38 & -.68 & .50 & -4.51 * * & .273 \\ \begin{array}{l}\text { Age, perceived heal th, } \\ \text { hospital stay (and } \\ \text { network scope) }\end{array} & .97 & -.68 & .50 & -4.28 * * & .297\end{array}$

$\begin{aligned} * 0 & \leq 0.05 \\ * * 0 & \leq 0.001\end{aligned}$ 


\section{TABLE XXII}

\section{RELATIVE MORTALITY RISK FOR NETWORK SCOPE BY AGE CATEGORIES, ADJUSTED FOR SIGNIFICANT CONTROL VARIABLES, FULL MODEL [THREE MULTIPLE LOGISTIC ANALYSES]}

\begin{tabular}{|c|c|c|c|c|c|}
\hline & $\begin{array}{c}\text { Model Fit, } \\
\text { p level }\end{array}$ & $\begin{array}{l}\text { Logistic } \\
\text { Coeff. } \\
\text { (Beta) }\end{array}$ & $\begin{array}{c}\text { Relative } \\
\text { Risk }\end{array}$ & $\begin{array}{l}\text { Z of } \\
\text { Beta }\end{array}$ & $\begin{array}{c}\text { Entropy } \\
\text { Multiple } \mathrm{B}\end{array}$ \\
\hline Age $35-49$ & .51 & .04 & 1.04 & $.14[N S]$ & .106 \\
\hline Age $50-65$ & .88 & -.59 & .55 & $-3.74^{\#+4}$ & .086 \\
\hline Age over 65 & .91 & -.71 & .49 & $-3.89 * *$ & .101 \\
\hline
\end{tabular}


TABLE XXIII

RELATIVE MORTALITY RISK FOR VARIABLES IN FULL LOGISTIC REGRESSION MODEL, WITH AND WITHOUT NETWORK VARIABLES ENTERING LAST (TWO LOGISTIC REGRESSION ANALYSES)

$\begin{array}{ccc}\text { Logistic } & \text { Relative } & \text { Z of } \\ \text { Coefficient (Eata) } & \text { Risk } & \text { Beta }\end{array}$

\section{Full Model}

Intercept

Age

Sex

Perceived Heal th

Length Hospital Stay

Network Scope
$-5.45$

1.54

.43

.49

.36

$-.52$

$$
\text { Model Fit, } \mathrm{e} \text { level }=.88
$$

4.66

1.53

1.63

1.43

.59

$\underline{\mathrm{N}}=2418$
$-12.84$

$14.91 * *$

$6.00 \% *$

$5.01 \div \div$

$3.95 *$

$-4.97 * *$

Full Model Without Network Variable

$\begin{array}{lccc}\text { Intercept } & -6.90 & & -22.12 \\ \text { Age } & 1.71 & 5.52 & 18.04^{* * *} \\ \text { Sex } & .44 & 1.55 & 6.29^{* * *} \\ \text { Perceived Heal th } & .56 & 1.75 & 5.89 * * \\ \text { Length Hospital Stay } & .38 & 1.46 & 4.26^{* * *} \\ \quad \text { Model Fit, D level }=.29 & \text { Entropy }=.3108 \quad \mathrm{~N}=2556\end{array}$


is .3108. Network scope thus contributes only .01 of the variance to the model; the other network variables contribute even less, as seen in entropy in other models displayed in the tables.

\section{HYPOTHESIS 2 : SOCIAL NETWORKS AS PREDICTORS}

\section{OF DISEASE INCIDENCE}

The series of logistic analyses just described confirms an independent prospective relationship between some social network indicators and mortality.

Other such studies of community populations have ended here. Fortuitously, the opportunity affords itself in this study to continue with an exploration of where social networks are most effective on the health/illness continuum. Do the health benefits of social resources occur early, preventing disease from beginning by, for instance, strengthening hast rasistance? Or do the health benefits come later, slowing disease progression once it has occurred? It is to these questions that we now turn.

Hypothesis 2 stated that adults with more visual network resources would have lower incidence of disease. Multiple linear regression was used to test this hypothesis, using the continuous versions of each of the variables. Before testing the hypotheses, however, bivariate relationships between age, sex, and network scope were assessed. This was done because it appeared from preliminary 
regression analyses that sex contributed much variance to the model. It thus seemed important to assess men and women separately. Table XXIV, showing netrork scape, age, and sex relationships with disease incidence as operationalized by initial doctor's office visits, reveals network scope lin 3 categoriesl to be a statistically nonsignificant predictor for women but significant $[\underline{E}=.04$ ] for men, using one-way ANOVA. Men with small networks made more initial doctor office visits, as hypothesized, except for the over 65 group. For men, age did not play a part in the number of initial visits made during the seven year time period. For women, however, age was highly significant [E 26.4]. Young women made many more initial visits than older women. (This finding was not unexpected. Previous analysis of this data set had shown that young women avail themselves of outpatient health care frequently [Hibbard \& Pope, 1983]). This does not mean that older women make fewer visits overall, however. Oldar women, with more chronic illnesses, probably simply make visits of a continuing nature.

Drdinary multiple regression analyses predicting disease incidence were completed for men and women separately in terms of the disease incidence outcome. A hierarchical, forced entry strategy was utilized with age added as the first control. In subsequent equations, additional control variables were added with network scope 
TABLE XXIV

MEAN RATES PER 10 PERSON YEARS OF INITIAL DOCTOR OFFICE VISITS * BY AGE, SEX, AND NETWORK SCOPE

$\begin{array}{lll}\text { Small } & \text { Medium } & \text { Large } \\ \text { Scope } & \text { Scope } & \text { Scope }\end{array}$

Men

Under 35

13.0

10.8

11.0

$35-49$

12.5

11.0

9.9

$50-65$

11.6

10.1

B.2

Over 65

10.8

11.9

11.6

Wongen

$\begin{array}{llll}\text { Under 35 } & 18.9 & 17.2 & 16.3 \\ 35-49 & 14.2 & 12.3 & 12.7 \\ 50-65 & 12.8 & 10.9 & 10.7 \\ \text { Over } 65 & 10.3 & 11.9 & 11.3\end{array}$

*Range: 0 - 94.3; mean: 12.0

One-way analysis of variance:

Men Age independent, $E=1.63, \mathrm{p}=.18$ [NS]

Scope independent $E=3.12, \underline{E}=.04$

Women Age independent, $E=26.36, \underline{E}=.0000$

Scope independent, $E=.15, \mathrm{E}=.85$ (NS)

NS = Nonsignificant 
always entering last. These analyses are displayed in Table XXV. For women, but not for men, age was an important predictor of disease incidence. However, in terms of the second hypothesis of this research, the scope of the network made no impact on disease incidence.

HYPOTHESIS 3 : SOCIAL NETWORKS AS PREDICTORS OF DISEASE PROGRESSION

Disease progression, as operationalized by changes in rates of outpatient contacts for the seven disease classes, was also first described in terms of relationships between network scope, age, and sex [see Table XXVI]. For men, neither age nor network were significantly related to rate changes, using one-way analysis of variance. (It will ba recalled that if patients were getting sicker, it would be expected that the rate changes would be in a positiva direction.J For women, again network scope did not make a difference. However, age was significant in that older people had a more positive rate of change. This meant, according to the interpretation of the dependent variables for disease progression in this research, that older women had more disease progression than those younger $[E=5.7$, e $<.007\}$.

To test hypothesis 3 , which stated that adults with more network resources would have less disease progression, 
TABLE XXV

HIERARCHICAL MULTIPLE LINEAR REGRESSION ANALYSES

FOR MEN AND WOMEN PREDICTING DISEASE

INCIDENCE ${ }^{\top}$ FROM NETWORK SCOPE

\begin{tabular}{|c|c|c|c|c|}
\hline \multicolumn{2}{|c|}{ Parameter } & \multicolumn{3}{|c|}{ Model } \\
\hline $\begin{array}{c}\text { Standardized } \\
\text { Beta }\end{array}$ & $E$ (Beta) & $\begin{array}{c}\text { Multiple } \\
\text { R }\end{array}$ & $\underline{R}^{2}$ & $\underset{\text { model }}{E[\text { lof }}$ \\
\hline
\end{tabular}

Men $[\underline{N}=1090]$

$\begin{array}{lrrrrr}\text { Age } & -.051 & 2.12 \text { (NS) } & .018 & .000 & .35 \text { (NS) } \\ \text { Socioeconomic Status } & -.055 & 3.16(\text { NS }) & .065 & .004 & 2.28 \text { (NS) } \\ \text { Smoke } & .000 & .00 \text { (NS) } & .065 & .004 & 1.52 \text { (NS) } \\ \text { Drink } & -.014 & .21(N S) & .066 & .004 & 1.17 \text { (NS) } \\ \text { Physical Activity } & -.041 & 1.66(N S) & .081 & .007 & 1.43 \text { (NS) } \\ \text { Network Scope } & -.031 & .79 \text { (NS) } & .085 & .007 & 1.33 \text { (NS) }\end{array}$

Women $(\underline{N}=1170)$

\begin{tabular}{|c|c|c|c|c|c|}
\hline Age & -.251 & $63.13 * *$ & .231 & .053 & $66.45^{*}$ \\
\hline Socioeconomic Status & -.018 & $.43[\mathrm{NS}]$ & .232 & .054 & $33.43 *$ \\
\hline Smoke & .000 & .00 (NS) & .232 & .054 & $22.27 \%$ \\
\hline Drink & -.018 & $.39(N S)$ & .232 & .054 & $16.77^{* *}$ \\
\hline Physical Activity & -.015 & .27 [NS ) & .232 & .054 & $13.41 *$ \\
\hline Network Scope & -.051 & $2.68[N S]$ & .237 & .056 & $11.64^{4 *}$ \\
\hline
\end{tabular}




\section{TABLE XXVI}

CHANGE IN MEAN RATE OF OUTPATIENT CONTACTS * BY AGE, SEX, AND NETWORK SCOPE

$\begin{array}{lll}\text { Small } & \text { Medium } & \text { Large } \\ \text { Scope } & \text { Scope } & \text { Scope }\end{array}$

Men

Under 35 .69

.10

.23

$35-49$

.91

.61

.18

$50-65$

$-1.39$

.85

.42

Over 65

1.72

.97

.32

Women

Under 35

$-.74$

$-.62$

$-.12$

$35-49$

$-.20$

$-.50$

$-.17$

$50-65$

$-.49$

1.01

.10

Over 65

2.21

.87

.77

*Range: -67.7 To +84.9

Mean: .27

One-way analysis of variance:

Men Age independent, $E=1.88, E=.13$ [NS

Scope independent, $\bar{E}=.48, \underline{p}=.62$ (NS)

Women Age independent, $E=5.70, \quad \underline{E}=.007$

Scope independent, $\bar{E}=.67, \mathrm{e}=.51$ [NS]

NS = Nonsignificant 
ordinary multiple regression procedures were utilized. Again a hierarchical, forced entry strategy was utilized whereby age was entered as the first control. In subsequent equations additional control variables were addad with network scope always entering last. As can be viewed in Table XXVII, network scope was not predictive of disease progression.

\section{SUMMARY}

In summary, the major findings of the study are:

1. Social networks predict mortality. Each of the summary indexes of four different network perspectives (scope, size, frequency of contact, and interactions independently predict mortality. Network scope is the strongest predictor.

A. In terms of the four sectors which comprise the scope index, scope of community activities, scope of friends, and scope of extended family each predict death. An indicator of the scope of the immediate family does not.

B. In terms of specific social relationships, the more intimate family connections with spouse, children, family of origin, and relatives do not affect risk of death. Relationships with friends do, as do relationships with co- 
TABLE XXVII

HIERARCHICAL MULTIPLE LINEAR REGRESSION ANALYSES FOR MEN AND WOMEN PREDICTING DISEASE' PROGRESSION FROM NETWORK SCOPE

\begin{tabular}{|c|c|c|c|c|}
\hline Parameter & & & Mode & \\
\hline $\begin{array}{c}\text { Standardized } \\
\text { Beta }\end{array}$ & $E[$ Beta] & $\begin{array}{c}\text { Multiple } \\
\text { R }\end{array}$ & $\underline{R}^{2}$ & $\begin{array}{l}E \text { [of } \\
\text { model }]\end{array}$ \\
\hline
\end{tabular}

Men $[\underline{N}=1090]$

Age

$\begin{array}{rrrrr}.039 & 1.30 \text { (NS) } & .040 & .001 & 1.77 \text { (NS) } \\ .043 & 1.94 \text { (NS) } & .058 & .003 & 1.80 \text { (NS) } \\ -.016 & .21 \text { (NS) } & .059 & .003 & 1.27 \text { (NS) }\end{array}$

Women $[\underline{N}=1170]$

$\begin{array}{lrcccc}\text { Age } & .080 & 6.53 * * & .083 & .007 & 8.08^{* *} \\ \text { Socioeconomic Status } & -.039 & 1.71 \text { (NS) } & .091 & .008 & 4.89^{* *} \\ \text { Network Scope } & .000 & .04[\mathrm{NS}] & .091 & .008 & 3.27^{*} \\ \text { TDisease Prograssion based on change in rate outpatient contacts } \\ \text { NS = Nonsignificant }\end{array}$

* $\mathrm{g} \leq 0.05$

** $\mathrm{E} \leq 0.01$ 
workers. Whether one attends church or is involved with voluntary associations is not predictive of mortality. The number of social leisure activities engaged in is the strongest individual predictor of daath.

C. Network scope is more influential in mortality outcomes for women than for men.

D. Network scope predicts death risk most strongly for people in the oldest age group. It does not predict death for those under 50 years.

E. Social factors account for only a small amount of the total variance in the logistic regression model.

2. Social networks do not predict disease incidence or disease progression. 
CHAPTER VI

DISCUSSION

The importance to an individual of a group of supportive people has long been recognized. This concept, now known as a social network, has been defined, elaborated, quantified, and in the past few years investigated in terms of health. It has been shown to predict mortality in community populations. The purpose of this research has been to determine the relationship between social networks and mortality in a cohort living in an urban area of the Pacific Northwest, and to extend that knowledge by delineating whether networks influence disease incidence or disease progression.

The findings of this study have been presented in the previous chapter. In this chapter, these findings will be discussed and placed in a broader perspective. This chapter features three sections. In the first section, the findings will be discussed in terms of the research hypotheses. The reasons why hypotheses 2 and 3 were not upheld will be explored. The results of the hypothesis testing will then be related to the theoretical framework of the study.

The second section of the chapter features a discussion of the network relationship sectors which were 
significant predictors of mortality in this study. The findings from these sectors are compared with those found in other similar studies. Reasons why contradictions across studies may have occurred are explored. Since the nature of the samples, analytic approaches, and social network measurements cannot be detached from the results themselves, methodological factors will be discussed in the third section.

HYPOTHESES

\section{HYxpothesis \#1}

The first hypothesis stated that, controlling for confounding factors, adults with more social network resources would have less risk of death. This hypothesis was confirmed. Summary measures of size, frequency, interaction, and network scope were shown to independently predict mortality in tha study population. This parallels the findings of Barkman and syme (1979), House et al. (1982), and Blazer (1982), who obtained similar results in community populations in San Francisco, Michigan, and North Carolina. All these studies point to social factors influancing mortality risk in a positive direction, which is important for community health.

Of the four structural measures of the network, network scope was the most important predictor, followed by network interaction. Network size and the frequency with 
which the respondents had contact with their networks were of lesser importance. This indicates that it is not so much the quantity within the particular network sections but the diversity or breadth of the network as a whole that is important. Each role relationship domain probably affords a particular kind of support, aach of which is important for maximum health pratection. When some are missing, one becomes more susceptible to environmental stress.

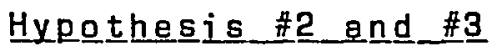

Mortality is but a crude measure of what is actually happening to people in terms of disease states which lead to death. A major purpose of this rasearch, as reflected in the second and third hypotheses, was to extend the networks/ mortality knowledge by assessing whether networks were more important in reducing disease incidence or retarding disease progression. It was hypothesized that adults with more social network resources would have lower disease incidence (hypothesis \#2), and that adults with more social network resources would have less disease progression lhypothesis \#3). Neither of these two hypotheses could be confirmed. There was no relationship between network scope, the network independent variable used, and disease incidence or disease progression. Why did this occur?

It has often been said that research results are only as good as the operationalization and measurement of the 
variables used. The operationalization and measurement of mortality in this study was definite and specific. However, the operationalization and measurement of the other two dependent variables, disease incidence and disease progression, were more problematic. Specific problems encountered in relation to these two dependent variables will now be discussed.

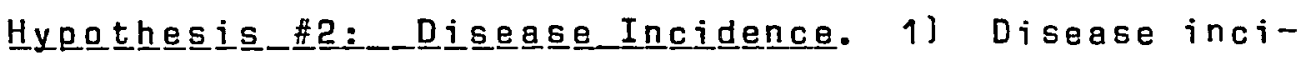
dence could only be counted if the individusl sought assistance from the health care system when ill. Many people choose to treat more minor illnesses by themselves. Also people with large networks may not seek assistance when symptoms develop, relying instead on netwark members to help them. This issue relates to the adequacy of health care utilization data to provide a measure of disease incidence, which, as pointed out by Kas/ (1983), is difficult to measure in any sense.

2) The disease incidence variable used initial visits from each of the ten classes of the Kaiser Disease Classification system. This meant that visits for preventive care, trauma, and obstetrics were included, resulting in a measure with a great deal of "noise." Rather than counting only initial visits that occurred because the individual was actually sick, visits concerning pregnancy conly the first visit of the entire pregnancy, however], accidents, or 
routine physical exams were also included in the number of initial visits.

It should be noted that the theoretically preferred method for determining incidence of disease is a prospective surveillance of a cohort, free of disease initially, who are assessed for a variety of possible risk factors and then are monitored for the development of cases of the disease IKasl, 1983].

However, it is possible that disease incidence was not associated with social networks because networks are not protective against episodes of new morbidity but only against such episodes being fatal. This relates to the need for theoretical refinement, which is discussed more fully in the succeeding chapter.

Hypothessis \#3: Disease Progresssion. 1) Disease progression was operationalized to be change in the rate of health care contacts. The baseline period for the time covered in this variable was the four years prior to the survey, as compared to tha three years subsequent to it. Three years was probably insufficient time to detact rate changes in disease progression due to networks. A more adequate measure of disease progression would be a comparison of, for instance, ten or more years of contacts following the baseline period. A longer time frame may be necassary because many chronic diseases progress slowly. This more extensive measurement of the disease progression 
variable will be possible when the planned linkage of the survey data and utilization data to 1980 is accomplished by the Conter.

2) The use of quantitative health care utilization data to measure disease progression can be problematic. For instance, the "worried well" lpeople who fear they may be sick but are not may make an inordinate number of outpatient contacts in proportion to the severity of their disease problems, giving an inaccuratepicture of disease status. Had it been possible to peruse patient records, a measuremore pertinent to actual change in disease states could have been developed in addition to, or combined with, health servica utilization data.

Ideally, disease progression would be assessed over time by the monitoring of new cases of specific diseases for additional medical outcomes. The outcomes of interest would include: (1) case fatality: frequency with which individuals with the disease die of the disease during a stated period; (2) repeat episodes: new medical events, such as myocardial infarction, amang people who have already experienced the initial event; (3) exacerbations; (4) length of recovery; and [5] amount of residual morbidity; i.e., among those recovering from a stroke, the range of motion remaining in the affected limb $\{K a s \mid, 1983]$. 
THE THEORETICAL FRAMEWORK

The model in Figure 1 provided the basis for the conceptual framework for this research. The results lend support to the theory that social support, delivered vie social networks, either buffers the ubiquitous stress in the environment of individuals or acts directly to promote health. Because no measure of stress or stressful life events was available on the survey, there is no way to distinguish between the buffering effects of social suppo:t and its main effects.

Because network scope was not significant in relation to both disease incidence and disease progression, it is not possible to advance this theory so as to be able to determine where on the health/illness continuum social support is most efficacious. It may be that social networks do not impact disease status at the junctions postulated in this theory. It may be that social support affects symptomreporting subsequent to disease initiation. People with more supportive ties may receive encouragement to seek medical care earlier, thus effecting early cure. This would be important in a disease such as cancer. The true mechanisms may be numerous and varied and specific for different social environmental conditions and different health outcomes. Or, the attempt to distinguish between disease incidence and disease prograssion may be untenable. 
Social support in both etiology and recovery may be similarly mediated.

\section{NETWORK RELATIONSHIPS AND MORTALITY}

A secondary aim of this dissertation was to assess which of the network relationships were most important in predicting health outcomes. Indexes of network sectors [family, friends, community] and role relationship domains [spouse, children, family, organizations] were used separately to predict mortality. (The outcomes of these analyses were presented in Tables XVIII and XX in Chapter v.) Previously published research of this type had provided conflicting evidence for the pertinence of specific aspects of the network. It should be kept in mind, however, that the variety of indexes developed across studies has been too great to expect more than very general consistency of results.

The relationship domains assessed in Table XX are now discussed and comparad to findings in other similar studies. Then, the possible reasons behind conflicting results are presented.

\section{Maㅁ도므ge}

In the study population, marriage did not predict mortality. This was true also in the studies by Blazer (1982) and Zuckerman et al. (1984). However, Berkman and 
Syme \{1979\}, House et al. (1982), and Schoenbach (1983) had found the presence of a spouse was important in prolonging life, particularly formen. This contradiction is hard to understand, as it is known that marriage usually positively affects a variety of health outcomes. One possible explanation relates to the fact that Blazer and Zuckerman and her colleagues both studied elderly samples and tracked them for shorter time periods 130 months end 24 months, respectively]. According to Zuckerman, marital status may have had a strong direct influence on the health status of the subjects for ten or more years before the start of the study and therefore an indirect influence on mortality during the two years of follow up. Because health status variables at the time of the survey are used as control variables in the regression analysis, an indirect influence wauld not be apparent. If marriage is more important in retarding mortality in people studied for at least a decade, however, the Kaiser study population should have also indicated that marriage was a significant pradictor of mortality.

\section{Family}

The family of origin (mother, father, siblings) index failed to predict death among the study population. Neither did having or not having children. However, for the aged cohort studied by Zuckerman et al. (1984), the absance of children predicted mortality. It makes sense that children 
might not be important predictors among younger people. However, children may be the most significant social contacts for the elderly in terms of maintaining health.

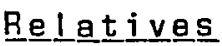

Relatives were also nonsignificant in predicting mortality for the study population. It is not possible to assess separately the effects of relatives on mortality in other studies because they were combined with friends into a single measure. Berkman and syme [1979] found an index of contacts with friends and relatives to significantly affect risk. House et al. did not find as strong an association between mortality and friond/relative contact. Schoenbach et al. (1983) found no such relationship. In the household interview survey, on!y information about relatives living nearby or a day's drive away was obtained. Thus, the index assessing interaction with relatives may be a weak indicator of the extent of this aspect of the social network.

\section{Friends and work As $\underline{\text { wa }}$ gciatas.}

A measure of close friends and a measure of other friends both prospectively predicted mortality. As noted above, most studies combined friends and relatives for a single measure, so a comparison of friends effects is not possible across studies. However, in Zuckerman's study \{1984\} which did include a measure of friends, mortality among the elderly poor was not related to friendship net- 
works or frequency of interaction among friends. In this study, having interaction with coworkers affectedrisk of death significantly. Most other studies did not include measures of this aspect of the social network. Friends and work associates will be discussed together, because, from the nature of the questions regarding interaction with coworkers outside of the work place [see Appendix C], it seems clear that these coworkers would be regarded by the respondent as friends.

Three types of friends, then, are assessed in this study--close friends, friends of s less intimate nature, and friends from the work place--and each is a prospective risk factor for mortality. Three reasons can be advanced which may account for this. (1) The content of exchanges that characterize friendship interactions may be the "commodity" that most influences health outcomes. According to Litwak and Szelenyi (1969), important exchanges distinguishing friends from interactions with other network members are emotional or moral support, positive affect, and mutual agreement. However, these are too non-specific to be of much value clinically. Further research would be needed to define more completely what it is that is differentially supportive about transactions between friends. (2) Choosing to have friends and be in contact with them is under the control of the individual more than are other network rela- 
tionships such as relativas, children, parents, or siblings. Making and keeping friends involves trusting and being willing to take social risks. Thus, a person who has a more positive trusting attitude toward life and feels more in control (what has been termed a sense of "coherence" by Antonoysky [1979]], may choose more interaction with friends. It has been postulated that people with more "coherence" have enhanced health status (Kobasa, 1982). The concept "sense of coherence" has not yet entered empirical investigations of mortality. (3) Intervening processes involving healthy life styles or specific health protective behaviors which have implications for lessening disease remain a possibility for accounting for some of the friends/ mortality association. Langlie (1977) found that health promotion behaviors were associated with a social network characterized by frequent interaction with nonkin. However, in the present study, smoking, drinking, and physical activity were ruled out as explanations. The association between health maintenance ectivities and network characteristics warrants further exploration.

\section{Qrganizations.}

With the study population in this research, belonging to organizations and attending meetings were not significant predictors of mortality. Berkman and syme found that people who belonged to formal and informal groups had lower mor- 
tality rates. However, the difference between those who did and those who did not participate in meetings was not as large as that observed for other kinds of contacts lmarriage, friends, and relatives]. House et al., however, found the opposite. In their cohort, there were weaker associations of mortality with friend and relative contact and stronger associations with organizational involvements. The measure of organizaitonal involvements used in this rasearch was different from the dichotomous variable used by the other investigators.

\section{Chhurch}

In this study, people who attended church did not have lower risk of death. In House et al.'s study, church attendance was a weaker predictor than organizational involvement, but still significantly influenced survival for women. Zuckerman found an index of religiousness lwhich included church attendancel a significant predictor of mortality among the elderly poor, particularly among those in poor health. Exploratory but not hypothesis-testing analysis of Schoenbach's data suggested that church activities were predictive of survivorship.

\section{Social Leisure}

Social leisure activities were the strongest predictor of survival for the Kaiser study group. This was also true 
of the House et al. (1982) data. Nane of the other longitudinal studies provided measures of this variable.

The social leisure question from the household interview survey upon which the index was based, was open-ended as opposed to that of House. Respondents were asked to name their leisure activities rather than being presented with a list of activities to which they were to indicate recent participation. This investigator made the decision as to which activities were social by judging whether other people were usually involved in the activity or whether it occurred outside the home where presumably other people would be encountered. (See the Overview Box describing the social leisure variable in Appendix D.J It may be that preferring social rather than solitary leisure time activities and then engaging in more of them depends upon personality factors not assessad in this study, such as happiness lZuckerman et al., 1984), self-esteem, or "coherence" (Kobasa et al., 1982), constructs also related to health outcomes. Or, the measure could have fayored younger, healthy people lactivities included camping, sports, going to the movies] in ways not controlled by the two measures of health status or by the age variable collapsed to four categories instead of continuous.

A third possibility axists which relates to the fact that social leisure activities are correlated with close friends $[\underline{r}=.16)$ and other friends $[\underline{r}=.21]$ to a larger 
extent than within any of the other relationship variables [see AppendixE]. It makes sense that people engaging in a wider variety of leisure time activities of a social nature would have more friends with whom to do them. It may be that it is actually the presence of friends that is critical to health with social leisure representing a dimension of the process of how these friend contacts occur.

\title{
UNDERSTANDING THE CONFLICTING FINDINGS ACROSS STUDIES
}

\begin{abstract}
When considering the contradictions about the importance of different network ties in the findings of this and other research, three salient aspects of comparison become apparent: the nature of the sample, the analytic methods used, and social network measurement. Differences in these three aspects may have resuited in some of the variations found.
\end{abstract}

\section{Nature of the Sample}

Four factors concerning the basic nature of the samples studied may have accounted for the differences obtained. These four factors are: old vs. young, urban vs. rural, healthy vs. unhealthy, and men vs. women.

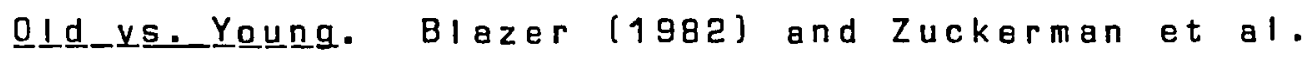
(1984) both used elderly samples of smaller size, followed for shorter periods of time. In addition, Zuckerman's subjects were a low-income group. There is a clear difference 
in these two samples and the other community population groups. The House et al. (1982\}, Schoenbach (1983), and Berkman and syma (1979) samples included middle-aged subjects from ages $30-69$. The study population for this research had a wider range of ages: the youngest was 19 and the oldest was 90. Because different network sectors may be in ascendancy at different stages of the life cycle li.e., in youth, friends sectors may be paramount; in old age children may be most importantl having a greater age span may have made a difference in outcomes across studies.

Urbagn $\underline{x}$. Rureal. House speculated that the reason his Tecumseh County study found extended ties more predictive of mortality in contrast to the findings of Berkman and syme was that his study involvad a rural/small town population while theirs was urban. House balieved that differing processes of social integration and activity might be in operation in the two locales. For instance, in a more rural area social relations and activities involving friends and relatives may be more a part of the normal pattern of daily I ife and not be especially noted, whereas in a metropolitan area such interactions may be seen as special events. As a result, some relationship measures may be less differentiating among people residing in a small tow than among those in urban areas. This interpretation, however, would not apply to the present data. 
Heathy_vg. Unhheaㅡㄴㅡy. How equal was the health status of the different samples studied at the time of the survey? Each socia! network/mortality study has attempted to control for health status, but a variety of measures have been used. It is not known which controls for health status are optimal. Those measures that have been used are physical measures lblood pressure and pulmonary function tests, for example), health services utilization data, perceived health assessments, and ordinal measures of disability. In this study, health service utilization data were used. If the people with chronic illnesses at the time of the survey were not accounted for in the study design, it might appear that people with small networks died sooner. The extent to which the confounding influences of health have been successfully removed in all these reports is not clear.

Men vs. Womenen. There were approximately equal numbers of men and women in each of the community samples studied for network/mortality associations, as was the case with the population used for the present study. This population was composed of family units, so mora than 2000 of the sample were husband-wife pairs. This was probably not true of the other community populations.

Many of the social questions on the survey were ansiared by the wife for herself and her spouse when a couple was involved. In turn, the husband answered questions of an economic nature for himself and his wife. In 
general, this would have made the network indexes less discriminating between males and females.

It is interesting to note that House and his colleagues (1982) speculated that the survey questions which they used may have more accurately assessed the social integration of men than women. Their study and a number of others (Berkman, 1977; Schoenbach, 1983) had found that networks predicted death more strongly for men than women. In the present study, by the design of the survey, the social networks of women were measured mora eccurately than men .

Women had more close friends than didmen, who were twice as likely to declare they had no close friends. There is thus a better distribution on the close friends measure for women than men. Because restriction of range makes it more difficult to find relationships, the difference in frequency distribution may have accounted for the fact that networks were more predictive of death for women than men.

\section{Analytic metionods}

The analytic methods used by the investigators in the different studies were primerily logistic regression. Blazer [1982] used binary linear regression, and Berkman and Syme (1979) used a variation of chi square in which additional controls could be included. Most of the logistic regression studies appeared to have used the BMD computer 
package where it is possible to use continuous variables. (However, it will be recalled that House et al. (1982) stated there was minimal difference in outcome between the three methods of doing regression with a binary dependent variable.) For the loglinear approach used in the present research, continuous variables had to be collapsed. It is possible that if "age" had been utilized in its continuous form rather than three or four categories, the network variables may not have been statistically significant. Both networks and mortality are highly related to age. Also, tighter controls for other confounding factors, such as health status, may have eliminated any remaining variance in mortality due to social ties. People with small networks who will die earlier may have fewer ties simply because illness precludes their being in sacial situations.

House and his colleagues used one-tailed tests of statistical significance in their study, which have given more power to detect statistical differences. Whether this decision was made a priari is unknown. In the present study, two-tailed tests were used. It should also be kept in mind that when working with large samples, it is relatively easier to achieve statistical significance in outcomes. 


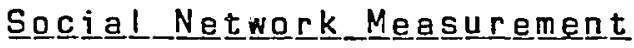

Weaknges lBerkman, 1984; Wallston et al., 1983; Eli, 1984; Jung, 1984) have lamented the wide variety of approaches used to measure networks, and the lack of consensus as to how to establish their reliability and validity. The summary network indexes used in this study certainly had low reliability. Mast of the other network/mortality studies of this nature did not report reliability for their measures.

Network sectors are usually measured by responses to one or two questions, either singly or combined in some fashion. It is when different network relationships are assessed individually against mortality that differences across studies occur. When network relationships are aggregated into indexes by whatever means, indexes usually predict mortality. It may be that indexes that assess only one part of a network are weak or unreliable: when combined together they become more discriminating. Berkman and Syme (1979) had found that the friends and relatives questions alone did not predict mortality, but when combined into a ranked index they did. Reed et al. [1983; 1984] found statistical significance only for their network index: individual questions alone were nonsignificant. In this study, when the relationship domain indexes were combined, the summary measures which resulted were statistically significant. Only a few of the relationship indexes were 
significant alone, but almost all showed a trend in the hypothesized direction.

House and his colleagues (1982) had suggested that people might have different interpretations of the survey questions depending upon whether they were urban or rural dwellers, or whether they were male or female. The same could possibly be true of young as opposed to older people. What is more likely is that questions on these surveys have been stretched to serve as social network measures, not having been specifically designed to gather the type of information needed to make network assessments. In this study, for example, the number of siblings identified by respondents was included in the family of origin index, although it was unknown whether they were still alive at the time of the survey. There was potential for overlapping categories because the difference between neighbors, friends, and relatives was not clearly specified. Other examples of this type of problem are detailed in Chapter IV. Undoubtedly the other investigators of network/mortality relationships in communty populations encountered similar problems.

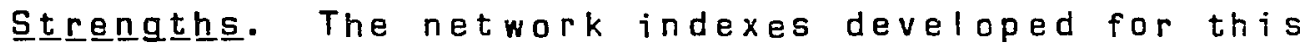
study, al though not perfect, do provide an acceptable measure of social connection. In particular, the network scope index, the index most frequently used as the network 
measure, would be hard to improve upon. This index provided a score of 1 for one or more relationships in each role domain. Measures of social support utilized in prior studies have often been limited, such as one or two global questionnaire items. For this study, more sophisticated network measures were prepared than had been possible in prior studias.

In a theoretical model concerning social support measurement [House \& Kahn, 1985), three salient domains of social support are identified. The first domain concerns social relationships, the second domain concerns the social network (structural aspects), and the third domain concerns social support. The network indexes in this study were able to assess the first two domains. It was not possible to directly measure social support. In terms of social relationships, their existence, quantity, and type were assessed. For the social network, structural aspects of size, scope, frequency, and interaction were assessed. Other network aspects such as density and reciprocity were not able to be measured. This research is important because not only were four structural properties of the network measured, but also nine relationship categories, providing more detail on the networks of the study population than has been possible in prior research. 


\title{
CONCLUSION
}

\begin{abstract}
Overall, the results indicate that social networks pradict mortality and that interacting with friends and engaging in social leisure activities are the strongest predictors. What mechanisms are involved in the link to mortality cannot be inferred from the data or from recent other studies using a comparable approach and conceptually similar variables.
\end{abstract}




\section{IMPLICATIONS AND SUGGESTIONS FOR FUTURE RESEARCH}

It has been shown that in a sample representative of a large city in the Pacific Northwest, elevated mortality risk is associated with having few social ties, particularly extended ones. Other studies in rural and urban areas of the United States have found similar results. The reasons why social networks have predicted mortality have been unclear. This research attempted to explore underlying mechanisms by discerning whether social networks impacted differentially on disease incidence or disease progression. Al though the effort was unsuccessful, it may not have been an adequate test of the research questions because of the methodological problems outlined in the previous chapter. We still do not know how social connections act to decrease mortality. It now remains to state how these research findings can be applied and extended. The first section of this chapter discusses social network interventions which have implications for community health and the quality of urban life. The second section provides suggestions for continued exploration of this area of research in terms of measurement, design, and theory. 


\section{SOCIAL INTERVENTIONS}

The social network/social support concept has appeal due to its potential implications for treatment and prevention. As noted by Cassel in 1975, "It seems more feasible to improve or strengthen the social supports rather than to reduce the exposure to stressors" (p. 121). This approach, focused on naturally occurring social systems, is fiscally appealing and in keeping with the basic philosophy of community health. The purpose of this dissertation was to attempt to highlight whether support was most beneficial as a general measure of primary disease prevention or as a more focused therapy with those already stricken with disease. It was hoped also that by observing the positive and negative influences associated with varicus network relationships it could be learned what it is that benefits people in terms of health.

Fortunately, network relationships involving friends were found predictive of mortality. This is fortunate because making and keping friends is more under individual control and choice than are relationships with family and relatives. Thus, friendship relations appear more amenable to interventions aimed at strengthening of quality and quanitity of social support, strategies often a part of current community health programs. Unfortunately, the 
pathway of the social network/disorder association was not uncovered in this research. Only the outcome of mortality was predicted by the social network measures. The study confirms the knowledge that social connections affect mortality in community populations.

Because this relationship has been shown to occur in a variety of communities in the United States and has been well publicized, many health professionals and warkers in community programs already have integrated network concepts into their practice and programs. The general positive value of social ties, not only for physical health but for mental health and general well-being, is understood, and social integration is fostered in a variety of urban settings with a variety of groups and clients. Gottlieb (1978) has outlined the manner in which attachments can be structured as systems of support: [1] self-help groups; [2] community caregivers where work roles involve them in handling the health problems of citizens; (3) neighborhoodbased helping networks; (4) the primary social network, composed of family members and social intimates.

Many self-help groups have been and are being organized for poople with chronic illnesses and their families. These feature prominently the provision of support to lessen the stresses accompanying chronic illness. For instance, the "I Can Copa" program for individuals with cancer has proven effective (Johnson, 1982). "I Can Cope," 
originating in Minneapolis, was adopted by the American Cancer Society, and has subsequently spread to many urban areas in the country.

Network therapy has become popular with social workers, nurses, and mental health professions in solving individual and family health-related problems (Macelveen, 1978; Halevy-Martini et al., 1984]. The broad purpose of such therapy is to heal rifts in society by reconstructing cooperatively functioning social groups which will then have a healing effect on the family and the client. The social network is defined as the group of people consisting of an identified client, the immediate family, the extended family, and all their relevant supporting social relations, such as neighbors, coworkers, and friends. Service providers and professional people are included in the network. Systems theory provides the theoretical base for social network intervention. Based upon this research, it would seem expedient to focus on enhancing relationships with friends when using network therapy to influence health outcomes.

Also apparently effective has been an innovative public education campaign in California which attempted to teach the public to strengthen natural support networks. The campaign appeared particularly effective with people who had experienced the death of someone close to them during 
the past year, and within that group, increases in support were largest among subjects below average in prior levels of support [Hersey et al., 1984].

It is suggested that continued encouragement and facilitation of the aforementioned systems of support in urban settings is indicated until future research is able to document more precisely how social resources facilitate heal t!: .

\section{SUGGESTIONS FOR FUTURE RESEARCH}

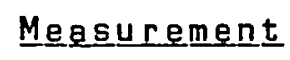

There is a clear need for better definition of the social network/support constructs and for development of better measures of support and the disease outcomes lincidence and progressionl. Although there has been much progress in the area of social support conceptualization and measurement in recent years, all of the studies of social networks and mortality similar to this one have employed network data collacted before recent developments. The use of a prospective longitudinal research design, needed to answer quastions of mortality a decade or more in the future, presents problems of cost and feasibility.

Design

Even with improved measurement methods, tha ability to carry this research area forward using epidemiological methods may be limited. Such population based methods can 
only assess broad outcomes in the aggregate. Research is needed where individuals can be tracked over time in terms of their network changes as these relate to health status changes. For individual people, social support may maka the difference between life and death in illness situations. Qualitative research is also needed to assess typas, meanings, and perceptions of support or non-support in health and illness states.

Cassel (1976) suggested that there was enough available evidence for the benefit of support on health to warrant clinical interventions with careful evaluation of outcomes. It may be that such field experiments are the most fruitful way now to advance our understanding in a practical manner. Laboratory studies using animal models are another possibility, and it is true that animal studies of stress and social interaction have been informative. But problems inherent in cross-species generalization, particularly in behavioral research, limit the possibilities of this type of research.

Prospoctive, longitudinal, clinical studies are needed to answer the questions posed by this research. Network measures must provide more than the rudimentary information gleaned from a few items on prior surveys. The comprehensive and sophisticated network and social support assessment and measurement methods that have been developed 
in recent years must be utilized. An adequate assessment of health status at the initial point of study is mandatory, as well as an analytical schema which controls for the effect of initial status on later outcome. Where patients are to be followed over a number of years, social network changes must also be accounted for.

\section{$\underline{\text { Su}} \underline{\underline{b}} \underline{\text { eㅡ드모 }}$}

Attempting to prospectively assess disease incidence in healthy community populations is a formidable task (Kasl, 1983). Intervention trials focused on high-risk individuals may be more fruitful. Social network and support variables could be the experimental interventions in terms of health outcomes. People with few network resources could have their social ties supplemented. The study of people with no close friends as opposed to those with many would be interesting. To study disease incidence, people at risk, such as those having undergone specific iffe crises such as bereavement, could be studied. Or, to study disease progression, individuals already affected by specific chronic diseases could have their support augmented. In both these models, experimental subjects would then be compared to similar control subjects. Or, a case-control design could be used which compared subjects with low support to those with adequate support in terms of disease outcomes. 


\section{Theeㅡy}

It is still unknown how social networks fit into a model of disease causation. It may be that networks do not prevent disease or episodes of disease exacerbation but simply prevent death from occurring. There may be some critical point in serious illness where social support makes the difference in the continuation of a trajectory towards death.

The direction of causality in the network/mortality relationship may actually be reversed i.e., health may predict social networks. However, since health status is controlled in the network/mortality studies, it is difficult to see how this theoretical approach is actually different from the conceptual framework utilized. An alternate causal model in which isolation causes ill health rather than support promoting better health is also a possibility. A more complex theoretical model is needed which is capable of explaining both buffering effects and main effects of social support, as well as providing new leads for research in terms of disease states.

Another basis for theoretical refinement would be to explore new intervening personality variables or variables of a psychological nature. It may be that such constructs as trust, locus of control, self-confidence, or will to live cause some people to have more social connections. For 
instance, a scale to measure "will to live" could be developed to determine if high levels of this variable predict more social resources. Instruments to measure "coherence" have been developed, but findings from studies utilizing this variable in relationship to mortality have not yet been published. Path analytic models similar to those reported by Kaplan (19E3) can be useful in sorting out interrelationships.

It is now generally accepted that social networks are associated with health. This research has rurther strengthened this knowledge in terms of mortality. The focus in the future should be upon the process of how support and health are linked. Are the effects of social support on health mediated by behavioral change, physiological change, parceptual change, or by some combination thereof? Further knowledge in this area has the potential to make clinical social network interventions more specific and health-enhancing for urban citizens.

\section{CONCLUSION}

In this study, social networks were found to predict mortality, particularly extended ties. The scope or breadth of the network was its most important aspect. Friends offered moreprotection than spouses or other family members. Leisure time spent in activities involving other people also was found protective against death. However, 
social factors were only weak influences on mortality compared, undoubtedly, to factors related to the physiological processes of the disease. We do not yet know when or how social factors affect disease states. Until such knowledge is forthcoming, non-specific strengthening of network ties, particularly those of friends, is advocated as a broad public health measure. More sophisticated research is needed based on more complex theories. 


\section{LIST OF REFERENCES}

Andrews, G., Tennant, C., Henson, D. M., \& Vaillant, G. E. (1978). Stress, social support, coping style, and risk of psychological impairment. Journal of Nervous and Mental Diseaseg, 116 $(5), 307-316$.

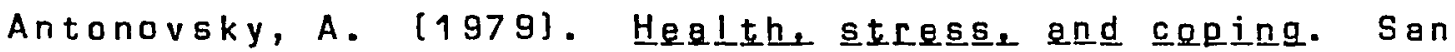
Francisco: Jossey-Bass.

Argyl, M. \& Furnham, A. [1983). Sources of satisfaction and conflict in longstanding relationships. Jeurnal of Merriage and the Fenmily, $8,481-493$.

Asher, C. C. \{1984\}. The impact of social support networks on adult health. Medical Care, 2? $349-359$.

Barrera, M. [1981]. Social support in the adjustment of pregnant adolescents. In B. H. Gottlieb [Ed.], Social

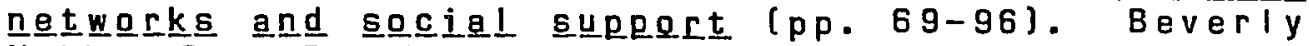
Hills: Sage Publications.

Barrera, M., \& Ajnlay, S. [1983]. The structure of social support: A conceptual and empirical enalysis. Journal of Community Psychology, 11, 133-143.

Berger, M., \& Wuescher, L. (1975). The family in the substantive environment. Journal of Community PsychoLogy, $3(3), 246-253$.

Berkman, L. F. \{1977\}. Social networks, host resistance, and mortality: A follow up study of Alameda County

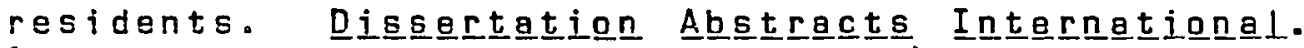
(University Microfilms No. 78-12, 490).

Berkman, L. F. [1982]. Social network analysis and coro-

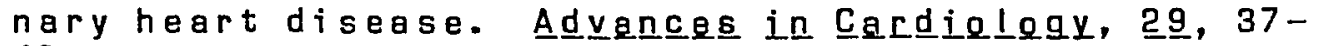
49 .

Berkman, L. F. $\{1984\}$. Assessing the physical health effacts of social networks and social support. Annual Revier Public He日lth, $5,413-432$.

Berkman, L. F., and Syme, L. \{1979\}. Social networks, host resistance, and mortality: A nine-year follow up study of Alameda County residents. American Journal of Epidemiology, 10g(2), $186-204$. 


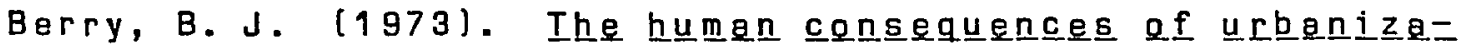
tion. New York: St. Martin's Press.

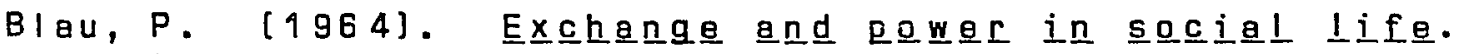
London: Wiley.

Blazer, D. G. [1980]. Social support and mortality in an elderly community population. Dissertation Abstracts International. (University Microfilms No. 8114790).

Blazer, D. G. [1982]. Social support and mortality in an

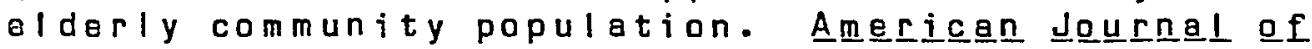
Epidemiology, 115[5], 684-694.

Bloom, J. R. (1982). Social support, accommodation to stress, and adjustment to breast cancer. Sogcial Science and Medicine, 16, 1329-1338.

Bott, E. [1955]. Urban families: Conjugal roles and social networks. Human Relations, 8 , 345-384.

Branch, L. G. \& Jatte, A. M. (1984). Personal health practices and mortality among the elderly. Americen Journal of Public Health, 74, 1126-1129.

Broadhead, W. E., Kaplan, B. H., James, S. A., Wagner, E. H., Schoenbach, V. J., Grimson, R., Heyden, S., Tibblin, G., \& Gehlbach, S. H. (1983). The epidemiologic evidence for a relationship between social support and health. American Lournal of Egidemiology, 117, $521-537$.

California Medical Association Introduction [1956] to California Relative Value Study. Cited in Relative Value Studies. San Francisco, CA: California Medical Association, 1964 .

Caplan, G. [1974]. Support systems. In G. Caplan [Ed.],

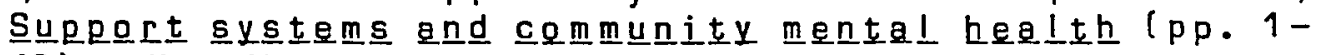
40). Naw York: Behavioral Publications.

Cassel, J. [1974]. Psychosocial procasses and "stress"

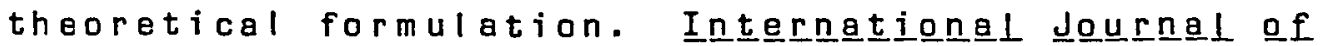
Health Scjencess, $4(3), 471-482$.

Cassel, J. (1976). The contribution of the social environment to host resistance. American Journal of Epidemiology, 104, 107-123. 
Cassileth, B., Lusk, E., Miller, D., Brown, L. [1984]. Psychosocial correlates in malignant disaase. American Society of Clinical Oncology Abstractes, May 1984, Abstract No. C-271.

Chandra, V., Szklo, M., Goldberg, R., \& Tonascia, J. (1983). The impact of marital status on survival after an acute myocardial infarction: A population-

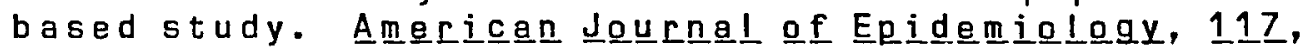
$320-325$.

Cobb, S. (1976). Social support as a moderator of life

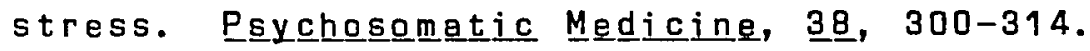

Coburn, D., \& Pope, C.R. (1974). Socioeconomic status and

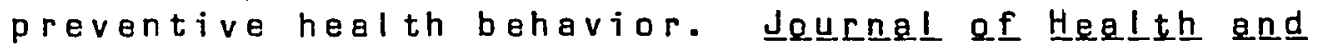
Sociel 1 Behavior, 15, 67-77.

Craven, P., \& Wel Iman, B. (1973). The network city. Socciological Inquíry, 4크, 57-88.

Davidson, T. N., Dowden, M. L., Tholen, M. S., James, M. H., \& Feller, I. (1981). Social support and post-burn adjustment. Archives of Physical Medicicine and rehabilitetion, $\underline{6} \underline{\underline{2}}, 274-278$.

Dean, A., \& Lin, N. (1977). The stress-buffering role of social support. Journal of Nervous and Mental Disease, 165, $403-417$.

DeAraujo, G., Van Ardsdel, P. P., Holmes, T. H., \& Dudley, D. L. [1973]. Life change, coping ability, and

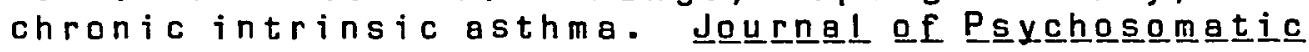
Besearch, 17, 359-363.

DiMatteo, M. R., \& Hays, R. (1981). Social support and serious illness. In B. H. Gottlieb (Ed.), Socoiel

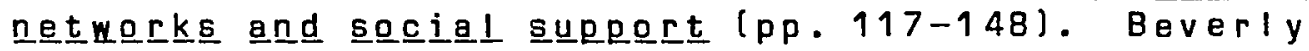
Hills: Sage Publications.

Dimond, M. [1979]. Social support and adaptation to chronic illness: The casa of maintenance hemodialysis. Research in Nursing and Health, 2, 101-108.

Dohrenwend, B. S., \& Dohrenwend, B. P. [Eds.\}. (1974). Stressful life events: Their nature and effects. New York: John Wiley \& Sons.

Dohrenwend, B. S., \& Dohrenwend, B. P. (Eds.). (1981).

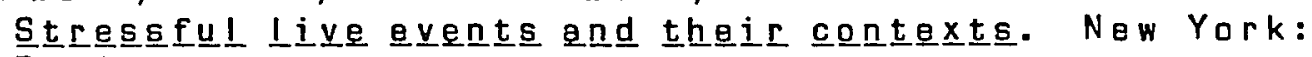
Prodist. 
Dubos, R. (1965). Mąn adeapting. New Haven: Yale University Press.

Duncan, D. D. (1961). A socioaconomic index for all occupations. In A. J. Reiss, Jr., [Ed.], oㅡçupations and social status $(p p$. 109-138). New York: Free Press.

Durkheim, E. [1951\}. Suicide日. New York: The Free Press.

Eaton, W. T. (1978). Life events, social supports, and psychiatric symptoms. A Reanalysis of the New Haven Data. Jounrnal of Health and Social Behavior, 19, 230234 .

Ell, K. [1984]. Social networks, social support, and health status: A review. Social Service Review, (3), $133-149$.

Finlayson, A. (1976). Social networks as coping resources. Social Science and Medicing, 10, 97-103.

Fischer, C. S. (1977). Networks and pleces. New York: The Free Press.

Freeborn, D., \& Pope, C. (1982). Health status, utilization, and satisfaction among enrollees in three private types of private health insurance plans. Group Health Journal, $3,4-11$.

Funch, D. P. \& Marsha!l, J. [1983). The role of stress, social support, and age in survival from breast cancer. Journal of Psychosomatic Research, 277, 77-83.

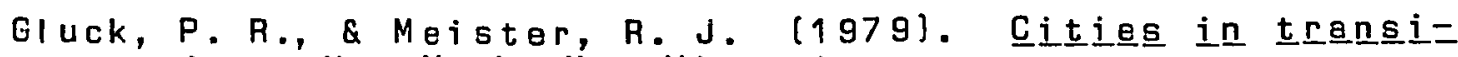
tion. New York: New Viewpoints.

Gnnnella, J. S., Hornbrook, M. C., Louis, D. Z. (1984).

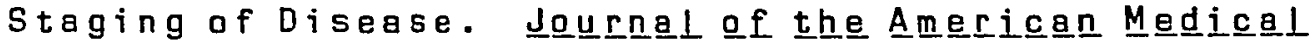

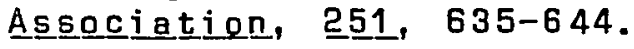

Goodman, L. A. (1972). A modified regression approach to the analysis of dichotomous variables. Americen Sociological Revien, 37, 28-46.

Gore, S. (1978). The effect of social support in moderating the health consequences of unemployment. Journal of Health and Social Behavior, 19, 157-165. 
Gore, S. [1981]. Stress-buffering function of social supports: An appraisal and clarification of research methods. In B. S. Doricaniond \& B. P. Dohrenwend

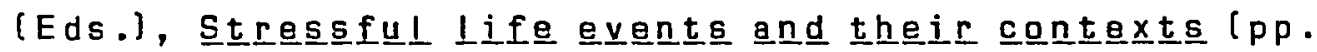
202-222]. New York: Prodist.

Gottlieb, B. H. (1978). The development and application of a classification schema of informal helping behaviors. Canadian Journal of Behavioral Science, 10, 105-115.

Greenlick, M. R., Hurtado, A. V., Pope, C. R., Saward, E. W., \& Yoshioka, S. S. (1968, November). Determinants of Madical Care Utilization. Paper presented to the Medical Care Section, American Public Health Association 96 th Annual Meeting, Detroit, Michigan.

Halevy-Martini, J., Hemley-Van der Velten, E. M., Ruhf, L., \& Schoenfeld, P. (1984). Process and strategy in network therapy. Family Process, 23, 521-533.

Hayes, S., Feinleib, M., \& Kannel, W. (1980). The relationship of psychosocial factors in coronary heart disease in the Framingham Study, III: Eight year incidence of coronary heart disease. American Journal of Epidemiology, 111, 37-58.

Heller, K., (1979). The effects of social support: Prevention and treatment implications. In A. P. Goldstein \&

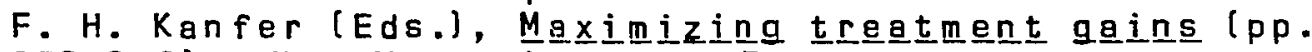
353-382]. New York: Academic Press.

Henderson, A. S. [1984]. Interpreting the evidence on social support. Social Psychiatry, 19, 49-52.

Henderson, A., Duncan-Jones, P., McAuley, H., \& Ritchie, K. (1978). The patient's primary group. British Journal of Psychiatry, 13ㄹ. 74-86.

Henderson, S., Byrne, D. G., Duncan-Jones, P., Adcock, S., Scott, R., Steele, G. P. (1978). Social bonds in the epidemiology of neurosis. Journal of Psychiatry. $132,463-466$.

Henry, J.P. (1982). The relation of sccial to biological processes in disease. Social Science in Medicine, 16, $369-380$.

Hersey, J. C., Klibanoff, L. S., Lam, D. J., \& Taylor, R. L. (1984). Promoting social support: The impact of California's "Friends can be good medicine" campaign.

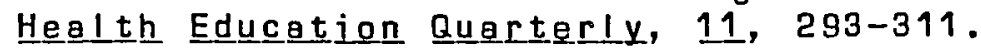


Hibbard, J. H., \& Pope, C. R. (1983). Gender roles, Illness orientation, and use of medical services. Social Science and Medicine, 17, 129-137.

Hinkle, L. E. [1973]. The concept of "stress" in the

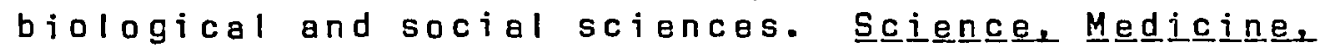
aㅡㅁㅡ Maㅡ, 르, $31-48$.

Holahan, C. J., \& Moos, R. H. (1981). Social support and psychological distress: A longitudinal analysis. Journal of Abnormal Psychology, g0, 365-370.

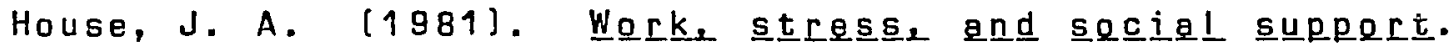
Reading, Massachusetts: Addison-Wesley.

House, J. S, \& Kan, R. L. [1985]. Measures and cancepts of social support. In S. Cohen \& S. L. Syme [Eds.], Sogcial supeort ang h heathㅡ (pp. 83-108). New York: Academic Press.

House, J. S., Robbins, C., \& Metzner, H. L. (1982). The association of social relationships and activities with mortality: Prospective evidence from the Tecumseh community health study. American Journal of Epidemiology, 116, 23-140.

Hubbard, P. Muhlenkamp, A. F., \& Brown, N. \{1984). The relationship between social support and self-care practices. Nursing Research, 33, 266-269.

Hurtado, A. V., \& Greenlick, M. R. [1971). A disease classification system for analysis of medical care utilization, with a note on symptom classification. Health Services Research, 16, 235-250.

Hurtado, A. V., \& Greenlick, H. R. The clinical-behavioral disease classification system. Paper available from Kaiser Center for Health Research, 4610 S. E. Belmont, Portland, Oregon 97205.

Johnson, C. L. (1983). Dyadic family relations and social support. Gerontologist, 2그, 377-383.

Johnson, J. (1982]. The effects of a patient education course on persons with a chronic illness. Cennceer Nursing, $\underline{5}, 117-123$.

Jung, J. (1984). Social support and its relation to health: A critical evaluation. Basic and Agplied Psychology, $\underline{5}, 143-169$. 
Kagan, A. R., \& Levi, L. (1974). Health and environment -

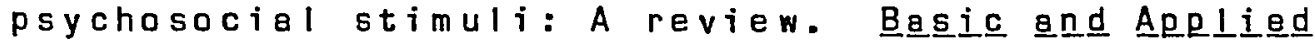
Psychology, $5,143-169$.

Kahn, R. L., \& Antonucci, T. C. [1980]. Convoys over the I ife course: Attachment, roles, and social support.

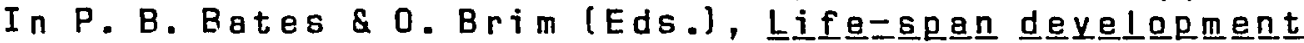
and behavior [pp. 253-286]. Boston: Lexington Press.

Kaplan, B. H., Cassel, J. C., \& Gare, S. (1977). Social support and health. Medical Care, 15(Suppl.), 47-57.

Kaplan, G. A. [1983]. Psychosocial aspects of chronic illness: Direct and indirect associations with ischemic heart disease mortality. Paper presented at the NATO Advanced Study Institute-Behavioral Epidemiology and Disease Prevention Conference in Bellagio, Italy.

Kaplan, G. A., \& Camacho, T. [1983]. Percaived health and mortality: A nine-year follow up of the Human Population Laboratory cohort. American Journal of Epidemi= ology, 117, 292-304.

Kaplan, G. A., \& Delongis, A. [1983]. Psychosocial factors influencing course of arthritis: A prospective study. Paper presented at the 91 st annual meeting of the American Psychological Association Conference, Anaheim, California.

Kasl, S. V. (1983). Social and psychological factors affacting the course of disease. In D. Mechanic [Ed.), Handbook of health, health cares, and the he health professions (pp. 683-708). New York: The Free Press.

Kasl, S. V. [1984]. Stress and Health. Annuaㅡ Revieㅛ of Public Health, 占, 319-341.

Knoke, D., \& Burke, P. J. (1980). 느g Lineeㅛ modㅡㄴㅗ. Beverly Hills: Sage Publications.

Kobasa, S. C., Maddi, S. R., and Kahn, S. [1982). Hardiness and health: A prospective study. Journgl of Personality and Social Psychology, 42, $168-177$.

Koskenvuo, M., Kaprio, J., Romo, M., \& Langinvainio, H. (1981). Incidence and prognosis of ischemic heart disease with respect to marital status and social class. Journal of Epidemiology and Community Health, 35. $192-196$. 
Langer, E. J., Janis, I. L., \& Wolfer, J.A. (1975). Reduction of psychological stress in surgical patients. Journal of Experimental Social Psychology, 11, $155-165$.

Langlie, d. K. (1977). Social networks, health beliefs, and preventive health behavior. Journal of Health and Social Behavior, 18, 244-260.

LaRocco, J. M. [1983\}. Theoretical distinctions between causal and interaction effects of social support. Journal of Hesalth and Social Behavior, 2느, 91-92.

Leavy, R. L. (1983). Social support and psychological disorder: A review. Journel of Cemmunity Psychologx, $11,3-18$.

Liem. J. H., \& Liem. R. (1976). Life events, social supports, and physical and psychological well-being. Paper presented at the annual meeting of the American Psychological Association.

Lin, N., Ensel, W. M., Simeone, R. S., \& Kuo, W. (1979). Sociel support, stressful life events, and illness: A

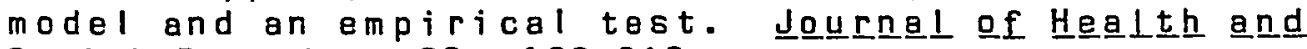
Social Behavior, 20, 198-219.

Litwak, E., \& Szelenyi, I. (1969). Primary group structures and their functions: Kin, neighbors, and friends. American Sociological heview, 34, 465-481.

Lowenthal, M. F., \& Haven, C. (1968). Interaction and adaptation: Intimacy as a critical variable. American Sociological Review, 33, 20-30.

MacElveen, P. M. (1978\}. Social networks. In D. C. Longo \& R. A. Williams [Eds.\}. Clinical practice in psycho= social nursing: Assessment and Interyention lpp. 318338j. New York: Appleton-Century-Crofts.

MacElveen, P. M. (1972). Cooperative Triad in Home Dialysis Care and Patient Outcomes. Communicating Nursing Research, $\underline{5}, 134-147$.

Maxwell, M. B. (1982\}. The use of social networks to help cancer patients maximize support. Cancer Nursina, $\underline{5}$, $275-282$.

McCallister, L., \& Fischer, C. S. [1978]. A procedure for surveying personal networks. Sociological Methods and 
Research, Z, 131-148.

McQueen, D. V., \& Celentano, D. D. [1982]. Social factors in the etiology of multiple outcomes: The case of blood pressure and alcohol consumption patterns. Social Science and Medicine, 16, 397-418.

McQueen, D. V., \& Siegrist, J. (1982). Social factors in the etiology of disease: An overview. Social Science and Medicine, 16, 353-367.

Medalie, J.H. \& Goldbourt, M. A. [1976]. Angina pectoris

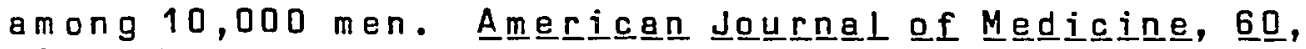
910-921.

Mermelstein, R., Lichtenstein, E., \& McIntyre, K. (1983). Partner support and relapse in smoking-cessation programs. Journal of Consulting and Clinical Psychology, 51, 465-466.

Mitchell, J. C. (1974). Social networks. Annual Reyiew of Anthropology, 3, 279-299.

Mitchell, R. E., \& Trickett, E. J. (1980). Task force report: Social networks as mediators of social support. Community Mentel Health Journal, 16, 27-44.

Mossey, f. M., \& Shapiro, E. [1982]. Self-rated health: A predictor of mortality among the elderly. Americen Journal of Pubㅣㄷㅡ Hesalth, 르, 800-808.

Mueller, D. P. [1980]. Social networks: A promising direction for research on the relationship of the social environment to psychiatric disorder. Socoial Sceience and Medicing, 14A, 147-161.

Norbeck, J. S., \& Tilden, V. P. (1983). Lifestress, social support, and emotional disequilibrium in complications of pregnancy. Health and Social Behavior. 2ㄴ. $30-46$.

Nuckolls, K. B., Cassel, J., \& Kaplan, B. H. (1972). Psychosocial assets, life crisis, and the prognosis of pregnancy. American Jounrnal of Epidemiolology, gㅗ, 431441 .

Parsons, T. [1951). The Sociel System. New York: The Free Press. 
Payne, C. (1977). The log-linear model for contingency tables. In C. O'Muircheartaigh \& C. Payne [Eds.], The

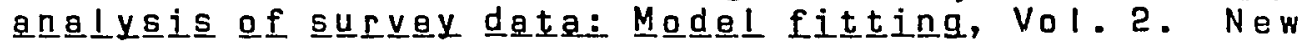
York: John Wiley \& Sons.

Pilisuk, M., \& Froland, C. [1978]. Kinship, social networks, social support, and health. Social science and Medicine, 12B

Pope, C. R. (1976). Data from the 1970-71 household interview survey: Report series \#1, Portland, Oregon. Kaiser Foundation Hospitals Health Services Research Center.

Pope, C. R. [1982]. Life-styles, health status, and medical care utilization. Medical Care, 20, 402-413.

Pratt, L. (1971). The relationship of socioeconomic status

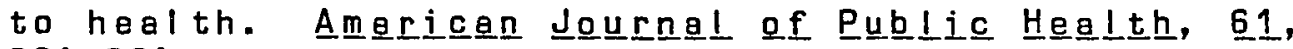
$281-291$.

Rabkin, J. G., \& Struening, E. L. (1976). Life events, stress, and illness. Sccienceg, 184, 1013-1020.

Reed, D., McGee, D., \& Yano, K. [1984]. Psychosocial procasses and general susceptibility to chronic disease. American Journal of Epidemiology, 119, 356-370.

Reed, D., McGee, D., Yano, K., \& Feinleib, M. [1983]. Social networks and coronary heart disease among Japanese men in Hawaii. American Journal of Epidesmiology, 117, 384-396.

Renner, V. J., \& Birren, J.E. (1977). Stress: Physiological and psychological mechanisms. In R. B. Slone (Ed.), Heandㅁook of ment 336). Englewood Cliffs, NJ: Prentice-Hall.

Rook, K. S. (9984). The negative side of social interaction. Journal of Personality and Social Psychology. 46. $1097-1108$.

Schaefer, C., Coyne, J. D., \& Lazarus, R. S. (1981). The health-related functions of social support. Journal of Behevioral Medicine, 4, 381-406.

Schoenbach, V. J., Kaplan, B. H., Kleinbaum, D. G., \& Fredman, L. $\{1983\}$. Social ties and mortality. Presented at the annul meeting of the American Public Health Association, Dallas, Texas. 
Schulz, R., \& Rau, M. T. (1984). Social support through the Iife course. In S. Cohen \& L. Syme (Eds.), Socoiel

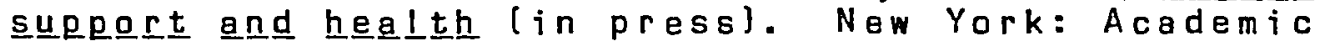
Press.

Simons, R. L. (1984). Specificity and substitution in the social networks of the elderly. International Journal of Aging and Human Development, 1, 121-139.

SP$\underline{S} \underline{X}$ User's Guide. (1983). Chicago: McGraw-Hill.

Thoits, P. (1982). Life stress, social support, and psychological vulnerability: Epidemiological considerations. Journal of Community Psychology, 10, 341-362.

Tolsdorf, C. C. (1976). Social networks, support, and

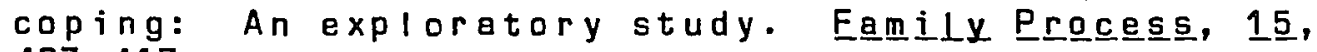
$407-417$.

Turner, R. J. (1981). Social support as a contingency in

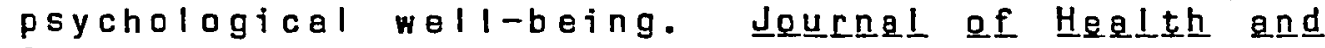
Social Behavior, 22, 357-367.

U.S. Dept. Health, Education, Welfara, Public Health

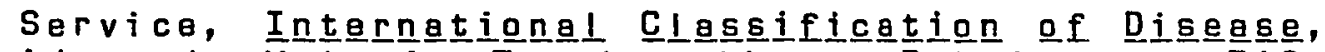
Adapted, Vol. 1, Tabular list. Publication 719, Washington, D. C., Government Printing Offica.

Walker, K. N., MacBride, A., \& Vachon, M. L. (1977). Social support networks and the crisis of bereavement. Sociel Science and Medicine, 14, 35-41.

Walker, S. H., \& Duncan, D. B. (1967). Estimation of the probability of an event as a function of several independent variables. Biometrika, 므, 167-179.

Waliston, B. S., Alaga, S. H., DeVellis, B. M., \& DeVallis, R. F. [1983]. Social support and physical health. Health Psychology, 2, 367-391.

Weisman, A. D., \& Worden, J. W. (1975). Psychosocial analysis of cancer deaths. Domega, Jounchal of Degeth a $\underline{\text { nd }}$ D文ing, $6,61-75$.

Weiss, R. S. (1969). The fund of sociability. Transaction, 6. $36-40$.

Wellman, B. (1981). Applying network analysis to the study

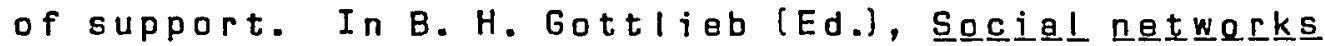
and sogcial suqoㅡㄹ, (pp. 171-200). Beverly Hills: Sage Publications. 
Whitten, N. E., \& Wo!fe, A. W. (1973). Network Analysis.

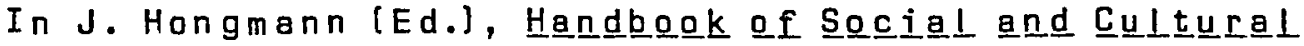
Anthropology \{pp. 717-745\}. New York: Rand McNally.

Wiley, J. A., \& Camacho, T. C. (1980). Life style and future health: Evidence from the Alameda County study. Preventive Medicine, g, 1-21.

Williams, A. W., Ware, J. E., Donald, C. A. [1981). A model of mental health, life events, and social supports applicable to general populations. Jouㄷaㅛ of Health and Social Behavior, 22, 324-336.

Wingard, D. L., Berkman, L. F., \& Brand, R. J. (1982). A multivariate analysis of health-related practices. American Journal of Epidemiology, 116, 765-775.

Winnubst, J. A., Marcelissen, F. H., \& Kleber, R. J. (1982). Effects of support in the stressor-strain

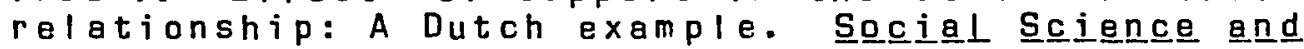
Medicine, 16, 475-482.

Woods, N. F., \& Earp, J. L. (1978). Women with cured breast cancer. Nursing Rese日ech, 르, 279-285.

Wortman, C. [1984]. Social support and the cancer patient. 므를er, 프(Suppl.), 2339-2362.

Zuckerman, D. M., Kasl, S. V., \& Ostfeld, A. M. [1984]. Psychosocial predictors of mortality among the elderly poor. American Journal of Egidemiology, 119, 410-423. 
APPENDIX A

FORMS USED BY CENTER FOR HEALTH RESEARCH TO RECORD UTILIZATION DATA

FROM MEDICAL RECORDS 


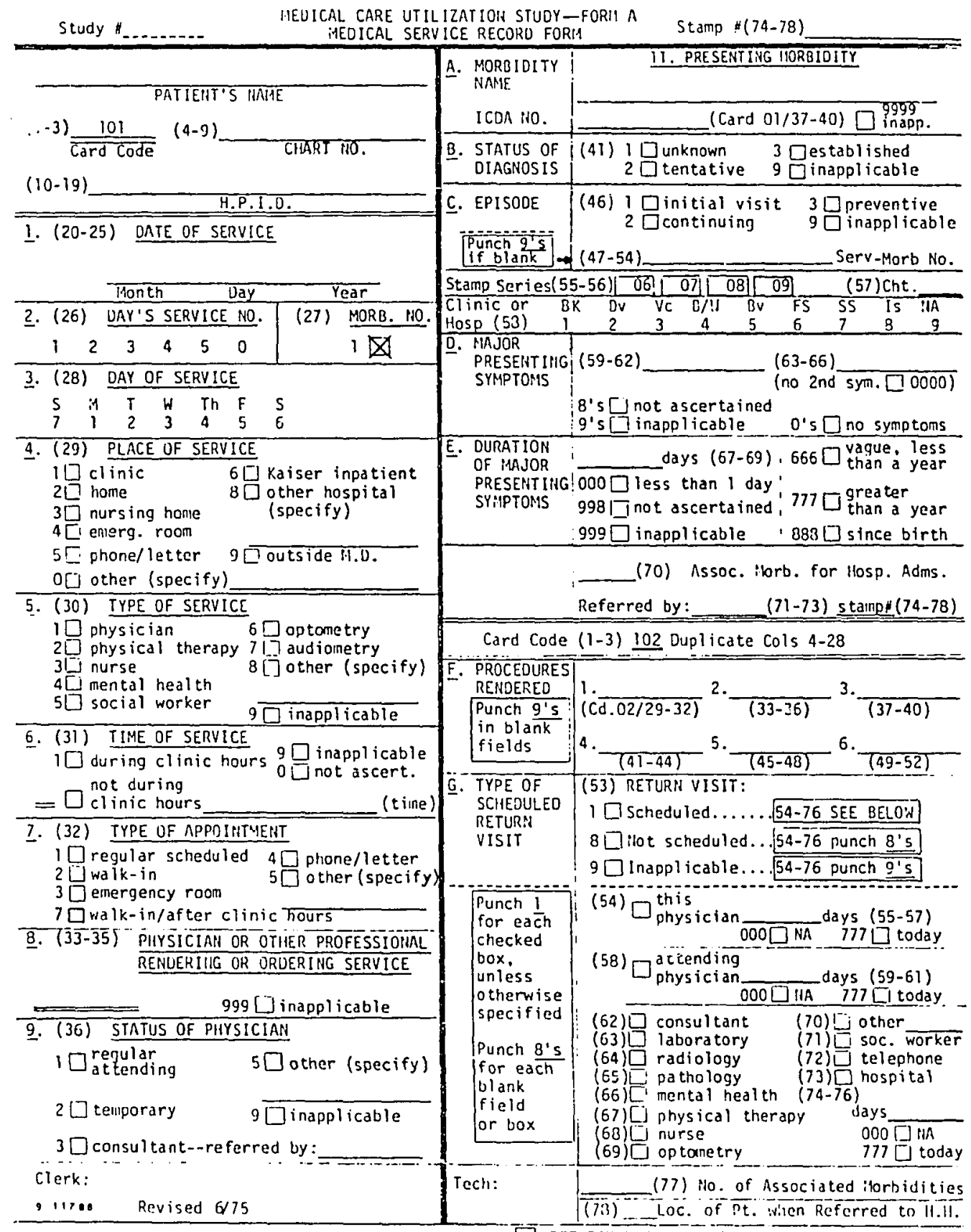


MEDICAL CARE UTILIZATION STUDY-FORM
SUPPLEMENTARY MORBIDITY RECORD FORM

\begin{tabular}{|c|c|c|c|}
\hline \multicolumn{2}{|c|}{ SUPPLEMENTARY MOROIDITY RECORD FORM } & \multicolumn{2}{|l|}{ CHART HO. } \\
\hline & 131 Card Code $(1-3) \subseteq$ Horb. No. (27) & 141 Card Code (1-3) 5 Morb. Mo. (27) & 151 Card Code (1-3) 6 Morb. Ho. (27) \\
\hline $\begin{array}{l}\text { SORB. RAMAE } \\
\text { ICDA NO. }\end{array}$ & (Card 31/37-40) $\square_{\text {inapp. }}^{9999}$ & $($ Card $4 l / 37-40) \square$ & (Card $51 / 37$ \\
\hline $\begin{array}{l}\text { B. STATUS OF } \\
\text { DIAGHOSIS } \\
\end{array}$ & 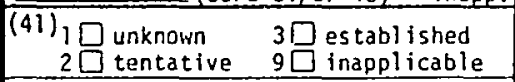 & $\begin{aligned} & \text { (41) } 1 \square \text { unknown } 3 \square \text { established } \\
& 2 \square \text { tentative } 9 \square \text { inapplicable } \\
&\end{aligned}$ & 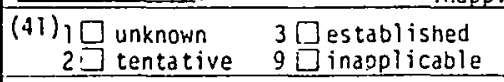 \\
\hline $\begin{array}{l}\text { C. EPISODE } \\
\begin{array}{l}\text { Punch g's } \\
\text { if blank- }\end{array} \\
\end{array}$ & \begin{tabular}{|cc}
$(46) 1 \square$ initial visit \\
$2 \square$ continuing & $\begin{array}{c}3 \square \text { prevent. } \\
9 \text { inapp. } \\
\text { Service- } \\
(47-54)\end{array}$ \\
\end{tabular} & 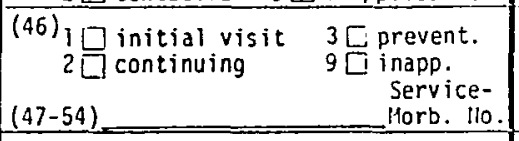 & $\begin{array}{rr}(46) 1 \square \text { initial visit } & 3 \square \text { prevent. } \\
2 \square \text { continuing } & 9 \square \text { inapp. } \\
\text { Service- } & \text { Marb. Ho } \\
(47-54) & \text { M }\end{array}$ \\
\hline $\begin{array}{l}\text { MAJOR } \\
\text { PRESENTING } \\
\text { SYIAPTOHS }\end{array}$ & 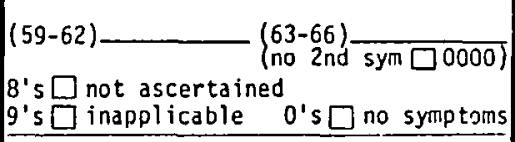 & $\begin{array}{l}(59-62) \_(63-66) \\
\text { (no 2nd sym } \square 0000) \\
8^{\prime} \leqslant \square \text { not ascertained } \\
9^{\prime} s \square \text { inapplicable 0's } 0 \text { no symptoms }\end{array}$ & $\begin{array}{l}(59-62) \_(63-66) \\
\text { (no 2nd sym } \square 0000) \\
8^{\prime} s \square \text { not ascertained } \\
9 \text { 's } \square \text { inapplicable } 0^{\prime} s \square \text { no symptoms }\end{array}$ \\
\hline $\begin{array}{l}\text { E. DURA } \\
\text { OF :H } \\
\text { PRES } \\
\text { SYMP }\end{array}$ & $\begin{array}{l}\text { days (67-69) } 666 \square \text { vague, less } \\
\text { than d year } \\
000 \square \text { less than } 1 \text { day } \\
998 \square \text { not ascert. } \\
999 \square \text { inapplicable } \\
\end{array}$ & 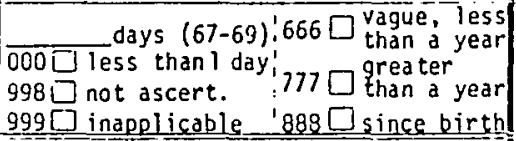 & 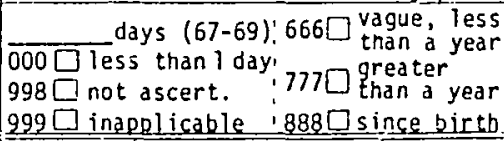 \\
\hline $\begin{array}{l}\text { PRR } \\
\text { RE } \\
\begin{array}{l}P u \\
\text { in } \\
f i\end{array} \\
\end{array}$ & Others $(\overline{c d} \cdot \overline{32 / 29-32)} 2 \cdot \overline{(33-36)}$ & $\begin{array}{l}\text { Others } \\
\text { (37-52) }\end{array}$ & $\begin{array}{l}152(1-3) \\
0 \text { thers } \\
(37-52)\end{array}$ \\
\hline $\begin{array}{l}\text { Punch } 1 \\
\text { for each } \\
\text { checked } \\
\text { box unless } \\
\text { otherwise } \\
\text { specified }\end{array}$ & 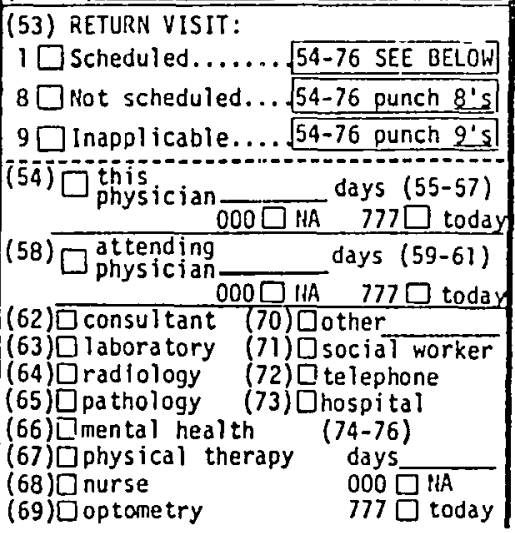 & 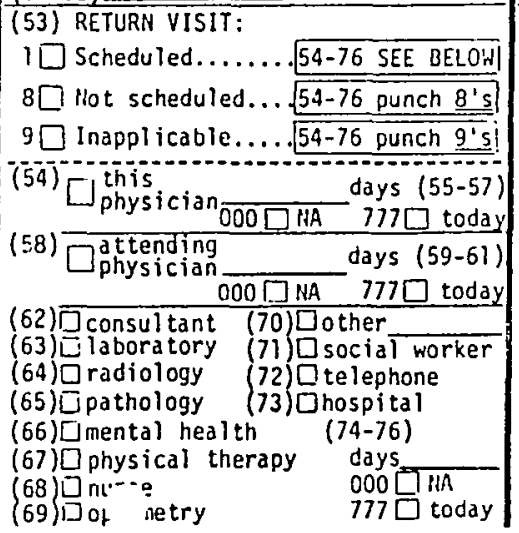 & 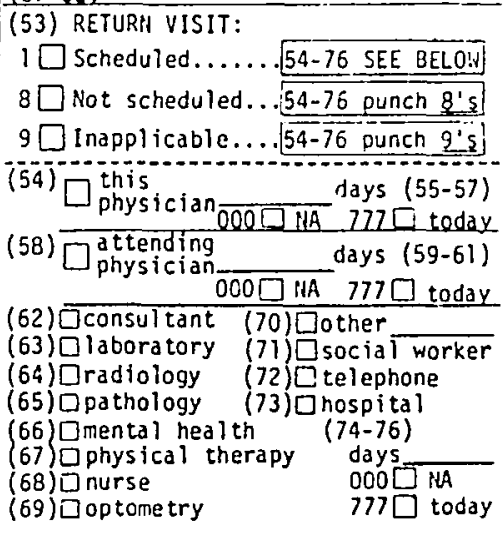 \\
\hline
\end{tabular}


MEDICAL CARE UTILIZATION STUDY - FORM B Laboralory. Radiology Other Senices

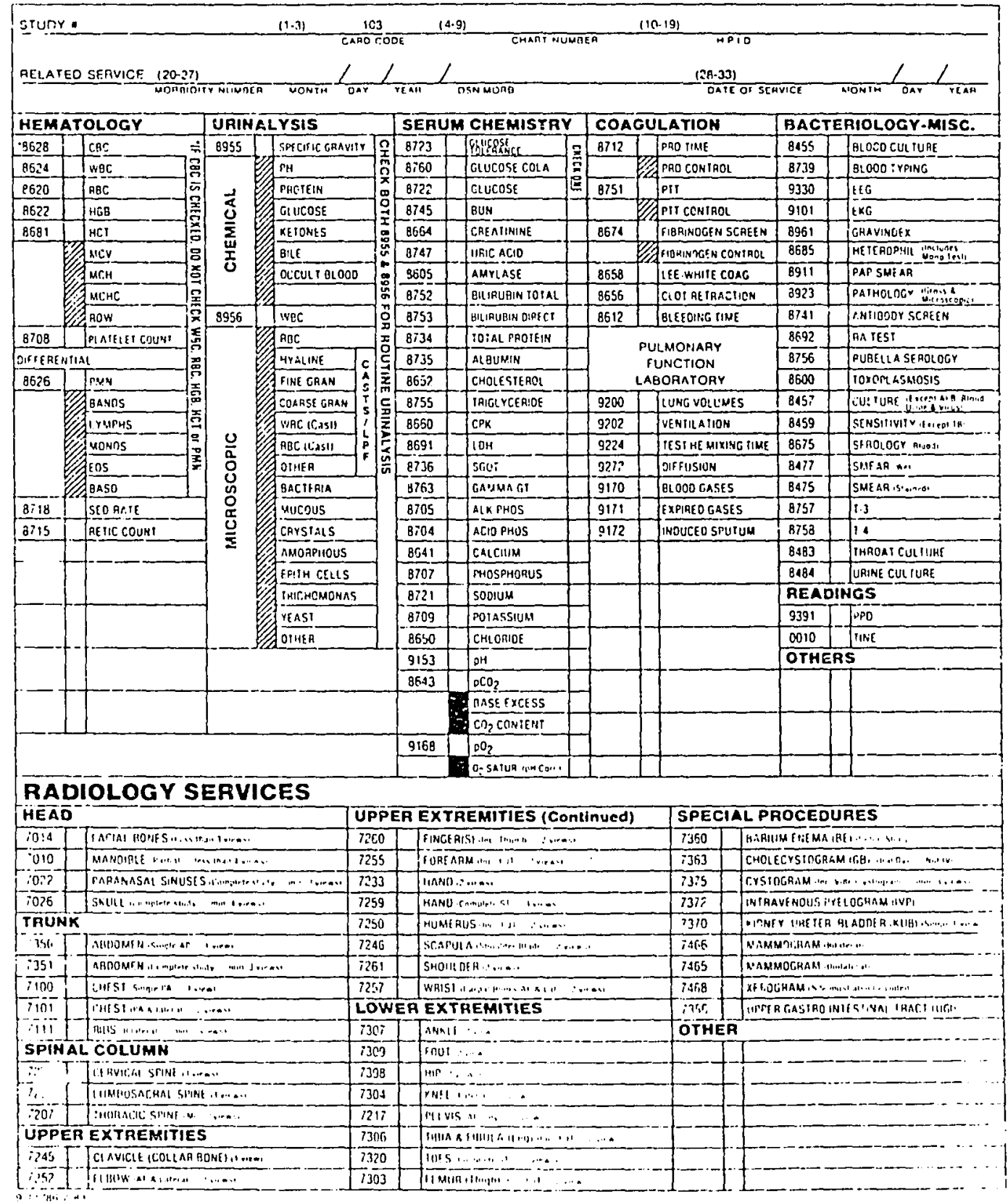


PAIIENT PERSONAL IIISTORY QUESIIORIMAIRE

DISCHARGE SUMMARY

(KEY PUNCH: SKIP ALL COLUMNS THAT ARE BLANK EXCF.PT STAITP NUHAERS)

CARD CODE 02 STAMP NO. CL. $\frac{2}{(1-2)}-\overline{(3-8)} \cdot \overline{(9-14)}$

\begin{tabular}{|c|c|c|c|}
\hline RACE: (15) & $\begin{array}{l}\text {-1-White } \\
\text {-2-Negro }\end{array}$ & $\begin{array}{l}\text {-3-Orierital } \\
\text {-4-Indian }\end{array}$ & -5 -0ther(specify) \\
\hline \multicolumn{4}{|c|}{$\begin{array}{l}\text { RELIGIOUS PREFERENCE: }(16) \\
\text {-1-Protestant -0-None } \\
\text {-2-Catholic } \\
\text {-3-Jewish }\end{array}$} \\
\hline
\end{tabular}

ADHISSION DATE: $(17-22)$

TIME OF ADIIISSION: (24)

$\begin{array}{llllllll}5 & M & T & H & \text { Th } & F & S \\ 7 & 1 & 2 & 3 & 4 & 5 & 6\end{array}$

-1 - 9:00am - 4:59pm, Mon. through Sat.

-2- 5:00pm - $11: 53 \mathrm{pm}$, Mon. through Sat.

-3- Midnight - 8:59am, Hon. through Sat.

-4- 9:00am - 11:59pm, Sun. \& Holldilys

-5- Midnight - 8:59am, Sun. \& Holidays

DISCHARGE OATE: $(25-30)$

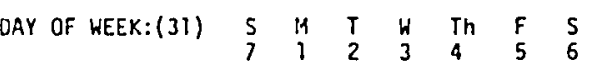

TIME OF DISCHARGE: (32)

$-1-9: 00 \mathrm{am}-4: 59 \mathrm{pm}$. Non. through Sat.

-2- 5:00pm - 11:59pm, !on. through Sat.

-3-Midnight - 8:59am, Mon. through Sat.

-4- 9:00am - 11:59pm, Sun. \& Hol idays

-5- Hidnight - 8:59am. Sun. \& Hol Hays

TOTAL LENGTH OF STAY:(33-35)

SERVICE (DISCHARGC). (36-37)

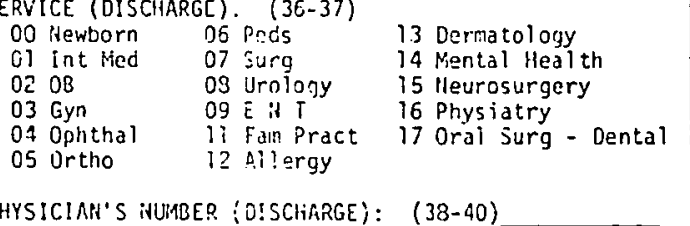

PHYSICINA'S iNUMBE? :O!SCliARGE): (38-40)

CONSULTATIONS:

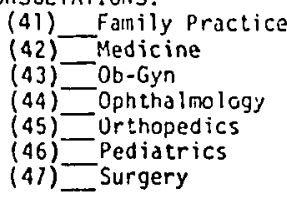
(48)_Urology
(49) E E T
(50) Hental Health Personnel
(M.o.'s \& Otners)
(51)_ Neurology/Heurosurgery
(52)_uther (M.D.'s only)

ADMITIILG DIAGNOSES: $\operatorname{PRIMARY}(53-56)$

SECONOARY $(57-60)$
DISCHARGE DIAGNOSES: PRIMARY

$(6)-6 \overline{4})$

(65-68) T69-72) (73-76) 77.801

CAP. CODE 03(1-2) STAMP NO. (3-8)

$\frac{(9-12)}{(21-24)} \frac{(13-16)}{(25-28)}-(\sqrt{1-20)}$

SURGICAL PROCEDURES: PRIMARY

$(29-3)$

$\frac{(32-34)}{(41-43)} \frac{(35-37)}{(44-46)}-\frac{(38-40)}{(47-49)}$

LAB TESTS:

\begin{tabular}{|c|c|}
\hline$(50-52)$ & Urine Tests \\
\hline$(53-55)$ & Hema tology \\
\hline$(56-58)$ & Chemistry and Serology \\
\hline$(59-60)$ & Transfusions \\
\hline$(61-62)$ & Bacteriology \\
\hline$(63-64)$ & Cross Match and Typing \\
\hline$(65-66)$ & Coagulation \\
\hline$(67)$ & Cervical/Vacinal Pap Sinear \\
\hline$(68-69)$ & Miscellaneous \\
\hline$(70-71)$ & Pathology \\
\hline
\end{tabular}

$X$-RAYS: $\operatorname{CHEST}(72) \quad$ OTHER(73-74)

EKG'S: $(75-76)$

OISCHARGE STATUS:(77) -1-Altve -2-Expired

Alive: -3-CCU $-5-1 \mathrm{CU}-7-\mathrm{CCU}$ \& ICU

Expired: -4-CCU -6-ICU -8-CCU \& ICU

AUTOPSY:(78) -1-Alive when discharged

-2- Expired--NO autopsy

-3- Expired-AUTOPSY

MOSPITAL INFECTION:(79) -0-No -i-Yes

STATUS OF PERSONAL HISTORY JUEST: $(80)$

-1 - Completed

-2- Patient expired before completion

-3- Patient unable to complete

-4- Refused

-5- Previous admission (P.A.)

-6- Hot completed--misc. reasons

-7- Newborn

-8-Partially completed (P.C.) 
PATIENT PERSONAL HISTORY QUESTIONNAIRE:

SUNNYSIDE MEDICAL CENTER

TODAY'S DATE

Your cooperation in answering the following questions will ald your physlclan and will provide information to help the Health Plan loprove service. Please read the questions carefully and $f 111$ in the blanks or check the appropelate boxes.

Your answers.w111 be strictly confidential. "thank you.

1. WHAT IS YOUR ADDRESS?

2. WHAT IS YOUR DATE OF BIRTH? (Month, day and year)

3. WHAT IS YOUR ETHNIC ORIGIN? (This question is optional and used for statistical purposes only)

$$
\begin{array}{ll}
4 \square \text { Native American (Indian) } & 3 \square \text { Aslan } \\
5 \square \text { Hispanlc } & 2 \square \text { Negro (Black) } \\
6 \square \text { Other (speclfy) } & 1 \square \text { Caucasian (White) }
\end{array}
$$

4. IHAT IS YOUR PRE.SENT MARITAL STATUS?

$$
\begin{array}{lll}
0 \square \text { Never marrled } & 2 \square \text { Rerarrled } & 4 \square \text { Widowed } \\
1 \square \text { Married } & 3 \square \text { Divorced } & 5 \square \text { Separated }
\end{array}
$$

5. WHAT SERIOUS ILLNESSES HAVE YOU HAD? (Like Pneumonia, Typhoid, etc.)

1 Disease

6. HOW MANY CHILIJRIN DO YOU HAVE? (Include newborns)

7. HOW MANY PEOPLF, LIVE IN YOUR RESIDENCE? (Include yourself)

8. HOW ILANY ROCMS ARE IN YOUR RESIDENCE? (Exclude bathrooms)

9. DO YOU PRESENTLY SMOKE CICARETTES? $1 \square$ Yes $0 \square$ No

IF YES: APPROXIMATEI,Y HOI MANY CITARETTES PER DAY DO YOU SHOKE? HOW MANY YEARS HLAVE YOII SMOKED?

10. IF YOU DON'T SMOKE NOW, DID YOU EVER REGULARI,Y SMOKE CICARETTES?

$1 \square$ Yes $0 \square$ No

IF YES: APPROXIMATELY HOW MANY CIGARETTES PER DAY DID YOU SMOKE? WHEN DID YOU QUIT? HOW MANY YEARS DID YOU SHOKE?

11. YOU REGULARLY SMOKE CIGARS OR A PIPE?

12. DO YOU DRINK ALCOHOLIC REVERAGES? $0 \square$ Never

2 Occasionally

1 Seldor 3 Frequenty

$4 \square$ Da11y

13. WIEN YOU DRINK, HOW MANY OF THE FOLLOWING DO YOU USUALLY DRINK DURING A DAY? Glasses of wine, and/or Bottles(glasses) of beer, and/or Drinks

14. COMPARED TO LAST YEAR ARE YOU NOW DRINKING: 1 M More $3 \square$ about the same

2 Less

15. DURING THE PAST YEAR HAVE YOU EVER BEEN WORRIED OR CONCERNED ABOUT YOUR DRINKINC? 2H

$$
1 \text { प Yes } 0 \text { № }
$$

PLFASE COHPLETE THE QUESTIONS ON THF. OTHER SIDE OF THIS FORM

1112 Rl:VISt: $1 / 79 \quad 10$ NUE: Complete 2 D NDE Incomplete


APPENDIX B

\section{KAISER CLINICAL-BEHAVIORAL CLASSIFICATION SYSTEM}


DISFASES

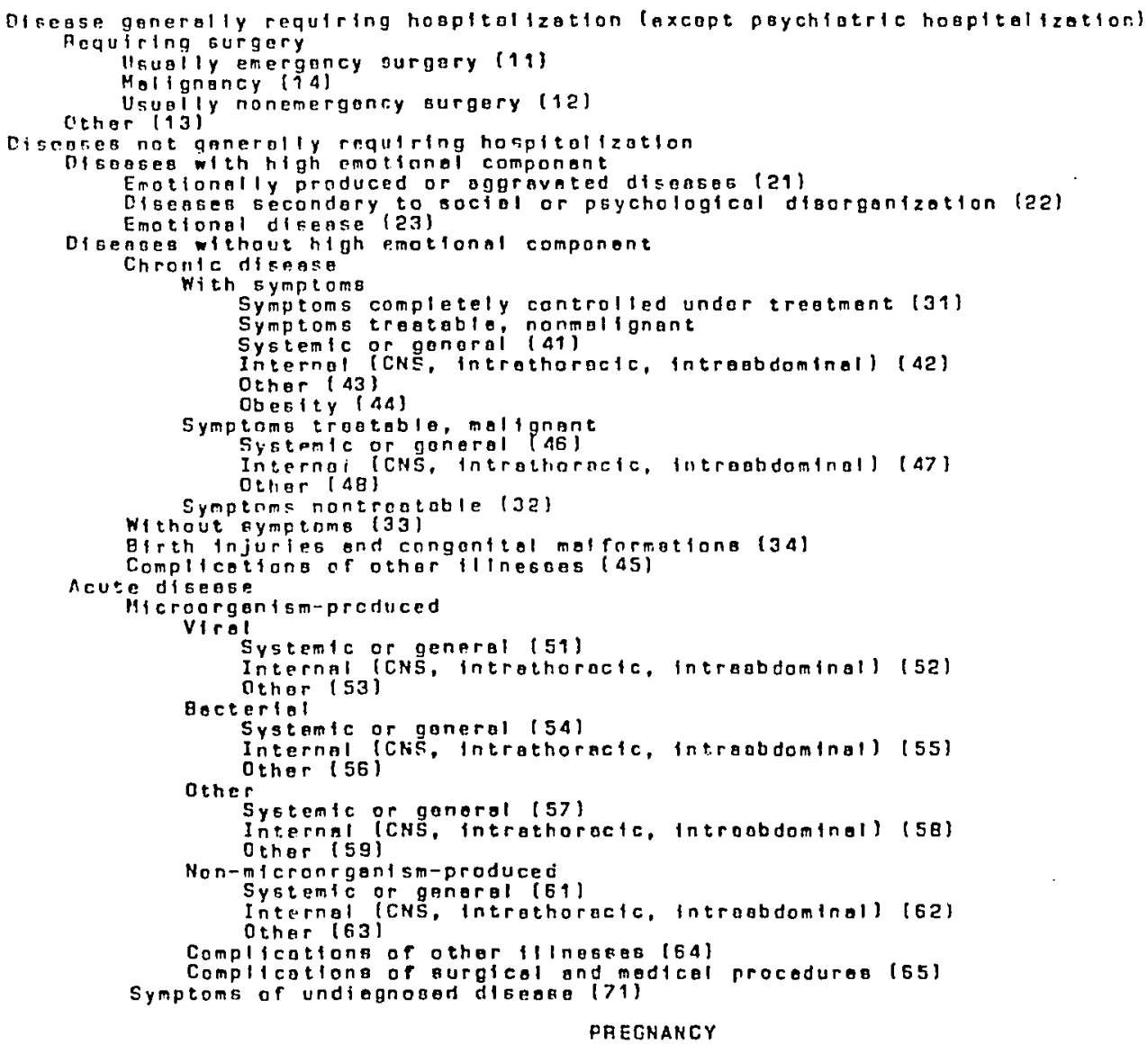

PREGNANCY

Prenotal and postnatal serytco (B1)

Complications (B2)

TPAUMA AND ADVERSE EFFECTS OF EXTEANAL CAUSE

Burns and traumatic fojuries and odverge effecto of chemicale bnd other external caver

Hosaltalization usuelly raquired \{ 91$\}$

Hoepltaltzotion not usue! Iy requirnd (92)

lota offect of trauna (ga)

Hebpltalization ard surgary uoualiy raquirod (95)

auveregerfocta of druge (gaj)

NONDISEASE, REFRACTIVE ERROR, AND MISCELLANEOUS

Proventive services (01)
No disease present [ICDA dognosis] (05)

Ninor ioj

Refractions 1041

hefractiva error 104

ho refroctivo error $(05)$

Cifntcal subgroups in tho Kalser Cilnteal-Bohovioral Clagelfication Syetem

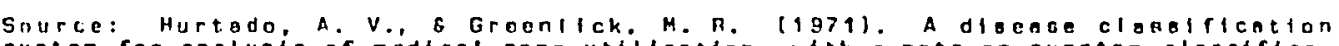

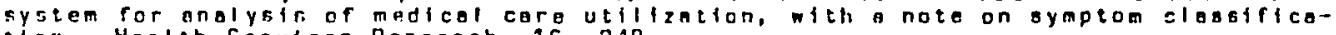
tion. Heglth Serxiges Heseecch, 1G, 240. 


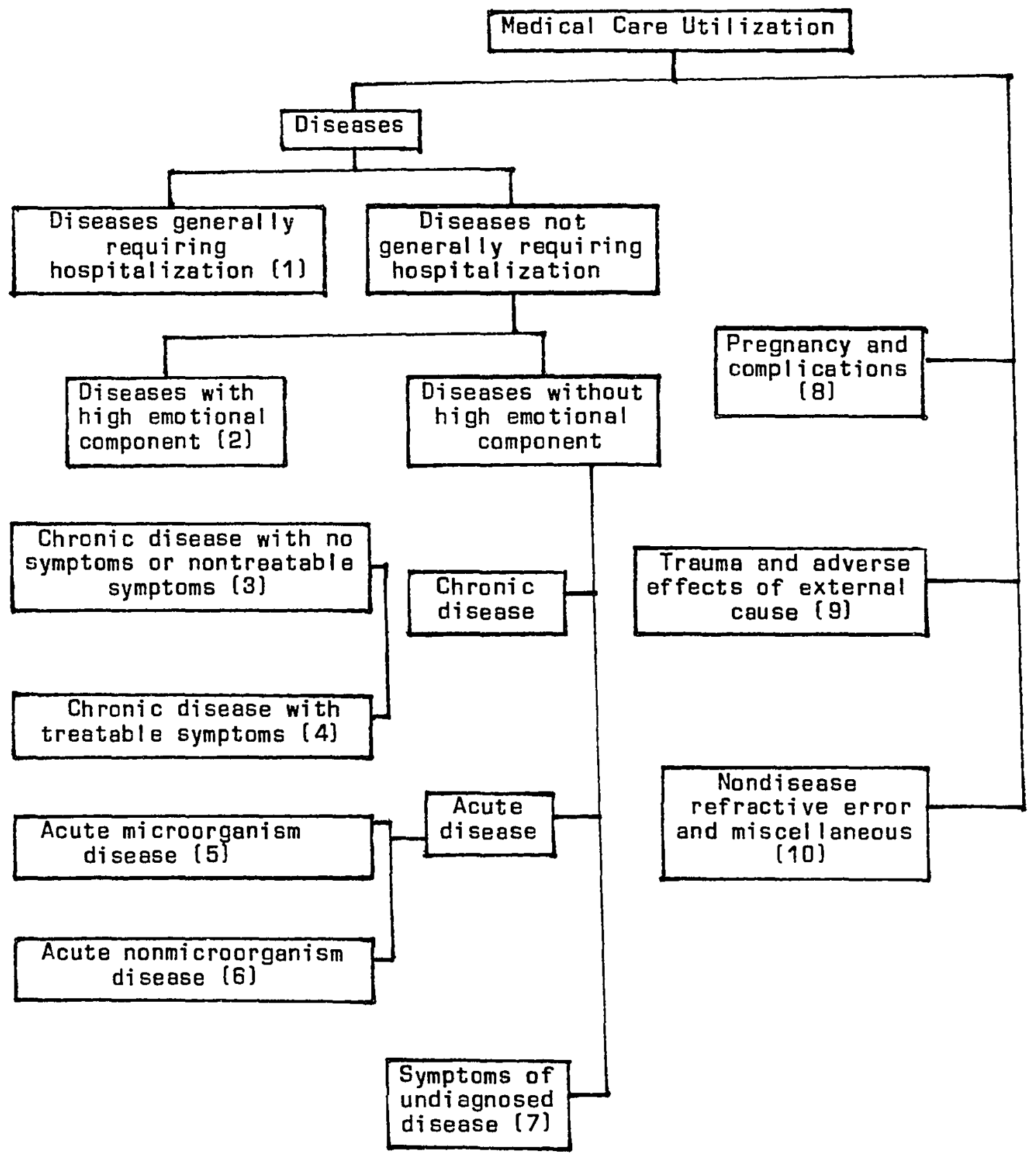

Basic structure of the Kaiser Clinical-Behavioral Classification System

Source: Hurtado, A.V. \& Greenlick, M.R. (1971). A disease classification system for analysis of medical care utilization, with a note on symptom classification. Health Services Research, 16, 239. 


\section{APPENDIX C}

AGE AND SEX-SPECIFIC RESPONSES TO SOCIAL NETWORK QUESTIONS ON THE HOUSEHOLD

INTERVIEW SURVEY 
DISTRIBUTION OF RESPONSES BY AGE AND SEX TO QUESTION,

"What is your marital status?"

\begin{tabular}{|c|c|c|c|c|c|c|c|c|}
\hline \multirow{2}{*}{$\begin{array}{l}\text { Marital } \\
\text { Status }\end{array}$} & \multicolumn{4}{|c|}{ MEN } & \multicolumn{4}{|c|}{ WOMEN } \\
\hline & $\begin{array}{l}\text { under } \\
35\end{array}$ & $35-49$ & $50-65$ & $\begin{array}{l}\text { over } \\
65\end{array}$ & $\underset{35}{\text { under }}$ & $35-49$ & $50-65$ & $\begin{array}{c}\text { over } \\
65\end{array}$ \\
\hline 1 Married & 87.0 & 91.5 & 91.5 & 80.9 & 87.1 & 88.5 & 79.1 & 49.6 \\
\hline $\begin{array}{l}2 \text { Never } \\
\text { Married }\end{array}$ & 7.3 & 3.2 & 4.1 & 5.3 & 3.0 & 2.1 & 2.4 & 2.8 \\
\hline 3 Wi dowed & .3 & 1.1 & 1.3 & 8.6 & .3 & 2.4 & 10.6 & 41.1 \\
\hline 4 Divorced & 5.3 & 4.3 & 3.2 & 5.3 & 9.6 & 7.9 & 7.9 & 6.5 \\
\hline $\begin{array}{l}\text { TOTAL } \\
\text { (N) }\end{array}$ & $\begin{array}{r}100 \\
{[301}\end{array}$ & $\begin{array}{c}100 \\
{[376]}\end{array}$ & $\begin{array}{r}100 \\
{[316}\end{array}$ & $\begin{array}{c}100 \\
{[209]}\end{array}$ & $\begin{array}{c}100 \\
{[396]}\end{array}$ & $\begin{array}{c}100 \\
(321)\end{array}$ & $\begin{array}{c}100 \\
{[378)}\end{array}$ & $\begin{array}{c}100 \\
{[246]}\end{array}$ \\
\hline
\end{tabular}

DISTRIBUTION OF RESPONSES BY AGE AND SEX TO QUESTION, "How many children do you have?"

\begin{tabular}{|c|c|c|c|c|c|c|c|c|}
\hline \multirow{2}{*}{$\begin{array}{l}\text { Number of } \\
\text { Children }\end{array}$} & \multicolumn{4}{|c|}{ MEN } & \multicolumn{4}{|c|}{ WOMEN } \\
\hline & $\begin{array}{l}\text { under } \\
35\end{array}$ & $35-49$ & $50-65$ & $\begin{array}{l}\text { over } \\
65\end{array}$ & $\begin{array}{l}\text { under } \\
35\end{array}$ & $35-49$ & $50-65$ & $\begin{array}{l}\text { over } \\
65\end{array}$ \\
\hline 0 None & 20.3 & 4.5 & 14.6 & 23.4 & 14.1 & 3.9 & 13.8 & 24.4 \\
\hline 1 & 24.6 & 9.3 & 17.1 & 24.4 & 20.7 & 8.4 & 22.2 & 22.0 \\
\hline 2 & 24.9 & 25.0 & 28.2 & 18.2 & 27.5 & 22.6 & 30.4 & 20.7 \\
\hline 3 & 16.9 & 24.7 & 15.5 & 20.1 & 20.2 & 24.9 & 13.5 & 17.1 \\
\hline 4 & 7.6 & 18.1 & 11.7 & 7.2 & 11.1 & 21.3 & 8.2 & 6.9 \\
\hline 5 or more & 5.6 & 18.4 & 13.0 & 6.7 & $E .3$ & 18.9 & 11.9 & 8.9 \\
\hline $\begin{array}{l}\text { TOTAL } \\
{[\mathrm{N}]}\end{array}$ & $\begin{array}{c}100 \\
{[301]}\end{array}$ & $\begin{array}{c}100 \\
{[376]}\end{array}$ & $\begin{array}{c}100 \\
{[316]}\end{array}$ & $\begin{array}{c}100 \\
{[209]}\end{array}$ & $\begin{array}{c}100 \\
{[396]}\end{array}$ & $\begin{array}{c}100 \\
{[381]}\end{array}$ & $\begin{array}{c}100 \\
{[378]}\end{array}$ & $\begin{array}{c}100 \\
{[246]}\end{array}$ \\
\hline
\end{tabular}


DISTRIBUTION OF RESPONSES BY AGE AND SEX TO QUESTION, "Is your father living?"

\begin{tabular}{|c|c|c|c|c|c|c|c|c|}
\hline \multirow{2}{*}{$\begin{array}{l}\text { Father } \\
\text { Living }\end{array}$} & \multicolumn{4}{|c|}{ MEN } & \multicolumn{4}{|c|}{ WONEN } \\
\hline & $\begin{array}{l}\text { under } \\
35\end{array}$ & $35-49$ & $50-65$ & $\begin{array}{c}\text { over } \\
65\end{array}$ & $\begin{array}{l}\text { under } \\
35\end{array}$ & $35-49$ & $50-65$ & $\begin{array}{c}\text { over } \\
65\end{array}$ \\
\hline 1 Deceased & 23.9 & 56.2 & 87.5 & 100.0 & 20.4 & 54.8 & 88.2 & 100.0 \\
\hline 2 Alive & 76.1 & 43.8 & 12.5 & 0 & 79.6 & 45.2 & 11.8 & 0 \\
\hline $\begin{array}{l}\text { TOTAL } \\
{[N]}\end{array}$ & $\begin{array}{c}100 \\
{[297]}\end{array}$ & $\begin{array}{c}100 \\
(370)\end{array}$ & $\begin{array}{c}100 \\
(313)\end{array}$ & $\begin{array}{c}100 \\
{[205]}\end{array}$ & $\begin{array}{c}100 \\
{[387]}\end{array}$ & $\begin{array}{c}100 \\
{[378]}\end{array}$ & $\begin{array}{c}100 \\
{[373]}\end{array}$ & $\begin{array}{c}100 \\
{[245]}\end{array}$ \\
\hline
\end{tabular}

DISTRIBUTION OF RESPONSES BY AGE AND SEX TO QUESTION,

"Is your mother living?"

\begin{tabular}{|c|c|c|c|c|c|c|c|c|}
\hline \multirow{2}{*}{$\begin{array}{l}\text { Mother } \\
\text { Living }\end{array}$} & \multicolumn{4}{|c|}{ MEN } & \multicolumn{4}{|c|}{ WOMEN } \\
\hline & $\begin{array}{l}\text { under } \\
35\end{array}$ & $35-49$ & $50-65$ & $\begin{array}{c}\text { over } \\
65\end{array}$ & $\begin{array}{l}\text { under } \\
35\end{array}$ & $35-49$ & $50-65$ & $\begin{array}{c}\text { over } \\
65\end{array}$ \\
\hline 1 Deceased & 6.0 & 32.6 & 66.3 & 96.1 & 7.6 & 31.9 & 75.1 & 97.2 \\
\hline 2 Alive & 94.0 & 67.4 & 33.7 & 3.9 & 92.4 & 68.1 & 24.9 & 2.8 \\
\hline $\begin{array}{l}\text { TOTAL } \\
\text { (N) }\end{array}$ & $\begin{array}{c}100 \\
{[299]}\end{array}$ & $\begin{array}{c}100 \\
{[374]}\end{array}$ & $\begin{array}{c}100 \\
{[315]}\end{array}$ & $\begin{array}{c}100 \\
{[206]}\end{array}$ & $\begin{array}{c}100 \\
{[395]}\end{array}$ & $\begin{array}{c}100 \\
{[379]}\end{array}$ & $\begin{array}{c}100 \\
{[377]}\end{array}$ & $\begin{array}{c}100 \\
{[246]}\end{array}$ \\
\hline
\end{tabular}


DISTRIBUTION OF RESPONSES BY AGE AND SEX TO QUESTION,

"Including yourself, how many children were in your family lof originl?"

\begin{tabular}{lcccccccc}
\hline \multirow{2}{*}{$\begin{array}{l}\text { Number } \\
\text { Siblings }\end{array}$} & \multicolumn{3}{c}{ MEN } \\
\cline { 2 - 9 } & $\begin{array}{c}\text { under } \\
\text { 35 }\end{array}$ & $35-49$ & $50-65$ & $\begin{array}{c}\text { over } \\
65\end{array}$ & $\begin{array}{c}\text { under } \\
35\end{array}$ & $35-49$ & $50-65$ & $\begin{array}{c}\text { WOMEN } \\
65\end{array}$ \\
\hline N None & 12.3 & 16.8 & 17.4 & 15.3 & 13.6 & 15.0 & 12.2 & 11.8 \\
1 & 21.6 & 16.5 & 14.6 & 8.6 & 21.7 & 19.2 & 10.8 & 3.3 \\
2 & 21.9 & 16.0 & 10.4 & 8.6 & 24.5 & 17.8 & 15.3 & 10.6 \\
3 & 16.6 & 15.7 & 13.3 & 12.0 & 6.6 & 12.6 & 13.5 & 12.2 \\
4 & 9.0 & 8.8 & 6.3 & 12.0 & 6.6 & 10.0 & 11.6 & 15.4 \\
5 or more & 18.6 & 26.3 & 38.0 & 43.5 & 16.6 & 25.5 & 36.5 & 46.7 \\
\hline $\begin{array}{l}\text { TOTAL } \\
\text { (N) }\end{array}$ & 100 & 100 & 100 & 100 & 100 & 100 & 100 & 100 \\
\hline
\end{tabular}

DISTRIBUTION OF RESPONSES BY AGE AND SEX TO QUESTION,

"How many families who are relatives of yours live in or around Portland or Vancouver?"l*

\begin{tabular}{|c|c|c|c|c|c|c|c|c|}
\hline \multirow{2}{*}{$\begin{array}{l}\text { Number of } \\
\text { Relatives } \\
\text { Near }\end{array}$} & \multicolumn{4}{|c|}{ MEN } & \multicolumn{4}{|c|}{ WOMEN } \\
\hline & $\begin{array}{l}\text { under } \\
35\end{array}$ & $35-49$ & $50-65$ & $\begin{array}{l}\text { over } \\
65\end{array}$ & $\begin{array}{l}\text { under } \\
35\end{array}$ & $35-49$ & $50-65$ & $\begin{array}{l}\text { over } \\
65\end{array}$ \\
\hline O None & 9.0 & 15.4 & 14.6 & 15.8 & 9.8 & 15.7 & 11.9 & 15.0 \\
\hline 1 & 11.6 & 13.6 & 14.3 & 19.6 & 11.4 & 11.8 & 16.7 & 17.9 \\
\hline 2 & 5.6 & 9.6 & 13.0 & 18.2 & 8.1 & 10.5 & 13.8 & 16.7 \\
\hline 3 & 7.0 & 9.8 & 7.3 & 10.5 & 8.1 & 8.4 & 10.1 & 13.0 \\
\hline 4 & 9.3 & 10.9 & 7.0 & 9.1 & 9.3 & 10.0 & 9.5 & 7.7 \\
\hline 5 & 8.3 & 6.9 & 5.7 & 2.4 & 9.3 & 7.3 & 5.6 & 4.1 \\
\hline $\begin{array}{l}6 \text { or more } \\
\text { Missing=2 }\end{array}$ & 49.2 & 33.8 & 38.1 & 24.4 & 43.9 & 36.2 & 32.4 & 25.6 \\
\hline $\begin{array}{l}\text { TOTAL } \\
{[N]}\end{array}$ & $\begin{array}{c}100 \\
{[301]}\end{array}$ & $\begin{array}{c}100 \\
{[376\}}\end{array}$ & $\begin{array}{c}100 \\
{[315]}\end{array}$ & $\begin{array}{c}100 \\
(209)\end{array}$ & $\begin{array}{c}100 \\
{[396]}\end{array}$ & $\begin{array}{c}100 \\
{[381\}}\end{array}$ & $\begin{array}{c}100 \\
(377)\end{array}$ & $\begin{array}{c}100 \\
{[246]}\end{array}$ \\
\hline
\end{tabular}

*Asked of wife only who provided answers for both herself and husband. 
DISTRIBUTION OF RESPONSES BY AGE AND SEX TO QUESTION, "How many of these families do you see often?"

\begin{tabular}{|c|c|c|c|c|c|c|c|c|c|}
\hline \multirow{2}{*}{\multicolumn{2}{|c|}{$\begin{array}{l}\text { Near } \\
\text { Relatives } \\
\text { Families } \\
\text { See Often }\end{array}$}} & \multicolumn{4}{|c|}{ MEN } & \multicolumn{4}{|c|}{ WOMEN } \\
\hline & & $\begin{array}{c}\text { under } \\
35\end{array}$ & $35-49$ & $50-65$ & $\begin{array}{c}\text { over } \\
65\end{array}$ & $\begin{array}{c}\text { under } \\
35\end{array}$ & $35-49$ & $50-65$ & $\begin{array}{c}\text { over } \\
65\end{array}$ \\
\hline 0 & Have none & 11.6 & 21.0 & 20.6 & 24.2 & 14.1 & 21.0 & 18.4 & 21.1 \\
\hline 1 & $<$ half & 19.3 & 17.0 & 12.7 & 8.2 & 19.2 & 14.7 & 9.6 & 8.1 \\
\hline 2 & About half & 29.2 & 21.5 & 23.2 & 16.9 & 27.5 & 21.8 & 22.4 & 16.7 \\
\hline 3 & $A \mid 1$ & 39.9 & 40.4 & 43.5 & 50.7 & 39.1 & 42.5 & 49.6 & 54.1 \\
\hline & $\begin{array}{l}\text { TOTAL } \\
\text { [N] }\end{array}$ & $\begin{array}{c}100 \\
{[301]}\end{array}$ & $\begin{array}{c}100 \\
{[376\}}\end{array}$ & $\begin{array}{c}100 \\
{[315]}\end{array}$ & $\begin{array}{c}100 \\
\{207\}\end{array}$ & $\begin{array}{c}100 \\
\{396\}\end{array}$ & $\begin{array}{c}100 \\
(381)\end{array}$ & $\begin{array}{c}100 \\
(375)\end{array}$ & $\begin{array}{c}100 \\
(246)\end{array}$ \\
\hline
\end{tabular}

DISTRIBUTION OF RESPONSES BY AGE AND SEX TO QUESTION,

"How many other families who are relatives of yours

do you have who live within a day's drive of Portland or Vancouver?"*

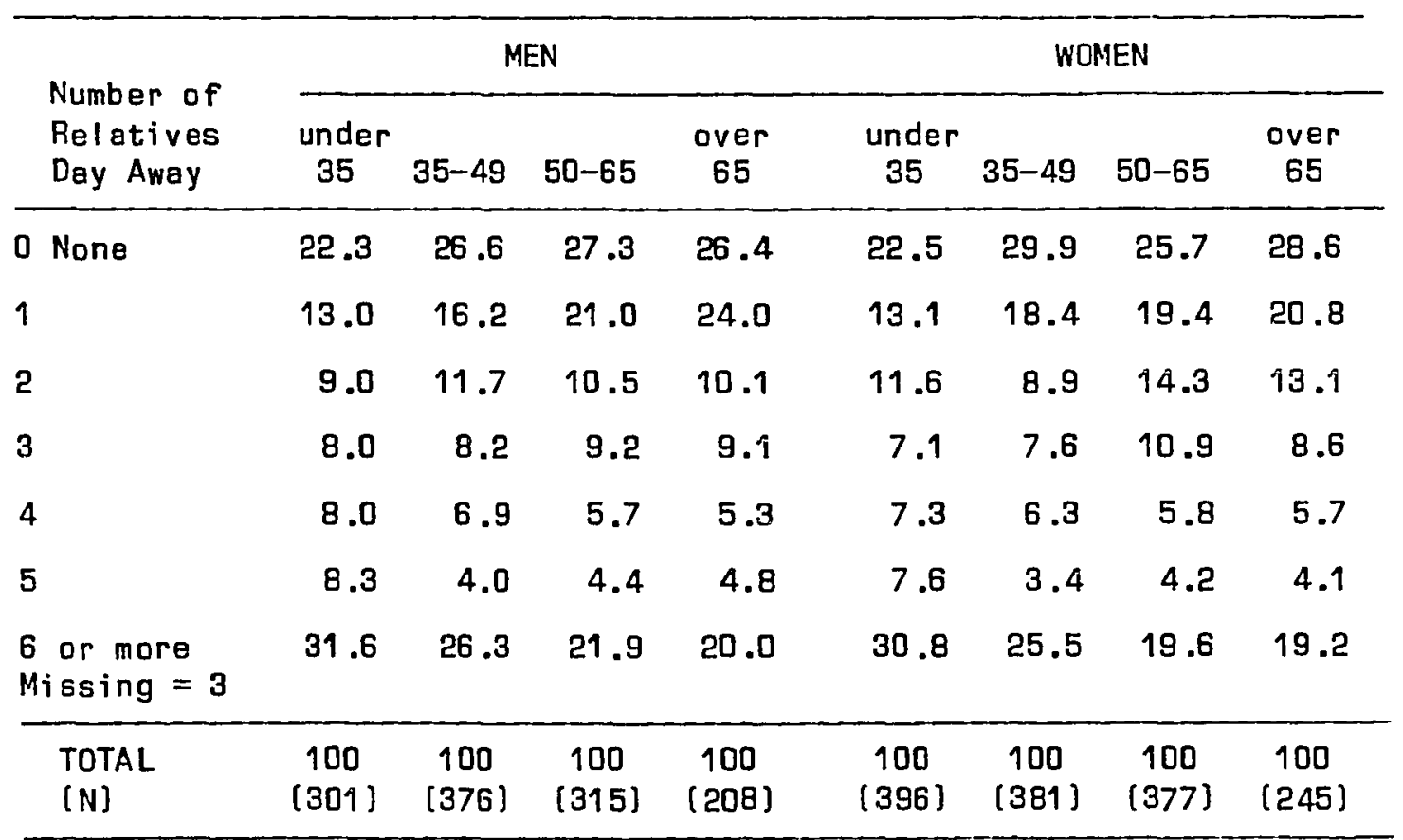

*Asked of wife only who provided answers for both herself and husband. 
DISTRIBUTION OF RESPONSES BY AGE AND SEX TO QUESTION, "How many of these [families] do you see fairly often?"\#

\begin{tabular}{|c|c|c|c|c|c|c|c|c|c|}
\hline \multirow{2}{*}{\multicolumn{2}{|c|}{$\begin{array}{l}\text { Relatives } \\
\text { Families } \\
\text { Sae One } \\
\text { Day Away }\end{array}$}} & \multicolumn{4}{|c|}{ MEN } & \multicolumn{4}{|c|}{ WOMEN } \\
\hline & & $\begin{array}{l}\text { under } \\
35\end{array}$ & $35-49$ & $50-65$ & $\begin{array}{c}\text { over } \\
65\end{array}$ & $\begin{array}{l}\text { under } \\
35\end{array}$ & $35-49$ & $50-65$ & $\begin{array}{c}\text { over } \\
65\end{array}$ \\
\hline 0 & None & 44.2 & 42.3 & 46.3 & 46.6 & 40.9 & 48.8 & 44.3 & 44.7 \\
\hline 1 & $<$ half & 20.6 & 16.5 & 14.3 & 11.5 & 19.7 & 14.4 & 13.8 & 9.4 \\
\hline 2 & About half & 18.6 & 18.4 & 13.3 & 13.0 & 19.4 & 14.7 & 16.4 & 14.8 \\
\hline 3 & All & 16.6 & 22.9 & 26.0 & 28.8 & 19.9 & 22.0 & 25.5 & 31.1 \\
\hline & $\begin{array}{l}\text { TOTAL } \\
{[\mathrm{N}]}\end{array}$ & $\begin{array}{c}100 \\
{[301]}\end{array}$ & $\begin{array}{c}100 \\
(376)\end{array}$ & $\begin{array}{c}100 \\
{[315]}\end{array}$ & $\begin{array}{c}100 \\
{[208]}\end{array}$ & $\begin{array}{c}100 \\
{[396]}\end{array}$ & $\begin{array}{c}100 \\
{[381]}\end{array}$ & $\begin{array}{c}100 \\
{[377]}\end{array}$ & $\begin{array}{c}100 \\
{[244]}\end{array}$ \\
\hline
\end{tabular}

DISTRIBUTION OF RESPONSES BY AGE AND SEX TO QUESTION, "Do you have any especially close friends-that is, people you feel free to talk with about personal things? How many do you have?"

\begin{tabular}{|c|c|c|c|c|c|c|c|c|}
\hline \multirow{2}{*}{$\begin{array}{l}\text { Number of } \\
\text { Close } \\
\text { Friends }\end{array}$} & \multicolumn{4}{|c|}{ MEN } & \multicolumn{4}{|c|}{ WOMEN } \\
\hline & $\begin{array}{l}\text { under } \\
35\end{array}$ & $35-49$ & $50-65$ & $\begin{array}{l}\text { over } \\
65\end{array}$ & $\begin{array}{l}\text { under } \\
35\end{array}$ & $35-49$ & $50-65$ & $\begin{array}{l}\text { over } \\
65\end{array}$ \\
\hline D None & 23.9 & 27.7 & 30.7 & 46.6 & 12.7 & 13.6 & 15.6 & 20.0 \\
\hline 1 & 9.0 & 6.9 & 4.7 & 5.8 & 12.2 & 16.0 & 12.2 & 10.6 \\
\hline 2 & 29.2 & 18.4 & 14.6 & 7.7 & 28.9 & 26.5 & 19.6 & 18.4 \\
\hline 3 & 12.6 & 13.3 & 12.3 & 9.1 & 24.8 & 19.2 & 20.4 & 17.6 \\
\hline 4 & 11.0 & 9.8 & 7.9 & 9.6 & 12.4 & 10.0 & 10.8 & 11.0 \\
\hline 5 & 11.3 & 18.9 & 17.4 & 12.5 & 8.6 & 12.9 & 17.5 & 16.3 \\
\hline $\begin{array}{l}6 \\
\text { Missing }=45\end{array}$ & 3.0 & 5.1 & 12.3 & 8.7 & 0.5 & 1.8 & 4.0 & 6.1 \\
\hline $\begin{array}{l}\text { TOTAL } \\
(\mathrm{N})\end{array}$ & $\begin{array}{c}100 \\
{[301\}}\end{array}$ & $\begin{array}{c}100 \\
{[376]}\end{array}$ & $\begin{array}{c}100 \\
{[316]}\end{array}$ & $\begin{array}{c}100 \\
{[208]}\end{array}$ & $\begin{array}{c}100 \\
{[395]}\end{array}$ & $\begin{array}{c}100 \\
(381)\end{array}$ & $\begin{array}{c}100 \\
\{378\}\end{array}$ & $\begin{array}{c}100 \\
{[245]}\end{array}$ \\
\hline
\end{tabular}

*Asked of wife only who provided answers for both herself and husband. 
DISTRIBUTION OF RESPONSES BY AGE AND SEX TO QUESTION,

"How often do you keep in touch with these especially close friends?"

\begin{tabular}{lccccccccc}
\hline $\begin{array}{l}\text { Frequency } \\
\text { See Close } \\
\text { Friends }\end{array}$ & \begin{tabular}{c} 
under \\
\cline { 3 - 8 }
\end{tabular} & $35-49$ & $50-65$ & $\begin{array}{c}\text { Mver } \\
65\end{array}$ & $\begin{array}{c}\text { under } \\
35\end{array}$ & $35-49$ & $50-65$ & $\begin{array}{c}\text { MVN } \\
65\end{array}$ \\
\hline $\begin{array}{l}\text { Never- } \\
\begin{array}{l}\text { (no close } \\
\text { friends })\end{array}\end{array}$ & 23.9 & 27.7 & 31.0 & 46.6 & 12.7 & 12.7 & 15.6 & 20.0 \\
$\begin{array}{l}\text { Seldom, } \\
\text { occasionally }\end{array}$ & 9.6 & 14.1 & 14.9 & 14.9 & 6.3 & 6.8 & 7.9 & 7.3 \\
2 Guite often & 27.9 & 25.3 & 26.3 & 17.8 & 22.5 & 26.3 & 27.8 & 21.2 \\
3 Very often & 38.5 & 32.8 & 27.8 & 20.7 & 58.5 & 53.2 & 48.7 & 51.4 \\
\hline $\begin{array}{l}\text { TOTAL } \\
\text { (N) }\end{array}$ & 100 & 100 & 100 & 100 & 100 & 100 & 100 & 100 \\
\hline
\end{tabular}

DISTRIBUTION OF RESPONSES BY AGE AND SEX TO QUESTION,

"How many different friends or families do you get together with throughout the year?"*

\begin{tabular}{|c|c|c|c|c|c|c|c|c|}
\hline \multirow{2}{*}{$\begin{array}{l}\text { Friends, } \\
\text { Families } \\
\text { See During } \\
\text { Year }\end{array}$} & \multicolumn{4}{|c|}{ MEN } & \multicolumn{4}{|c|}{ WOMEN } \\
\hline & $\begin{array}{c}\text { under } \\
35\end{array}$ & $35-49$ & $50-65$ & $\begin{array}{c}\text { over } \\
65\end{array}$ & $\begin{array}{c}\text { under } \\
35\end{array}$ & $35-49$ & $50-65$ & $\begin{array}{c}\text { over } \\
65\end{array}$ \\
\hline 1 A few & 25.6 & 32.2 & 41.6 & 52.4 & 25.5 & 34.6 & 44.3 & 42.6 \\
\hline 2 Some & 47.5 & 44.1 & 38.7 & 31.6 & 48.0 & 43.0 & 36.1 & 32.8 \\
\hline 3 Great many & 26.9 & 23.7 & 19.7 & 16.0 & 26.5 & 22.3 & 19.6 & 24.6 \\
\hline \multicolumn{9}{|l|}{ Missing $=5$} \\
\hline $\begin{array}{l}\text { TOTAL } \\
{[\mathrm{N}]}\end{array}$ & $\begin{array}{c}100 \\
\{301\}\end{array}$ & $\begin{array}{c}100 \\
(376)\end{array}$ & $\begin{array}{c}100 \\
{[315]}\end{array}$ & $\begin{array}{c}100 \\
(206)\end{array}$ & $\begin{array}{c}100 \\
{[396]}\end{array}$ & $\begin{array}{c}100 \\
{[381]}\end{array}$ & $\begin{array}{c}100 \\
{[377]}\end{array}$ & $\begin{array}{c}100 \\
{[244]}\end{array}$ \\
\hline
\end{tabular}

*Asked of wife only who provided answers for both herself and husband. 
DISTRIBUTION OF RESPONSES BY AGE AND SEX TO QUESTION, "How often do you get together with friends?"*

\begin{tabular}{|c|c|c|c|c|c|c|c|c|}
\hline \multirow{2}{*}{$\begin{array}{l}\text { How Often } \\
\text { Get With } \\
\text { Friends }\end{array}$} & \multicolumn{4}{|c|}{ MEN } & \multicolumn{4}{|c|}{ WOMEN } \\
\hline & $\begin{array}{l}\text { under } \\
35\end{array}$ & $35-49$ & $50-65$ & $\begin{array}{c}\text { over } \\
65\end{array}$ & $\begin{array}{c}\text { under } \\
35\end{array}$ & $35-49$ & $50-65$ & $\begin{array}{c}\text { over } \\
65\end{array}$ \\
\hline 1 Rarely & 7.7 & 14.7 & 20.6 & 27.1 & 8.4 & 18.4 & 20.2 & 21.3 \\
\hline 2 Occasionally & 40.1 & 41.1 & 30.2 & 34.8 & 41.3 & 37.0 & 34.6 & 29.9 \\
\hline 3 Frequently & 51.3 & 44.3 & 49.2 & 38.2 & 50.4 & 44.6 & 45.2 & 48.8 \\
\hline \multicolumn{9}{|l|}{ Missing $=8$} \\
\hline $\begin{array}{c}\text { TOTAL } \\
\text { [N] }\end{array}$ & $\begin{array}{c}100 \\
(300)\end{array}$ & $\begin{array}{c}100 \\
(375)\end{array}$ & $\begin{array}{c}100 \\
{[315]}\end{array}$ & $\begin{array}{c}100 \\
{[207]}\end{array}$ & $\begin{array}{c}100 \\
{[395]}\end{array}$ & $\begin{array}{c}100 \\
{[381]}\end{array}$ & $\begin{array}{c}100 \\
{[376]}\end{array}$ & $\begin{array}{c}100 \\
{[244]}\end{array}$ \\
\hline
\end{tabular}

DISTRIBUTION OF RESPONSES BY AGE AND SEX TO QUESTION,

"About how many other employees do you see and talk to at work during a typical day?"

\begin{tabular}{|c|c|c|c|c|c|c|c|c|c|}
\hline \multirow{2}{*}{\multicolumn{2}{|c|}{$\begin{array}{l}\text { Coworkers } \\
\text { Interact } \\
\text { With }\end{array}$}} & \multicolumn{4}{|c|}{ MEN } & \multicolumn{4}{|c|}{ WOMEN } \\
\hline & & $\begin{array}{c}\text { under } \\
35\end{array}$ & $35-49$ & $50-65$ & $\begin{array}{c}\text { over } \\
65\end{array}$ & $\underset{35}{\text { under }}$ & $35-49$ & $50-65$ & $\begin{array}{c}\text { over } \\
65\end{array}$ \\
\hline \multirow{3}{*}{\multicolumn{2}{|c|}{$\begin{array}{l}\text { Not working } \\
0 \text { or don't } \\
\text { interect } \\
11-2\end{array}$}} & & & & & & & & \\
\hline & & 8.5 & 7.9 & 24.9 & 93.2 & 60.4 & 49.3 & 53.5 & 92.7 \\
\hline & & 4.1 & 6.0 & 3.2 & 1.5 & 2.3 & 2.9 & 4.0 & 0 \\
\hline 2 & $3-10$ & 31.5 & 30.4 & 27.2 & 1.5 & 15.4 & 20.7 & 16.2 & 4.1 \\
\hline 3 & $11-25$ & 36.3 & 33.9 & 25.6 & 2.9 & 14.4 & 18.4 & 17.0 & 2.0 \\
\hline \multirow[t]{2}{*}{4} & Over 25 & 19.7 & 22.0 & 19.2 & 1.0 & 7.6 & 8.7 & 9.3 & 1.2 \\
\hline & $\begin{array}{l}\text { TOTAL } \\
\text { (N] }\end{array}$ & $\begin{array}{c}100 \\
\{295\}\end{array}$ & $\begin{array}{c}100 \\
{[369\}}\end{array}$ & $\begin{array}{c}100 \\
(313)\end{array}$ & $\begin{array}{c}100 \\
{[206]}\end{array}$ & $\begin{array}{c}100 \\
{[396]}\end{array}$ & $\begin{array}{c}100 \\
{[381]}\end{array}$ & $\begin{array}{c}100 \\
\{376\}\end{array}$ & $\begin{array}{c}100 \\
{[246]}\end{array}$ \\
\hline
\end{tabular}

*Asked of wife only who provided answers for both herself and husband. 
DISTRIBUTION OF RESPONSES BY AGE AND SEX TO QUESTION, "How often do you spend time away from the job with your coworkers ?"

\begin{tabular}{|c|c|c|c|c|c|c|c|c|}
\hline \multirow{2}{*}{$\begin{array}{l}\text { Frequency } \\
\text { See Co- } \\
\text { Workers } \\
\text { Outside Worl }\end{array}$} & \multicolumn{4}{|c|}{ MEN } & \multicolumn{4}{|c|}{ WOMEN } \\
\hline & $\begin{array}{l}\text { under } \\
k 35\end{array}$ & $35-49$ & $50-65$ & $\begin{array}{l}\text { over } \\
65\end{array}$ & $\begin{array}{l}\text { under } \\
35\end{array}$ & $35-49$ & $50-65$ & $\begin{array}{c}\text { over } \\
65\end{array}$ \\
\hline $\begin{array}{l}\text { Not working } \\
0 \text { or don't see }\end{array}$ & 5.1 & 4.1 & 19.4 & 90.2 & 58.8 & 47.0 & 51.2 & 91.9 \\
\hline 1 Rarely & 34.4 & 39.7 & 48.9 & 5.4 & 21.5 & 29.9 & 26.9 & 3.7 \\
\hline 2 Dccasionally & 51.7 & 48.9 & 28.2 & 4.4 & 17.4 & 19.9 & 20.5 & 4.4 \\
\hline 3 Very often & 8.8 & 7.3 & 3.6 & 0 & 2.3 & 3.1 & 1.3 & 0 \\
\hline \multicolumn{9}{|l|}{ Missing $=32$} \\
\hline $\begin{array}{l}\text { TOTAL } \\
\text { (N) }\end{array}$ & $\begin{array}{c}100 \\
{[294]}\end{array}$ & $\begin{array}{c}100 \\
{[368]}\end{array}$ & $\begin{array}{c}100 \\
{[309]}\end{array}$ & $\begin{array}{c}100 \\
{[205]}\end{array}$ & $\begin{array}{c}100 \\
(396)\end{array}$ & $\begin{array}{c}100 \\
(381)\end{array}$ & $\begin{array}{c}100 \\
{[375]}\end{array}$ & $\begin{array}{c}100 \\
{[246]}\end{array}$ \\
\hline
\end{tabular}

DISTRIBUTION OF RESPONSES BY AGE AND SEX TO QUESTION,

"Here is a list of various kinds of organizations.

Do you belong to any of these organizations, clubs or groups? How many? How often do you attend meetings of this organization?"

\begin{tabular}{|c|c|c|c|c|c|c|c|c|c|}
\hline \multirow{2}{*}{\multicolumn{2}{|c|}{$\begin{array}{l}\text { Frequency } \\
\text { Attend Meet- } \\
\text { ings Organ- } \\
\text { ization \#1 }\end{array}$}} & \multicolumn{4}{|c|}{ MEN } & \multicolumn{4}{|c|}{ WOMEN } \\
\hline & & $\begin{array}{l}\text { under } \\
35\end{array}$ & $35-49$ & $50-65$ & $\begin{array}{l}\text { over } \\
65\end{array}$ & $\begin{array}{l}\text { under } \\
35\end{array}$ & $35-49$ & $50-65$ & $\begin{array}{c}\text { over } \\
65\end{array}$ \\
\hline 0 & $\begin{array}{l}\text { Inepprop. } \\
\text { or never }\end{array}$ & 38.5 & 26.1 & 29.6 & 44.5 & 48.1 & 36.5 & 44.4 & 42.7 \\
\hline 1 & Sel dom & 24.4 & 24.3 & 24.2 & 15.3 & 12.5 & 13.5 & 12.2 & 12.2 \\
\hline 2 & Occasionally & 13.4 & 24.8 & 24.8 & 20.6 & 12.7 & 20.5 & 17.0 & 15.4 \\
\hline 3 & Regularly & 2.3 .7 & 24.8 & 21.3 & 19.6 & 26.8 & 29.7 & 26.3 & 29.7 \\
\hline & $\begin{array}{l}\text { TOTAL } \\
\text { (N) }\end{array}$ & $\begin{array}{c}100 \\
(299)\end{array}$ & $\begin{array}{c}100 \\
(375)\end{array}$ & $\begin{array}{c}100 \\
(318)\end{array}$ & $\begin{array}{c}100 \\
{[209]}\end{array}$ & $\begin{array}{c}100 \\
{[395]}\end{array}$ & $\begin{array}{c}100 \\
(381)\end{array}$ & $\begin{array}{c}100 \\
(376)\end{array}$ & $\begin{array}{c}100 \\
{[246]}\end{array}$ \\
\hline
\end{tabular}


DISTRIBUTION OF RESPONSES BY AGE AND SEX TO QUESTION,

"How often do you attend meetings of a second organization?"

\begin{tabular}{|c|c|c|c|c|c|c|c|c|c|}
\hline \multirow{2}{*}{\multicolumn{2}{|c|}{$\begin{array}{l}\text { Frequency } \\
\text { Attend } \\
\text { Meetings } \\
\text { Organ. \#2 }\end{array}$}} & \multicolumn{4}{|c|}{ MEN } & \multicolumn{4}{|c|}{ WOMEN } \\
\hline & & $\begin{array}{l}\text { under } \\
35\end{array}$ & $35-49$ & $50-65$ & $\begin{array}{l}\text { over } \\
65\end{array}$ & $\begin{array}{l}\text { under } \\
35\end{array}$ & $35-49$ & $50-65$ & $\begin{array}{c}\text { over } \\
65\end{array}$ \\
\hline 0 & $\begin{array}{l}\text { Never, } \\
\text { inapprop. }\end{array}$ & 62.5 & 48.8 & 60.8 & 71.8 & 70.6 & 55.3 & 67.9 & 66.7 \\
\hline 1 & Sel dom & 10.0 & 16.8 & 9.5 & 8.6 & 5.8 & 8.7 & 7.7 & 4.5 \\
\hline 2 & Occasionally & 9.0 & 12.3 & 12.7 & 6.2 & 4.3 & 12.6 & 6.9 & 8.5 \\
\hline 3 & Regularly & 18.4 & 22.1 & 17.1 & 13.4 & 19.2 & 23.4 & 17.5 & 20.3 \\
\hline & $\begin{array}{l}\text { TOTAL } \\
{[N]}\end{array}$ & $\begin{array}{c}100 \\
{[299]}\end{array}$ & $\begin{array}{c}100 \\
{[370]}\end{array}$ & $\begin{array}{c}100 \\
{[316]}\end{array}$ & $\begin{array}{c}100 \\
{[209]}\end{array}$ & $\begin{array}{c}100 \\
{[395]}\end{array}$ & $\begin{array}{c}100 \\
{[380]}\end{array}$ & $\begin{array}{c}100 \\
(377)\end{array}$ & $\begin{array}{c}100 \\
(246)\end{array}$ \\
\hline
\end{tabular}

DISTRIBUTION OF RESPONSES BY AGE AND SEX TO QUESTION,

"How often do you attend meetings of a third organization?"

\begin{tabular}{lccccccccc}
\hline Frequency & \multicolumn{4}{c}{ MEN } & \multicolumn{4}{c}{ WOMEN } \\
\cline { 2 - 8 } $\begin{array}{l}\text { Attend of } \\
\text { Meetings }\end{array}$ & under & & & over & under & & & over \\
Organ. \#3 & 35 & $35-49$ & $50-65$ & 65 & 35 & $35-49$ & $50-65$ & 65 \\
\hline
\end{tabular}

Never,

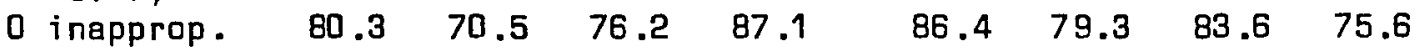

$\begin{array}{lllllllll}1 \text { Seldom } & 3.3 & 4.8 & 5.1 & 3.8 & 2.3 & 3.7 & 3.4 & 4.5\end{array}$

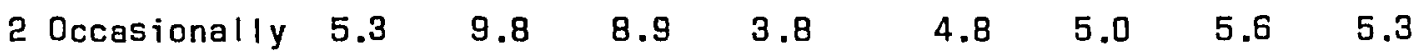

$\begin{array}{lllllllll}3 \text { Regularly } & 11.0 & 14.9 & 9.8 & 5.8 & 6.6 & 12.1 & 7.4 & 94.6\end{array}$

\begin{tabular}{lcccccccc}
\hline $\begin{array}{l}\text { TOTAL } \\
(N)\end{array}$ & 100 & 100 & 100 & 100 & 100 & 100 & 100 & 100 \\
{$[300)$} & {$[376)$} & {$[315]$} & {$[209]$} & {$[396]$} & {$[380]$} & {$[377]$} & {$[246]$} \\
\hline
\end{tabular}


DISTRIBUTION OF RESPONSES BY AGE AND SEX TO QUESTION,

"How often do you attend meetings of a fourth organization?"

\begin{tabular}{|c|c|c|c|c|c|c|c|c|c|}
\hline \multirow{2}{*}{\multicolumn{2}{|c|}{$\begin{array}{l}\text { Frequency } \\
\text { Attend } \\
\text { Meetings } \\
\text { Organ. } 4\end{array}$}} & \multicolumn{4}{|c|}{ MEN } & \multicolumn{4}{|c|}{ WOMEN } \\
\hline & & $\begin{array}{l}\text { under } \\
35\end{array}$ & $35-49$ & $50-65$ & $\begin{array}{c}\text { over } \\
65\end{array}$ & $\begin{array}{l}\text { under } \\
35\end{array}$ & $35-49$ & $50-65$ & $\begin{array}{c}\text { over } \\
65\end{array}$ \\
\hline 0 & $\begin{array}{l}\text { Never, } \\
\text { inapprop. }\end{array}$ & 92.0 & 85.4 & 89.2 & 93.3 & 94.7 & 91.1 & 92.9 & 87.0 \\
\hline 1 & Sel dom & 1.3 & 2.9 & 2.5 & 1.9 & 1.5 & 2.1 & 0.5 & 0.8 \\
\hline 2 & Occasionally & 1.7 & 2.9 & 3.8 & 1.9 & 0.8 & 1.0 & 2.4 & 2.4 \\
\hline 3 & Regularly & 5.0 & 8.8 & 4.4 & 2.9 & 3.0 & 5.8 & 4.2 & 9.8 \\
\hline & $\begin{array}{l}\text { TOTAL } \\
{[N]}\end{array}$ & $\begin{array}{c}100 \\
{[301]}\end{array}$ & $\begin{array}{c}100 \\
{[376]}\end{array}$ & $\begin{array}{c}100 \\
(316)\end{array}$ & $\begin{array}{c}100 \\
{[209]}\end{array}$ & $\begin{array}{c}100 \\
{[396]}\end{array}$ & $\begin{array}{c}100 \\
{[381]}\end{array}$ & $\begin{array}{c}100 \\
{[378]}\end{array}$ & $\begin{array}{c}100 \\
{[246]}\end{array}$ \\
\hline
\end{tabular}

DISTRIBUTION OF RESPONSES BY AGE AND SEX TO QUESTION, "How often do you attend meetings of a fifth organization?"

\begin{tabular}{|c|c|c|c|c|c|c|c|c|c|}
\hline \multirow{2}{*}{\multicolumn{2}{|c|}{$\begin{array}{l}\text { Frequency } \\
\text { Attend } \\
\text { Meetings } \\
\text { Organ. \#5 }\end{array}$}} & \multicolumn{4}{|c|}{ MEN } & \multicolumn{4}{|c|}{ WOMEN } \\
\hline & & $\begin{array}{l}\text { under } \\
35\end{array}$ & $35-49$ & $50-65$ & $\begin{array}{c}\text { over } \\
65\end{array}$ & $\begin{array}{l}\text { under } \\
35\end{array}$ & $35-49$ & $50-65$ & $\begin{array}{c}\text { over } \\
65\end{array}$ \\
\hline 0 & $\begin{array}{l}\text { Never, } \\
\text { inapprop. }\end{array}$ & 96.3 & 92.3 & 94.3 & 97.1 & 96.7 & 96.1 & 95.5 & 93.1 \\
\hline 1 & Sel dom & 0.3 & 0.8 & 2.2 & 0 & 0.8 & 1.0 & 0.8 & 0.8 \\
\hline 2 & Dccasionally & 0.7 & 2.1 & 1.3 & 0 & 1.0 & 1.0 & 1.6 & 2.4 \\
\hline 3 & Regularly & 2.7 & 4.8 & 2.2 & 2.9 & 1.5 & 1.8 & 1.7 & 3.7 \\
\hline & $\begin{array}{l}\text { TOTAL } \\
\text { (N] }\end{array}$ & $\begin{array}{c}100 \\
(300)\end{array}$ & $\begin{array}{c}100 \\
{[376]}\end{array}$ & $\begin{array}{c}100 \\
{[316]}\end{array}$ & $\begin{array}{c}100 \\
{[209]}\end{array}$ & $\begin{array}{c}100 \\
{[396]}\end{array}$ & $\begin{array}{c}100 \\
(381)\end{array}$ & $\begin{array}{c}100 \\
{[378]}\end{array}$ & $\begin{array}{c}100 \\
{[246]}\end{array}$ \\
\hline
\end{tabular}


DISTRIBUTION OF RESPONSES BY AGE AND SEX TO QUESTION, "How often do you attend meetings of $a$ sixth organization?"

\begin{tabular}{|c|c|c|c|c|c|c|c|c|c|}
\hline \multirow{2}{*}{\multicolumn{2}{|c|}{$\begin{array}{l}\text { Frequency } \\
\text { Attend } \\
\text { Meetings } \\
\text { Organ. \#6 }\end{array}$}} & \multicolumn{4}{|c|}{ MEN } & \multicolumn{4}{|c|}{ WOMEN } \\
\hline & & $\begin{array}{l}\text { under } \\
35\end{array}$ & $35-49$ & $50-65$ & $\begin{array}{l}\text { Over } \\
65\end{array}$ & $\begin{array}{l}\text { under } \\
35\end{array}$ & $35-49$ & $50-65$ & $\begin{array}{l}\text { over } \\
65\end{array}$ \\
\hline 0 & $\begin{array}{l}\text { Never, } \\
\text { inapprop. }\end{array}$ & 98.0 & 95.2 & 97.5 & 98.6 & 98.5 & 97.9 & 99.2 & 94.7 \\
\hline 1 & Sel dom & 0.3 & 2.7 & 1.3 & 1.0 & 0.5 & 0.5 & 0 & 0.4 \\
\hline 2 & Occasionally & 1.3 & 0.8 & 0.9 & 0 & 0 & 0.3 & 0.3 & 0.8 \\
\hline 3 & Regularly & 0.3 & 1.3 & 0.3 & 0.5 & 1.0 & 1.3 & 0.5 & 4.1 \\
\hline & $\begin{array}{l}\text { TOTAL } \\
(N)\end{array}$ & $\begin{array}{c}100 \\
(301)\end{array}$ & $\begin{array}{c}100 \\
(376)\end{array}$ & $\begin{array}{c}100 \\
{[316]}\end{array}$ & $\begin{array}{c}100 \\
{[209]}\end{array}$ & $\begin{array}{c}100 \\
(396)\end{array}$ & $\begin{array}{c}100 \\
{[381]}\end{array}$ & $\begin{array}{c}100 \\
{[378]}\end{array}$ & $\begin{array}{l}100 \\
246\}\end{array}$ \\
\hline
\end{tabular}

DISTRIBUTION OF RESPONSES BY AGE AND SEX TO QUESTION, "If you attend church (or synagogua), how often do you usually attend?"

\begin{tabular}{|c|c|c|c|c|c|c|c|c|c|}
\hline \multirow{2}{*}{\multicolumn{2}{|c|}{$\begin{array}{l}\text { Frequency } \\
\text { Attend } \\
\text { Church }\end{array}$}} & \multicolumn{4}{|c|}{ MEN } & \multicolumn{4}{|c|}{ WOMEN } \\
\hline & & $\begin{array}{l}\text { under } \\
35\end{array}$ & $35-49$ & $50-65$ & $\begin{array}{l}\text { over } \\
65\end{array}$ & $\begin{array}{l}\text { under } \\
35\end{array}$ & $35-49$ & $50-65$ & $\begin{array}{c}\text { over } \\
65\end{array}$ \\
\hline 0 & Never & 31.7 & 30.8 & 26.6 & 38.1 & 24.5 & 23.0 & 21.1 & 22.8 \\
\hline & $\begin{array}{l}\text { Few times } \\
\text { a year }\end{array}$ & 39.9 & 32.1 & 39.3 & 23.9 & 34.0 & 29.7 & 28.5 & 22.0 \\
\hline 2 & Monthiy & 5.5 & 6.6 & 6.6 & 5.6 & 7.7 & 9.6 & 8.4 & 7.9 \\
\hline 3 & $\begin{array}{l}\text { Several } \\
\text { times a mo. }\end{array}$ & 5.1 & 8.8 & 4.3 & 3.0 & 9.0 & 8.6 & 9.1 & 8.3 \\
\hline 4 & & 13.0 & 15.4 & 16.7 & 24.4 & 18.8 & 20.3 & 22.5 & 27.8 \\
\hline 5 & $\begin{array}{l}\text { More than } \\
\text { once weekly }\end{array}$ & 4.8 & 6.3 & 6.6 & 5.1 & 5.9 & 8.8 & 10.3 & 11.2 \\
\hline & $\begin{array}{l}\text { TOTAL } \\
(N)\end{array}$ & $\begin{array}{c}100 \\
{[293]}\end{array}$ & $\begin{array}{c}100 \\
{[364]}\end{array}$ & $\begin{array}{c}100 \\
{[305]}\end{array}$ & $\begin{array}{c}100 \\
{[197]}\end{array}$ & $\begin{array}{c}100 \\
(388)\end{array}$ & $\begin{array}{c}100 \\
{[374]}\end{array}$ & $\begin{array}{c}100 \\
{[364]}\end{array}$ & $\begin{array}{c}100 \\
{[246]}\end{array}$ \\
\hline
\end{tabular}


DISTRIBUTION OF RESPONSES BY AGE AND SEX TO QUESTION,

"What are some of the things you do in your leisure or spare time, when you are not working?"

\begin{tabular}{|c|c|c|c|c|c|c|c|c|}
\hline \multirow{2}{*}{$\begin{array}{l}\text { Social } \\
\text { Lei sure } \\
\text { Score } \\
\text { (Collapsed] }\end{array}$} & \multicolumn{4}{|c|}{ MEN } & \multicolumn{4}{|c|}{ WOMEN } \\
\hline & $\begin{array}{l}\text { under } \\
35\end{array}$ & $35-49$ & $50-65$ & $\begin{array}{l}\text { over } \\
65\end{array}$ & $\begin{array}{l}\text { under } \\
35\end{array}$ & $35-49$ & $50-65$ & $\begin{array}{l}\text { over } \\
65\end{array}$ \\
\hline $\begin{array}{l}0 \text { No social, } \\
\text { leisure }\end{array}$ & 11.1 & 16.7 & 25.3 & 37.3 & 13.2 & 13.0 & 20.4 & 21.3 \\
\hline 1 & 33.6 & 27.9 & 32.1 & 28.0 & 19.7 & 20.4 & 25.5 & 29.8 \\
\hline 2 & 22.8 & 24.1 & 17.3 & 23.8 & 26.1 & 24.6 & 21.4 & 20.9 \\
\hline 3 & 18.3 & 16.7 & 16.7 & 7.3 & 20.3 & 19.8 & 18.8 & 16.6 \\
\hline 4 & 8.3 & 10.4 & 7.4 & 1.6 & 11.9 & 11.6 & 8.6 & 8.5 \\
\hline 5 Maximum & 5.9 & 4.1 & 1.3 & 2.1 & 8.9 & 10.6 & 5.4 & 3.0 \\
\hline \multicolumn{9}{|l|}{ Missing $=63$} \\
\hline $\begin{array}{l}\text { TOTAL } \\
{[N]}\end{array}$ & $\begin{array}{c}100 \\
{[289]}\end{array}$ & $\begin{array}{c}100 \\
{[365]}\end{array}$ & $\begin{array}{c}100 \\
{[312]}\end{array}$ & $\begin{array}{c}100 \\
{[193]}\end{array}$ & $\begin{array}{c}100 \\
{[395]}\end{array}$ & $\begin{array}{c}100 \\
{[378]}\end{array}$ & $\begin{array}{c}100 \\
{[373]}\end{array}$ & $\begin{array}{c}100 \\
{[235]}\end{array}$ \\
\hline
\end{tabular}

DISTRIBUTION OF RESPONSES BY AGE AND SEX TO QUESTION,

"How frequently do you keep in touch through telephone calls or letters with relatives who live away from the Portland area?"*

\begin{tabular}{|c|c|c|c|c|c|c|c|c|}
\hline \multirow{2}{*}{$\begin{array}{l}\text { Frequency } \\
\text { Contact f } \\
\text { Relatives } \\
\text { Far Away }\end{array}$} & \multicolumn{4}{|c|}{ MEN } & \multicolumn{4}{|c|}{ WOMEN } \\
\hline & $\begin{array}{l}\text { under } \\
35\end{array}$ & $35-49$ & $50-65$ & $\begin{array}{l}\text { over } \\
65\end{array}$ & $\begin{array}{l}\text { under } \\
35\end{array}$ & $35-49$ & $50-65$ & $\begin{array}{l}\text { over } \\
65\end{array}$ \\
\hline 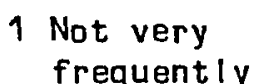 & 35.5 & 36.9 & 28.6 & 28.2 & 34.4 & 31.6 & 28.1 & 27.6 \\
\hline $\begin{array}{l}2 \text { Somewhat } \\
\text { regularly }\end{array}$ & 36.8 & 35.8 & 36.7 & 36.9 & 35.9 & 37.3 & 37.3 & 30.3 \\
\hline $\begin{array}{l}3 \text { Very } \\
\text { frequently } \\
\text { Missing }=74\end{array}$ & 27.7 & 27.4 & 34.7 & 34.9 & 29.8 & 31.1 & 34.6 & 42.1 \\
\hline $\begin{array}{l}\text { TOTAL } \\
{[N]}\end{array}$ & $\begin{array}{c}100 \\
{[296]}\end{array}$ & $\begin{array}{c}100 \\
{[369]}\end{array}$ & $\begin{array}{c}100 \\
(311)\end{array}$ & $\begin{array}{c}100 \\
(195)\end{array}$ & $\begin{array}{c}100 \\
{[393\}}\end{array}$ & $\begin{array}{c}100 \\
(367)\end{array}$ & $\begin{array}{c}100 \\
{[370]}\end{array}$ & $\begin{array}{c}100 \\
{[228]}\end{array}$ \\
\hline
\end{tabular}

*Asked of wife only who provided answers for both herself and husband. 


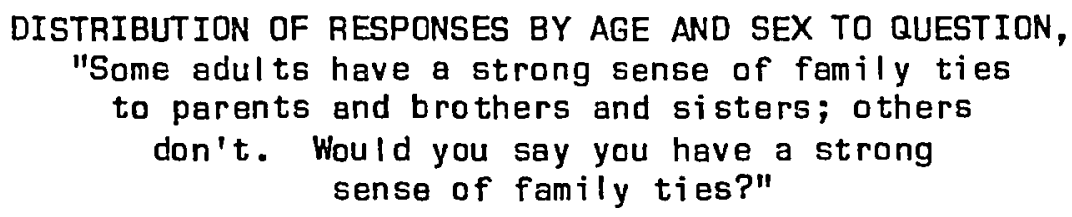

\begin{tabular}{|c|c|c|c|c|c|c|c|c|}
\hline \multirow{2}{*}{$\begin{array}{l}\text { Strength of } \\
\text { Family ties }\end{array}$} & \multicolumn{4}{|c|}{ MEN } & \multicolumn{4}{|c|}{ WOMEN } \\
\hline & $\begin{array}{l}\text { under } \\
35\end{array}$ & $35-49$ & $50-65$ & $\begin{array}{l}\text { over } \\
65\end{array}$ & $\begin{array}{l}\text { under } \\
35\end{array}$ & $35-49$ & $50-65$ & $\begin{array}{c}\text { over } \\
65\end{array}$ \\
\hline $\begin{array}{l}1 \text { Not very } \\
\text { strong }\end{array}$ & 20.5 & 29.8 & 25.8 & 26.2 & 10.7 & 14.4 & 11.7 & 10.8 \\
\hline $\begin{array}{l}2 \text { Fairly } \\
\text { strong }\end{array}$ & 42.7 & 42.1 & 38.1 & 32.6 & 40.6 & 34.0 & 34.9 & 26.5 \\
\hline 3 Very strong & 36.9 & 28.1 & 36.1 & 41.3 & 48.7 & 51.6 & 53.4 & 62.8 \\
\hline \multicolumn{9}{|l|}{ Missing $=74$} \\
\hline $\begin{array}{l}\text { TOTAL } \\
\text { (N) }\end{array}$ & $\begin{array}{c}100 \\
{[293]}\end{array}$ & $\begin{array}{c}100 \\
{[359]}\end{array}$ & $\begin{array}{c}100 \\
{[291]}\end{array}$ & $\begin{array}{c}100 \\
(172)\end{array}$ & $\begin{array}{c}100 \\
(394)\end{array}$ & $\begin{array}{c}100 \\
{[376]}\end{array}$ & $\begin{array}{c}100 \\
{[367]}\end{array}$ & $\begin{array}{c}100 \\
{[223]}\end{array}$ \\
\hline
\end{tabular}

DISTRIBUTION OF RESPONSES BY AGE AND SEX TO QUESTION,

"While you were growing up, how close knit would you say your family was?"

\begin{tabular}{lccccccccc}
\hline & \multicolumn{3}{c}{ MEN } & \multicolumn{5}{c}{ WOMEN } \\
\cline { 2 - 9 } $\begin{array}{l}\text { Family } \\
\text { Close Knit }\end{array}$ & $\begin{array}{c}\text { under } \\
35\end{array}$ & $35-49$ & $50-65$ & $\begin{array}{c}\text { over } \\
65\end{array}$ & $\begin{array}{c}\text { under } \\
35\end{array}$ & $35-49$ & $50-65$ & $\begin{array}{c}\text { over } \\
65\end{array}$ \\
\hline Not very & 16.0 & 12.8 & 10.6 & 8.3 & 14.4 & 12.1 & 7.2 & 8.1 \\
2 Somewhat & 41.0 & 48.2 & 41.9 & 44.3 & 42.0 & 37.2 & 35.3 & 29.7 \\
3 Extremely & 43.0 & 39.0 & 47.4 & 47.3 & 43.5 & 50.7 & 57.5 & 62.3 \\
Missing = 55 & & & & & & & & \\
\hline $\begin{array}{l}\text { TOTAL } \\
\text { (N) }\end{array}$ & 100 & 100 & 100 & 100 & 100 & 100 & 100 & 100 \\
\hline
\end{tabular}


DISTRIBUTION OF RESPONSES BY AGE AND SEX TO QUESTION,

"About how many families in this neighborhood do you know well enough to drop in on unexpectedly for a visit?"*

\begin{tabular}{|c|c|c|c|c|c|c|c|c|}
\hline \multirow[b]{2}{*}{ Nei ghbors } & \multicolumn{4}{|c|}{ 价EN } & \multicolumn{4}{|c|}{ WOMEN } \\
\hline & $\begin{array}{c}\text { under } \\
35\end{array}$ & $35-49$ & $50-55$ & $\begin{array}{c}\text { over } \\
65\end{array}$ & $\begin{array}{c}\text { under } \\
35\end{array}$ & $35-49$ & $50-65$ & $\begin{array}{c}\text { over } \\
65\end{array}$ \\
\hline D None & 14.7 & 11.7 & 15.2 & 13.0 & 14.6 & 14.2 & 15.7 & 10.3 \\
\hline 1 & 18.0 & 6.1 & 9.8 & 8.7 & 13.6 & 8.4 & 9.3 & 8.3 \\
\hline 2 & 14.7 & 14.4 & 10.2 & 14.0 & 15.7 & 14.2 & 12.8 & 15.3 \\
\hline 3 & 12.0 & 12.5 & 14.9 & 12.6 & 12.4 & 12.9 & 14.6 & 9.5 \\
\hline 4 & 10.7 & 11.7 & 11.7 & 6.3 & 11.1 & 11.0 & 10.1 & 9.1 \\
\hline 5 & 5.7 & 8.5 & 7.6 & 7.2 & 7.6 & 6.6 & 7.7 & 7.4 \\
\hline 6 or more & 24.3 & 35.1 & 30.5 & 38.2 & 25.0 & 32.8 & 29.8 & 40.1 \\
\hline \multicolumn{9}{|l|}{ Missing $=10$} \\
\hline $\begin{array}{l}\text { TOTAL } \\
{[N]}\end{array}$ & $\begin{array}{c}100 \\
(300)\end{array}$ & $\begin{array}{c}100 \\
{[376]}\end{array}$ & $\begin{array}{c}100 \\
(315)\end{array}$ & $\begin{array}{c}100 \\
(207)\end{array}$ & $\begin{array}{c}100 \\
{[396]}\end{array}$ & $\begin{array}{c}100 \\
{[381]}\end{array}$ & $\begin{array}{c}100 \\
{[376]}\end{array}$ & $\begin{array}{c}100 \\
{[242]}\end{array}$ \\
\hline
\end{tabular}

*Asked of wife only who provided answers for both herself and husband. 
APPENDIX D

OVERVIEW BOXES FOR SOCIAL NETWORK INDEXES 


\section{FAMSCOP1}

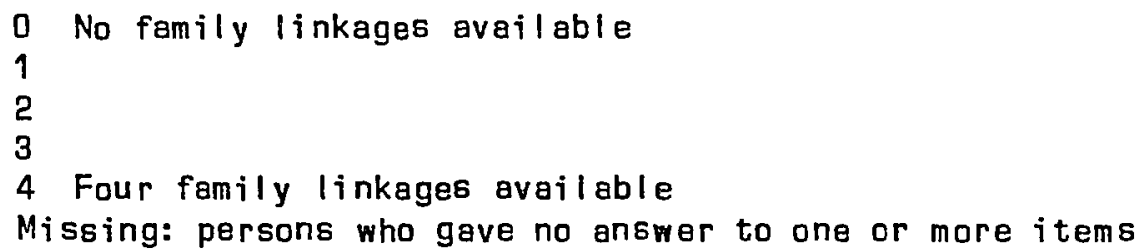

\section{Conceptual meaning:}

Scope or breadth of immediate family reflects how many of four potential immediate family linkages [spouse, parents, children, siblings] are available to the respandent. Those receiving the highest score reported the presence of a spouse in the household and at least one living parent, one child, and one sibling. Moderate scores reflect the presence of two or three potential immediate family linkages.

\section{Index construction procedures:}

The new variable was set at zero and constructed such that being married added 1, having either a father or a mother alive added 1 , having at least one sibling added 1 , and having at least one child added 1 . 
FAMSCOP1 (continued)

ITEM

RESPONSE SCORE

\begin{tabular}{|c|c|c|}
\hline \multirow{2}{*}{$\begin{array}{l}\text { Marital status of respondent } \\
\text { R013 }\end{array}$} & Married & +1 \\
\hline & $\begin{array}{l}\text { Never married } \\
\text { Widowed } \\
\text { Divorced }\end{array}$ & \\
\hline Respondent's father living & Alive & \\
\hline R015 & Dead & \\
\hline $\begin{array}{l}\text { Respondent's mother living } \\
\text { R021 }\end{array}$ & $\begin{array}{l}\text { Alive } \\
\text { Dead }\end{array}$ & \\
\hline \multirow[b]{2}{*}{$\begin{array}{l}\text { Total children family of origin } \\
\text { R056 } \\
\text { [siblings] }\end{array}$} & One [only child] & \\
\hline & $\begin{array}{l}\text { Two } \\
\text { Three } \\
\text { Four } \\
\text { Five } \\
\text { Six } \\
\text { Seven or more }\end{array}$ & +1 \\
\hline \multirow[b]{2}{*}{$\begin{array}{l}\text { Total number of respondent's } \\
\text { children } \\
\text { F033 } \\
\begin{array}{c}\text { Children } \\
\text { home }\end{array} \\
\begin{array}{c}\text { Children } \\
\text { left past } \\
\text { year }\end{array}\end{array}$} & None & \\
\hline & $\begin{array}{l}\text { One } \\
\text { Two } \\
\text { Three } \\
\text { - } \\
\dot{T}_{\text {welve }}\end{array}$ & +1 \\
\hline
\end{tabular}

Disposition of "no answer" responses:

If eny item in this index was unanswered, respondent was coded "missing" on this score.

Percent with "missing" scores: $1.6 \%$

Frequency distribution

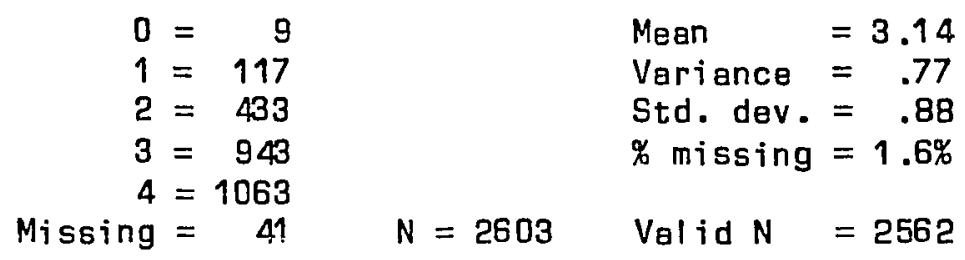


INDEX OF SCOPE OF TOTAL FAMILY

\section{FAMSCOP2}

O No family linkages

$\cdot$

$\dot{6}$

Missing: persons who gave no answer to one or more items

\section{Conceptual meaning:}

Scope of total family reflects how many of 6 potential total linkages (spouse, children, parents, sibling, relatives living nearby, and relatives living one day arayl are available to the respondents. Those receiving the highest score on this index reported the presence of a spouse in the household, and at least: one living parent, one child, one sibling, one relative nearby, and ane relative a day away. Respondents receiving the lowest score reported that none of these 6 family linkages exist for them. Moderate scores reflect the presence of two, three, or four of the potential total family scores.

\section{Index construction procedures:}

The new variable was set to equal FAMSCOP1 and constructed such that having at least one relative nearby added $\uparrow$ and having at least one relative a day away added 1. 
FAMSCOP2 [continued]

\begin{tabular}{|c|c|c|}
\hline ITEM & RESPONSE & SCORE \\
\hline $\begin{array}{l}\text { Index of scope immediate family } \\
\text { FAMSCOP1 }\end{array}$ & $\begin{array}{ll}0 & \text { No family linkages } \\
1 & \\
2 & \\
3 & \\
4 & \text { All immediate family } \\
\text { linkage's present }\end{array}$ & $\begin{array}{r}0 \\
+\quad \cdot \\
\cdot \\
4\end{array}$ \\
\hline $\begin{array}{l}\text { How many relatives live nearby } \\
\text { F109 }\end{array}$ & $\begin{array}{l}\text { None } \\
\text { One } \\
\text { Two } \\
\text { Three } \\
\text { Four } \\
\text { Five } \\
\text { Six }\end{array}$ & $\begin{array}{l}+ \\
\quad+1\end{array}$ \\
\hline $\begin{array}{l}\text { How many relatives live day away } \\
\text { F112 }\end{array}$ & $\begin{array}{l}\text { None } \\
\text { One } \\
\text { Two } \\
\text { Three } \\
\text { Four } \\
\text { Five } \\
\text { Six }\end{array}$ & $\begin{array}{l}\ldots \\
+1\end{array}$ \\
\hline
\end{tabular}

Disposition of "no answer" response:

If any item in this index was unanswered, respondent was coded "missing" on this score.

Percent with "missing" scores: $1.7 \%$

Frequency distribution

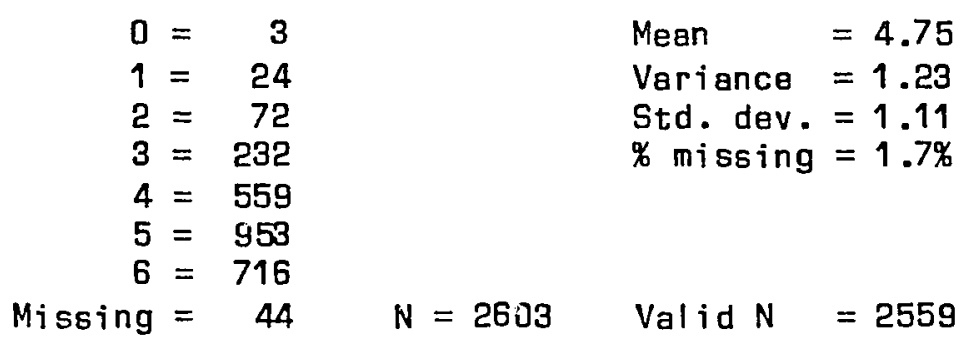


INDEX OF SCOPE OF FRIENDS

\section{FRNSCOPE}

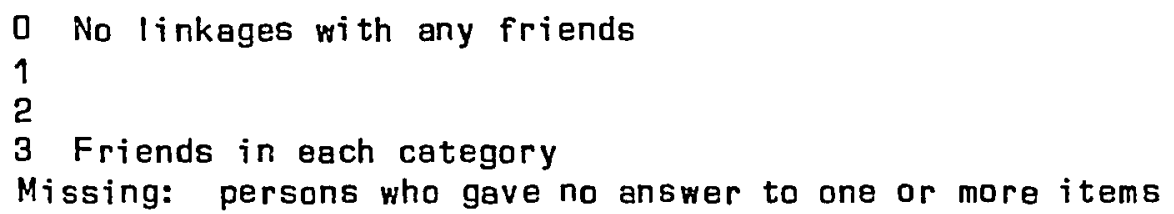

\section{Conceptual meaning:}

Scope of friends index reflects how many of 3 potential linkages within the friends sector (close friends, neighbors, coworkers) is available to the respondent. Those receiving the highest score reported the presence of at least one close friend, at least one neighbor that was visited in the home, and the potential to have work associates because they were employed.

\section{Index construction procedures:}

Three items were used to construct this score. FANSCOPE was first set at zero. If one or more close friends were available, 1 was added. If one or more neighbors were available, 1 was added. If the person was working or would soon be working again, 1 was added. 
FRNSCOPE (continued)

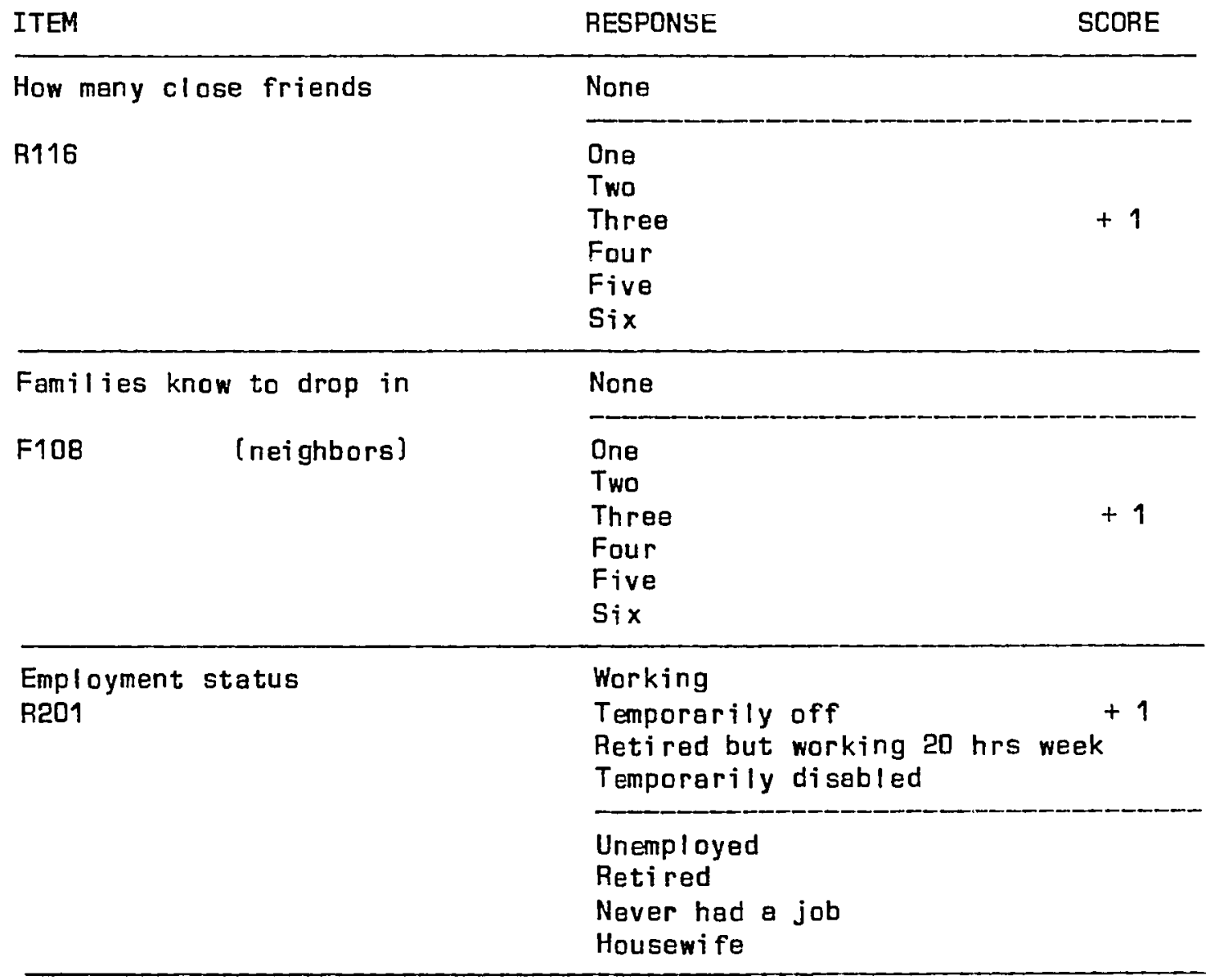

\section{Disposition of "no answer" response:}

If any item in this index was unanswered, respondent was coded "missing" on this score.

Percent with "missing" scores: $0.6 \%$

Frequency distribution

$\begin{array}{rlrl}0 & =29 & & \text { Mean }=2.25 \\ 1 & =343 & & \text { Variance }=.52 \\ 2 & =1155 & & \text { Std. dev. }=.72 \\ 3 & =1060 & & \% \text { missing }=0.6 \% \\ \text { Missing } & =16 & N=2603 & \text { Valid } N=2587\end{array}$


INDEX OF SCOPE OF COMMUNITY INVOLVEMENT

COMMSCOP

0 No community involvement

1

2

3

4 Maximum breadth of involvement

Missing: persons who gave no answer to one or more items

\section{Conceptual meaning:}

This index indicates breadth of participation in the social life of the community. If the respondent attends meetings of one or more groups or organizations, if he attends church at all, and if he participates in leisure social activities at two levels he scores high. Those who score low do not attend meetings or churches or engage in social leisure.

\section{Index construction procedures:}

First, LEISURE was collapsed so that those who engaged in one or two social leisure activities $=1$ and those who engaged in 3 or more social activities $=2$.

Second, R318 was revised so that if the respondent never attended church he received a score of 0 . The values were also reversed so that the low numbers meent little attendance and higher numbers indicated greater frequency of attendance.

The new variable was set at zero. If the respondent attended church at all he received 1 . If he attended meetings at all he received 1. If he engaged in one or two social ectivities he received a score of 1 ; if three or more social activities, he received 2 points. 
COMMSCOP [continued]

ITEM

RESPONSE

SCORE

Frequency of attendance at church Never

R318 (reversed order) Few times year

About monthly

Several times a month $\quad+1$

About weekly

More than once a week

Index of frequency of attendance 0 Never

at meetings of organizations

FREQMEET

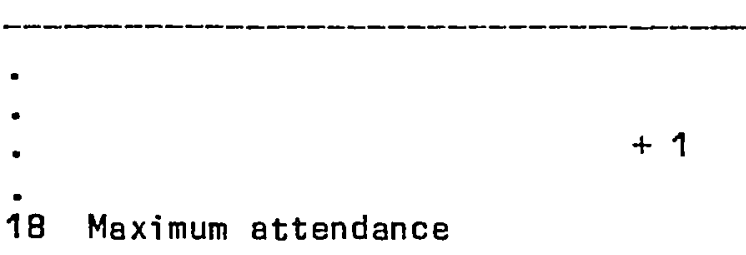

Index of social leisure $\mathrm{R} 201$

\section{None}

One - two activities +

Three or more activities

$+2$

\section{Disposition of "no answer" response:}

If any item in this index was unanswered, respondent was coded "missing" on this score.

\section{Percent with "missing" scores: $5.1 \%$}

Frequency distribution

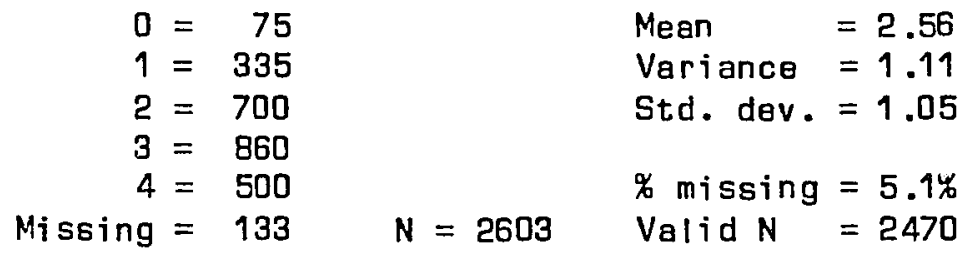


NETSCOP1

o No breadth of linkages available

-

$\cdot$

13 Maximum linkages

Missing: persons who gave no answer to one or more items

\section{Conceptual meaning:}

This index reflects how many of 13 potential linkages from family, friends, and community sectors are available to respondents. High scorers would have persons available in all the possible role relationships and community involvements. Low scorers would have very limited social resource categories.

Index construction procedures:

This index is the sum of three scope indexes already created.

ITEM

RESPONSE SCORE

Index scope total family FAMSCOP2

0 No family at all 0

EAMScOP

1 No 1

$2 \quad 2$

$3+3$

44

5

6 Maximum family linkages 6

\begin{tabular}{lllr}
\hline Index scope of friends & 0 & No friends & 0 \\
FRNSCOPE & 1 & & 1 \\
& 2 & & + \\
& 3 & Maximum friend linkages & 3 \\
\hline Index scope community involvement & 0 & No community participation & 0 \\
COMMSCOP & 1 & & 1 \\
& 2 & & 3 \\
& 3 & & \\
& 4 & Maximum commun. particip. & 4 \\
\hline
\end{tabular}


NETSCOP1 (continued)

Disposition of "no answer" response:

If any item in this index was unanswered, respondent was coded "missing" on this score.

Percent with "missing" scores: $6.8 \%$

Frequency distribution

$$
\begin{array}{rlrlrl}
1 & =2 & & \text { Mean } & =9.62 \\
2 & =2 & & \text { Variance }=3.76 \\
3 & = & 6 & & \text { Std. dev. }=1.93 \\
4 & =17 & & \text { \% missing }=6.8 \% \\
5 & =50 & & \\
6 & =92 & & \\
7 & =159 & & \\
8 & =304 & & \\
9 & =410 & & \\
10 & =488 & & \\
11 & =501 & & \\
12 & =312 & & \\
13 & =82 & & & \\
\text { Missing } & =178 & N=2603 & & \text { Valid } \mathrm{N}=2425
\end{array}
$$

Reliability

Coefficient Alpha .43

ITEM

Marriage

Children

Mother living

Father living

Siblings

Relatives near

Relatives far

Close friends

Other friends

Nei ghbors

Work associates

Organizations

Church

Leisure activities
ITEM-

TOTAL

CORRELATION

$$
\begin{array}{r}
.14159 \\
.16295 \\
.08401 \\
.13688 \\
-.01914 \\
.15884 \\
.17771 \\
.15943 \\
.30781 \\
.17920 \\
.07488 \\
.27967 \\
.19143 \\
.20925
\end{array}
$$

ALPHA

IF ITEM

DELETED

.42395

.40633

.42663

.42205

.46109

.40997

.40278

.40688

.39579

.40090

.42954

.36500

.39718

.39511 
CORRELATION MATRIX FOR SCALE NETSCOP1

\begin{tabular}{|c|c|c|c|c|c|c|c|c|c|c|}
\hline & MARAI AGE & CHILDREN & $\begin{array}{l}\text { MOTHER } \\
\text { LIVING }\end{array}$ & $\begin{array}{l}\text { FATHER } \\
\text { LIVING }\end{array}$ & SIBLINGS & $\begin{array}{c}\text { RELATIVES } \\
\text { NEAR }\end{array}$ & $\begin{array}{l}\text { RELATIVES } \\
\text { FAR }\end{array}$ & $\begin{array}{l}\text { CLOSE } \\
\text { FRIENDS }\end{array}$ & $\begin{array}{l}\text { OTHER } \\
\text { FRIENDS }\end{array}$ & NEIGHBORS \\
\hline MARRIAGE & 1.00000 & & & & & & & & & \\
\hline CHILDREN & .16345 & 1.00000 & & & & & & & & \\
\hline MOTHER LIVING & .10602 & .00767 & 1.00000 & & & & & & & \\
\hline FATHER LIVING & .14558 & .05365 & .47053 & 1.00000 & & & & & & \\
\hline SIBLINGS & -.08273 & .06009 & -.1921 & -.21265 & 1.00000 & & & & & \\
\hline RELATIVES NEAR & .10180 & .11424 & .10194 & .13119 & .01359 & 1.00000 & & & & \\
\hline RELATIVES FAR & .11552 & .05643 & .08940 & .11124 & .02075 & .1459 & 1.00000 & & & \\
\hline CLOSE FRIENDS & -.04526 & -.00649 & -.03231 & -.02866 & .01428 & .02855 & .03535 & 1.00000 & & \\
\hline OTHER FRIENDS & .02962 & .01163 & .10095 & .13071 & -.06378 & .12599 & .10398 & .18043 & 1.00000 & \\
\hline NEIGHBORS & .12829 & .06457 & -.04142 & -.03416 & .00089 & .02053 & .11988 & .09222 & .18660 & 1.00000 \\
\hline WORK ASSOCIATES & .02150 & .02749 & .15968 & .29491 & -.08555 & .08442 & .03865 & .03320 & .05944 & -.06275 \\
\hline ORGANIZATIONS & .07082 & .09315 & .00657 & .04925 & -.03056 & -.00127 & .04515 & .13497 & .19875 & .19207 \\
\hline CHURCH & .00460 & .12336 & $-.035 \approx$ & -.04824 & .06514 & .02596 & .02155 & .12417 & .14416 & .10797 \\
\hline \multirow[t]{2}{*}{ LEISURE ACTIVITIES } & -.02441 & .03269 & .09591 & .13978 & .00624 & .04742 & .04197 & .13175 & .20984 & .04631 \\
\hline & $\begin{array}{l}\text { WORK } \\
\text { ASSOCIATES }\end{array}$ & $\begin{array}{l}\text { ORGANI- } \\
\text { ZATIONS }\end{array}$ & CHURCH & $\begin{array}{l}\text { LEISURE } \\
\text { ACTIVITIES }\end{array}$ & & & & & & \\
\hline WORK ASSOCIATES & 1.00000 & & & & & & & & & \\
\hline ORGANIZATIONS & .12498 & 1.00000 & & & & & & & & \\
\hline CHURCH & -.07867 & .23701 & 1,00000 & & & & & & & \\
\hline LEISURE ACTIVITIES & .07956 & .21852 & .07333 & 1.00000 & & & & & & \\
\hline
\end{tabular}




\section{INDEX OF CHILDREN}

\section{ALLKIDS}

0 No children

12 Maximum number of children

\section{Conceptual meaning:}

This measure is a sum of all the children of the respondent, and includes those currently living at home, those who left home during the past year, and those who have been living away from home for one or more years. Younger people would have children living at home, while older would be expected to have more in the latter category.

\section{Index construction procedures:}

Number of children from the 3 raw score variables are summed.

\begin{tabular}{llr} 
ITEM & RESPONSE & SCORE \\
\hline $\begin{array}{l}\text { Number of children at home } \\
\text { F033 }\end{array}$ & None & +1 \\
& $\cdot$ & +2 \\
& $\cdot$ & $\cdot$ \\
\hline $\begin{array}{l}\text { Number of children left home } \\
\text { past year }\end{array}$ & None & +1 \\
F045 & $\cdot$ & +2 \\
& $:$ & $:$ \\
\hline $\begin{array}{l}\text { Number of children left home } \\
\text { one or more years }\end{array}$ & None & . \\
F071 & $\cdot$ & +1 \\
& $:$ & + \\
\hline
\end{tabular}


ALLKIDS [continued]

Frequency distribution

$$
\begin{aligned}
0 & =365 & & \text { Mean } \\
1 & =466 & & \text { Variance }=3.43 \\
2 & =657 & & \text { Std. dev. }=1.78 \\
3 & =503 & & \text { \% missing }=0.0 \% \\
4 & =316 & & \\
5 & =177 & & \\
6 & =55 & & \\
7 & =42 & & \\
8 & =16 & & \\
9 & =9 & & \\
10 & =1 & & \\
11 & =2 & & \\
12 & =3 & &
\end{aligned}
$$


INDEX OF FAMILY OF ORIGIN INTERACTION

\title{
FAMINTER
}

\author{
0 Minimum interaction \\ $\cdot$ \\ $\cdot$ \\ $2 i$ Maximum interaction
}

Conceptual meaning:

This index indicates the interaction with family of origin in terms of numbers of these family members and how often they are seen. Because there is no direct measure of frequency of contact, a proxy measure was created (FAMTIES) which indicates strength of family ties and thus indirectly how often they might be seen. Thus, someone with weak ties would see these family members less than someone with strong ties. A respondent with a mother living, a father living, and up to 7 siblings who has a strong sense of family ties would receive the highest score. Someone without a living parent who was an only child and had a weak sense of family would be a low scorer.

\section{Index construction procedures:}

The index FAMTIES was collapsed to a metric of D-3 so as to have the same metric of the other frequency variables used in index constructions. A small number (51) of the respondents had been coded "a" (missing) in addition to those coded as "g" (missing), non-applicable. Presumably these 51 had no family members. Thus these zeros were permitted to enter the computations as 0 . Number of living parents and siblings were summed and then multiplied by the FAMTIES index. 
FAMINTER (continued]

\begin{tabular}{|c|c|c|c|c|c|c|}
\hline ITEM & RESPONSE & SCORE & & ITEM & RESPONSE & SCORE \\
\hline $\begin{array}{l}\text { Father living } \\
\text { R015 } \\
\text { Mother living } \\
\text { R021 } \\
\text { Siblings } \\
\text { R056 }\end{array}$ & $\begin{array}{l}\text { No } \\
\text { Yes } \\
\text { No } \\
\text { Yes } \\
0 \\
1 \\
2 \\
3 \\
4 \\
5 \\
7 \text { or more }\end{array}$ & $\begin{array}{l}+1 \\
+1 \\
+1 \\
+2 \\
+3 \\
+4 \\
+5 \\
+6\end{array}$ & $x$ & $\begin{array}{l}\text { Sense of } \\
\text { Family ties } \\
\text { FAMTIES } \\
\text { (Proxy measure } \\
\text { for frequency) } \\
\text { R074 }\end{array}$ & $\begin{array}{l}\text { [no family] } \\
\text { Weak } \\
\text { Moderate } \\
\text { Strong } \\
\end{array}$ & $\begin{array}{r}0 \\
1 \\
2\end{array}$ \\
\hline
\end{tabular}

Frequency distribution

$$
\begin{aligned}
0 & =149 & & \text { Mean }=7.78 \\
1 & =53 & & \text { Variance }=24.61 \\
2 & =148 & & \text { Std. dev. }=5.0 \\
3 & =155 & & \\
4 & =248 & & \\
5 & =132 & & \\
6 & =370 & & \\
7 & =26 & & \\
8 & =186 & & \\
9 & =128 & & \\
10 & =260 & & \\
12 & =229 & & \\
14 & =56 & & \\
15 & =221 & & \\
18 & =78 & & \\
21 & =45 & &
\end{aligned}
$$




\section{INDEX OF FAMILY TIES}

FAMTIES

O Minimum sense of family

$\cdot$

$\cdot$

$\dot{g}$ Maximum sense of family
Pearson's r: . .42

Percent missing scores: $3.2 \%$

\section{Conceptual meaning:}

This index combines two variables which indicate how strong the respondent's ties to his family were and are. Since there is no variable concerned with frequency of contact with family of origin, it was created to give a proxy measure of how often the respondent might see these femily members based on his feelings of closeness to them. A low score is given if a sense of family ties is not very strong and his/her family was not very close knit. A high score indicates a very strong sense of family tias and an extremely close knit family of origin.

\section{Index construction procedures:}

Both variables were recoded to reverse direction to from low to high. They were then multiplied together.

\begin{tabular}{|c|c|c|c|c|c|c|}
\hline ITEM & RESPONSE & SCORE & & ITEM & RESPONSE & CORE \\
\hline \multirow{3}{*}{$\begin{array}{l}\text { Was family lof } \\
\text { origin] close } \\
\text { knit } \\
\text { R073 } \\
\text { [recoded] }\end{array}$} & Not very & 1 & \multirow{3}{*}{$x$} & \multirow{3}{*}{$\begin{array}{l}\text { Sense of } \\
\text { family ties } \\
\text { RO74 } \\
\text { [ recoded] }\end{array}$} & Not strong & 1 \\
\hline & Somewhat & 2 & & & Fairly strong & $g 2$ \\
\hline & Extremely & 3 & & & Very strong & 3 \\
\hline
\end{tabular}


INDEX OF INTERACTION WITH RELATIVES

\section{RELINTER}

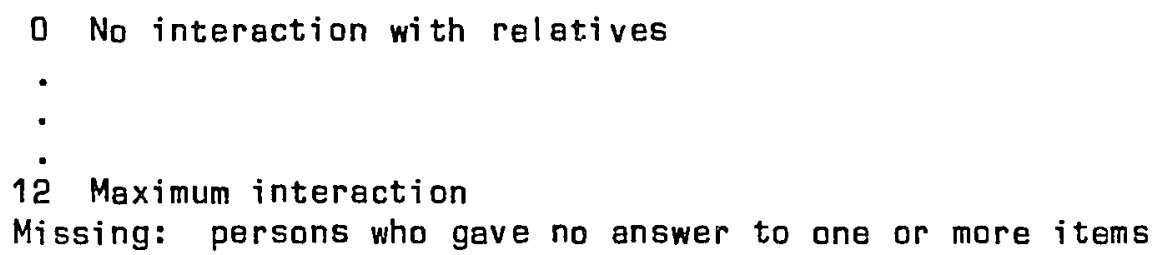

\section{Conceptual meaning:}

This index combines the number of relatives living nearby and a day away with the frequency with which they are seen by the respondent. It includes a measure of the frequency with which the respondent keeps in touch with relatives far away. Low scorers have no or few relatives with whom they interact seldom. High scorers have many relatives and see them often.

\section{Index construction procedures:}

First, three variables concerning frequency of contact were summed to create a new index, FREQREL1. Each was in a metric of 0-3. Each was recoded so the order went from low to high. People who did not have relatives living nearby or day away with whom they could have contact had been coded 100 (missing). These people were recoded to a value of 0 so they could be entered in the computations. Otherwise there would have been almost half the sample excluded from the index FREQREL1.

Next, the two variables cancerned with the number of relatives nearby and a day away were summed for a new index SIZEREL.

Finally, the new variable, INTERREL, was set at zero, and FREQREL1 and SIZEREL were multiplied. 
RELINTER (continued)

This is how FRERREL1 was constructed:

Range: $1-9$

\begin{tabular}{|c|c|c|}
\hline ITEM & RESPONSE & SCORE \\
\hline $\begin{array}{l}\text { Keep in touch with away } \\
\text { relatives } \\
\text { F115 }\end{array}$ & $\begin{array}{l}\text { All nearby } \\
\text { Not very frequently } \\
\text { Somewhat frequently } \\
\text { Very frequently }\end{array}$ & $\begin{array}{r}0 \\
+1 \\
+\quad 2 \\
+3\end{array}$ \\
\hline $\begin{array}{l}\text { Near relatives family see often } \\
\text { RFAM }\end{array}$ & $\begin{array}{l}\text { None or inappropriate (have } \\
\quad \text { no near relatives] } \\
\text { Less than half } \\
\text { About half } \\
\text { All }\end{array}$ & $\begin{array}{r}0 \\
+1 \\
+\quad 2 \\
+3\end{array}$ \\
\hline $\begin{array}{l}\text { Relatives families one day away } \\
\text { See often } \\
\text { RFAMDAY }\end{array}$ & $\begin{array}{l}\text { None or inappropriate (have } \\
\text { no day away relatives) } \\
\text { Less than half } \\
\text { About half } \\
\text { All }\end{array}$ & $\begin{array}{r} \\
0 \\
+\quad 1 \\
+2 \\
+3\end{array}$ \\
\hline
\end{tabular}

Percent with "missing" scores: $0.8 \%$

This is how SIZEREL was constructed:

Range: $1-12$

\begin{tabular}{|c|c|c|c|}
\hline & ITEM & RESPONSE & SCORE \\
\hline $\begin{array}{l}\text { How many } \\
\text { F109 }\end{array}$ & relatives live nearby & $\begin{array}{l}\text { None } \\
\text { One } \\
\text { Two } \\
\text { Three } \\
\text { Four } \\
\text { Five } \\
\text { Six or more }\end{array}$ & $\begin{array}{r}0 \\
+1 \\
+2 \\
+3 \\
+4 \\
+5 \\
+6\end{array}$ \\
\hline $\begin{array}{l}\text { How many } \\
\text { F112 }\end{array}$ & relatives live day away & $\begin{array}{l}\text { None } \\
\text { One } \\
\text { Two } \\
\text { Three } \\
\text { Four } \\
\text { Five } \\
\text { Six or more }\end{array}$ & $\begin{array}{r}0 \\
+1 \\
+2 \\
+3 \\
+4 \\
+5 \\
+6\end{array}$ \\
\hline
\end{tabular}

Percent with "missing" scores: $0.2 \%$ 
RELINTER [continued\}

Finally, this is how RELINTER was constructed:

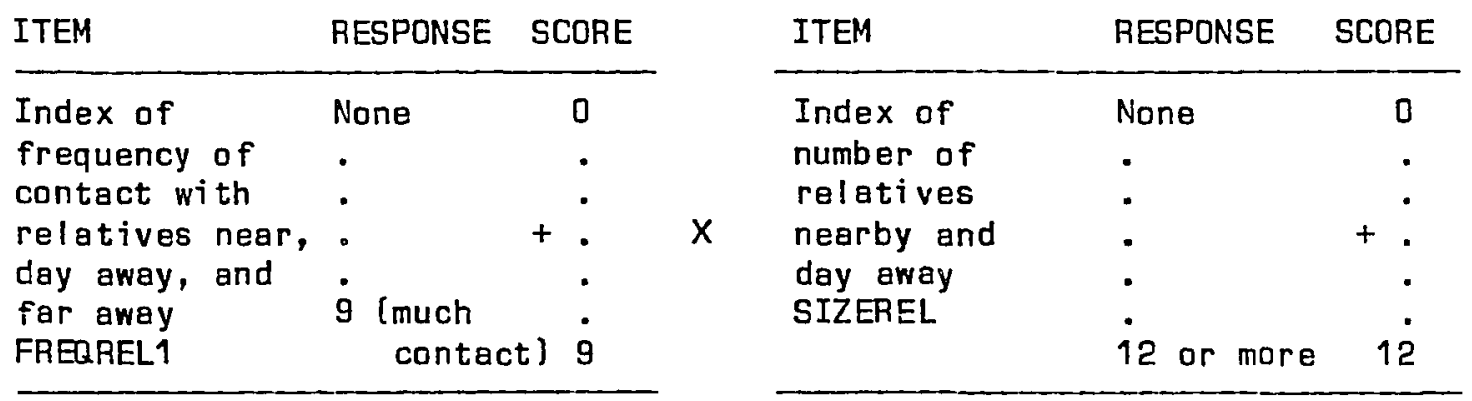

Percent_with_"missing"_scores: $\underline{0.6 \%}$

Disposition of "no answer" response:

If any item in this index was unanswered, respondent was coded "missing" on this score.

Frequency distribution

$$
\begin{aligned}
& 0=266 \\
& 2=2 \\
& 3=115 \\
& 4=62 \\
& 5=24 \\
& 6=215 \\
& 7=38 \\
& 8=46 \\
& 9=76 \\
& 10=42 \\
& 11=6 \\
& 12=231 \\
& 14=31 \\
& 15=71 \\
& 16=21 \\
& 18=146 \\
& 20=34 \\
& 21=45 \\
& 22=22 \\
& 24=157 \\
& 25=23 \\
& 27=46 \\
& 28=44 \\
& 30=109 \\
& 32=41 \\
& 33=12 \\
& 35=47 \\
& 36=147 \\
& 40=76 \\
& 42=64 \\
& 44=24 \\
& 45=34 \\
& 4 \mathrm{~B}=110 \\
& 50=24 \\
& 54=22 \\
& 55=10 \\
& 60=65 \\
& 66=8 \\
& 72=32 \\
& \text { Missing }=15 \\
& N=2603 \quad \text { Valid } N=2588
\end{aligned}
$$




\section{INDEX OF CLOSE FRIENDS INTERACTION}

FRNINTER [close friends interaction measure)

o No clase friends, so no interaction

-

$\cdot$

18 Maximum interaction

Missing: persons who gave no answer to one or more items

\section{Conceptual meaning:}

This index measures the extent of the respondent's interaction with close friends. If he has over 10 close friends and sees them frequently, he receives a high score. If he has few friends and sees them seldom, he receives a low score.

\section{Index construction procedures:}

First, R117 was recoded to reverse the order to low to high frequency. At the same time, the pilot response of "often" was included in "very often" so as not to have to count those 85 responses as missing. It was a choice between including the 85 with "very often" or "fairly often," and it seemed more reasonable that what was meant by those respondents fit better with "very often."

The new variable was set at 0 . R116 was multiplied by R117. Those with no friends with 0 [missing] were entered into the computations.

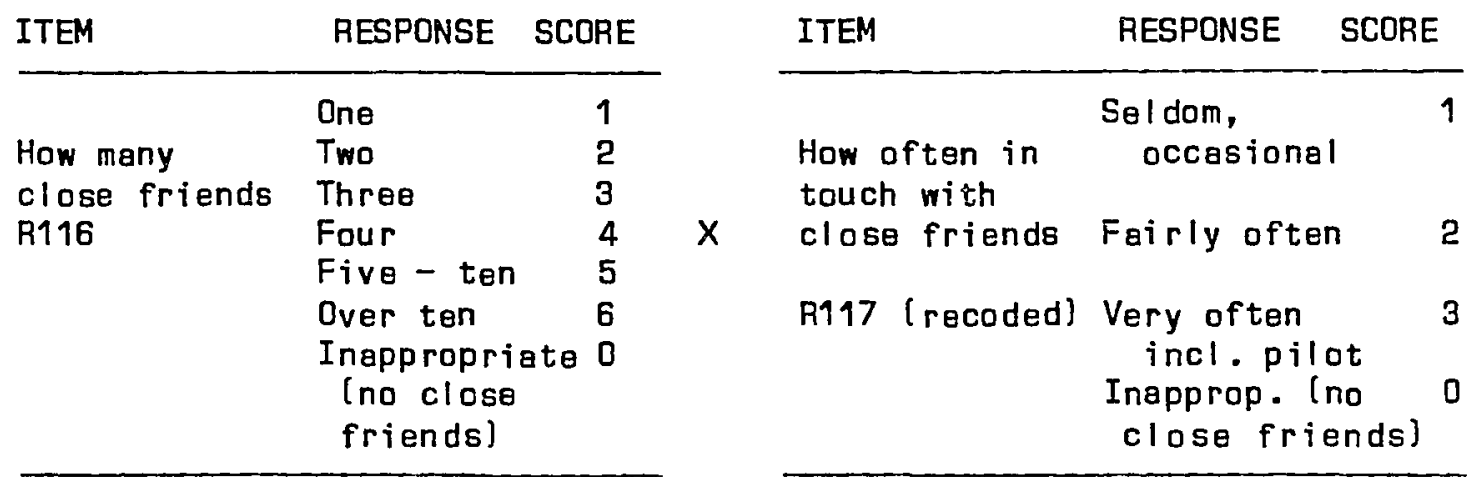


FRNINTER (continued)

\section{Disposition of "no answer" response:}

If any item in this index was unanswered, respondent was coded "missing" on this score.

Percent with "missing"_scores: $0.2 \%$

Frequency distribution
$0=581$
$i=33$
$2=138$
$3=220$
$4=185$
$5=42$
$6=495$
$\mathrm{B}=90$
$9=229$
$10=146$
$12=191$
$15=187$
$18=61$
Missing $=5 \quad \mathrm{~N}=2603 \quad$ Valid $\mathrm{N}=2598$

$$
\begin{aligned}
& \text { Mean }=5.90 \\
& \text { Variance }=23.97 \\
& \text { Std. dev. }=4.90 \\
& \text { \% missing }=0.2 \%
\end{aligned}
$$


INDEX OF OTHER FRIENDS INTERACTION

\section{FRIQNDS}

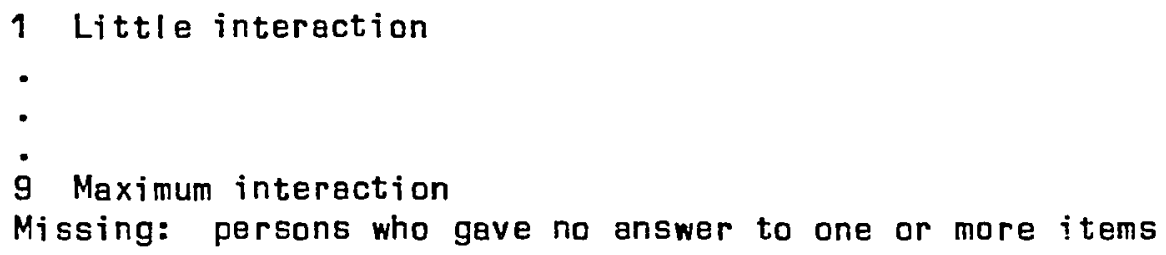

\section{Conceptual meaning:}

This index measures categarically whether one sees few or many families of friends and how often these people are seen. In contrast to the measure of close friends which is primarily a measure of persons with whom one interacts on a more intimate basis, this index assesses a broader sweep of friend's families. These relationships would be considered more distant ones. Low scorers would have only a few such relationships and see them rarely. High scorers would have a great many of these friend relationships and see them often.

\section{Index construction procedures:}

The recoded yariables from the Masterfile were used as they both measured low to high. These two variables were then multiplied.

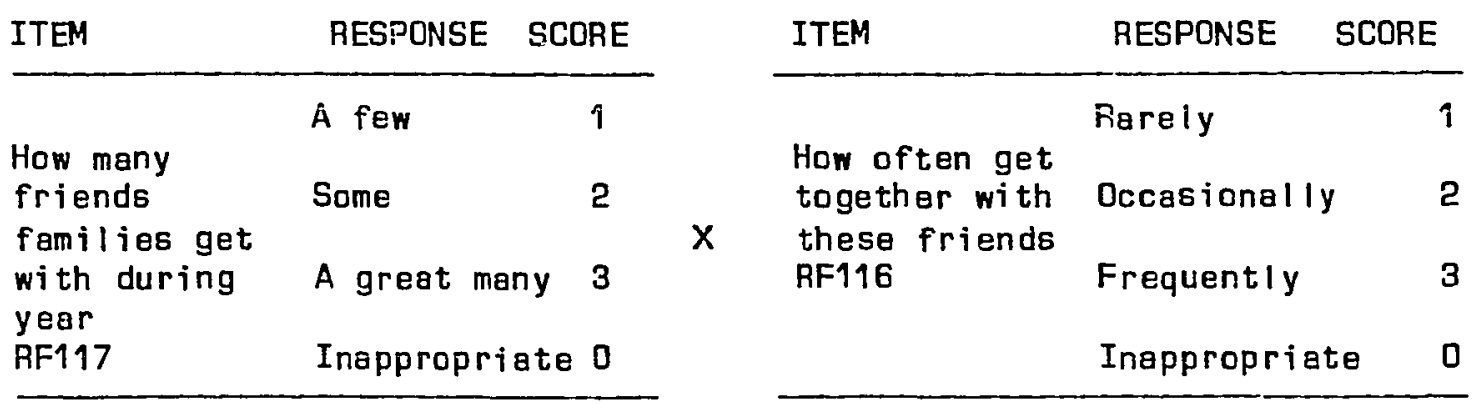

\footnotetext{
Disposition of "no answer" response:

If any item in this index was unanswered, respondent was coded "missing" on this score.
} 
FRIENDS (continued)

Frequency distribution

$\begin{array}{rlrlrl}0 & =12 & & \text { Mean } & =4.54 \\ 1 & =134 & & \text { Variance }=7.30 \\ 2 & =456 & & \text { Std. dev. }=2.70 \\ 3 & =226 & & \text { \% missing }=0.6 \% \\ 4 & =471 & & \\ 6 & =616 & & \\ 9 & =479 & N=2603 & \text { Valid } N=2603\end{array}$


INDEX OF WORK INTERACTION

WORKINT

1 Unemployed, or does not interact at work

-

-

12 Maximum interaction with friends and associates from work Missing: persons who gave no answer to one or more items

\section{Conceptusl meaning:}

This index indicates interaction within the respondent's work network. It is a measure of the number of people he talks to at work multiplied by how often he sees work friends apart from the work situation. Many of the respondents are housewives, and quite a few are retired, so they do not have a work network. Low scorers would not be working, or have jobs where they do not work with others. If they were working they would seldom see their work associates outside their $p$ !ace of employment.

\section{Index construction procedures:}

First, R257 was collapsed to combine categories one and two due to small numbers in each. Thus, one and two $=1$, three $=2$, four $=3$, and five $=4$.

Second, R277 was recoded so that "works alone" (four) was included in "zero, inappropriate."

The new variable was set at zero and R257 and R277 multiplied.

\begin{tabular}{|c|c|c|c|c|c|c|}
\hline ITEM & RESPONSE & JRE & & ITEM & RESPONSE & \\
\hline & $1-2$ & 1 & & & Rarely & 1 \\
\hline $\begin{array}{l}\text { People talk } \\
\text { to at work }\end{array}$ & $\begin{array}{r}3-10 \\
11-25\end{array}$ & $\begin{array}{l}2 \\
3\end{array}$ & & $\begin{array}{l}\text { Spend time } \\
\text { off job with }\end{array}$ & $\begin{array}{l}\text { Occesionally } \\
\text { Very often }\end{array}$ & 3 \\
\hline $\mathrm{R} 257$ & $\begin{array}{l}\text { Over } 25 \\
\text { Inapropriate } \\
\text { [reti red, } \\
\text { housewives] }\end{array}$ & $\begin{array}{l}4 \\
0\end{array}$ & $x$ & $\begin{array}{l}\text { coworkers } \\
\text { R277 }\end{array}$ & $\begin{array}{l}\text { Inappropriate } \\
\text { (retirad, } \\
\text { housewives) }\end{array}$ & 0 \\
\hline
\end{tabular}


WORKINT (continued)

Disposition of "no answer" response:

If any item in this index was unanswered, respondent was coded "missing" on this score.

Percent with "missing" scores: $1.2 \%$

Frequency distribution

$\begin{array}{rlrlrl}0 & =1178 & & \text { Mean } & =2.40 \\ 1 & =43 & & \text { Variance }=8.03 \\ 2 & =323 & & \text { Std. dev. }=2.83 \\ 3 & =228 & & \\ 4 & =304 & & \text { \% missing }=1.2 \% \\ 6 & =283 & & \\ B & =151 & & \\ 9 & =26 & & \\ 12 & =36 & & & \\ \text { Missing } & =31 & N=2603 & \text { Valid } N=2572\end{array}$


INDEX OF INVOLVEMENT IN ORGANIZATIONS OR CLUBS

FREQMEET [Frequency of attendance at meetings of 6 organizations]

1 No involvement with organizations, clubs, or groups

$\cdot$

-

18 Much involvement

Missing: persons who gave no answer to one or more items

\section{Conceptual meaning:}

Organizational involvement reflects how many clubs, groups, or organizations the respondent belongs to as well as how much he attends meetings of the organizations. This would indicate integration into the community, and being in relationship to other people who could be supportive. People who scored highest on this index would belong to 6 organizations and go to meetings of each organization regularly. Peopla who scored lowest would not belong to organizations or clubs.

\section{Index construction procedures:}

First, R173, R178, R183, R188, R193, R198 were each recoded to reverse the order so that $1=$ seldom, $2=$ occasional!y, and $3=$ regularly. 4 was recoded to $0=$ never. Also set at 0 were the missing variables that were inappropriate. These represented respondents who did not belong to organizations. The zeros could be entered in the calculations. Missing values 9 were set at 99 .

Then the six variables were summed. Scores ranged from 0-18. 
FREQMEET (continued)

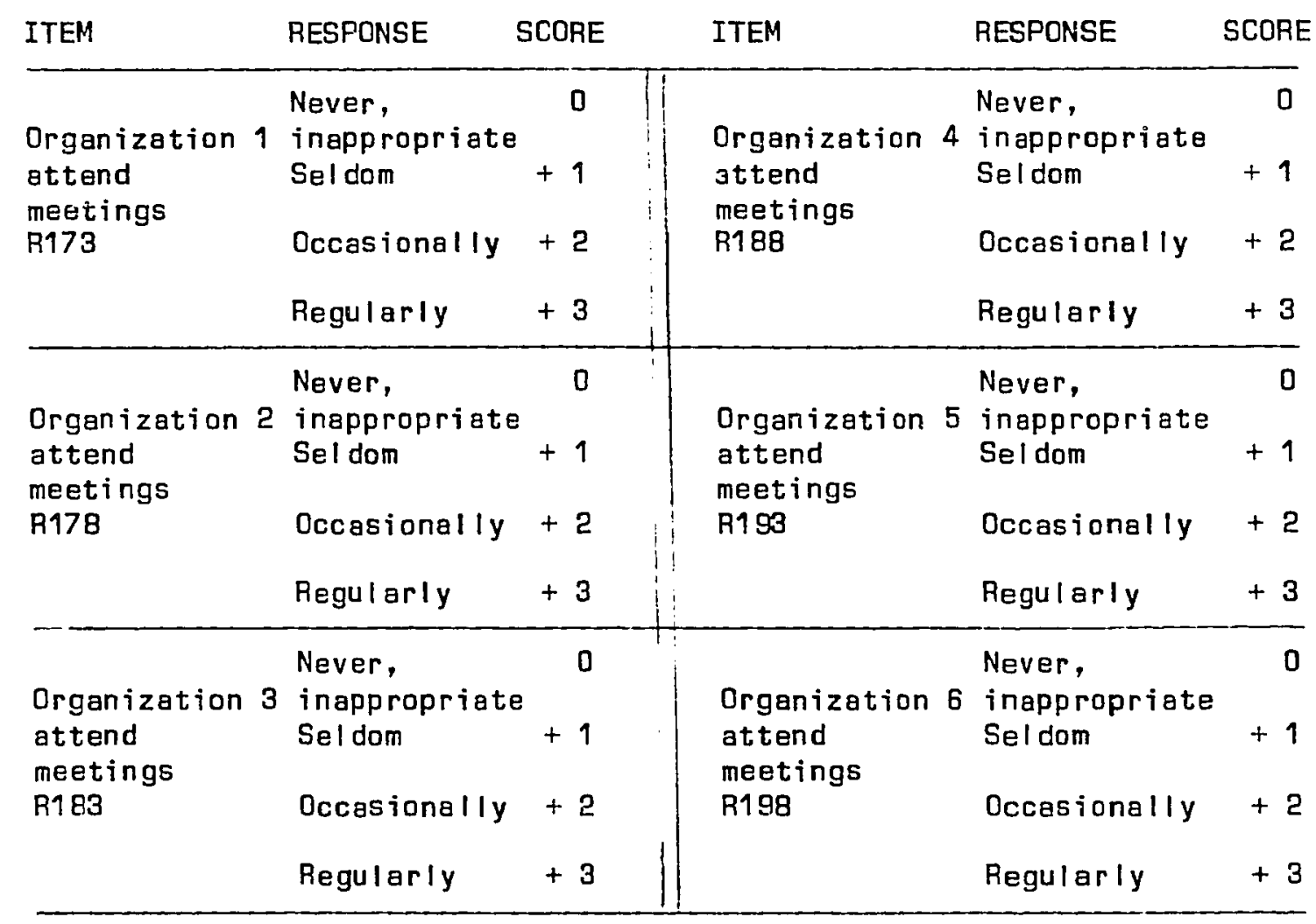

\section{Disposition of "no answer" response:}

If any item in this index was unanswered, respondent was coded "missing" on this score.

Percent with "missing" scores: $0.6 \%$

Frequency distribution

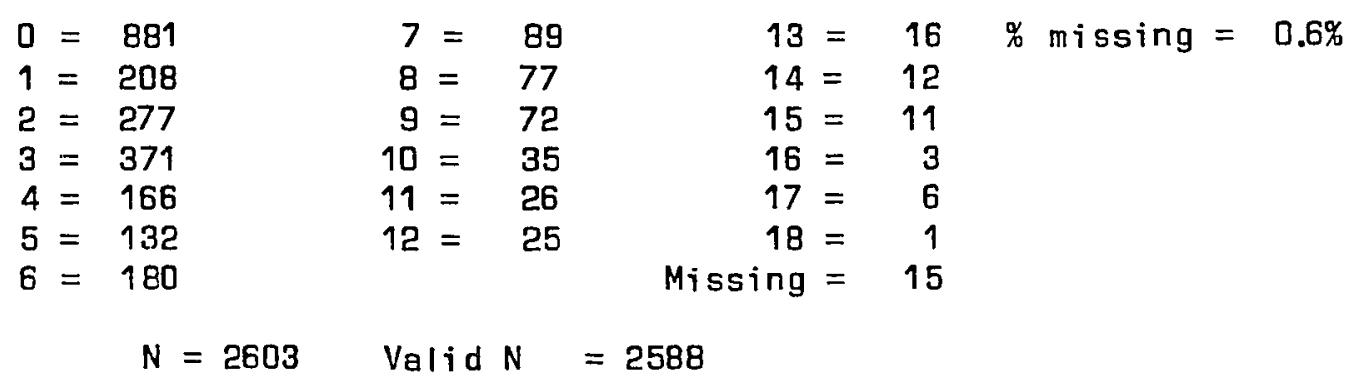


INDEX OF ORGANIZATION AND CHURCH INTERACTION

FREQMECH

o No church or organization interaction

-

$\cdot$

10 Maximum interaction

Missing: persons who gave no answer to one or more items

\section{Conceptual meaning:}

This index measures church and organizational involvement such that church attendance is given the same weight as the measure of attendance at meatings of organizations, FREQMEET. Thus, church is considered very important as a sourca of social linkages and support. High scorers attend church frequently and belong to many organizations and attend their meetings.

\section{Index construction procedures:}

First, R318 was revised to reverse order from low to high, and six $=0$ [none $]$. R318.

Then, FREQMEET was collapsed to a metric of five to be the same as

The new variable was set at zero and FREQMEET and R318 added together. 
FREQMECH [continued]

\begin{tabular}{llr} 
ITEM & RESPONSE & SCORE \\
\hline $\begin{array}{ll}\text { Index of Organizational } \\
\text { Involvement }\end{array}$ & 0 No interaction & 0 \\
FREQMEET & - & + \\
& & 5 \\
\hline Frequency of attendance at church & Never & 5 \\
R318 (reversed order) & Few times year & +1 \\
& About monthly & +2 \\
& More than monthly & +3 \\
& Weekly & +4 \\
& More than weekly & +5 \\
\hline
\end{tabular}

\section{Disposition of "no answer" response:}

If any item in this index was unanswered, respondent was coded "missing" on this score.

Percent with "missing" scores: $3.3 \%$

Frequency distribution

$$
\begin{aligned}
0 & =306 \\
1 & =336 \\
2 & =227 \\
3 & =239 \\
4 & =360 \\
5 & =277 \\
6 & =213 \\
7 & =175 \\
8 & =185 \\
9 & =161 \\
10 & =39 \quad \quad \mathrm{~N}=2603 \quad \text { Valid } N=2518
\end{aligned}
$$


INDEX OF SOCIAL LEISURE

\section{LEISUR2}

- No social leisure activities

-

.

14 Maximum social leisure

Missing: persons who gave no answer to one or more items

\section{Conceptual meening:}

The social leisure index is an indication of how many leisure activities the respondent engages in that involve doing things with other people or involve getting him or her out of the house in situations that would involve others. From a potential list of about 30 leisure activities that the respondents reported they did in their spare time, 14 were selected by the investigator as being social las opposed to solitary activities]. Each one of these social activities that the respondent mentioned added one point to his score.

\section{Index construction procedures:}

The new variable was set ar zero. If a social leisure activity was noted by the respondent, 1 was added to the score. These were summed for the total score. 
LEISUR2 (continued)

\begin{tabular}{l|l|llll} 
ITEM & RESPONSE & SCORE & ITEM & RESPONSE SCORE \\
\hline R121 Camping & $\begin{array}{l}\text { Yes } \\
\text { No }\end{array}$ & +1 & R135 Attend Plays & $\begin{array}{c}\text { Yes }+1 \\
\text { No }\end{array}$ \\
\hline R122 Attend meetings & $\begin{array}{l}\text { Yes } \\
\text { No }\end{array}$ & +1 & R140 Shopping & $\begin{array}{l}\text { Yes }+1 \\
\text { No }\end{array}$ \\
\hline R124 Attend concerts & $\begin{array}{l}\text { Yes } \\
\text { No }\end{array}$ & +1 & R141 Spectator sports & $\begin{array}{l}\text { Yes }+1 \\
\text { No }\end{array}$ \\
\hline R125 Entertaining & $\begin{array}{l}\text { Yes } \\
\text { No }\end{array}$ & +1 & R142 Sports participant & Yes +1 \\
\hline R128 Going out & $\begin{array}{l}\text { Yes } \\
\text { No }\end{array}$ & +1 & R144 Visiting & $\begin{array}{l}\text { Yes }+1 \\
\text { No }\end{array}$ \\
\hline R131 Movie attendance & $\begin{array}{l}\text { Yes } \\
\text { No }\end{array}$ & +1 & R145 Volunteer work & $\begin{array}{l}\text { Yes }+1 \\
\text { No }\end{array}$ \\
\hline R134 Play cards & $\begin{array}{l}\text { Yes } \\
\text { No }\end{array}$ & +1 & R150 Other social & $\begin{array}{l}\text { Yes }+1 \\
\text { No }\end{array}$ \\
\hline
\end{tabular}

Disposition of "no answer" response:

If any item in this index was unanswered, respondent was coded "missing" on this score.

Percent with "missing" scores: $2.4 \%$

Frequency distribution

$$
\begin{aligned}
0 & =471 \\
1 & =673 \\
2 & =579 \\
3 & =444 \\
4 & =231 \\
5 & =85 \\
6 & =38 \\
7 & =13 \\
8 & =3 \\
9 & =2 \\
10 & =1 \\
\text { Missing } & =63 \quad \mathrm{~N}=2603 \quad \text { Valid } N=2540
\end{aligned}
$$


INDEX OF NETWORK SIZE

NETSIZE (Total network size)

D Nobody in network

-

$\cdot$

10 Maximum number people in network

Missing: persons who gave no answer to one or more items

\section{Conceptual meaning:}

Network size is a simple count of the total number of individuals enumerated by the respondent, adding down all available categories of social relationships (family, kin, friends, neighbors, coworkers]. It is an overall measure of the size of the group of people from whom support could be drewn. Respondents receiving the highest score would have large nuclear and extended families and many friends, neighbors, and work associaes. The lowest score would be received by never married subjects with few friends and kin who were unemployed.

\section{Index construction procedures:}

Two previously constructed indexes, SIZEFAM2 [size total family) and SIZEFRND (size friends network) were summed for this index.

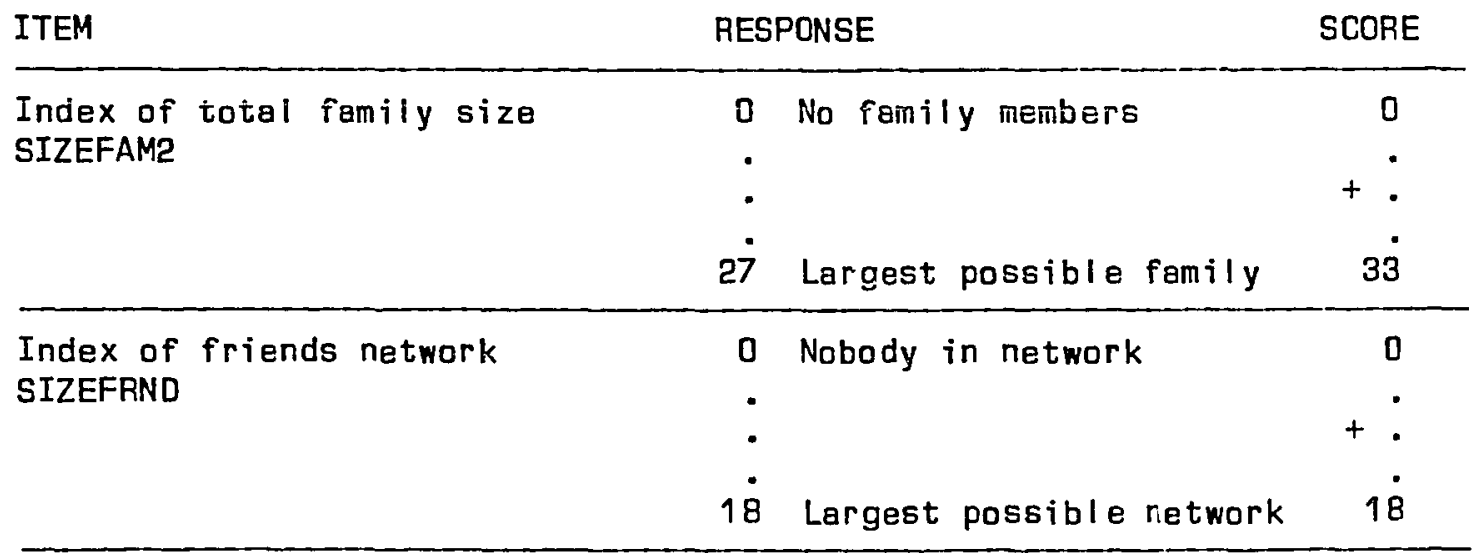




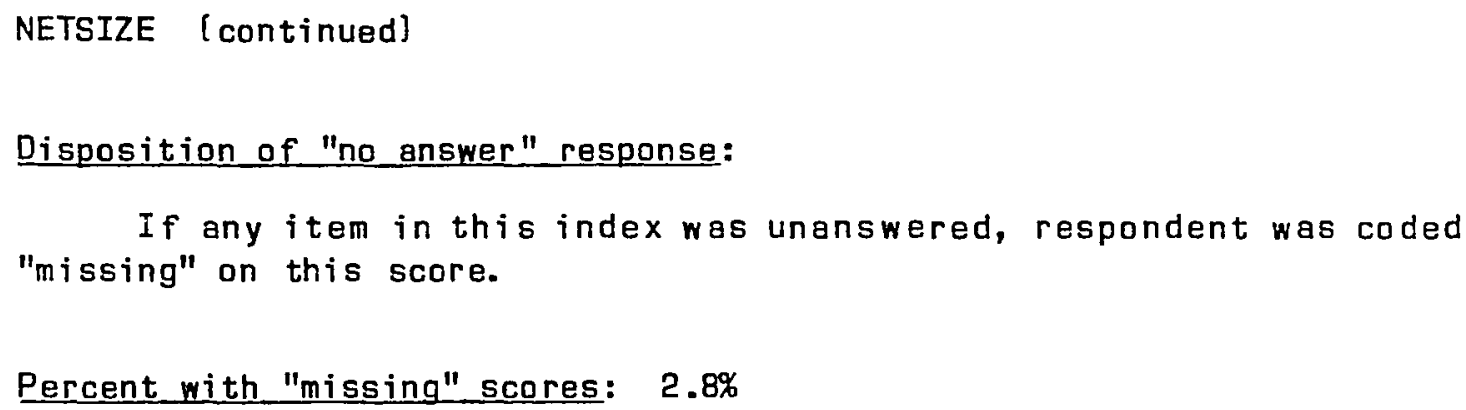

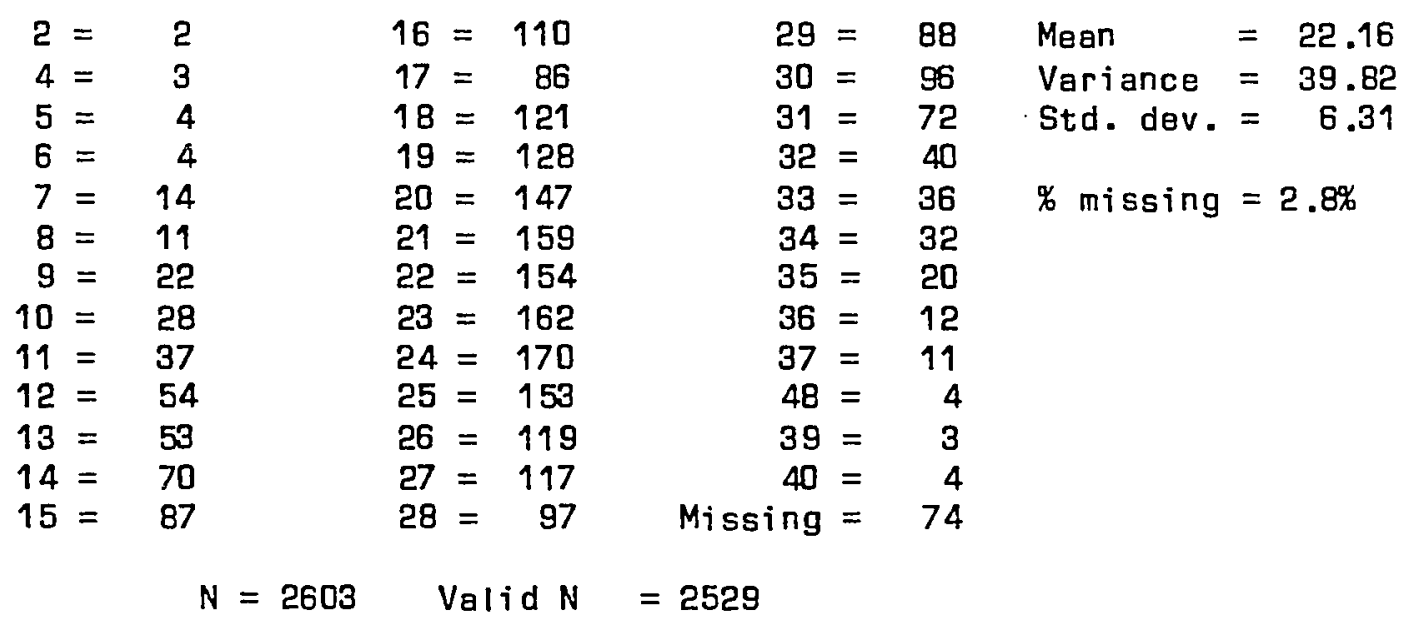

Reliability Coefficient Alpha .30

ITEMTOTAL

ITEM

Marriage

Children

Mother living

Father living

Siblings

Relatives near

Relatives far

Close friends

Other friends

Nei ghbors

Work associates

\section{CORRELATION}

.16327

.10931

.09956

.14925

$-.01999$

.19937

.20076

.08732

.22964

.11661

.05289
ALPHA

IF ITEM

DELETED

.29282

.28227

.29678

.29005

.34417

.22700

.22501

.29346

.26636

.28078

.30513 
FAMSIZE1 [size of immediate family]

0 No immediate family members

$\cdot$

21 Maximum number immediate family members

Missing: persons who gave no answer to one or more items

\section{Conceptual meaning:}

This index is a simple count which reflects how many persons are available in the respondent's immediate family. Potential family members are: one spouse, two living parents, up to twelve children, and up to six (or more) siblings.

Index construction procedures:

Five items were used to construct this index. The presence of each possible family member added 1 and the score for that person is the total sum. 
FAMSIZE1 [continued]

\begin{tabular}{|c|c|c|}
\hline ITEM & RESPONSE & SCORE \\
\hline Marital status of respondent & Married & +1 \\
\hline $\mathrm{R} 013$ & $\begin{array}{l}\text { Never married } \\
\text { Widowed } \\
\text { Divorced }\end{array}$ & \\
\hline Respondent's father I iving & Alive & +1 \\
\hline R015 & Dead & \\
\hline Respondent's mother living & Alive & +1 \\
\hline R021 & Dead & \\
\hline $\begin{array}{l}\text { Total children family of origin } \\
\text { R056 } \\
\text { [siblings] }\end{array}$ & $\begin{array}{l}\text { One (anly child) } \\
\text { Two } \\
\text { Three } \\
\text { Four } \\
\text { Five } \\
\text { Six } \\
\text { Seven or more }\end{array}$ & $\begin{array}{r}0 \\
+1 \\
+2 \\
+3 \\
+4 \\
+5 \\
+6\end{array}$ \\
\hline 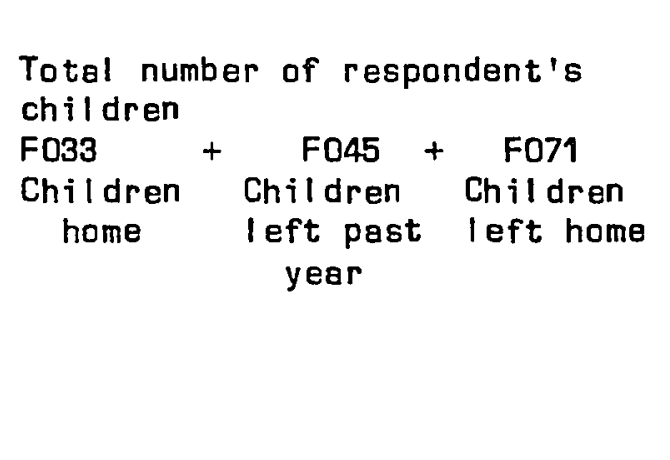 & $\begin{array}{l}\text { None } \\
\text { One } \\
\text { Two } \\
\text { Three } \\
\text { Four } \\
\text { Five } \\
\text { Six } \\
\text { - } \\
\text { - } \\
\text { Twelve }\end{array}$ & $\begin{array}{r}0 \\
+1 \\
+2 \\
+3 \\
+4 \\
+5 \\
+6 \\
\quad \\
\quad \\
+12\end{array}$ \\
\hline
\end{tabular}

\section{Disposition of "no answer" responses:}

If any item in this index was unanswered, respondent was coded "missing" on this score. 
INDEX OF TOTAL FAMILY SIZE

SIZEFAM2 [Size of total family)

0 No family members

-

$\cdot$

33 Maximum number family members

Missing: persons who gave no answer to one or more items

\section{Conceptual meaning:}

This index is a simple count of all the immediate and extended family members available to the respondent. It includes all the immediate family members [spouse, parents, siblings, children] from the FAMSIZE1 and adds kin. A score of up to 6 is added if the respondent has 6 or more relatives living nearby. A score of up to six is also added if the respondent has 6 or more relatives a day away. This index considers family size as inclusive of not only the immediate family but also kin.

\section{Index construction procedures:}

This index starts at zero and adds the Index of Immediate Family Size [FAMSIZE1], the number of relatives who live nearby, and the number of relatives who live at a day's distance. 
SIZEFAM2 [continued]

\begin{tabular}{|c|c|c|c|}
\hline ITEM & & RESPONSE & SCORE \\
\hline $\begin{array}{l}\text { Index of immediate } \\
\text { FAMSIZE1 }\end{array}$ & family size & $\begin{aligned} & 0 \text { No immediate family members } \\
&: \\
& 21 \text { Maximum number immediate } \\
& \text { family members }\end{aligned}$ & $\begin{array}{r}0 \\
+\dot{.} \\
\dot{21}\end{array}$ \\
\hline $\begin{array}{l}\text { How many relatives } \\
\text { F109 }\end{array}$ & live near & $\begin{array}{l}\text { None } \\
\text { One } \\
\text { Two } \\
\text { Three } \\
\text { Four } \\
\text { Five } \\
\text { Six or more }\end{array}$ & $\begin{array}{r}0 \\
+1 \\
+2 \\
+3 \\
+4 \\
+5 \\
+6\end{array}$ \\
\hline $\begin{array}{l}\text { How many relatives } \\
\text { F112 }\end{array}$ & live day away & $\begin{array}{l}\text { None } \\
\text { One } \\
\text { Two } \\
\text { Three } \\
\text { Four } \\
\text { Five } \\
\text { Six or more }\end{array}$ & $\begin{array}{r}0 \\
+1 \\
+2 \\
+3 \\
+4 \\
+5 \\
+6\end{array}$ \\
\hline
\end{tabular}

Disposition of "no answer" responses:

If any item in this index was unanswered, respondent was coded "missing" on this score. 
SIZEFRND [Size of friends network]

o No friends

-

$\cdot$

18 Maximum number of friends

Missing: persons who gave no enswer to one or more items

\section{Conceptual meaning:}

Size of friends network counts those people outside the family circle that the respondent knows well and with whom he socializes. Included in this index are up to six values for close friends, up to six values for neighbors he knows well enough to drop in on, up to three values for associates he talks to at work, and up to 3 values for families of less close friends he sees. The latter two categories of friends are ranges which have been weighted so that they count less than close friends and neighbors because they are assumed to be less intimate to the respondent in terms of providing social support. Of course, if the respondent is not employed, he would not have anyone in his work network.

\section{Index construction procedures:}

Four items were used to construct this score. R257 was first collapsed from 5 to 3 values. Thus, 1,2 , and 3 , were merged to 1 [010) because there were very few cases in both 1 and 2 .

The new inciex was set at 70 so and the four $i$ tems were summed. 
SIZEFRND [continued]

ITEM

RESPONSE

SCORE

\begin{tabular}{|c|c|c|}
\hline $\begin{array}{l}\text { How many close friends } \\
\text { F116 }\end{array}$ & $\begin{array}{l}\text { None } \\
\text { One } \\
\text { Two } \\
\text { Three } \\
\text { Four } \\
\text { Five to ten } \\
\text { Over ten }\end{array}$ & $\begin{array}{r} \\
+1 \\
+\quad 2 \\
+3 \\
+4 \\
+5 \\
+6\end{array}$ \\
\hline $\begin{array}{l}\text { Fanilies know to drop in } \\
\text { F108 }\end{array}$ & $\begin{array}{l}\text { None } \\
\text { One } \\
\text { Two } \\
\text { Three } \\
\text { Four } \\
\text { Five } \\
\text { Six or more }\end{array}$ & $\begin{array}{r}0 \\
+1 \\
+2 \\
+3 \\
+4 \\
+5 \\
+6\end{array}$ \\
\hline $\begin{array}{l}\text { How many others talk to at work } \\
\text { (collapsed) } \\
\text { R257 }\end{array}$ & $\begin{array}{l}\text { Don't work } \\
\text { Cne to ten } \\
\text { Eleven to twenty-five } \\
\text { Over twenty-five }\end{array}$ & $\begin{array}{r}0 \\
+1 \\
+2 \\
+3\end{array}$ \\
\hline $\begin{array}{l}\text { How many friends get together } \\
\text { with during year } \\
\text { R277 }\end{array}$ & $\begin{array}{l}\text { A few } \\
\text { Some } \\
\text { A great many }\end{array}$ & $\begin{array}{l}+1 \\
+2 \\
+3\end{array}$ \\
\hline
\end{tabular}

Disposition of "no answer" responses:

If any item in this index was unanswered, respondent was coded "missing" on this score. 
NETFREQ

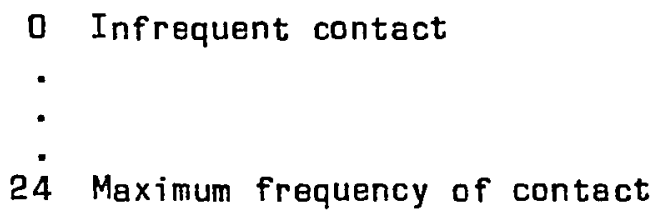

\section{Conceptual meaning:}

This index indicates categorically the amount of contact the respondent has with network members other than $i m m e d i a t e$ family and family of origin. High scorers see their kin, friends, and work associates very frequently, and attend meetings and church very frequently. Low scorers see these network members seldom.

\section{Index construction procedures:}

Many of the 8 row score variables were already in a metric of 3 . Those that were not were collapsed to a metric of 3 . Recodes were done so all the variables went from low to high. Then the 8 raw score variables were summed. 
NETFREQ (continued]

\begin{tabular}{|c|c|c|}
\hline ITEM & RESPONSE & SCORE \\
\hline $\begin{array}{l}\text { Keep in touch with away relatives } \\
\text { F115 }\end{array}$ & $\begin{array}{l}\text { All nearby } \\
\text { Not very frequently } \\
\text { Somewhet frequently } \\
\text { Very frequently }\end{array}$ & $\begin{array}{r}0 \\
+1 \\
+2 \\
+3\end{array}$ \\
\hline $\begin{array}{l}\text { Nearby relatives families } \\
\text { see often } \\
\text { RFAM }\end{array}$ & $\begin{array}{l}\text { None or inappropriate } \\
\text { Less than half } \\
\text { About half } \\
\text { All }\end{array}$ & $\begin{array}{r}0 \\
+1 \\
+\quad 2 \\
+3\end{array}$ \\
\hline $\begin{array}{l}\text { Relatives femilies one day away } \\
\text { see often } \\
\text { RFAMDAY }\end{array}$ & $\begin{array}{l}\text { None or inappropriate } \\
\text { Less than half } \\
\text { About half } \\
\text { All }\end{array}$ & $\begin{array}{r}0 \\
+1 \\
+\quad 2 \\
+3\end{array}$ \\
\hline $\begin{array}{l}\text { How often in touch with close } \\
\text { friends } \\
\text { R117 }\end{array}$ & $\begin{array}{l}\text { No close friends } \\
\text { Seldom, occasionally } \\
\text { Fairly often } \\
\text { Very often }\end{array}$ & $\begin{array}{r}0 \\
+1 \\
+\quad 2 \\
+3\end{array}$ \\
\hline $\begin{array}{l}\text { How often get with friends } \\
\text { RF116 }\end{array}$ & $\begin{array}{l}\text { Rarely } \\
\text { Cccasionaliy } \\
\text { Frequently }\end{array}$ & $\begin{array}{l}+1 \\
+2 \\
+3\end{array}$ \\
\hline $\begin{array}{l}\text { Spent time off with coworkers } \\
\text { R277 }\end{array}$ & $\begin{array}{l}\text { not applicable or never } \\
\text { Rarely } \\
\text { Occasionally } \\
\text { Very often }\end{array}$ & $\begin{array}{r}0 \\
+1 \\
+2 \\
+3\end{array}$ \\
\hline $\begin{array}{l}\text { Frequency of attending meetings } \\
\text { of } 6 \text { organizations } \\
\text { FREQMEET }\end{array}$ & $\begin{array}{l}\text { Never } \\
\text { Low } \\
\text { Medium } \\
\text { High }\end{array}$ & $\begin{array}{r}0 \\
+1 \\
+2 \\
+3\end{array}$ \\
\hline $\begin{array}{l}\text { Frequency of attending church } \\
\text { R318 }\end{array}$ & $\begin{array}{l}\text { Never } \\
\text { Few times a year } \\
\text { Monthly, several times month } \\
\text { about weekly or more }\end{array}$ & $\begin{array}{r}0 \\
+1 \\
+2 \\
+3\end{array}$ \\
\hline
\end{tabular}


NETFREQ [ continued]

Frequency distribution

$$
\begin{array}{rlrlrl}
2 & =4 & & \text { Mean } & =13.15 \\
3 & =5 & & \text { Variance }=13.68 \\
4 & =18 & & \text { Std. dev. }=3.70 \\
5 & =31 & & \text { \% missing }=6.7 \% \\
6 & =41 & \\
7 & =66 & \\
8 & =105 & \\
9 & =132 & \\
10 & =179 & \\
11 & =200 & \\
12 & =252 & \\
13 & =249 & \\
14 & =224 & \\
15 & =259 & \\
16 & =199 & & \\
17 & =174 & & \\
18 & =128 & & \\
19 & =75 & & \\
20 & = & & \\
21 & = & 26 \\
22 & = & &
\end{array}
$$

$\begin{array}{lcc}\text { ITEM } & \begin{array}{c}\text { ITEM- } \\ \text { TOTAL } \\ \text { CORRELATION }\end{array} & \begin{array}{c}\text { ALPHA } \\ \text { IF ITEM } \\ \text { DELETED }\end{array} \\ \text { F115 } & .09624 & \\ \text { RFAM } & .11738 & .37340 \\ \text { RFAMDAY } & .10115 & .36718 \\ \text { RRR117 } & .19180 & .37580 \\ \text { RF116 } & .29247 & .33351 \\ \text { RR277 } & .06108 & .31842 \\ \text { FREOMEET } & .25867 & .38527 \\ \text { R318 } & .19631 & .28353 \\ & & .32928\end{array}$


INDEX OF OVERALL NETWORK INTERACTION

NET INTER

0 No network interactions

$\cdot$

-

48 Maximum network ineteraction

Conceptual meaning:

This index is an overall measure of the respondent's total interaction with family, friends, and work associates as well as involvement in the community by attending meetings, church, and engaging in social leisure.

\section{Index construction procedures:}

This index was constructed by summing all the interaction indexes after they were all collapsed to a metric of 6 . Being married was considered e very important tie, so it was weighted 8 in this variable to take into consideration that all married people see their spouses very frequently. [Recall that the frequency of contact variables had a metric of 3 , with 3 indicating very frequent contact.) Each number variable was multiplied by the frequency of contact variable to form an interaction index for that relationship domain.

Since children represent the family with whom the respondent is living (or they are at least very closel they are considerad to also have the maximum frequency of contact. Since multiplying the number of children by 3 would not change the frequency distribution, this variable was simply collapsed to the same metric as the other variables entering the overall index. 


\begin{tabular}{|c|c|c|c|c|c|}
\hline INDEX LABEL & & $\begin{array}{l}\text { RES } \\
\text { col } \mid\end{array}$ & $\begin{array}{l}\text { PONSE } \\
\text { apsed] }\end{array}$ & SCORE & \\
\hline Index of marital status & $\mathrm{R013}$ & $\begin{array}{l}\text { Ye } \\
\text { No }\end{array}$ & & & +8 \\
\hline Index of total children & ALLKIDS & $\begin{array}{l}0 \\
\dot{5}\end{array}$ & $\begin{array}{l}\text { None } \\
\text { Maximum }\end{array}$ & & $\begin{array}{l}0 \\
. \\
5\end{array}$ \\
\hline $\begin{array}{l}\text { Index of interaction with } \\
\text { family of origin }\end{array}$ & FAMINTER & $\begin{array}{l}0 \\
\dot{5}\end{array}$ & $\begin{array}{l}\text { None } \\
\text { Maximum }\end{array}$ & & $\begin{array}{l}0 \\
\dot{5}\end{array}$ \\
\hline Index of relatives interaction & CRELINTE & $\begin{array}{l}0 \\
\dot{5}\end{array}$ & $\begin{array}{l}\text { None } \\
\text { Maximum }\end{array}$ & & $\begin{array}{l}0 \\
\dot{5}\end{array}$ \\
\hline $\begin{array}{l}\text { Index of close friends } \\
\text { interaction }\end{array}$ & FRNINTER & $\begin{array}{l}0 \\
\dot{5}\end{array}$ & $\begin{array}{l}\text { None } \\
\text { Maximum }\end{array}$ & & $\begin{array}{l}0 \\
\dot{5}\end{array}$ \\
\hline $\begin{array}{l}\text { Index of other friends } \\
\text { interaction }\end{array}$ & FRIENDS2 & $\begin{array}{l}0 \\
\dot{5}\end{array}$ & $\begin{array}{l}\text { Minimum } \\
\text { Maximum }\end{array}$ & $\begin{array}{l}\text { interaction } \\
\text { interaction }\end{array}$ & $\begin{array}{l}0 \\
\dot{5}\end{array}$ \\
\hline Index of work interaction & WORKINT & $\begin{array}{l}\dot{0} \\
\dot{5}\end{array}$ & & & $\begin{array}{l}0 \\
\dot{5}\end{array}$ \\
\hline $\begin{array}{l}\text { Index of meeting interaction } \\
\text { [including church] }\end{array}$ & FREQMECH & $\begin{array}{l}0 \\
\dot{5}\end{array}$ & & & $\begin{array}{l}0 \\
\dot{5}\end{array}$ \\
\hline Index of social leisure & LEISUR2 & $\begin{array}{l}0 \\
\dot{5}\end{array}$ & & & $\begin{array}{l}0 \\
\dot{5}\end{array}$ \\
\hline
\end{tabular}


NETINTER (continued)

Frequency distribution

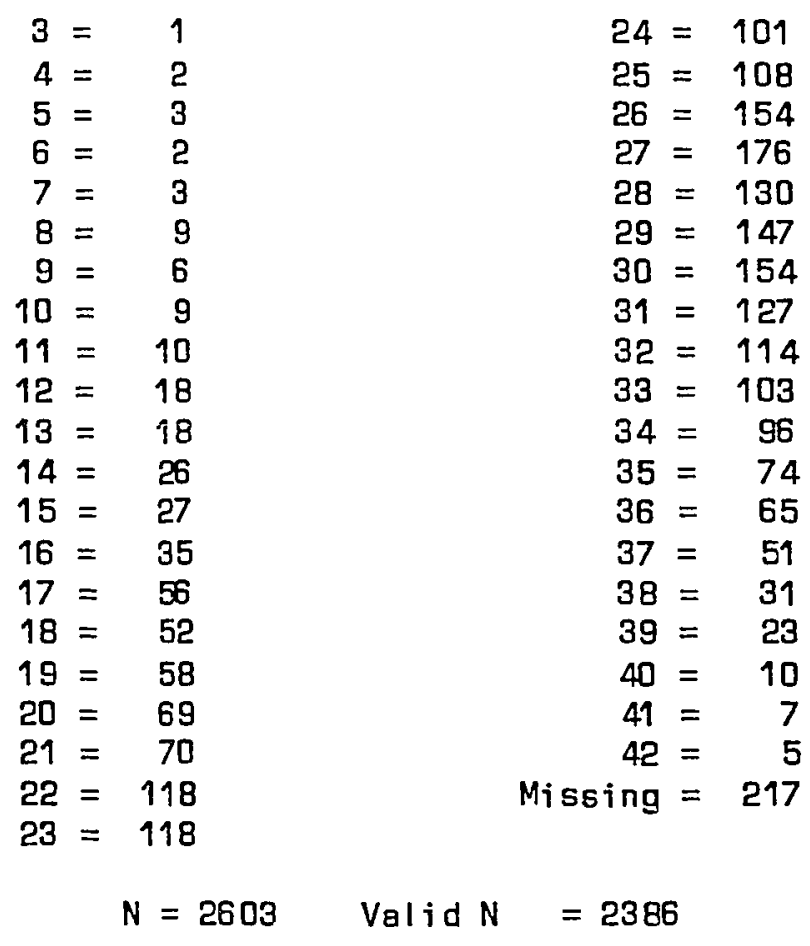

Mean $=26.72$

Variance $=43.16$

Std. dev. $=6.58$

$\%$ missing $=8.3 \%$

$N=2803$ Valid $N=2380$

$\begin{array}{lcc} & \text { Reliability } & \\ & \text { Coefficient Alpha } & .44 \\ & \text { ITEM- } & \\ \text { ITEM } & \text { TOTAL } & \text { ALPHA } \\ & \text { CORRELATION } & \text { IF ITEM } \\ \text { MARRIAGE } & .06115 & \text { DELETED } \\ \text { ALLKIDS } & .08925 & .44150 \\ \text { FAMINTER } & .10327 & .44573 \\ \text { CRELINTE } & .19328 & .43842 \\ \text { FRNINTER } & .21705 & .40432 \\ \text { FRIENDS2 } & .34198 & .39373 \\ \text { WORKINT } & .10722 & .35109 \\ \text { FREQMECH } & .27283 & .44456 \\ \text { LEISUR2 } & .25517 & .36769 \\ & & .38089\end{array}$


CORRELATION MATRIX FOR SCALE NETINTER

\begin{tabular}{|c|c|c|c|c|c|c|c|c|c|}
\hline & MARRIAGE & ALLKIDS & FAMINTER & CRELINTE & FRNINTER & FRIENDS2 & WORKINT & FREQMECH & LEISURE? \\
\hline MARRIAGE & 1.00000 & & & & & & & & \\
\hline ALLKIDS & .15672 & 1.00000 & & & & & & & \\
\hline FAMINTER & -.03113 & .34171 & 1.00000 & & & & & & \\
\hline CRELINTE & .12122 & .10506 & .15432 & 1.00000 & & & & & \\
\hline RFNINTER & -.07320 & -.02086 & .04609 & .07453 & 1.00000 & & & & \\
\hline FRIENDS2 & .01475 & -.03160 & .03930 & .19351 & .25829 & 1.00000 & & & \\
\hline WORKINT & .00944 & -.00207 & -.03547 & .02480 & .07570 & .12227 & 1.00000 & & \\
\hline FREQMECH & .06084 & .13736 & .05037 & .04958 & .15809 & .23132 & .07713 & 1.00000 & \\
\hline LEISUR2 & -.03326 & .03306 & .07072 & .04084 & .16078 & .25659 & .10324 & .18343 & 1.00000 \\
\hline
\end{tabular}


APPENDIX E

CORRELATIONS OF INDEPENDENT, DEPENDENT, AND CONTROL VARIABLES 
ZERO-ORDER PAIRWISE CORRELATIONS OF INDEPENDENT, DEPENDENT, AND CONTROL VARIABLES, USING CONTINOUOUS VERSIONS

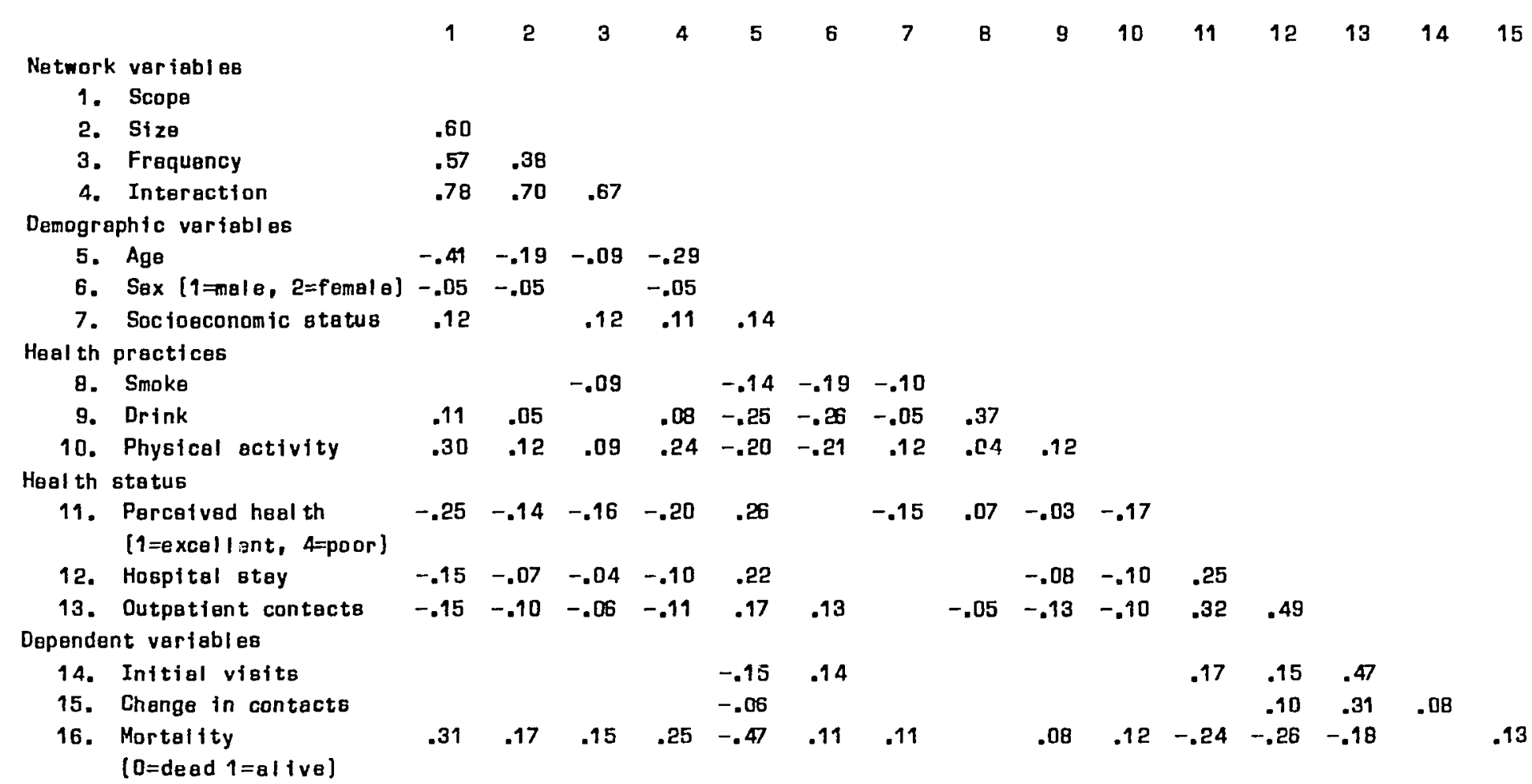

Note: Those shown $\mathrm{e} \geq 0.05$

All coded low-high except where indicated 
ZERO-ORDER PAIRWISE CORRELATIONS OF INDEPENDENT, DEPENDENT, AND

CONTROL VARIABLES, USING DICHOTOMOUS VERSIONS

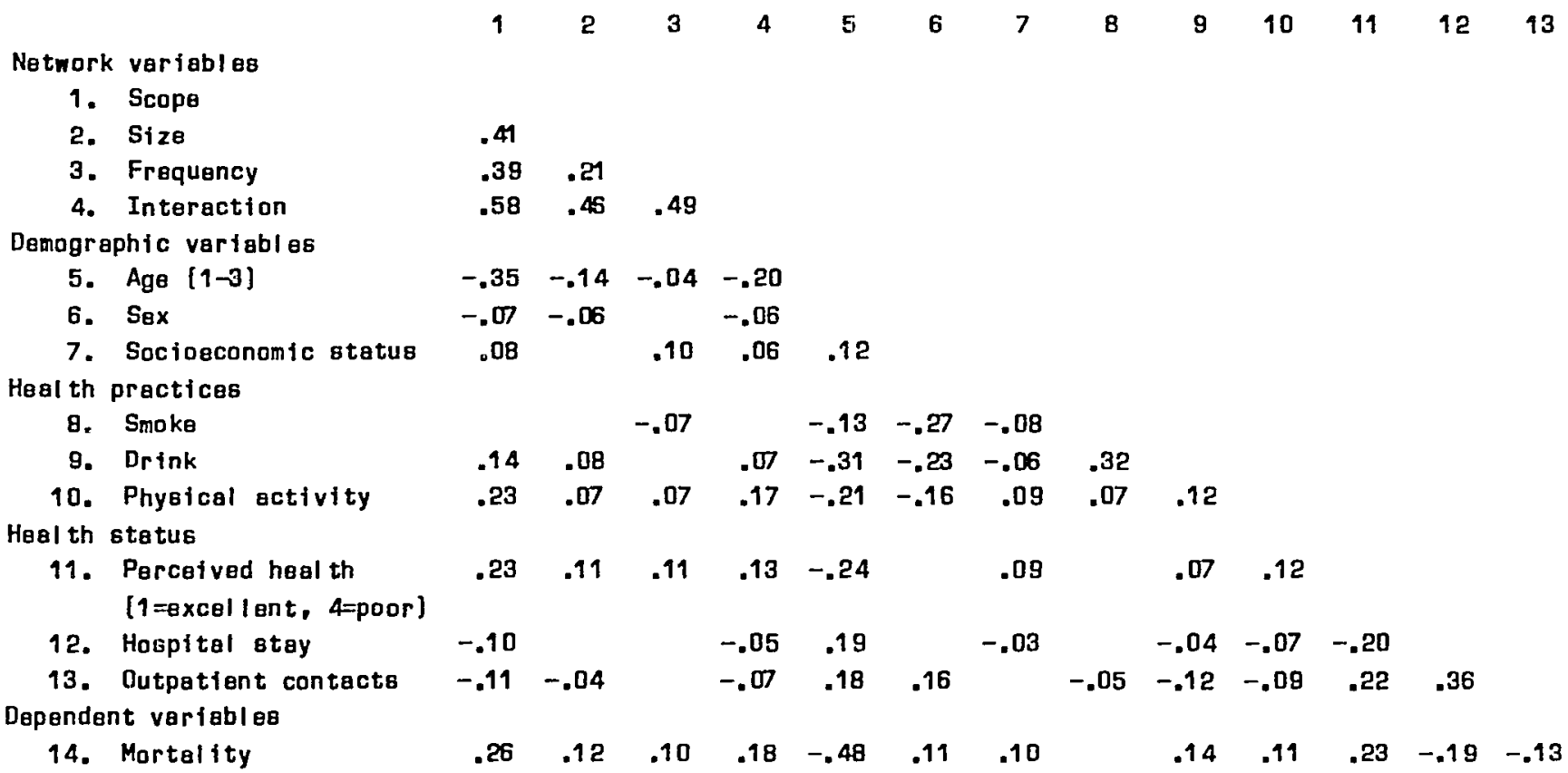

Note: Those shown $\mathrm{p} \geq 0.05$ 
ZERO-ORDER PAIRWISE CORPELATIONS OF RELATIONSHIP DOMAIN INDEXES, CONTROL VARIABLES, AND MORTALITY

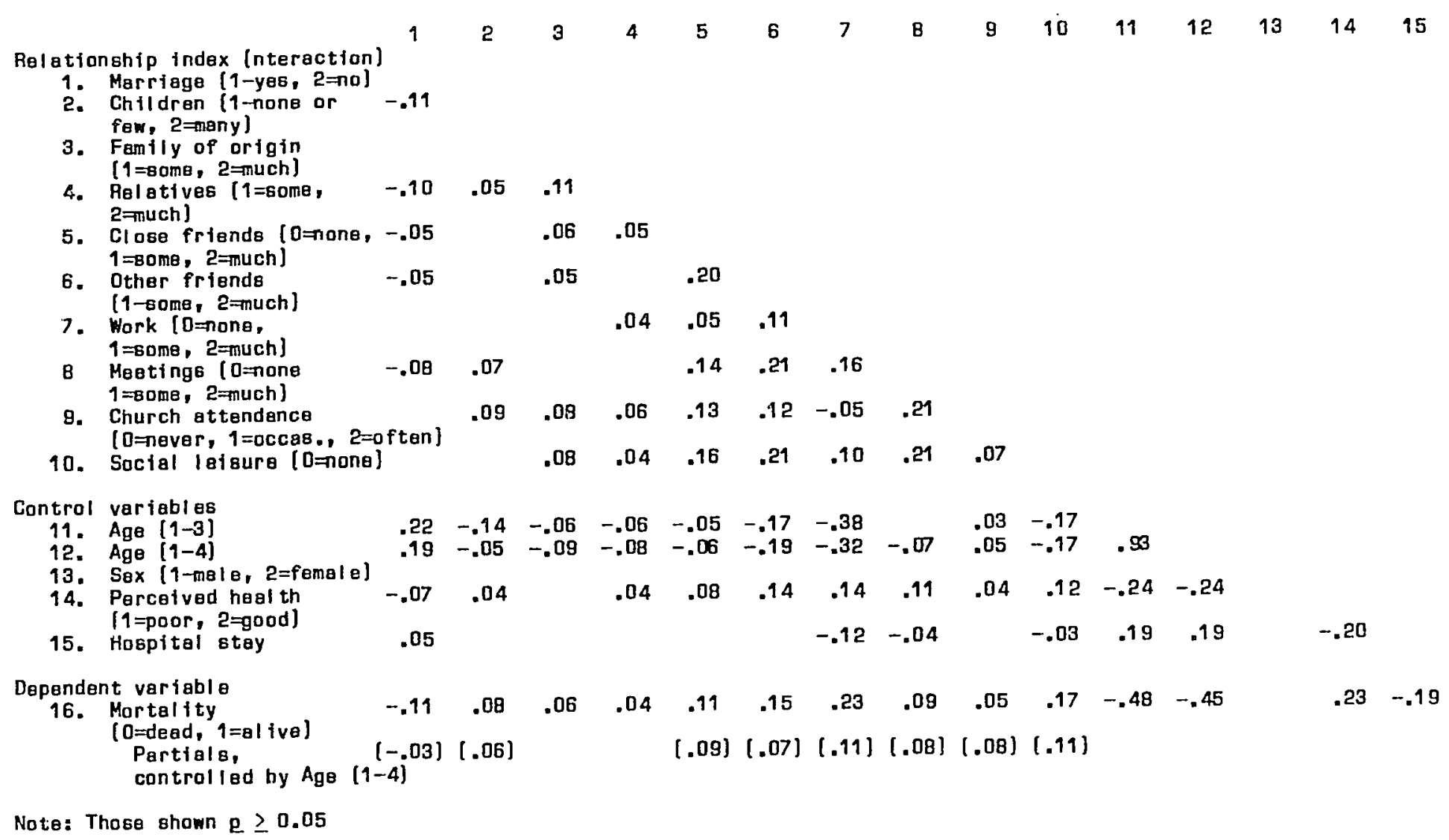


APPENDIX F

CODING OF COLLAPSED VARIABLES FOR

LOGISTIC REGRESSION ANALYSES 


\section{CODING OF COLLAPSED CONTROL VARIABLES FOR LOGISTIC ANALYSES IN TABLES XIII THROUGH $X X$ \\ [ALL TOTAL 2603]}

AGE

$$
\begin{array}{rlr}
\text { Version A } 1=18-49 \text { yrs } & N=1454 \\
2 & =50-64 & 694 \\
3 & =\text { over } 65 & 455 \\
\text { Version B } 1 & =18-34 \text { yrs } & N=697 \\
2 & =35-49 & 757 \\
3 & =50-64 & 694 \\
4 & =\text { over } 65 & 455
\end{array}
$$

694

SEX

$$
1=\operatorname{mala} \quad N=1202
$$$$
2=\text { female } \quad 1401
$$

SOCIOECONOMIC $1=$ IOW

STATUS

$2=$ high

Missing
PHYSICAL $\quad 1=$ low $\quad \mathrm{N}=1198$

ACTIVITY $2=$ high $\quad 1342$

Missing 63

NETWORK SCOPE

$$
\begin{array}{clr}
\text { Version A } & 1=\text { small } N=1186 \\
& 2=\text { large } & 1239 \\
& \text { Missing } & 178 \\
\text { Version B } & 1=\text { small } N= & 632 \\
& 2=\text { medium } & 898 \\
& 3=\text { large } & 895 \\
& \text { Missing } & 178 \\
& & \\
\text { MORTALITY } & 0=\text { dead } N=376 \\
& 1=\text { alive } & 2227
\end{array}
$$

PERCEIVED HEALTH

$\begin{array}{llr}\text { Version A } & 1 \text { = poor } & N= \\ & 2 \text { = good } & 471 \\ & \text { Missing } & 2085 \\ \text { Version B } & 1 \text { = excell ent } N= & 47 \\ & 2 \text { = good } & 1193 \\ & 3=\text { fair or poor } r \\ & \text { Missing } & 471 \\ & & 47\end{array}$

LENGTH HOSPITAL STAY

$$
\begin{aligned}
& \text { Version A } 1=\text { none } \quad \mathrm{N}=2075 \\
& 2=\text { one or more } 528 \\
& \text { Version B } 1=\text { none } \quad N=2075 \\
& 2=\text { some } \quad 261 \\
& 3=\text { much } 267 \\
& \text { OUTPATIENT } \quad 1=\text { none } / \text { ow } N=1310 \\
& \text { VISITS } 2=\text { many } 1293 \\
& \text { SMOKE } \quad 1=\text { never } \quad \mathrm{N}=1054 \\
& 2 \text { = current smoke } 1534 \\
& \text { Missing } \\
& 15 \\
& \text { light } \quad N=1549 \\
& 2 \text { = moderate, } \\
& \text { Missing } \\
& \text { or heavy } 916 \\
& 138
\end{aligned}
$$



CODING OF COLLAPSED NETWORK VARIABLES FOR LOGISTIC ANALYSES IN TABLES XVI AND XVII
(ALI. TOTAL 2603)

\begin{tabular}{|c|c|c|c|c|c|}
\hline NETWORK SCOPE & $\begin{array}{l}1= \\
2= \\
3= \\
M i s 8\end{array}$ & $\begin{array}{l}\text { small } \\
\text { medium } \\
\text { large } \\
\text { ing }\end{array}$ & $\mathrm{N}$ & $=$ & $\begin{array}{l}632 \\
898 \\
895 \\
178\end{array}$ \\
\hline NETWORK SIZE & $\begin{array}{l}1= \\
2= \\
3= \\
\text { Miss }\end{array}$ & $\begin{array}{l}\text { 6mal I } \\
\text { madium } \\
\text { large } \\
\text { ing }\end{array}$ & $\mathbf{N}$ & $=$ & $\begin{array}{r}833 \\
792 \\
904 \\
74\end{array}$ \\
\hline NETWORK FREQUENCY & $\begin{array}{l}1= \\
2= \\
3= \\
\text { Miss }\end{array}$ & $\begin{array}{l}\text { smal I } \\
\text { medium } \\
\text { large } \\
\text { ing }\end{array}$ & $\mathrm{N}$ & $=$ & $\begin{array}{l}781 \\
725 \\
923 \\
174\end{array}$ \\
\hline NETWORK INTERACTION & $\begin{array}{l}1= \\
2= \\
3= \\
\text { Miss }\end{array}$ & $\begin{array}{l}\text { smal I } \\
\text { medium } \\
\text { large } \\
\text { ing }\end{array}$ & $\mathrm{N}$ & $=$ & $\begin{array}{l}710 \\
816 \\
860 \\
217\end{array}$ \\
\hline SCOPE IMMEDIATE FAMILY & $\begin{array}{l}1= \\
2= \\
3= \\
\text { Miss }\end{array}$ & $\begin{array}{l}\text { smal I } \\
\text { medium } \\
\text { large } \\
i n g\end{array}$ & $\mathrm{~N}$ & $=$ & $\begin{array}{r}559 \\
943 \\
1060 \\
41\end{array}$ \\
\hline SCOPE EXTENDED FAMILY & $\begin{array}{l}1= \\
2= \\
3= \\
\text { Miss }\end{array}$ & $\begin{array}{l}\text { smal I } \\
\text { medium } \\
\text { large } \\
\text { ing }\end{array}$ & $\mathbf{N}$ & $=$ & $\begin{array}{r}890 \\
953 \\
716 \\
44\end{array}$ \\
\hline SCOPE FRIENDS & $\begin{array}{l}1= \\
2= \\
3= \\
\text { Miss }\end{array}$ & $\begin{array}{l}\text { small } \\
\text { medium } \\
\text { large } \\
\text { ing }\end{array}$ & $\mathrm{N}$ & & $\begin{array}{r}372 \\
1155 \\
1060 \\
16\end{array}$ \\
\hline SCOPE OF COMMUNITY ACTIVITIES & $\begin{array}{l}1= \\
2= \\
3= \\
\text { Miss }\end{array}$ & $\begin{array}{l}\text { smal I } \\
\text { medium } \\
\text { large } \\
\text { ing }\end{array}$ & $\mathrm{N}$ & $=$ & $\begin{array}{r}1110 \\
860 \\
500 \\
133\end{array}$ \\
\hline
\end{tabular}




\section{CODING OF COLLAPSED RELATIONSHIP DOMAIN \\ INDEXES (INTERACTION) FOR LOGISTIC \\ ANALYSIS IN TABLE XVIII \\ (ALL TOTAL 2603)}

\begin{tabular}{|c|c|c|c|}
\hline MARA I AGE & $\begin{array}{l}1=\text { married } \\
2=\text { not married }\end{array}$ & & $\begin{array}{r}N=2167 \\
436\end{array}$ \\
\hline CHILDREN & $\begin{array}{l}1=\text { none } \\
2=\text { one or two } \\
3=\text { three or mor }\end{array}$ & & $\begin{array}{r}356 \\
1123 \\
1124\end{array}$ \\
\hline FAMILY OF ORIGIN & $\begin{array}{l}1=\text { lom } \\
2=\text { moderate } \\
3=\text { high } \\
\text { Missing }\end{array}$ & & $\begin{array}{l}753 \\
842 \\
890 \\
118\end{array}$ \\
\hline RELAT IVES & $\begin{array}{l}1=\text { low } \\
2=\text { moderete } \\
3=\text { high } \\
\text { Missing }\end{array}$ & & $\begin{array}{r}844 \\
875 \\
869 \\
15\end{array}$ \\
\hline CLOSE FRIENDS & $\begin{array}{l}1=\text { none } \\
2=10 w \\
3=h i g h \\
\text { Missing }\end{array}$ & & $\begin{array}{r}581 \\
1113 \\
904 \\
5\end{array}$ \\
\hline OTHER FRIENDS & $\begin{array}{l}1=10 \mathrm{w} \\
2=\text { moderate } \\
3=\text { high }\end{array}$ & & $\begin{array}{r}811 \\
697 \\
1095\end{array}$ \\
\hline WORK & $\begin{array}{l}1=\text { don't work o } \\
2=\text { moderate } \\
3=\text { high } \\
\text { Missing }\end{array}$ & $10 \mathrm{w}$ & $\begin{array}{r}1178 \\
594 \\
800 \\
31\end{array}$ \\
\hline CHURCH & $\begin{array}{l}1 \text { = never attend } \\
2 \text { = occasionally } \\
3 \text { = often attend } \\
\text { Missing }\end{array}$ & attend & $\begin{array}{r}675 \\
802 \\
1054 \\
72\end{array}$ \\
\hline MEETINGS & $\begin{array}{l}1=\text { none } \\
2=\text { low } \\
3=\text { high } \\
\text { Missing }\end{array}$ & & $\begin{array}{r}881 \\
856 \\
851 \\
15\end{array}$ \\
\hline SOCIAL LEISURE & $\begin{array}{l}1=\text { none } \\
2=\text { some } \\
3=\text { many } \\
\text { Missing }\end{array}$ & & $\begin{array}{r}471 \\
1252 \\
817 \\
53\end{array}$ \\
\hline
\end{tabular}




\section{APPENDIX G}

MORTALITY RATES FOR CONTROL VARIABLES AND SCOPE VARIABLE USED IN TABLE XIII 


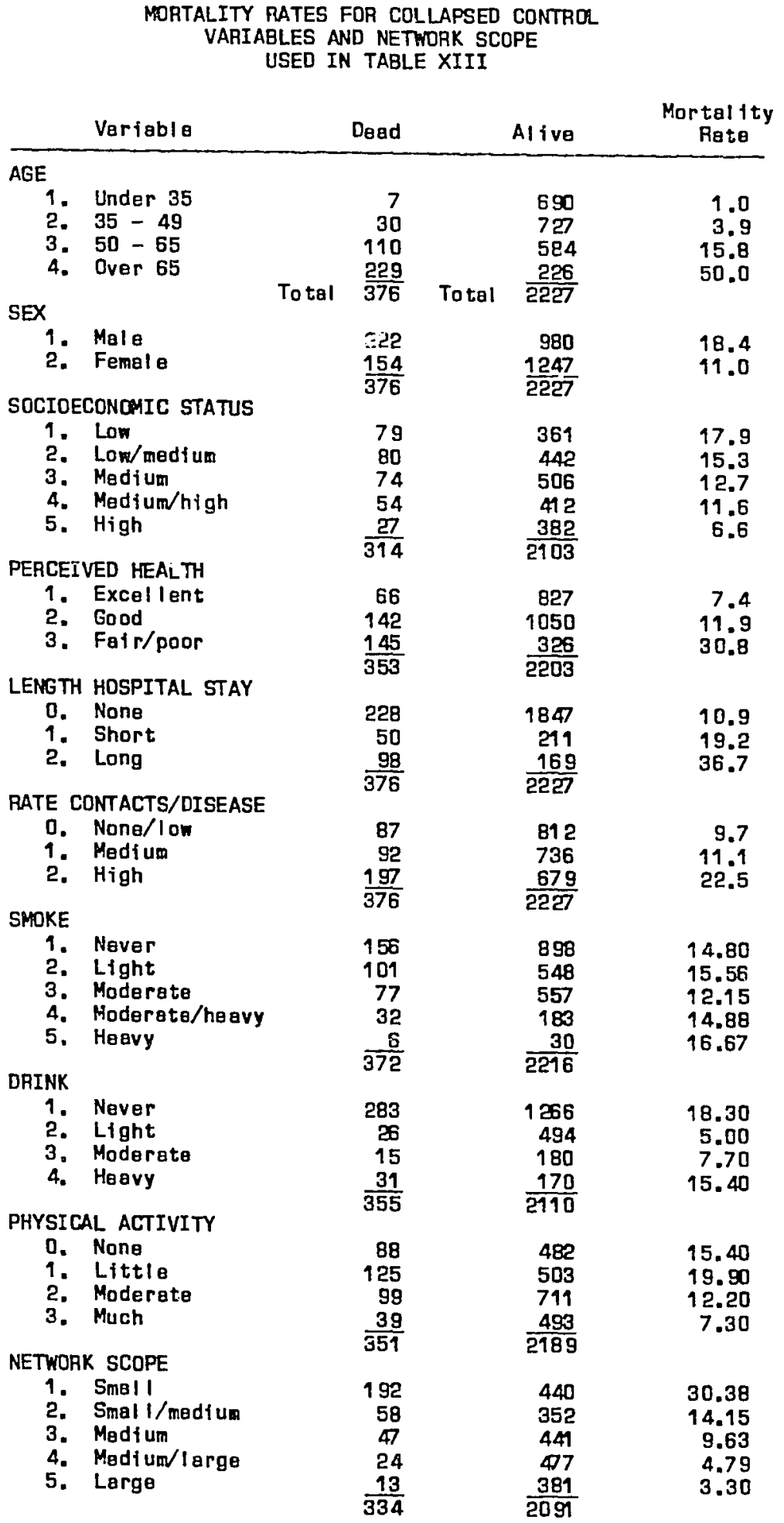

